
$2 / 6$ 
Lume, Grange

if ot thentise

from

Good bonetwee

185.9 
THE

\section{CHEMISTRY OF CREATION:}

BEING

d Eketely' of the chemital Wheromoua

OF

\section{'THE EARTH, THE AIR, THE OCEAN.}

\section{By ROBERT ELLIS, F.L.S.}

M.R.C.S. ETC.

PUBLISHED UNDER THE DIRECTION OF THE COMMTTEE OF GENERAL LITERATCRE AND EDLCATION, APPONTED BY THE SOCIETY FOR PROMUTING

- CHRistiaN KNoWLEDGE.

THE EIGHTH THOUSAND.

,

\section{O N D O N :}

PAINTED FOR THE

SOCIETY FOR PROMOTING CHRISTIAN KNOWLEDGE;

SOID AT THE DEPOSITORIES, GREAT QDEEN STRFET, LINCOLN'S INN FIELDS;

4. ROTAL EXCHANGR; 16, HANOVER STREET, HANOVER SQUARE; AND BY ALL BOOKSELLERS. 
LONDON: PRINTED BY W. CLOWES AND SONS, STAMFORD STREET. 


\section{PREFACE.}

Notwithstanding the excrcise of much labour and thonght during the progress of this volume through the press, in the endeavour to bring it below its present limits, the importance and variety of the subjects on which it treats have precluded the. possibility of so doing: When the student of nature:investigates the connexions and natural dependencies of those kingdoms which together constitute the scheme of creation, and even when only in one direction, as in the present case, the subject is exhaustless. The Chemistry of Creation is a theme not for one, but for many volumes.

In the present Work the attempt has been made to introduce all the recent dis- 
coveries in chemical science, related to Nature's chemistry, and to apply them to the explanation of the chemical phenomena presented in the earth, the air, and the ocean. That this attempt has been made in the use of familiar language, and with the desire to avoid the technicalities of science, will not be allowed to detract from the value and importance of the narrated facts and discoveries of chemical philosophy.

That this volume may be the companion of the lover of nature, and that it may assist him to trace in its varied and beautiful chemical phenomena the work of Him who is perfect in knowledge and excellent in working, is the desire of the writer, and the object of his book.

R. E.

Chelsea, 1850. 


\section{CONTEN'TS.}

\section{INTRODUCTION.}

Origin of Chemistry - Egypt - Arabia - China - Glassblowers in Egypt-Enrope-Dreams of the AlchemistsTransmutation of Metals - Juggling Tricks-Elixir of Life -Universal Solvent-Birth-time of Scientific ChemistryProgress of the Science - Cavendish - Watt - Davy Dalton - Faraday - Liebig-Prout-Present Importance of the Science-Knowledge of the Chemistry of Nature limited

\section{PART I.-THE EART'H.}

\section{CHAPTER I.}

THE INORGANIC CHEMISTRY OF NATURE.

Common and Philosophical Observation-The Scene-What is an Element?-Gases-Fluids - Solids - Remarkable Arrangement in Nature-Laughing Gas-Economy of Creation-Imperfection of our Kinowledge-Oxygen-Hydrogen - Nitrogen - Carbon-Iron rusting-Why ?-Chemieal Affinity-Composition of a Dew Drop-Chemical Laws-The First-Oxygenated Water-The Second-The Third-The Fourth-Importance and Influence of these Laws-This is not all-Lrent-Prismatic SpectrumComposition of a Sunbeam-Influence of Sunlight-Light and Colours-HEaT-Operation of, in Nature-FlowersAcrivisy-Chemistry of Sunlight-" Nature's sweet Restorer "-Daguerreotype-Talbotype-Magnetic Registers -Electricity, necessary in Operations of Nature-Use and Importance to Man-Electric Telegraph-Electric Clock-Magnetism-Gravity - Whether Modifications of one Principle? . . . . . . . . . . p. 21 


\section{CHAP'TER 11.}

\section{CHEMISTRY OF THE LAND.}

Apparent uneluangeableness of the Aspects of Nature-Not real-Secret Chemieal Forees-Destruetion slow, silent, but sure-Ageneies-Water-Carbonic Aeid-Oxrgen-Niagara Falls - Reeession of-Salt-field of Northwich-Crystal 1sland-Powerful Effeet of Carbonated Water-1'rofessor Rogers' Experiments-Effect of Oxygen-Disease of the Granite-The Kettle and Pans-Poreelain Clay-Formation of, out of Granite-Silver Mines-Californian GoldPersistenee of Favptian Monuments-Its Cause-DébrisI'roduction of-DIont Blanc-Alps-Rluine-Valleys of the Cordilleras-Alluvium-Composition und History of-Rocks and Hills crumbling to Dust . . . . . . 1. 6.

\section{CHAPTEI III}

CHEMISTHY OF THE SOIJ.

Composition of the Vegetable Soil-Mother-eartl-MouldChemical History of a Valley-A Delta-Clothing with Plants-Death of a Tree-Dispersion of its ElementsChemistry of its Deatl-The Farm-yard-The Dmer-le:ap) - Humes-Use of Vegetable Soil-Carbon-Formation of Conl-Mackenzie River-Chemistry of Coal-Peenliar Claraeter of its Decay-Arrangement of Coal-beds-Thu Dismond-Chemical Origin of Amber . . . . . 1, ! 2

\section{CHAPTER IT:}

\section{CUEMISTRY OF TIE INTERIOK.}

Disquiet within our Planet-Deej Chemistries of the EarthHigh Temperature of Interior-Proofs of-Artesian Wedls - Source of 'T'errestial Heat-The Sun-Chemical Deromposition in Crust-Central Heat-Experiments of $\mathrm{Mr}$. Grove and Dr. Robinson-Curious I'roperty of Interise Heat - The Earthquake - Phenomena of - Causes of Electrieal Origin of-Protection against - Earthonakes in Britain - The Voleano-Chemistry of - Jortllo - The Moffettes- Lpas-tree and Valley-Choke-damp-Iake of the Solfatara-Clemistry of Cares-Fire-clann]-Niagarit - Salt-mine-Singular Evolution of Gas-sifte-lamp"Blower's" in Coal-mines-Nud Voleanos Air Vülanos- 
Springof Rock-oil-BoracicLagoons-Remarkable Natural Barometer-Metamorphism of liocks-Experiments of Mitseherlich-Chemieal Plıenomena of Iceland-Remarkable A spect of the Country-Boiling Springs-Origin and Explanation of-Palagonite Rock-Decomposition of by VolcanicEmanations-Detection of Sulphuretted Hydrogen Gas by a Cigar-Formation of the Geyser's-Professor Bunsen's Discoveries-Great Geyser-Explanation of-Countries rising-Repose and Activity of the Intcrior of the Planet, alternate

\section{PART' II.-T'HE' AIR.}

\section{CHAPTER I.}

ITS PHYSICAL CONSTITUTION.

The Air travels with the Eartlı-Jimits of Air-A Journey to the Moon-Finite Extent of the Atmosphere-Extreme Rarefuction-Gay Lussac's Balloon Ascent-Tides in the Air-Cause-Solar and Lunar Influence-Atmospheric Waves-Indian Summer-Weight of the Air-Barometer -Weight of dry Air-Weight of Water in the Air-Effeet on Barometer-Effect of Pressure-Aneedote-Results of Pressure-Limit to Aërial Navigation-Cold of Expansion -Machines for Ice-making-Line of Perpetual SnowSnowy Mountain in Africa-Blueness of the Air-Remarkable Instance of Polarised Light--The Polar Clock-Electricity of the Air. p. 165

\section{CHAP'TER II.}

CHEMICAL CONSTITUTION OF THE AIR.

Oxygen-The Fire Annihilator-Nitrogen-Rude Analysis -Eudiometer-Accurate Analysis-Result--Exact Composition of Air-Air taken by a Balloon-Air not a Chemical Compound-Physical Constitution-Source of Oxygen-Constancy of Composition-Carbonic Aeid in AirProportion-Properties-Power of Diffusion-EffectsCoal Gas-Ammonia in Air-Variation of-Nitrogen in Food-Source-Manures-Operation of-Effect of Charcoal on a liose-trce-Normal Composition of the Atmospliere-Propertics of Air. 


\section{CHAP'I'ER III.}

OCCASIONAL INGREDIENTS OF TIL AIR.

Malaria-Fpidemics-Origin-Propagation of-Air of London-Air of Towns-Dew of Rooms-Organic Impurities in Air-Asiatic Cholera-Defieient Eleetrieity-MI. Quêtelet's Results - Inorganie Impurities in Air-Dry FogSaleniuretted Hydrogen-Black Rain-Ozone-Properties of-Effeets of-Test for-Sulphuretted Hydrogen-Decompositions in the Air-Chemistry of Putrefuetion-Remarkable Exceptions-Upper Egypt-The A tmosphere-Earth's Treasury.

\section{CHAP'TEIR IV.}

THE WATERS OF THE AIR.

Water in a Gaseous Form-Philosophy of Dew-Daniell's Hygrometer-Phenomena of Dew-Magical Properties of - Hoar Frost-Office of Dew-Force of Evaporation-Fog -Vesicular?-Clouds-Forms of-Rain-Phenomena of -Rain withont Clonds-Chemieal Fumetions of-Importance of-Rain and Plants-Rain and Man-Progress of Water into the Earth-Self-purification of the Soil-Hail - Snow Crystals-Electrical Origin of Rain, \&c.-Effeets of Fires-Ärtificial Kain . . . . . . . . p. 268

\section{CHAPTER V.}

\section{MOVEMENTS OF THE AIR.}

Cause of Motion in Air-Absorption of Solar Rays-Heat of Sum-Land and Sea Breczes-Trade Winds-Philosoplyy of-Diseovery of Two Currents-Local Winds-Rotatory Theory of Storms-Chemistry of Aërial NiovementsInsensible Movements-Cause of-Chemieal Effects of Wind-Benefits of a Fickle Climate-Effeets of Irregular Currents-Effects of Trade Winds. . . . . . . . p. 309

\section{CHAPTER VI.}

\section{THE ATMOSPHERE AXD AXIMALS.}

liespiration-Chemistry of Breathing-The Lungs-The Blood-Animal Heat-Combustion in the Body-The 
Esquimaux and Hindoo-Cold and Appetite-Sources of Animal Heat-The Breath of Life-Breathing in Insects -Changes in the Animal Frame-Chemistry of Starvation -Death . . . . . . . . . . p. 333

\section{CHAPTER VII.}

THE ATMOSPHERE AXD VEGETATIOY.

Germination-Nutrition of Plants-The Orchids-Soil not the chief Source of Carbon-Proofs-Experiment on a Vine Branch-Carbonic Acid in the Air-Forests of New World - Effect of Vegetation on Air-Sunlight and Plants-Actinism-Light-Heat-Relation of to Plants-Purification of the Air-Trade Winds-The Air and the Soil-General Constitution and Laws of the Atmosphere . . . p. 353

\section{PART III.-THE OCEAN.}

\section{CHAPTER I.}

ITS PHYSICAL CONSTITUTION.

Depth-Deep Soundings-Pressure of the Waters-Elasticity of Water-Light in the Ocean-Colour-Blue and Green Grottos-Phosphorescent Seas-Luminosity of Marine Beings-Temperature of the Ocean-Zones of Animal Life - Stratum of uniform Temperature-Remarkable Law or Water-Ground Ice-Climate of the Channel Islands p. 383

\section{CHAPTER II.}

\section{CHEMISTRY OF THE OCEAN.}

Analysis of Sea-water-Saline Contents-Prof. Forchhammer's Results-Fresh-water overlying Salt-Constancy of - Composition-Origin of Saline Matter-ExplanationSpecial Arrangement-The End in View-Organic Matter in Sea-water-Chemistry of Phosphorescence-Discoveries of Ehrenberg-Ozone and Phosphorescence-Fluorine in Sea-water-Self-purifying Property of the Ocean ? p. 407 


\section{CHAP'TER III.}

\section{MOVEMENTS OF THE WATERS.}

Effects of Heat and Cold-Waves-Analysis of a WaveGreat Tidal Wave-Bore-Order among Waves-Mr. Scott Russell's Discoveries-Speed and Height of WavesCapillary Waves-Oceanic Currents-Equatorial-Polar -Eftect of-Gulf-Stream-Submarine Currents-Chemistry of the Tides-Effeets of Air upon Mud-Decompositions. of Sea-weed-The Elubing Tide-Mcelanical Effeet of Waves-Remarkable Rocks-Grind of Navir--Disintegration of the Coast-Deposit of Sediment-Extranrdinary Accident-Chemical liesults of Wares-Ocean Circulation . . . . . . . . . p. 43 5

\section{CHAP'TER IV.}

LIFE IN THF WATERS.

The Algr-Zones of Vegetation-Drcdging ResearehesAntarctic Vegetations-Kelp-Analysis of Sea-weedOrigin of its Constituents-Purifying Influence of $\mathrm{A}_{\mathrm{a}} \mathrm{a}-$ weed-Iight, and Sea-plants-Investigations on the C'se of Sea-weed-Animal Marine Life-Innumerable hosts of Microseopic Beings-Zones of Animal Life--Researehes of Prof. Forbes-Chain of Animal Life-Respiration of Mrarine Animals-Products of-Molluscous Animals-Coral Islands and Seas-Reefs-Conclnsion. . . . . p. 477 


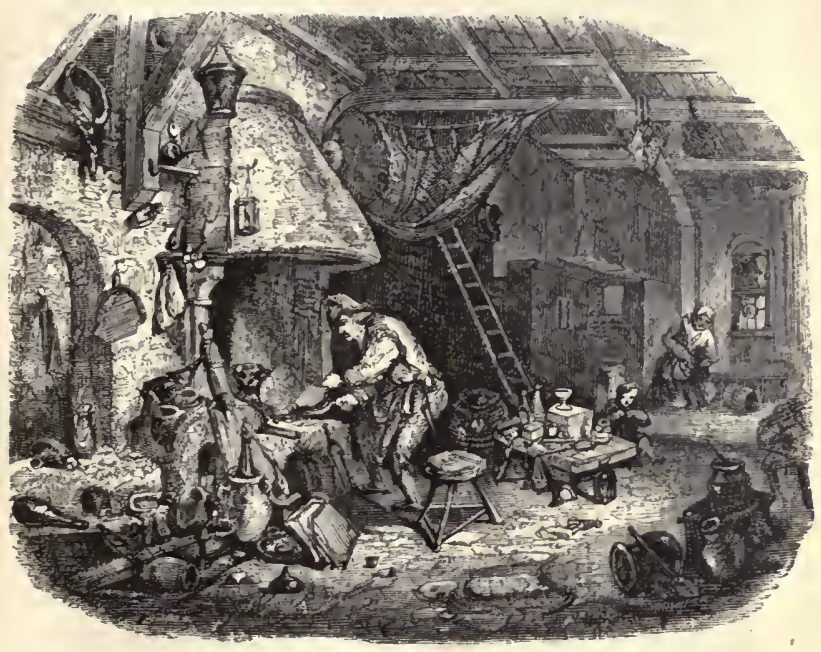

THE ALCHEMIST.

\section{INTRODUCTION.}

WE must look through a long vista of ages if we would discover, buried in the obseurity. of time, the origin of what is now rightly called the seienee of Chemistry. We know little about the time when the few facts which formed its first beginnings were gathered together, but it appears probable that Egypt was the country where this took place. Some one, it is probable, wiser than his fellows; first found out and applied the chemistry of a few common bodies; he may have diseovered the properties of a common acid, such as acetic acid; or of a cummon 
alkali, such as potash; and combining or mixing them together, he found a substance produced which was neither acid nor alkaline. This would lead him to reflection, and reflection to experiment, and experiment to a certain acquaintance with the properties of a number of substances around or familiar to him. Such a man was the first chemist. Imparting his knowledge to a few, of intellects as keen as his own, in the course of a little time chemistry was acknowledged as a distinct occupation, although, from its very nature, it was confined to a few persons whose delight or whose interest it was to make it as mysterious a subject as possible. Those who have made the deepest researeh into this subject inform us that there can be little doubt that the philosopher we have thus alluded to was Hermes Trismegistus, who, in their opinion, is to be considered as the parent of the science. But it is questionable even whether such a man as he of this name ever existed; and, it must be confessed, it is in our day a matter of but little moment whether he ever did or not; it being sufficient for us to remember that it was in Egypt, and at a very remote and hidden period, that ehemistry probably took its origin.

From Egypt the knowledge of this new art and mystery was earried into Arabia. Here, a celebrated person of the name of Geber, a physician, paid great attention to it, and discovered some most important facts, such as several salts, acids, and metals, which appear to liave been either unknown to his predecessors, or to have been concealed in their usual manmer by describing them only in a language unknown to 
the rest of the world. From this country the science extended to surrounding nations by slow degrees. Even in far-distant China it appears certain that there was, at an early period, some knowledge of chemistry; for we find that they were well acquainted with many chemical dyes, and with several metals, such as gold, silver, mercury, lead, copper, iron, tin, and zinc, besides several salts and chemicals, and also medicinal preparations. In Egypt, also, the arts of working in metals, of manufacturing soap, and more singular still of manufacturing glass of the most beautiful description, were practised, in all probability, even before philosophers in that ancient country caught a glimpse of the beautiful science which was intimately connected with these processes. Nevertheless, the mere knowledge of the right employment of the different substances used in these arts was a kind of chemistry, though not an enlightened one; it was the chemistry of experience. It is very surprising to find how successful both the Egyptians and the Chinese were in these arts, notwithstanding their deep ignorance of the laws of the science. Some of the colours employed by the Chinese for their porcelain, and some of their dyes, cannot be equalled even in our, day, when so much is known about the principles and practice of chemistry. The Egyptians, before the Exodus of the children of Israel, or about three thousand five hundred years ago, were well acquainted with the means of colouring glass in the most exquisite manner by some chemical substance, so that they used to make artificial gems, such as the 
amethyst, of glass, which could not be distinguished from the stone itself. The accompanying hieroglyphics assure us also of the fact that they knew how to blow glass in the same manner as we do, and thus they may have formed useful chemical vessels for the early professors of this art. So far had the glass-workers of Egypt advanced in their art that even coffins were sometimes made of glass.
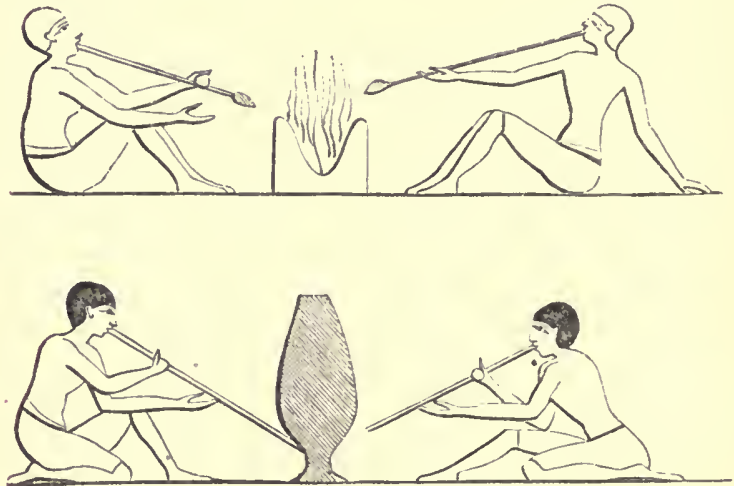

GLASS-BLOWING IN EGYPT.

The knowledge of chemistry came at length into Europe. During the dominion of the Moors in Spain, science of all kinds was much encouraged, and the arts and learning flourished luxuriantly. An immense library of books upon every subject existed at Cordova, whither the learned of Europe flocked, and where, in all probability, they first became acquainted with 
the writings of the Arabian chemists; the knowledge they thus obtained being afterwards communicated by them to others on their return home. The crusaders also, on their return from the Holy Land, are said to have brought the knowledge of chemistry into Spain, and from hence it spread into Germany, Italy, and France, and eventually into England.

Up to this time, which reaches to the twelfth century, very little progress was really made in chemical knowledge, and we might in a few lines sum up every simple or compound substance whose nature was accurately known to the early chemists. Passing these purely historical details, we may go on to mention some of those curiosities in the history of chemistry which are of a more extraordinary and interesting character than are to be found in the records of any other science whatever. Astrology forms a very curious portion, it is true, of the history of the noble science, Astronomy; but neither it nor any other delusion is to be compared to those which are unfolded to us as we look upon the chemistry of the past.

We might say that chemists have had three dreams. First was the dream that they could turn the common metals into gold; next was the dream that they could or might discover the water of immortality; and, lastly, was the singular dream that they could invent a liquid which would dissolve every thing! We can ascribe it to no other cause than the dcep-rooted covetousness of the human heart, that, from the very first, men regarded chemistry as a means of making gold. It is a most remarkable 
circumstance, that whether derived from ancient Egypt or the remote empire of China, early chemistry was chiefly occupied in the attempt to turn the baser metals into grold. In short, for ages chemistry was supposed to have no other object in view, no other value than this; and the alchemists, its first professors, were men who, from youth to age, toiled on in the arduous and ruinous task of attempting this art, called the transmutation of metals. Had they then no success? Were we to eredit their own accounts, we must acknowledge that in a few instances their success was remarkable. Thus, one of them tells us, "I had long doubted whether gold could be made from quicksilver. One who wished to convince me of my error, sent me a drachm of a certain powder of a red colour having a peculiar odour, with which I was to make the experiment. To avoid the possibility of fraud, I purchased the requisite ressels and materials from an ordinary warehouse: I put the mercury into the vessel and cast the powder into it; a strong heat was then applied, and immediately the whole inass was transmuted into ten drachms of the finest gold!" We are even told in history that a celebrated philosopher, in the presence of King Edward VI., by means of a certain powder, converted a mass of iron into gold, which was afterwards coined into rosenobles. The powder of the true philosopher's stone (if one could only procure some of it) was so powerful, it was said, that a few grains of it would turn twenty tons of lead into gold!

These statements are sufficient of themselves to satisfy the modern reader of the painful 
amount of falsehood and deception which characterises the records of the alchemists; yet, on a smaller scale, it is undoubtedly true that they appeared to possess the power of producing gold at pleasure. It was effected by clever juggling. Sometimes a piece of gold was slipped into the crucible by sleight of hand, - sometimes the instrument used to stir the mixture contained it, - and sometimes the crucible was artfully scooped out at the bottom, a small mass of gold having been put in, and covered over so as to be rendered invisible by a little paste. When the leat of the furnace had driven off the volatile substances forming the pretended mixture, the glittering yellow metal would then be discovered lying at the bottom. A similar trick was to-make a nail half of gold, half of iron, which was painted over so as to look like a rusty nail, and on being put into a crucible would, of course, come out halfas they said-turned into gold. Sometimes we cannot doubt that the experimenters were sincere, although they were the victims of deceit on the part of others, or of self-deception in themselves.

Such was the first, and, strange to say, the last also of the chemical dreams; for while the two others were of little influence and short duration, this lived down even to the end of the last century, one of its latest victims being a Dr. Price, of Guildford, who destroyed himself in disappointment at discovering the delusion under which he had been labouring. We need scarcely say the philosopher's stone, that wonderful compound, which was to turn all metals 
into virgin gold, was never discovered, and the " art of making gold," as it was termed, usually ended in reducing its professors to rags. Its vanity and certain results are well told in the following shrewd lines by the poet Spenser:-

"To lose good days, that might be better spent;

To waste long nights in pensive diseontent ;

To speed to-day, to be put back to-morrow;

To feed on hope, to pine with fear and sorrow ;

To fret their souls with erosses and with eares;

To eat their hearts, with comfortless despairs :

Unhappy wights! born to disastrous ced,

That do their lives in tedions tendance spend."

It was a striking example of that unquenchable hope, which will hope against hope, that the idea of an Elixir conferring immortality could ever have long occupied the attention of men styling themselves philosophers. The origin of this remarkable error admits of being traced, like that of so many errors, to an exaggeration of original circumstances. A celebrated physician of ancient time, by name Actuarius, makes mention in his works of a certain famous medicine which would preserve the body in health to the end of life. Geber, the alchemist, then asserted that he positively possessed a medicine capable of curing every disease, however desperate, and of renewing " man's strength like the eagles." Succeeding alchemists then declared that they possessed the Elixir of Immortal Life. 'It was a natural effect in some respects, that the growing science of making gold should have the consequence of extending the desires of men to search for a draught which, when their exhaustless riches were supplied, would enable the possessor to satiate himsclf 
therewith. Discovering also, in the worship of their idol, the persistence and apparent immortality of gold, a foolish and illogical train of reasoning led them to believe that a solution of this precious metal was the grand desideratum; and that in fact the elixir of immortality was a preparation of fluid gold.

How lightly after all did they really estimate the misery of immortal life to an individual in the present world! An immortality of the beholding of suffering, sorrow, and sin, of withering hopes, dying friends, unsatisfying occupations -was this the object of their search? Surely it was the voice of mercy, not of wrath, which pronounced, in solemn accents, death to be the wages of sin, that it might add the glorious intelligence that the gift of God is eternal life, through Jesus Christ our Lord.

The alcahest, or universal solvent, was the last of these three delusions. It may be considered also the most harmless. Properly speaking, it was simply a foolish fantasy of chemistry. The idea was, that some fluid might be produced which would instantly dissolve all substances exposed to its influence; and it seems to have had a long existence as a fanciful speculation, rather than as a subject of arduous experiment and tedious research. The explanation of this is not difficult. The Universal Solvent had little to offer which could excite the hopes, and nothing which could inflame the cupidity of mankind. Wealth was not in its right hand, nor length of days in its left. It was a reverie of the laboratory, without interest, because it was without effect upon the 
longings or passions of the great masses of the human family. Yet there were a few chemists at different times fully possessed with this folly also, and ardently engaged in its pursuit. The whole idea of the alcahest is overturned by a very simple consideration which has been frequently well put. If an universal solvent were possible, what vessel could retain for an instant such a fluid?

Nothing eould have been more truly injurious to the true advancement of the seience of chemistry than the prevalence of these three dreams, and particularly of the first of them. So long as the philosophers thought they had a chance of opening, so to speak, a vein of gold in their laboratories; so long they neglected the truly useful and lucrative application of the powers of ehemistry to common manufactures, and so long also they remained indifferent to the discovery of any of the principles and laws of the science. Thus while much was known about chemical substances, nothing was known abont what is termed chemical philosophy, that is, that part of the science of chemistry which teaches us the laws and governing prineiples of these substances.

It was about the middle of the serenteenth century, a period which was like the very birthtime of all scientific knowledge, that, recognising at length the absurdities of their predecessors, philosophers began to lay the foundations of that noble system of chemistry, which is now at once the offspring, the pride, and the trimmph of experimental philosophy. The principles laid down in the celebrated work, called Novum Organum, of 
the illustrious Francis Bacon, proved most beneficial to the development of true knowledge, and assisted to destroy many of the foolish systems of philosophy which had so long held it a captive. As chemical philosophy was among the earliest to benefit by these principles, so it soonest began to expand and to gather continual strength. The origin and further progress of the science has been happily compared to Milton's fine description of the erection of Pandemonium :-

"Soon had his erew

Opened into the hill a spacious wound And digged out ribs of gold. . . . . . . Anon out of the earth, a fabric huge Rose like an exhalation . . . . .

Built like a temple."

About this period also the great scientific societies first took origin: the Royal Society in 1662; the Academy of Sciences at Paris in 1666. Thus the progress of knowledge received a most powerful impulse. The learned communicated periodically with each other, and united in the prosecution of similar scientific inquiries. Chemistry enjoyed much of their attention; and soon began to exhibit the hitherto concealed energies of a most important department of knowledge. Many of the elementary bodies were now known; and new ones were in continual process of being added to the list. Phosphorus, that most curious and peculiar substance, at first the chemist's toy, and sold at the rate of one hundred shillings the ounce, now, in the form of the lucifer, our most common domestic resource, with many salts, acids, and chemical preparations, became common. The 
advance, if not characterised by method, was rapid and certain.

It was now time that chemistry should receive the requisite framework of a science. $A$ vast number of experiments, with their results, were on record, and these were continually increasing. Gleams of the laws of combination, like scattered rays of light, darted upon the minds of experimenters. The comprehensive mind which should seize these indications, and reduce them to form and order, was yet wanting. - Nerertheless, chemistry was gradually assuming the definite character of a science. The doctrine of affinity, or of elective attractions, by which it is taught that some bodies unite chemically with others by preference, in the presence of other substances for which they have a fecble attraction, was promulgated by Bergman, and became an important doctrine of chemistry. That a great and most salutary revolution had been effected in the minds of the followers of this seience may be learned, when we read, toward the close of this period, the good confession of one who, scorning the pursuit of science for the sake of gold, could write, "My kingdom is not of this world. I trust that I have got hold of my pitcher by the right handle; the true method of treating this study. For the pseudo (or false) chemists seek gold; but the true philosopher, science, which is more precious than any gold." It was in the same spirit that a just reproof was given by D'Alembert to an ambitious young man, and as it deserves remembering, we venture to record it. "Science," said he, "must be loved 
for its own sake; and not for any advantage to be derived from it: no other principle will enable a man to make progress in the sciences."

Remarkable discoveries upon the nature of combustion' succeeded, and were followed by the labours of Hales, Black, and Cavendish, in their important investigations upon the chemistry of gases. The great discovery of the gas, oxygen, and of a part of the chemistry of vegetation, were next in order of progression. Water was formed, by Cavendish, by the union of its constituent gases, hydrogen and oxygen. This discovery is justly considered as deserving a special place in the history of chemistry. Mr. Watt appears to have arrived at the right conclusion as to the composition of this fluid, even before Cavendish; losing, however, as it is said, the honour of his discovery from the delay in the publication of his experiments. It would be tedious to follow in consecutive order the further progress of the science, and we shall, therefore, hasten to a close. With each successive year, it became richer in stores of facts, and more extensively applicable to the arts, comforts, and luxuries of mankind. The celebrated Dr. Dalton, the propounder of the atomic theoryone of the most beautiful of the science-published his views in 1803; and shortly after the immortal Davy rose to eminence by his electrical investigations. Subsequently Dr. Michael Faraday, by his splendid researches upon the electric principle and its important bearings upon Chemistry and chemical phenomena in general, gave an impetus to the science 
which will continue to be felt to the most distant ages of the future. TTe are thus rapidly and imperfectly brought to the state of the science in our own day. The remarkable speculations and discoveries of Dr. Prout on animal, and of Baron Licbig on regetable chemistry, and the chemistry of agriculture, together with the wonderinl discoveries of the phenomena of the chemical rays of the sunbeam by Niepce, Daguerre, Hersehel, R. Hunt, and others, may be fairly taken as the most raluable additions made in recent times to this department of knowledge.

In considering the present aspeet and relations of chemistry, we are struck with the extent of its influence, and with the importance of the position it occupies. Advancing years are continually extending the one, augmenting the other. Every branch of the arts now experienees its salutary reign. While it has eomtributed much to the growth of other seiences, by no means directly, or in the abstract, related to it, it has also added a varicty of substances to our present list of domestic comforts and conveniences. While it has tinged the purple and bleached the fine linen of the great, it has endowed with equal snowiness, and an equally durable, though more homely lustre, the calieo and coarsest fabric of the poor. Nor has it been less valuable in adding to our remedies for the sick. For medicine, in fact, it will probably in future time do more, and this by reason of its intimate connexion with that axt, than for any other department of scienee. In many instances chemistry deteets the disease, and points with much significance to the appropriate 
remedy. It analyses the processes constantly in operation in the mysterious laboratory of the human frame; and indicates with precision many of the changes which matter undergoes in the performance of the essential functions of life. It teaches us the most appropriate food for the strong and vigorous; and directs us how to modify and re-arrange the diet of the sick and feeble.' Chemistry too bears more directly than will be readily conjectured upon the life and destinies of nations. It has engines of tremendous power* for the annihilation of fleets and armies; yet, in its most peaceful applications, to renew and invigorate the soil, it gives promise to shed a full measure of peace and prosperity upon ages to come. In its products, while it has contributed much to the adornment of our persons, it has also" warmed, lighted, and ventilated our dwellings, purified our beverage, and supplied us with the most exquisite utensils for our meals. While we are enumerating the boons conferred upon us by this science, the dim oriental outlines of the fabled genii rise to recollection, by whose supernatural agencies, held in control by the magic lamp or ring, houses were built and stocked, and many other wonderful works easily performed. Such a heaven-born power is ours in the science of chemistry-the plaything of. the child, the fascination of the student, the servant of man, obedient to his bidding, who

* In all probability, Captain Warner's celebrated apparatus for the destruction of vessels at a great distance is an ingenious piece of mechanism charged with some explosive chemical compound-perhaps the remarkable fluid, the Chloride of Nitrogen. 
has the true amulet of power - knowledge. Surely the philosopher's stone, if it were a real existence, would prove a poor possession contrasted with the riches placed at our command by this science.

The instructive example has now been set before us of a science almost fruitless, and unproductive, when applied to base and unworthy ends, becoming, when directed to its legitimate objects, an inexhaustible source of blessing to mankind. It is an instance too striking to be lightly passed by, of the really. withering consequences of a persistence in opposition to the wise and merciful ordinances of the "Creator of the ends of the earth," and of the truly valuable results which flow from using lawfully the knowledge given to us by the Author and Giver of every good and perfeet gift.

It has been thought usefinl to present this short sketch of the origin and progress of chemistry up to the present time, in order that it may be seen what a tide of ignorance and folly flowed over, and concealed that knowledge of the chemistry of natural things, which. as gradually developed by modern experimenters, we are now enjoying. The poor alchemist, or he who ran after the phantom of an immortal-life-bestowing liquid, while skilled in the chemistry of the metals and in the preparation of purely chemical substances, was absolutely ignorant of the chemistry of nature. He could not have told us why his fire burned, still less could he have even guessed at the exquisite chemistry of a blade of grass. He knew not why the wind blew or the rain fell; and was 
ignorant even of the composition or mode of formation of a drop of dew. For a very long time, even after chemistry was pursued scientifically, the most fascinating of all its departments - the Chemistry of Nature-was totally neglected. Dr. Priestley and Sir Humphry Davy almost alone seem to have caught sight of its interest and importance. And almost all the knowledge we now possess of this subject has been brought to light exclusively during the last few years. As may therefore be imagined, our information upon this point, although of great extent, is still very imperfect; and we require many experiments, and much labour of investigation, to clear up our present difficulties. If, then, instead of vainly groping after gold, or gasping after an elixir of life, or indulging in such-like dreams and abstractions, the early chemists had but applied themselves to the study of the chemistry of the humblest objects in nature: if they had only tried to solve the problem, How does a flower spring up? how far advanced might we not at this time have been! Instead of occupying a place at the threshold, we might almost have reached the goal. Let us be thankful, however, that a brighter time in the history of the science has arrived; and let us look hopefully forward for the day when the ehemistry of nature will be as well understood as that of the ordinary substances which find a place in the laboratory of the experimenter, or in the shop of the chemist.

It is the intention of this work to explain the leading ehemical phenomena observed in 
nature, and to do so, as far as possible, without the unnecessary use and encumberment of scientific terms or expressions. In carrying out this design, the simplest plan appeared to be, to treat successively the chemistry of the earth, the air, and the ocean; by which means, almost all that is of importance to be learned of the chemistry of nature, will come simply and naturally under diseussion. Sueh a notice of the general principles of the science, as is requisite to render the subsequent pages free from difficulty, is added by way of a prefatory section to the ehemistry of the earth. 



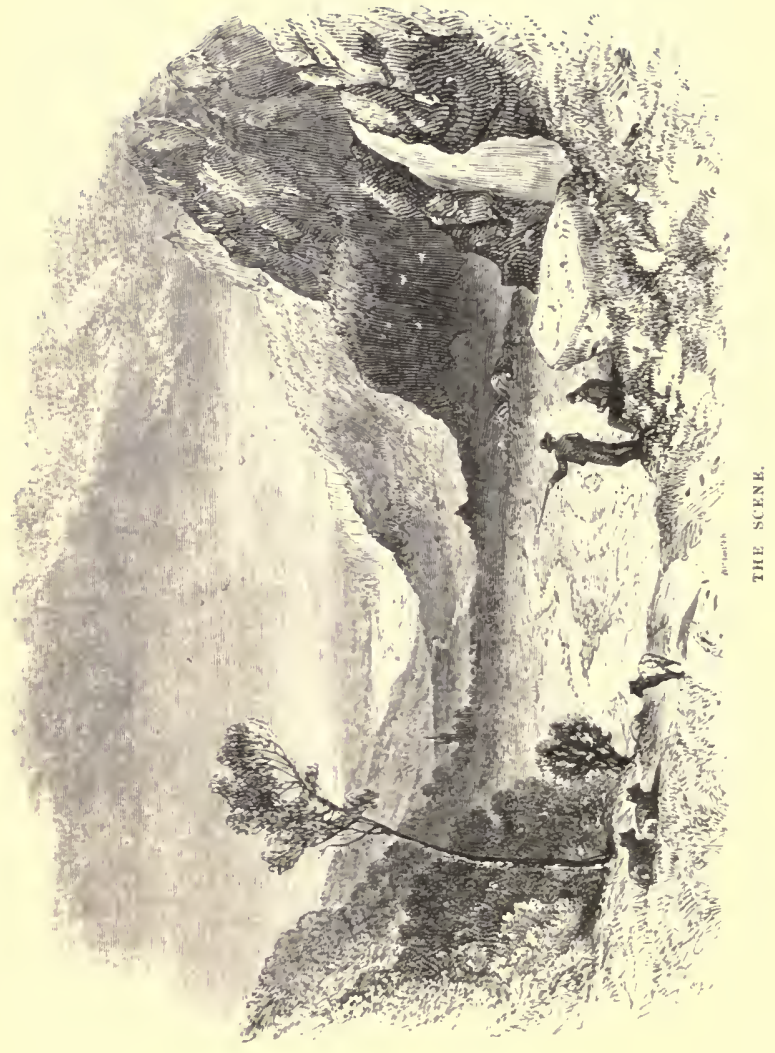




\title{
THE
}

\section{CHEMISTRY OF CREATION.}

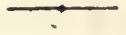 \\ PART I.-THE EARTH. \\ - "HIS HANDS PREPARED THE DRY LAND." \\ CHAPTER I.
}

THE INORGANIC CHEMISTRY OF NATURE.

WHEN an admirer of paintings walks through a long gallery in which are displayed the most , famous works of a great artist; he stands perchance before, one which more than all the rest attracts his attention, and becomes lost in the contemplation of its various excellences. The rich hues of the foreground become contrasted with the pale receding tones of colour on the horizon, and with these the deep transparent sky is exquisitely harmonized, the whole picture producing an impression upon his mind highly favourable to the skill of the painter. He goes 
away, and the impression remains deeply engraved upon his memory; yet if called upon to account for this impression by separating the individual peculiarities of the painting in the form of an analysis, probably not one spectator out of a thousand could execute the task. The picture was agreeable to his mind as a whole, and not as a combination of various parts, of different tints, and contrasted colours.

But if, on the contrary, a student stands wrapped in thoughtful admiration before the same painting, one whose own hand has laboured at the brush and palette, and in whose breast the aspiration after the highest honours of his art is nursed in hope, how different the effect upon his mind to that we have just been considering! Having been carefully tutored in the principles of the art, he is able to recognise in the work before him, the various steps and processes by which the unity and harmony of the whole have been produced. He marks with a scrutinizing and admiring eye the careful manner in which the different portions of the picture are worked out so as to be in keeping with the tenor of the entire work; and in various ways he is enabled to detect the development of the peculiar principles upon which the art of painting fundamentally rests. The other gazed upon the picture and was pleased- 
he knew not why. This spectator also gazes upon it with gratification; but it is of a higher and more refined nature, simply because he is acquainted with the various rules and axioms which guided the artist in its execution.

Such is, in a word, the difference between "common" and "philosophical" observation, or, to use a more homely phrase, between " eyes and no eyes." The great majority of persons, when beholding the majestic landscape which the Divine hand has created, come under the first of these designations,-they are common observers. It is true they mark with real and perhaps exalted pleasure the beauties of the scene, but they do not attempt to define the parts which in their union form the pleasing "whole." They see but they do not analyze; or in other words, they observe the scene as a scene, but do not discover and separate from one another the various parts which enter into its composition. It is the privilege of him whose mind has been opened to receive the truths of science, when placed in a similar situation, to enjoy all the gratification produced by the contemplation of the scene before him in its entireness, and in addition, the pure and intellectual pleasure of distinguishing the operation of various laws by the means of which he is aware that the harmony of the landscape has 
arisen and is preserved. To the enjoyment of this privilege, in so far as the knowledge of the principal chemical phenomena of nature is concerned, it is intended that the present work shall assist the reader.

Place we ourselves then in such a scene.* On all sides but one, the rugged forms of ancient rocks project into the sky, their summits capped with meagre herbage, and their sides the occasional resting places of some mountainflower. The roar of a cascade, formed by the accumulated waters shed from the hills in the distance, comes every now and then upon the ear. 'Above is the blue streteh of an almost unclouded sky. As the eye travels toward the horizon through the opening already alluded to, it sweeps over many miles of fertile land adorned with trees or yellow with corn, and enlivened by an occasional traveller, or by herds of cattle, until it rests upon the blue line of the ocean in the extreme distance. Here let us take our stand, and in the spirit of observation of which we have spoken, let us bring under review the interesting matters for chemical discourse presented to us by such a spot.

In so doing it is our intention to take up in suceession the chemistry of the inorganic, the animal, and the vegetable kingdoms of nature, so

* Vide the Frontispiece to this Part. 
far as it can be conveniently considered under the three great divisions of our work, the earth, the air, and ocean. An outline of many of the truths of chemistry will thus be brought under notice: but for purposes of scientific information of a more profound kind, and for the more abstruse doctrines of the science, the reader will naturally seek elsewhere. The object in view is more humble; yet this work may fulfil a legitimate calling in provoking the desires of some minds to deeper investigation, and in other instances, in giving that peculiar interest in the objects of nature which arises from a perception of some of the intricate and beautiful machinery which directs and controls their movements.

Attractive as the possession of this knowledge appears, it is not to be acquired nor retained without a general acquaintance with some of the fundamental principles of the science; and as this is by no means a difficult task, we propose, as briefly as maý be, to acquaint the reader with a few of their leading features.

Here our first attempt must be to reduce all material substances to their elementary or simple condition; our next to discover the laws by which the elements are governed in their behaviour one toward another. The ancient idea of the Elements was, as is well known, that there 
were but four-fire, air, earth, and water. But in truth none of these were elements; three are compounds; that is, each consists of two or more substances, and the fourth (fire) is only a condition of substances undergoing rapid chemical union. What then is an element? It may be described as a simple substance, which cannot be analyzed, or, in more popular terms, subdivided into two or more different substances. As an example we may select the element iron. All experiments upon this substance lead to the conclusion that it cannot be decomposed or subdivided into anything else than this simple element-iron. Let the chemist try his powers on the other hand upon water; very different is the result; the fluid disappears, and two gases arise, thus informing us of the fact that water is a compound, while iron is a simple substance. Such then, is the difference between an element and a compound. To lay down the constitution of an element in precise terms, we should say it is a simple substance, separate and distinct from all other substances, and incapable of being resolved into any further constituents. Yet it is to be remembered that an element is proved to be so only negatively; that is to say, we cannot discover it to be anything else by our present apparatus and means of analysis. It may, or may not, remain for the chemists of 
future years to develop the truth or falsity of a view which has been entertained by the minds of some of the profoundest philosophers, as well as by those of the wildest of the alchemists, that all matter has a common origin; that in fact, there is but one element, of which all the others are but modified forms.

Modern chemists have laboured to reduce, as far as possible, all substances within their reach to their ultimate constituents; to separate them, that is to say, until it was impossible to separate them any further. In so doing it has been discovered that a number of bodies once conceived to be elementary, have no real claim to that character. Such bodies have been found to be in fact composed of two or more elements. The number of chemical elements at present recognised as such is sixty-two.* But several of these are doubtful; and as science proceeds, it will probably remove màny from the list. The phenomena exhibited by some of the so-called elements, in different experiments of the laboratory, are so suspicious as to perplex the mind of the chemist as to their real constitution, leading him to suppose that they are anything but simple bodies, and many are looking forward to a period when it will be found that the number of true elements is small indeed.

* Dr. Fownes. 
It is convenient to arrange them under the following heads: 1 , gases; 2 , fluids; 3 , solids. Or they may be also described as 1, metallic; 2, non-metallic: 3, gaseous. But in these conditions bodies shade as it were into each other, the same body being under some circumstances solid, and under others fluid, such as water or mercury when frozen, and at the common temperature.

Out of the number above mentioned, fortyseven are tolerably well-marked metallic substances, about which little doubt now prevails; thus the majority of the elements belong to this division. There are but four gases; that is, of course, elementary or primary gases; these are oxygen, hydrogen, nitrogen, and chlorine. The remaining eleven are the non-metallic elements, or elements of intermediate characters.

When we come to consider the amount of relative importance which is borne by each of these elements to the rest of creation, we arrive at an interesting and somewhat startiing result. It would have been more in accordance with the ideas and expectations of the human mind to anticipate that a number of elements comparatively so small as that specified (sixty-two), was inadequate to form such singularly contrasted objects as surround us in creation, and to produce such varied results as are presented to us in the 
kingdom of nature. Or, if we allowed that number to be sufficient, man would anticipate the entire exhaustion of its powers, and would suppose that the whole number of elements had been employed and put together in various ways, in the work of constructing a universe full of the most varied and opposite substances. Chemistry teaches us that such is far from being the case. Do we look to the framework of the solid globe, triumphantly expecting to discover in its countless constituents the exhaustion of the whole range of elementary bodies? Our investigations supply a very different answer, and we may almost without an hyperbole say that so far as the crust of the globe is accessible to our experiments and analysis, and our researches penetrate deep therein, chemistry declares in round terms that the earth en masse is composed of but seven elements! These are silicium, calcium, aluminum, magnesium, potassitum, and sodium, united with the gas oxygen. Do we turn to the zoological and vegetable worlds, point to the countless myriads of species, and to the innumerable products of these kingdoms? How strange to discover that these are after all chiefly carbon, nitrogen, hydrogen, and oxygen! Lastly, do our eyes rest upon the broad ocean, constituting as it does three-fourths of the area of our planet? This vast accumulation of fluid 
may have its principal components expressed in two words,-oxygen and hydrogen. The number of the metals employed in the work and service of man is equally small in comparison with the number known to chemistry. Gold, silver, iron, copper, zine, lead, and tin being in commonest use; the larger number of metallic substances being obtainable with so much diffculty as to render them of little comparative utility; and the metals on the whole, properly so called, form but a very small part of the crust of the globe.

Thus while the forms in which material substances and organizations present themselves to our notice, are of the most pleasing aspect and unbounded variety, and though the bodies themselves possess the most opposite and dissimilar properties, all are reducible to a comparatively very small number of elements, or in other words, ultimate constituents. The results of this arrangement are very striking. How surprising to find that a gas (carbonic acid), diffused in fractional quantities even in the purest air, in one of its principal constituents (carbon) is one and the same with the solid material composing the dense forests! How wonderful to learn that the millions of tons of wood contained in some of the primeval forests of the earth were actually in a great measure directly 
derived from this gas dissolved in water, carried up by the roots, and metamorphosed in the leaves!

This variety of result may be illustrated in another manner. The acrid, dangerous, and highly corrosive liquid well known to every person as aquafortis, or impure nitric acid,-in its pure condition one of the most powerful re-agents of the laboratory, is composed of nitrogen and oxygen. These are also the constituents of the summer breeze! Whence then this notable change? The answer is, 1st, the relative proportions or quantities of the two elements are not the same-in the one the proportion of oxygen to that of nitrogen is much greater than in the other; and $2 \mathrm{nd}$, in the case of the nitric acid the elements are in chemical union, in the air they are only in a state of mixture. Thus an apparently trivial alteration in chemical conditions and proportional numbers effects a change of the most unexpected and startling order! Another alteration again in our atmosphere would produce "laughing gas," a substance whose stimulating properties have supplied its title. Not to proceed further, here are three products, of the most entirely opposite and unlike character, namely, nitric acid, atmospheric air, and laughing gas, composed of precisely the same elements. Why then 
do they differ so strikingly from one another? Because air is only a mixture of the two elements, laughing gas is a true chemical compound of the same, and nitric acid is also a chemical compound, but has five times the quantity of oxygen possessed by the laughing gas. But these are familiar examples. A more surprising vein of thought is opened when it is stated that chemistry is aequainted with substances which are absolutely identical, in the number and relative proportions or quantities of their elements, yet are as totally unlike one another in their sensible properties, such as colour, odour, and taste, as might be conceived of substances in noways related to them.

Such then is that peculiar and most wonderful feature in the constitution of creation,- the accomplishment of astonishing variety out of the fewest materials, which at the very onset chemistry presents to our admiration. And such in fact is the universal language of science; it may be called the economy of the creation. The Creator has taken, as it were, a mere handful of elements, and has formed out of them not only the gorgeous structure on which we dwell, but also ourselves, that is our material bodies, and our fellow-occupants of the earth, and the inhabitants of the air and the sea. Chemistry alone can disclose this fact, because it has found it out 
by searching and experiment. Yet while it catches a sure glimpse of this and other general laws, it also beholds phenomena of which it may take a dim cognizance, but as yet cannot comprehend. Do we ask why? The solemn voice of revelation answers, "Now we know only in part." The foreground mists of ignorance disappear indeed before the light of science; eternity and space, in their unfathomed realities, lie beyond.

If, then, it has pleased God to rear this beautiful creation upon so small a comparative number of predominant elements; if it has pleased Him to show his glorious attributes of power and wisdom in the formation of such multifarious products out of, in the main, but a few materials; what powers of developing new and exquisite harmonies, fresh and yet more lovely combinations of matter than earth has ever beheld, does chemistry suggest to us, should it be consistent with his will, in the formation of a new heaven and earth, to call into more extensive use the elements which in the present plan take so comparatively an insignificant part in the work of creation! If, as we may be permitted to conjecture, out of such limited resources such an astonishing variety has been produced, what may not the beauty of creation be, should all the resources we know 
to exist be brought prominently into operation! If, to illustrate mure clearly this idea, a great musician can produce charming music out of an instrument of but a few notes' compass, what soul-stirring melodies may we not expect when he is seated at a musical instrument better suited to display his powers! These and other considerations which we might adduce, show us how partial and imperfect is our highest knowledge. We only see, we only hear in part. Creation is but a partial display of the power and wisdom of its Author.

It has been well said not to be a scheme of optimism. Beautiful as creation, so far as our world is concerned, appears, nature as yet only wears what we might call her working dress. When the sabbath of the world dawns, then will she appear all glorious in apparel, all beautiful in form. And if so fair and lovely now, what will she not then be!

The thoughts we have here attempted to throw out, not to pursue, are intended to quicken our aspirations after that long-desired and yet future time, for which all creation waits and groans, when in more of their fulness the attributes of the Creator will be displayed before our wondering eyes.

We must consider the almost universally diffused element Oxygen, as occupying important 
perhaps the most important, offices in the chemistry. of nature. It is therefore by far the most abundant of the elementary bodies. It is the largest constituent by weight of the ocean, forming eight-ninths by weight of pure water. It forms a fifth part, by bulk, of the atmosphere: and it enters into a large number of combinations with, the solid ingredients of the globe. It is possessed of the most extensive range of chemical affinities; that is, it is capable of entering into chemical union with by far the greatest number of the other elementary or simple substances. Its connexion with, and its relation to, the vital functions of the animal frame, the necessities of mankind, the purity of the atmosphere, and the renovation of the face of the earth, will come into consideration in different portions of this work. When it combines with another body, the chemical name of that process of union is "oxidation," and when it is completed the resulting substance is an "oxide."

Hydrogen is also an important, element. It forms about one-ninth of the weight of water, which is, in fact, an oxide of hydrogen; it also enters largely into the composition of animal and vegetable structures.

Nitrogen forms one of the chief constituents of the atmosphere. It is remarkable chiefly for 
its indifference to the other elements, not readily uniting with the majority of them. But when under proper management it is made to combine with oxygen, the resulting substances are possessed of the most intense energies. United with the gas, hydrogen, it forms the important substance ammonia, upon which the life of vegetation, and, indirectly, of man himself and the animal world, appears to be dependent.

Finally, the element, Carbon, must also be considered important. It exists in minute proportions in union with oxygen in the atmosphere, as a gas, and in the solid form it composes, together with the elements of water and nitrogen, the chief part of the woods and vegetable clothing of the present, and of the coal formations belonging to a former period in the history of the earth.

Such is a short and simple outline of the characters of the most active and abundant elementary substances entering into the composition of the animal and vegetable worlds. In the mineral world we find a greater number of substances taking a prominent part in the chemistry of nature. The most important of these are silicon, calcium, magnesium, potassium, sodium, aluminum, iron, phosphorus, and sulphur. As we proceed we shall have suc- 
cessively to consider the innumerable links of union which connect these together, and which, as a whole, constitute the beautiful scheme of the chemistry of creation.

If a piece of polished iron is left in the open air, and is slightly moistened, we all know that it will very shortly rust, turning quite brown. Why does the iron rust? It is, because it, as an element, has a certain attraction for another element which is oxygen; so much so, that when they are placed together in favouring circumstances they will unite, or join together, so as to form a new substance-the rust. A certain unseen power draws the two elements together, and retains them by the closest bond in a new condition of union. This power or attraction is called Chemical Affinity. Each of the elements is under the influence of this power; that is, every element has a tendency to unite with one or more of the other elements; some with a greater, some with a smaller number. The iron unites with the oxygen because it is thus influenced. It is now found to be a general rule, that the more unlike to each other in their chemical properties bodies are, the stronger is their tendency to unite with one another. The tendency to unite between oxygen and iron is very powerful indeed; for these two elements 
are strongly opposed to each other in their chemical properties. Hydrogen and iron, on the contrary, have little or no disposition to unite, for they exhibit many chemical properties in common.

Bearing in mind this tendeney of every element to unite or combine with its dissimilars, we may readily imagine what sad confusion would take place in nature if the power which they are thus endowed with were not itself subject to certain fixed rules beyond which it could not operate. To-day, for example, iron might unite with one element, to-morrow with another; to-day it might be found in one condition, to-morrow in another; water might be to-day the fluid known to us as such, to-morrow it might be converted into one of another composition, and the third day might be resolved into its constituent gasesoxygen and hydrogen, the great ocean, and the seas and rivers disappearing into the air, to the destruction of the animal and vegetable worlds. In a word, it is not too much to say that the entire system of our globe would be speedily broken up, and the elements would return to their original state of confusion or chaos. To obviate such a result, that Almighty Creator, who is not the Author of confusion but of order, has appointed certain fixed laws 
which limit this tendency to unite among the elements in a very simple and remarkable manner. A drop of dew supplies us with an excellent illustration of the operation of these controlling laws, by which we may hope to render their action readily intelligible. This drop of dew consists of two gases, oxygen and hydrogen, which are chemically united into one substance-the water. Having obtained the same gases by chemical means, let us mix them together; if we then set fire to the mixture there follows a great explosion, and we find the jar in which the gases were contained no longer filled with. air, while drops of water bedew its sides.* Let the reader now ask himself, Why is this? Why are we quite sure that on mixing these gases thus together, and firing them, we shall produce water?. Why not something else? The reason is, that although these gascs have a powerful tendency to unite together, there are certain laws which compel them to unite in a certain manner, and to produce, so long as they do so, a certain result. If these laws did not exist, it would be impossible for us to tell what would be produced when we mixed and lighted the

* This experiment should only be performed with small quantities of the gases, and the jar should be thick and strong, and covered, all but the mouth, with a coarse cloth. . 
two gases. These laws are the laws of chemical. combination.

Having thus alluded to the elements, to their tendencies to combine together, and to the results that would without doubt follow were no controlling principles in existence to direct, harmonize, or neutralize the contending powers, we may briefly mention the laws which effect these objects, and by their simple but beautiful adjustments, produce much of that harmony which we behold in nature. Other laws may be broken or rendered inoperative by the force of circumstances; but these laws are fixed and unalterable. They are four in number.

1st. The same chemical compound (say water) must always possess a definite and unalterab̄le constancy of composition.

For example:-If we tonk a glass-full of water from a way-side brook in England, and another from the bosom of the Ganges deep in Hindostan, or a third from some mountaintorrent of the Alps, and examined them each chemically, of course taking care to distil them separately so as to obtain the water free from all earthy or other impurities, we should find that the water in these three instances had precisely the same composition; that is, by weight, eight parts oxygen, and onc hydro- 
gen. If, again, we wished to form water by uniting its constituent gases, we should find that we must take eight parts by weight of oxygen gas, and one of hydrogen, and that no other proportion would succeed. From these two experiments it would be manifest that water, wherever or however formed, is always the same substance, and is made up of the same component gases in the same relative proportions. If, again, we found a clear fluid, having all the appearance and character of water, and discovered, on analyzing it, that it contained sixteen parts of oxygen by weight to one of hydrogen, we should be immediately justified in declaring, on this account alone, that this was not water. Such a compound of oxygen and hydrogen actually exists, and has been called peroxide of hydrogen, or oxygenated water. From the circumstance of its possessing a different composition to that of water, however like that fluid it may appear, it is nevertheless a different substance. And this would be, because the first law of chemical combination declares that "the same chemical compound must always possess a definite and unalterable constancy of composition for the same substance."

"The converse of this rule, however, is not so universally true; the same elements com- 
bining in the same proportions, do not of necessity generate the same substance. Organic chemistry furnishes numerous instances of this very remarkable faet, in which the greatest diversity of properties is associated with identity of chemical composition."* Thus, while the same substance is always made up of the same elements in the same proportion, the same elements, in the same proportion, do not always form the same substance. This may appear paradoxical, but it is strictly true, although at present we are not quite able to explain or understand the eause.

2nd. Every ehemical body, in uniting with other bodies, does so in a eertain definite quantity or proportion, or in multiples of that quantity, and this is called the "equivalent," or combining proportion of the body.

For example:-When oxygen unites with hydrogen to form water, it does so in this proportion,-eight parts oxygen to one hydrogen. Four parts oxygen would not unite with one of hydrogen, nor any other number but eight, or a multiple of eight, such as sixteen. Again, nitrogen unites with oxygen in the proportion of fourteen parts by weight to eight of this gas. Every other element has what is called its combining proportion, or equivalent,

* Fownes: Chemistry, p. 174. 
by which is to be understood, in the words of the law, that "certain definite quantity" in which, and in none other, will it unite with other elements. These proportions or equivalents are all different from each other, though some approach remarkably close to a common number; thus, the "equivalent" of carbon is 6 ; that of lithium $6 \cdot 43$.

3rd. When a chemical body, say oxygen, unites with another in several quantities or proportions, or "equivalents," these proportions bear a simple relation to each other.

For example:-Oxygen unites with nitrogen in five different quantities, or proportions, thus :

Nitrogen 14 unites with 1 oxygen or 8 parts by weight.

\begin{tabular}{|c|c|c|c|}
\hline ", & $"$ & $"$ & 2 oxygen or 16 \\
\hline " & $"$ & $"$ & 3 oxygen or 24 \\
\hline$"$ & " & $"$ & 4 oxygen or 32 \\
\hline 业 & , & " & 5 oxygen or 40 \\
\hline
\end{tabular}

In this table, while the proportion of nitrogen remains constant, that of oxygen increases in the simple ratio of $8,16,24,32,40$.

4 th. The combining quantity, or "equivalent" of a compound substance, is the sum of the combining quantities of its component elements.

For example:-Nitric acid, without any water in its composition, is composed of fourteen 
parts of nitrogen, and forty parts of oxygen; that is, one equivalent of nitrogen, or $14+5$ equivalents of oxygen or 40 . Add these together, and we have 54 as the equivalent or combining quantity of this acid. Of how great importance the knowledge of this, and indeed of all the laws of chemical philosophy, is in the Arts, need scarcely to be told. As an illustration,-if it were requisite to make pure nitrate of soda, and nitric acid and the alkali, soda, were put into our hands to form it with, this last rule teaches us exactly how much nitric acid and how much soda we ought to use, so that the one shall be in exact cumbining proportion to the other, and so prevent our wasting either of these substances.

\begin{tabular}{|c|c|c|}
\hline \multirow[t]{2}{*}{ Thus, Soda is } & \multicolumn{2}{|c|}{ Sodium $23 \cdot 27$} \\
\hline & Oxygen & \\
\hline & & $31 \cdot 2$ \\
\hline
\end{tabular}

We already know the combining quantity of nitric acid to be 54; therefore, in order to produce nitrate of soda, we must weigh out 31.27 grains or pounds of soda, and 54 grains or pounds of nitric acid. On mixing them we should exactly form nitrate of soda with neither acid nor alkali in excess. The immense works now in full operation as chemical 
factories, where many hundred weights of materials are used at one operation, would succeed very indifferently, if at all, were not this last law taken as the guide of all their proceedings. Soda, glass, soap, paint, and a number of other substances, are now prepared in these works on purely scientific principles; and were it otherwise -as, indeed, it used once to be when the laws of chemistry were not known-vast losses would in many instances take place from one or other of the materials employed in excess or the contrary.

The harmonious regularity and order of the world around us are dependent upon these laws. There is no confusion of substances and elements without a definite purpose, and without stability, in nature. Every particle of which this great earth is formed is held bound by the chain of these laws; they direct its behaviour towards other particles, and the result is that the chemistry of nature, instead of presenting us with a scene of disorder and destruction, appears before us like some beautiful structure, every part of which has. its appointed place, every stone its niche, every bolt its proper resting-place, while the whole is of exquisite beauty and design.

When we have enumerated the elements, of many of which every object we behold, as we 
stand on this fair spot, and of the whole, the round world and all that therein is, are composed,-we have indeed learned much of the chemistry of nature. We can take up a stone and say, Such and such substances form it; or we can point to the tumbling waters of that cascade, and say, It is after all chiefly oxygen and hydrogen. We can say more-we can declare that the elements which go to form all this lovely ereation are under eertain laws which we can lay down with the utmost precision. This is to know much more still of this interesting subject. But this is not all. Had these blades of grass a voice, they would echo baek, This is not all. Had the sunbeam a tongue, it would ery, This is not all. Had those fleecy clouds which have crept up from the horizon, and are now gently sailing above us, had these the power of specch, they too would cry, This is not all. Nay, could these very rocks cry out, they must tell the same truth, and say, This is not all. We should be very ignorant of what is going on all around us if we alone were to answer back, This is all. No! there are wonderful forees in active operation on every side, so delicate in their mode of action, and so subtle in their nature, that until we are informed of their existence, it were scarecly to be wondered at if we were 
to exclaim,-Surely the knowledge of the elements, and of the laws which they observe, must comprise all that can be learned of the fundamental chemistry of creation.

If we were to aș, Why is this grass so green, that flower so fair in its coloured raiment, this gentle air so warm and balmy, and every object around us, glittering with light? we must apply to the sunbeam for an answer, and in the answer we shall find that pervading all nature, and performing the most important part in its operations, there are three distinct principles-all united in the sun-ray-heat, light, and chemical power, or actinism. Could we break up these bright streams of light which are now pouring down on hill and dale, giving joy, gladness, and life to the scene, into individual rays, and by some process separate one from all the rest, we should find all three in it-that is, we should find it to consist of a ray of heat, a ray of light, and a ray of chemical force or actinism, each of these rays being itself made up of several others. A simple experiment will prove that these three different classes of rays co-exist in a ray of sunlight. If on a bright summer's day we allow the rays of the sun to pass through a hole into a dark room, and then through a glass prism, we shall find, on holding up a white card a cortain dis- 
tance off the prism, that the ray of light is broken up into a strip of various colours, which is called the prismatic spectrum. (See cut.)

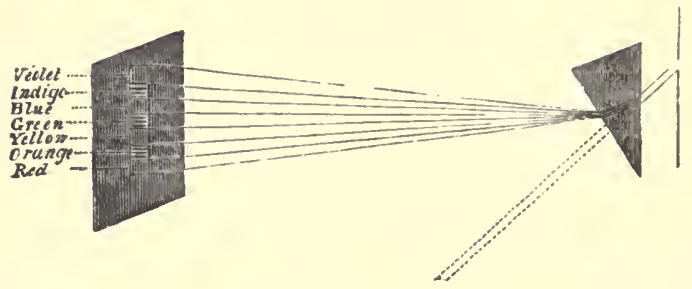

PRISMATIC SPECTROM.

This shows us that the ray of light is made up of several rays-three, as it is commonly now believed, the others being made up by the mingling of these in various ways together. This streak of beautiful colours exhibits to us, then, the Light of the solar ray; how are we to detect its Heat and Actinic force? If we take a very delicate thermometer, and put it first in the violet part of the streak, then bring it gradually downwards to the red, it would be found that the mereury rose very little in the violet part, and very much in the red part, and, strange to say, even a little beyond it, where we can see no colour at all, it would be highest of all! This shows us not only the heat of the sunbeam, but also the curious fact, 
that it exists chiefly in part of the prismatic spectrum where the red rays lic, and even where there is no light visible. It is supposed that this is accounted for by the rays of heat being less bent out of their direction by the prism than are the rays of light. We have still got to show the existence of that curious and interesting class of rays - the Actinic. This also may be readily done. A piece of paper on which some solution of nitrate of silver, or lunar caustic, as it is commonly called, has been brushed, after it has been dried, must be placed in the streak of coloured light. After a little time it will be found that the paper is blackened where the violet and indigo colours shone, and even beyond them, but less quickly, or to a very trifling degree, where the other colours are placed. The truth has been, that the nitrate of silver has been decomposed by the actinic, or chemical rays which exist chiefly in the upper part of this prismatic streak. It is supposed that the actinic rays are most bent out of their direction by the prism, so that they appear at the highest point of the spectrum.

Thus we see that every ray pouring down from the sun consists of light rays, of heat rays, and of chemical or actinic rays. Need it be said these have each a vastly important 
influence upon the many chemical processes of nature? We may spend profitably a few moments in glancing at these three principles, upon which so much depends in the beautiful world around us.

It is very remarkable that in the sublime, Divinely-inspired account which Moses has been authorized to give us of the Creation, it is related that the first step was the creation of Light. "And God said, Let there be light: and there was light." Thus showing us the infinite importance that this principle bears to all created things. Light is even now absolutely necessary to life, not less so than then, when its first beams darted upon a yet unfashioned world "without form and void." To every animal and plant, and equally to man, the monarch of creation himself, light is indispensable, and is inseparably connected with health, motion, and activity. What a gloomy world were ours if a deep canopy of black overhung the sky, leaving its inhabitants in darkness and the shadow of death! Unhappy persons, for offences of a political 'kind, have been long immured in prisons where no ray of light ever stole to enliven the solitude and horror of their dungeon, and the result has been invariably that such persons become of a death-like paleness, and lose every power both of mind 
and body, being ultimately reduced to a pitiablé wretchedness of condition. These effects are doubtless chiefly to be attributed to the absence of light. Little though it may be generally known, the flowers of various hues, the feathered tribes of glorious plumage, and the bright and beautiful among the insect tribes, and of those which inhabit the great deep-all owe their many-coloured aspeet to the influence of light. Is it not in the glowing atmosphere of the Tropies that we find the most splendid flowers and birds and insects? There, where the shadow of a cloud seldom flies over the bright and burning plains, where no fogs and vapours like those of our " distempered climate" interfere with the power and brilliancy of the solar rays, every, object is in holiday attire, and gleams with colours such as we should seek in vain in our more temperate, but after all, more highlyfavoured region.' Some remarks by Professor Edward F'orbes, in his Report on the Molluscous and -Radiate animals of the Egean Sea, exhibit this very elearly:-_ "The animals of Testacea and the Radiata of the higher zones are much more brilliantly coloured than those of the lower, where they are usually white, whatever the hue of the shell may be. Thus the genus Trochus is an example of a group of forms, mostly, presenting the most brilliant 
hues, both of shell and animal; but whilst the animals of such species as inhabit the littoral (or sea-shore) zone are gaily chequered with many vivid hues, those of the greater depth, though their shells are almost as highly coloured as the coverings of their allies nearer the surface, have their animals, for the most part, of a uniform yellow, or reddish hue, or else entirely white. The clief cause of this increase of intensity of colour as we ascend, is doubtless the increased amount of light above a certain depth." The sea-weeds and fish which have their abode near the surface of the water are far more beautiful than those which are found deeper down; and where the finny tribe live at the bottom, or at depths where a mere glimmer of light is all that distinguishes day from night, they become nearly colourless. On a future page, it will become necessary for us to enter more filly into the chemical influence of light upon the vegetable world, where it will be found that the wood and green parts of plants are principally formed by its agency.

Not less important is the principle of Heat in the phenomena of nature. It is this which assists to call into activity the germ of life lying dormant in the seed; this bids the insect's, egg awake and live; this breaks up the hard and stony surface of the ice-bound field, 
and lets a thousand cold-imprisoned plants go free; this clothes the forest with its leafy honours, ripens the green untempting burden of the orchard, and makes all creation to rejoice. All the day long the sun pours down upon the earth unfailing streams of this lifegiving principle, which then become diffused into the surrounding air; so making the breeze soft and warm, or penetrate a little distance into the soil, whence they again in part disperse into the air at night, when the sun has left us. Every object we behold is influenced to a greater or less degree by this principle. This nettle and that blade of grass; the one all covered with hairs, the other polished and glistening, are both affected by the warm summer rays, but not both alike. The nettle, being rough, is a good radiator, and therefore loses heat faster than the grass which is smooth and a bad radiator; but then the nettle is also a good absorber of heat, whereas the grass absorbs it slowly. Undoubtedly this difference of properties as respects heat was not appointed. in vain. We do not know why, but it is certainly necessary for the well-being of both plants, that they should be as they are. Perhaps the nettle may require to absorb much heat, and very quickly, in order to perfect some of the chemical phenomena of its growth; 
and the contrary with respect to the blade of grass.

But more than this: while every flower that blows is dependent upon heat for its expansion, and the perfection of its various functions, flowers differ from one another in what we may call the amount of their debt. Some absorb much heat, and with great rapidity; others absorb less, and that slowly. Strange to say, this is conneeted with their various colours, for it has been proved by philosophical experiments that bodies variously coloured have different absorbing and radiating powers with respect to heat. Dr. Franklin plaeed pieces of cloth of different colours in the sunshine on the surface of snow in winter, and found that in proportion to the depth of the colour, the snow melted most rapidly, in eonsequence of the deepcoloured pieces having absorbed heat much faster than the rest. When we look therefore at the flower-garden all begemmed with brilliant colours, how interesting is it to remember these colours were not given, in vain. The streaked tulip and the spotless garden lily do not absorb or radiate heat alike. The deep blush of the rose, the pale azure of the blue-bell, the glowing gold of the meadow butter-eup, are not therefore merely ornaments, or intended only to give variety to the scene, though doubtless 
that may be another object accomplished, by their different hues, but were all admirably adapted in order to enable the flowers to drink in that portion of the quickening influences of the sun's rays, which is most expedient for their peculiar wants.

The heat of the sun's rays performs other duties of a more momentous kind than any hitherto indicated. It is the grand agent by which currents are produced in the air. Yet, little do we think that the summer breeze that fans our cheek, little does the sailor think that the steady wind which impels his vessel, or the storm which threatens him and his ship with destruction, are alike put into movement by the subtile beams of the sun! Thus the circulation necessary for the preservation of the purity of the atmosphere is sustained,-thus the clouds are wafted to drop their burden on our thirsty fields,-thus man can spread his canvas wings, and fly to the ends of the earth -all as a consequence of this warm flood of sunshine in which the insects bask, and the landscape lies bathed and asleep. The heat of the sun is the great cause of the evaporation of water, and thus it lifts into the air the vapour, which, when condensed, comes down as the grateful shower to fertilize our land. Also, since chemical changes of all kinds go on much 
more rapidly at high than at low temperatures, the heat of the sun is largcly concerned in cach of the chemical phenomena, which are constantly taking place throughout nature.

The most remarkable of the three principles hitherto found in the sunbeam is the Actinic ray. The discovery of this most remarkable principle-if that is a correct term for it-is quite recent, comparatively with that of the two others. Yet its effects have becn known for ages. From time immemorial chemists have known that on exposing preparations of silver to the sun they become decomposed, and entirely altered in character. The rescarches of many philosophers in modern times have now, as we have already shown, proved the cxistence of these rays of actinism, in the most unquestionable manner. It is at present impossible to explain the real nature of the actinic force. We must rest satisfied by describing it as that power in the sun's ray which produces the chemical changes taking place in bodies exposed to the light.

These delicate yet potent rays fall, like the sunlight in which they are found, upon every portion of the surface of the landscape, and together with those of heat and light, they then produce effects of a most important kind. The towering trees of yonder forest, as well as 
the humble moss which clusters on their bark, owe their health and vigour, nay, their very existence to the actinic rays. Take away these from them, and they become sickly and feeble, and die. To this subject, however, we shall have occasion to return by and by. It is almost more surprising to discover that these rays exert a most powerful influence upon inanimate bodies. It is found that it is impossible to expose any solid substance, whatsoever its nature, to the sun's rays without its undergoing some change in consequence of the operation of these rays on its surface. Wonderful thought I the sunbeam cannot even impinge upon a plate of the hardest steel without leaving a trace of its passage behind. Every object in this scene is affected by this agency; those rugged cliffs, and those tall and frowning mountains, are for every hour that the sunlight strikes them undergoing a destructive change, and the most extensive effects would soon, be produced, were it not that a beautiful remedy has been provided, by which the injurious results that would otherwise follow are entirely obviated. If the world had not, like man, its stated time of rest, it would soon undergo the most serious changes, the end of which would be undoubtedly an entire alteration of every object on its surface. During the silent hours of night, however, it has been 
found that all these effects of the solar ray pass off, and all bodies restore themselves again to their original condition. It is not, therefore, to man and the animate world in general, and to vegetation, alone, that night and gentle sleep come "as Nature's sweet restorers;" the great earth must rest likewise. These ficlds and yonder bills slcep, and become restored and refreshed equally with the living and moving beings on their surface. Night is precious alike to all; in truth, it is indispensable.

The beautiful contrivance now so largely employed for the purpose of portrait taking, the Daguerreotype, exhibits in a singularly striking manner to us the potency and rapidity of action of the actinic rays of the sunbeam. In a darkened chamber, generally in a little box appropriately fitted, the rays of light proceeding from the sitter's figure are collected by means of a lens, and are caused to fall upon a silvered plate, which has been prepared by exposing it to the vapour of iodine and bromine. In a second of time the most faithful picture of the person is fixed upon the metal surface, in lincs which years cannot efface. By means of a camera obseura, and paper prepared in a peculiar manner, Mr. Fox Talbot has succeeded in producing the most exquisite sun-pictures, in which all the varying tones of 
light and shade, and every line of the scene, is exhibited with an accuracy to which no painter has, nor can attain. This invention is called the Talbotype. Thus the researches of modern science have enabled us to press the sunbeam into our service as an artist more speedy in execution, and more admirably accurate in its productions than the most skilful of men. Nature's own pencil is now employed to depict itself-the fairest landscape imprints its own image upon the enduring surfaces of metal or paper; the most minute points of detail are thus indelibly preserved to us, and the wanderer in foreign climes needs little exertion of his own to store his portfolio with pictures drawn by the sun, which on his return may often serve to bring to his recollection scenes and objects far distant then. An important improvement has recently taken place in the photographic art, in the substitution of plates of glass for sheets of paper. The pictures thus obtained are extremely beautiful. At Greenwich a great number of the various observations are self-registered by employing the actinic power of light. The details are too complicated to be easily undertood; this application, however, is chiefly made in the case of the magnetical observations by little mirrors placed upon the needles, which reflect the light of a lamp on to a sheet of pre- 
pared paper. Thus, when the ncedles move, they cause the reflected light also to move a certain distance on the paper, and wherever this light falls it leaves its mark in the discoloration that instantly takes place. It has also been proposed to copy objects in the microscope by easting the image on prepared paper. This would be highly useful. This delightful art is called Photography, that is, light-drawing, but it would be preferable to style it Heliography or sun-drawing, since it is the actinic rays, not the strietly light-or luminous rays of the sunbeam which produce them. Hitherto we can only be said to have perfectly succeeded in producing pictures of one tint alone; but some singular experiments have been made, and are still in the course of prosecution, which seem to indicate that in time it will be even possible to produce perfect pictures, each object being represented in its natural colours.* This would indeed be a triumph in the science of light.

The warm and pleasant sunshine then, gently though it flies from hill to hill, and lies on the valley and distant waters, is an agent of astonishing power, and of the most vital im-

* Recent announcements have shown the possibility of this. It is said that pictures have actually been taken impressed with the natural colours of the objects. 
portance to all things around us. Though we cannot quite say, with the poet, that the glorious sun

" plays the alchemist,

Turning with splendour of his precious eye

The meagre cloddy earth to glitt'ring gold ;"

yet when we look at all the exquisite colours and forms which owe their existence to its beams, we can say that a ray of light fulfils a wonderful part in the chemistry of creation. We shall have occasion, as we proceed, to refer to its varied influences in the different kingdoms whose chemistry we propose to consider.

Yet the sunshine after all only forms one of several agencies which combine together to give life to, and to preserve the many beauties of our landscape. The earth, the grass, the trees, yon shining river, and those sailing clouds, could they be again interrogated, would disclose to us yet another agent, which influences them all, and is for ever darting from and to them, silently and unseen, assisting in all the phenomena they exhibit, and consequently intimately concerned in the various processes of the chemistry of creation. This agent is electricity. This quick and wonderful principle passes incessantly through the soil on which we tread, influencing in various ways the chemical ingredients it contains. Every blade of grass is sensible of 
its passage through its juicy colls into the air, and every leaf, and every trec, is constantly either parting with it, or receiving it, and conducting it to the soil. Even the animal frame is pervaded by it. 'The wide atmosphere is a grand receptacle in which immense quantities of it are stored. No chemical change can take place in nature without the development of this agent, or, at any rate, without its becoming implicated in the process.

More wonderful even than the application of the actinic power of light to the wants and purposes of man, is that of Electricity. By its aid, with the assistance of the ingenious contrivance of the Electric telegraph, we can communicate in a second of time our wishes or commands to immense distances. Recent improvements have enabled us even to print by electricity, and this at any interval of space, so that the Royal speech may be printed and distributed at the very ends of our island on the afternoon of its delivery. By it also, even portraits can be painted; so that if a criminal were on his flight, not only would electricity immeasurably outstrip him and carry the news to the terminus, but it might also be made to depict his correct likeness, and so infallibly secure his detection and arrest. Electric messages are now also sent bencath the waters of 
the Channel, forming a chord of communication between England and France. The electricity of low intensity produced by means of the galvanic battery is now largely employed in multiplying casts of medallions and in overlaying articles of various kinds with silver and gold. A beautiful application of the same power, and one which affords us a pleasing evidence of the fact that electrical currents are constantly flying through the solid crust beneath our feet, is the Electrical clock. Mr. Bain has, by arranging plates in the earth, with connecting wires attached to them, conveyed away sufficient electricity from these currents to keep in constant and regular motion a clock of peculiar construction; and he proposes to regulate all the clocks in a large city by this means, so that all should exhibit precisely the same time! In addition to the forces already enumerated, the powers of Magnetism and of Gravity bear in a particular manner importantly upon a variety of the chemical phenomena of nature. Into the consideration of these, however, we shall not enter.

Thus, standing on this point which commands a view of the whole of the scene $*$ before us, we have found that a number of subtle principles or forces have been exhibited to us as con* See p. 24. 
cerned in the countless chemical phenomena which are taking place so silently and imperceptibly around, above, and beneath us. All nature owns the sway of light, heat, actinism, electricity, magnetism, and gravity. Yet the real constitution of every onc of these powers is hidden from us. Philosophy is completely at a loss, when she is asked what are light, or heat, or any of the other active agencics enumerated. We can estimate and correctly describe their effects; but there we must stop. Many men of science in the present day appear to think they are all modifications of one principle; we have, however, much to learn before this can be rendered a probable, or at least, a satisfactory view of the subject. It is a reflection full of consolation to the Christian mind to remember that all these agencies, so active in themselves, and so powerful, are only subordinate instruments in the hands of an ever-superintending God, the Creator, and can only do that which $\mathrm{He}$ pleases -fulfil that which $\mathrm{He}$ has first commanded. Other thoughts, however, and a new range of inquiry, await us. 


\section{CHAPTER II.}

\section{CHEMISTRY OF THE LAND.}

Standixg on this elevated spot we may take a survey of the scene before us. All is still; the breeze has died away, the air is now clear, and without a cloud, and the ear listens in vain to catch a sound, beyond the low and fitful rushing of those foaming waters, which, as they leave their rocky channel and flow through the fields beneath, again become silent, and roll noiselessly into the sea. The shepherd's flock lies under the shadow of the overarching elm-tree, the cattle are standing in the shady hollow by the river-side, and the cowherd himself stretches his lazy length upon the soft grass on the bank. These green meadows, so fresh and luxuriant in their appearance, seem also asleep. The humble and soberly-arrayed flowers which bedeck the soil, lift up their gaze to the light, and seem athirst for a refreshing shower. Although it is midday, and every object is bathed in sunshine, all is so quiet and so motionless, that the repose is like that of the night. 
We may return home, and on another opportunity revisit the spot. If we go in Autumn, we shall find that it has shed its golden tones of colour over hill and valley, the earth has yielded its increase, and the fields, bared of their waving burden, look empty and naked. If in Winter, the waterfall is hung round with pendants of ice, the surface of the river is hard and solid, and a white canopy of snow enrelopes the whole face of the landscape. With these natural changes we are made familiar by the continual round of the seasons; but beyond these, to the unscientific observer it would appear that all things continue as they were. From year to year the hard lineaments of the rocks, and the rounder figure of the hills, are as familiar to our eyes as are the well-known faces at the fireside, and the elastic sod seems in all respects the same as that on which we danced in childhood.

Is it, however, so in reality? Are there no changes taking place around us of a different kind to those of the seasons? In truth there are, and those of a most important kind. Chemical forces are in ceaseless operation, the tendency of which is to bring down to the dust of the earth the hardest of those proud eliffs, now looking so strong and enduring. 'The substance of these rocks is gently crumbling away and 
falling in fine particles to become united with that of the plains at their feet. The green sward, though apparently the same, is in reality not so even from year to year; its materials are being constantly removed, altered, and re-deposited. The air we breathe is incessantly altered in composition, and restored again, and its particles are in constant commotion and change of place and condition. The ocean is the scene of similar events.

The face of the earth is for ever renewed, altered, and re-formed. Generations of men, animals, and plants, perish and pass away, and with the fall of each, the constituents and character of the surface perpetually vary. All is in process of change; yet all presents the appearance of a profound repose. All things are working together and without cessation, even in the natural kingdom, and for good. The chemical energies know no such condition as quiescence in nature. They take no rest; the cessation of one process is only the commencement of another; there is no absolute rest. They could cease from action only when they had reduced the whole earth to a smooth, level ball; and all that it contains to a certain fixity of composition. But there are wise counteracting causes which forbid such a result, and these very laws of change often also react 
upon themselves, so that the real condition of nature is an equilibrium-an equilibrium, however, which is preserved by continual cfforts on each side to upset the balance.

This is a strong expression of the facts silently presented to us eren in such a quict scene as we have been contemplating. And it is neccssary to offer them with one qualification. Many of the changes thus ceaselessly occurring are absolutely inappreciable by the ordinary tokens: thus, chemistry alone can tell us that the atmosphere is constantly undergoing changes of addition, subtraction, and restitution, to the most enormous amount; but the senses cannot discover it. And with regard to the surface-changes, the amount of alteration at any one time is minute, and the extent can only be measured by a long lapse of years. It is important therefore to remember that these changes are in constant progress under our eyes, however silent and imperceptible may be their occurrence. By little and little the beautiful fabric of our globe gets out of repair, and is repaired again; its features the meanwhile not sensibly altered, although continually altering. The rocks which shut in the valley in which we have placed ourselves are dropping to pieces. Could years be compressed into hours, we should see their rugged sides crumbling down in great 
heaps; and could a thousand years be as one day, we should probably see many of them swept away and levelled to the ground before our feet.

It will now be interesting to inquire by what processes these destructive, wearing-down operations are accomplished. The apparently feeble and contemptible powers are Water, Carbonic Acid, and Oxygen. Water acts in two ways, first simply as a mechanical agent, or as a solvent of various matters; and secondly as a medium by which carbonic acid and oxygen in a dissolved state are applied to the substances undergoing the change. The sacred philosopher long since wrote:- "The dropping of water weareth away the stones," and undoubtedly in mountainous regions where the force of running water is very great, or in any other place where a large mass of water sweeps along the earth, the mechanically-destructive powers of water are very great. At the Falls of Niagara, for example, geologists are considered to have proved that in the course of time the river has cut its way back through several miles of rock, and is still gradually receding, though with extreme slowness, at the rate, it is said, of a foot a year.* In so doing it is difficult even

* It will be understood that while admitting this fact, no assent is thereby given to the argument as to the assumed age of the earth, which is conceived to be supported by this phenomenon. 
to calculate how many millions of tons of solid rock the water must have worn away in the time occupied in the removal of the Falls from their previous to their present position. The manner in which this process of disintegration is

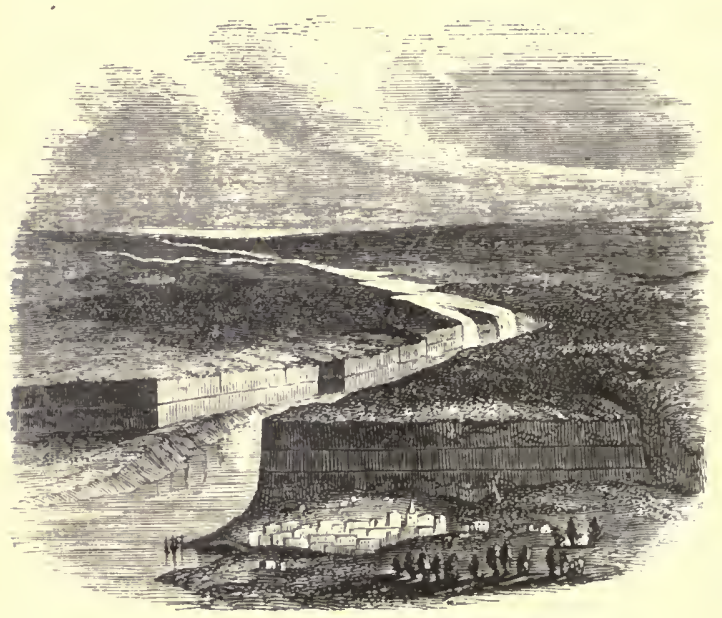

BIRD'S-EYE VIEW OF SIAGAKA FALLS AND COTYTRY AhOLID,

effected is described by Sir C. Lyell in the following terms:-_" The waters, after cutting through strata of limestone, about fifty feet thick in the Rapids, descend perpendicularly at the Falls over another mass of limestone, about ninety feet thick, beneath which lie soft shoals of equal thickness, continually undermined by the 
action of the spray driven violently by gusts of wind against the base of the precipice. In consequence, of this disintegration portions. of the incumbent rock are left unsupported, and tumble down from time to time, so that the cataract is made to recede southwards. The descent of huge rocky fragments of the undermined limestone at the Horse-shoe Fall in 1828, and another at the American Fall, in 1818, are said to have shaken the adjacent country like an earthquake."

In particular districts the simple dissolving power of water produces alterations of the most serious kind. One of the most interesting examples of this kind fell under the observation of the writer in the salt districts of Cheshire, and it is probably unique of its kind. The reader is, doubtless, aware that at a certain depth beneath the soil in these districts, exist vast beds of common salt. Some of these are worked in the usual manner by mining, shafts being bored down to them, and the salt being then dug and blasted out. By this means, the hard, impure substance, called "Rock Salt," is procured. But ordinary table salt is obtained in a different manner. In various parts of the districts, what are called brine springs have been found; these are simply springs of water charged with a large quantity of salt, and are 
naturally formed by water percolating through the soil to the salt-beds, there dissolving a portion of the salt, and then being pumped up by machinery. From this brine table-salt is procured by boiling down in large flat iron pans, in which it crystallizes, and from which it is ladled out, poured into wooden moulds, and dried.

There are a large number of salt-works constantly in operation, which by means of powerful steam-engines are continually pumping up immense quantities of brine, and so removing constantly large portions of the salt-beds beneath, which disappear under the dissolving influenec of water. At a very large salt-work the annual quantity of salt thus dissolved out is considerably upwards of 52,000 tons! In other words, we may say that water in the immediate neighbourhood of this factory carries away every year upwards of 52,000 tons of solid material from the ground beneath. Conceive the effect of this in twenty or thirty years! Above all, conceive the effect of many large works, each draining away many thousands of tons even in a single year! Multitudes of railway excarators could not make such a cavity in the earth in the same space of time as does the water acting simply as a solvent. As may be imagined, all this does not go on 
without sensibly affecting matters on the surface; in fact, the effects are most extensive, and even disastrous. Every year the land in the vicinity of Northwich, near the banks of the river Weaver, subsides to a greater or less degree, and as it subsides the river encroaches upon it, converting what was formerly meadowland. into a lake of many acres in extent. Those works which are placed near the stream are every year compelled to be raised to a higher and higher level to avoid the encroaching waters. What was once a pleasant walk is now a pleasant sail, for it is covered with deep water! Cottages, landmarks, footpaths, are all gently, but surely, becoming submerged by the sinking of the land. Buildings in these spots are rendered most insecure by the gradual failure of the foundation. Some are bound together with iron girders to keep them from falling. Tall chimneys present a most ludicrous appearance; many of them lean as much as the leaning tower of Pisa, and are only kept from tumbling down by strong iron. rods which are attached to them to hold them up. In short, the whole district around the brine springs is settling down, at a rate which is proportionate to the amount of solid salt dissolved by the water, so as to fill up the vacuity left. Water has performed a curious office also for the rocks 
of one of the islands of the Preitic. These rocks are composed of erystallized carbonate of lime, perhaps originally coral, but by exposure to the air, and by the percolation of water, the loose particles of calcareous matter have been washed away, and the whole mass presents in consequence a very brilliant erystalline appearance.

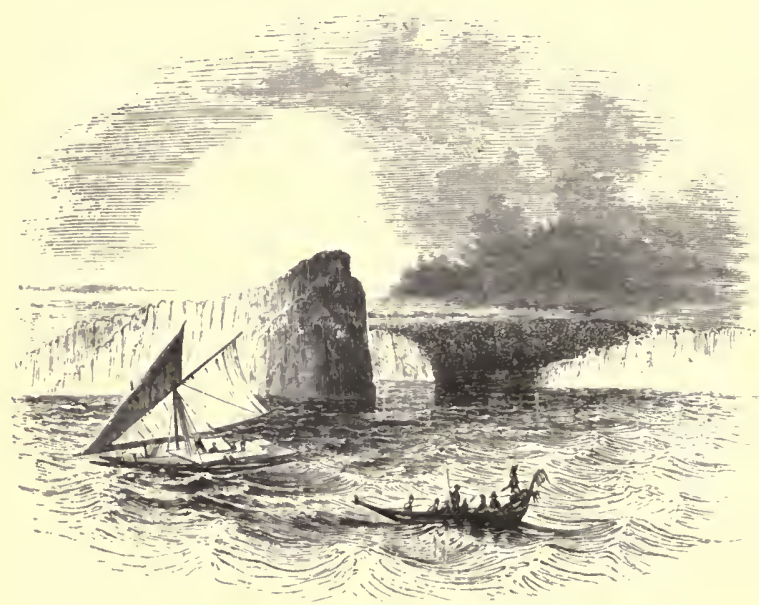

THE CNYSTAL ISLAND.

The island is represented in the eut. Other instances* of the extensive influence of the dis-

* The baths of San Philippo, in Tuscany, are mentioned by Sir Charles Iryell as yiclding waters which contain so much lime in solution as to yield a stratum a foot thick in four 
solving power of water might be mentioned, but none so strikingly illustrate the fact as those here detailed. The mechanical influence of water upon our sea-cousts will receive notice in another part of this work. We must pass by, however, the simply mechanical and solvent powers of water as concerned in the phenomena of nature, to the far more important consideration of its chemical effects.

In this respect-that is, as a chemical agentwater acts chictly as a vehicle for the application of another chemical body-Carbonic acid. This gas is capable of being largely dissolved by water, and so becomes peculiarly applicable to fulfil the duties of a chemical agent, since such bodies always act most readily in solution. It has been found that felspar, which forms a great part of the hard' rocks, granite and porphyry, will withstand, almost without injury, for some time, the action of cold muriatic acid, which is a powerfully corrosive, fuming liquid. But water, charged with carbonic acid gas, affects it rapidly, causes it to decompose, and

months. In a pond into which they are conductcd, they have deposited a solid mass, thirty feet thick, in the period of twenty years. The mineral contents of the water are turned to profitable account by the establishment of a manufactory for medallions in basso-relievo. Moulds are exposed to the spray of falling waters, and in a short time are coated over with a beautifully white crust, as hard as marble. 
breaks up the obdurate mass into particles. Thus granite, one of the most dense and enduring rocks entering into the construction of our planet, of all others perhaps the lcast generally affected by chemical re-agents, yields to the gentle influence of a chemical power so apparently feeble as that of carbonated water. We shall immediately have to notice how great are the effects produeed in nature by this means; but it may be stated, in the meanwhile, that the manner in which earbonated water produces these wonderful and important effects, appears to be as follows:-Granite being largely composed of felspar, contains a considerable quantity of alkali in its composition, for which the carbonated water has an affinity-that is, it has a tendency to unite with and to dissolve out the alkali. The consequence is, that the alkali being dissolved out of the mass, it crumbles in pieces, and in course of time becomes, as we shall see, quite a different substance.

The Professors Rogers, of America, have recently instituted an elaborate series of experiments upon the actual dissolving and decomposing power of water, pure, and charged with carbonie aeid gas. They find that the influence here attributed to these simple chemical agents has not been over-rated; and that rocks of all kinds, those without an alkali in their com- 
position, as well as those which possess one, are decomposed or dissolved by this means, with comparative rapidity.

Oxygen gas, forming a part of the air, also acts in a powerful manner upon rocks of various kinds. It does so chiefly when they contain iron in their composition. Many times must the reddish brown stains on the exposed surface of various rocks have attracted notice. Such stains generally indicate that the rocks contain some compound of iron in their substance, and show the influence of the air and water in decomposing it, and so causing it to be removed and washed away. This gas, uniting with the iron, causes the particles of the rock to lose their mutual cohesion, and consequently the hard mass becomes cracked and softened, and ultimatcly, after a sufficient lapse of time, is actually reduced to a powdery condition. This gas is, like carbonic acid, soluble in water, although only to a very slight extent. We may conceive, therefore, that in a dissolved state, as, for example, in rain-water, it may have some decomposing power over the rocks washed by the winter shower, which, though trifling at a time, may become important in its accumulated effects.

Having thus alluded to the influence of the most important agents employed in the chemistry of nature for the purpose of wearing down 
the hard rocks and minerals exposed to their action, we may proceed to seleet a few instances which will exhibit the importance of their operations on the large scale. D'Aubuisson relates that the granite country of Auvergne and the Eastern Pyrenees is often so much decomposed, that the traveller may imagine himself upon large tracts of gravel. And to show that this process, under favouring circumstances, may be of sufficient rapidity to be observable in a few years, the same author mentions, that in a hollow way which had been only six years blasted through granite, it was found on examination that its walls were so much decomposed by the influence of carbonic acid, that the solid rock, to the depth of three inches, was in a crumbling condition. Dolomicu ealls the peculiar effect produced by this gas a "disease of the granite," la maladie du granite. In such districts, masses of granite are found, which look quite solid, yet when touched by the hand, or trodden by the foot of the traveller, fall to powder. Such is the influence of this decomposition in granite, that it is found in the quarries at Dartmoor, to the depth of fifty or sixty feet, to be more or less decomposed. Consequently, this granite, which is called surface granite, is less durable than that obtained beyond the influenee of decom- 
position. The prison at Dartmoor is formed of this surface granite, and the result is, that each block has become a spongy mass, absorbing moisture continually, rusting the iron bars, and rendering the cells so damp that they can only be used by covering the walls within and without with Roman cement or tiles. The granite used for the Nelson Monument in

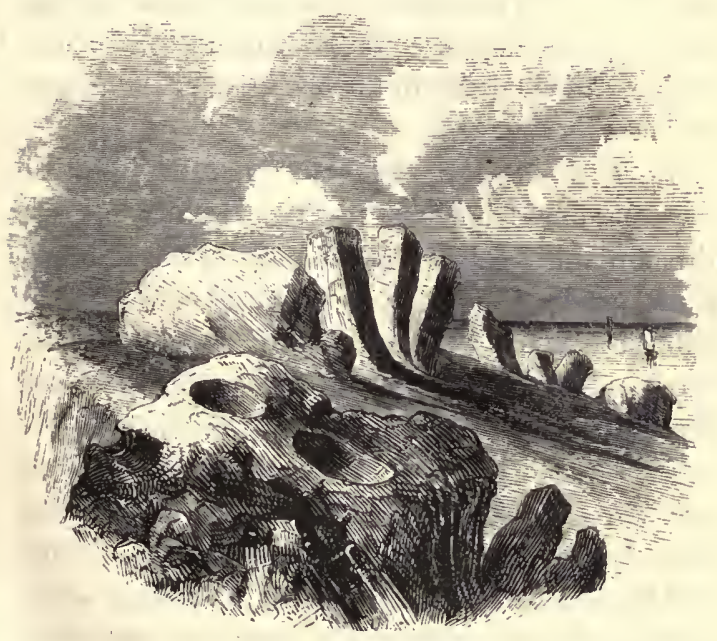

THE KETTLE AND PANS.

London is obtained from beyond the influence of atmospheric decomposition. The most curious and grotesque results often arise from this cause. Many of the strangely-fashioned stones 
which antiquaries take pleasure in considering to be the work of Druid hands, have been chiselled by these decomposing powers alone. Sir H. de la Beche mentions a singular specimen of such natural sculpture, as oecurring at a point on the Isle of St. Mary, Scilly Islands, called the "Kettle and Pans." This curiosity consists of several basins, apparently hewn out of the rock, some of which are eighteen feet in circumferenee, and six in depth. It is believed they are entirely attributable to the operation of the eauses in question.

It is a singular fact that we are indebted for all our porcelain to the results of the decomposing agents just described! All our earthenware, from the eommonest jug to the house-tile and flower-pot, is in like manner produced from a material which is formed by the influenee of water, air, and carbonic acid, upon rocks of various kinds, but all more or less agreeing in composition as to their chief ingredients. In certain distriets in Devonshire and Cornwall, there exist rocks of a fine white granite, which exhibit the decomposing effect of these agents in a remarkable inanner.*

* At Shaw, a few miles from Plymouth, the surface for hundreds of acres consists of decomposed felspar, in a state resembling flour. When purified and baked it forms a fine porcelain. 
On the surface, and for a considerable depth into their substance, the rock is altered to a soft matter resembling mortar. This is collected and washed; the water which comes from the washing of it being of the colour of milk, in consequence of its containing a quantity of white earthy substance suspended in it, is conducted into tanks, and in its passage through several reservoirs, deposits this white earthy matter at the bottom. The tanks are then emptied of water, and the white deposit being removed and dried in the open air, and subsequently more completely by a drying-stove, constitutes the beautifully fine white clay employed in the manufacture of porcelain. Not less than 10,000 tons of this white clay, thus derived from the decomposed material of the granite rock, is exported annually for the use of the potteries. Its chemical composition-the composition in great part of our china cups and ornamental ware-is alumina (the basis of common alum), silicic acid, a little alkali and lime, and in the unburnt state, a large proportion of water, together with a variable amount of sand. The Chinese, as well as ourselves, employ the same material for the manufacture of their exquisite porcelain.

The composition of granite, unchanged as contrasted with that which has been thus de- 
composed, shows us which of its ingredients goes to form the white clay spoken of. Unaltered granite, upon analysis, is found to consist of quartz, mica, and felspar. It is the latter ingredient, as we have already noticed, which undergoes decomposition by the influence of water, carbonic acid, and air. Consequently, the two others, quartz and mica, are left behind, and form the heavy particles of the decomposing rocks which remain after the white clay has been washed away.

Clay of every description is produced in the same manner; yet, as is familiarly known, it is only the best china which is of a pure white colour. Common earthenware is more or less yellowish, or brown, or even red. This does not essentially depend upon any difference in the mode of formation of the clay from which it is made; it is all equally derived from the decomposition of felspar, but arises simply from the fact, that some rocks containing felspar contain also iron, or other colouring matter, which of course communicates its stain to the clay obtained from it.

Surprise has often been expressed how mines of silver have been discovered in such extraordinary situations as some of those on the bleak summits of the Cordilleras of South America. But a little consideration of the 
effects of the agents we are speaking of would, in a simple manner, have removed the difficulty. Silver, it is well known, resists the action of the air and weather, while the rocks in which the 'veins of the metal lie, are readily decomposed, and worn away. The natural result is, that in process of time, the veins of silver are left standing out from the surface of the cliff, which has been worn away all around them, and so the first wanderer that passes by finds a mass of the precious metal sticking out of the rock. We are told by Mr. Darwin that the celebrated and rich mine of Chanuncillo, from which silver, to the value of many hundred thousand pounds, has been raised in the course of a few years, was discovered by a man who threw a stone at his loaded donkey, and thinking that it was very heavy, he picked it up, and found it full of pure silver. 'The vein occurred at no great distance, standing up like a wedge of metal.

That vast supply of gold which has been recently discovered in the sands of rivers, and in the valleys of Australia and California, is another indirect result of the disintegrating influences of air, carbonic acid, and water. This noble metal being scattered in small particles through the substance of various ancient rocks, is at length, by the constant wearing down of the latter, set loose, and is then washed down and borne by 
mountain-torrents to a distance from its original position. Its great weight and density render it easily separable, simply by washing, which carries away the lighter particles of sand and mud, leaving the heavy metal behind.

In Egypt, the student of the chemistry of nature is presented with a highly remarkable illustration of the operation of these causes of waste and decay. In countries where the atmosphere is charged with moisture, and rain is frequent, or wind prevalent, the destructive effects of these agents upon the strongest buildings soon become evident. This is strikingly exemplified in the Delta and the rest of Lower Egypt, which are affected by the exhalations arising from the neighbouring sea. The consequence is, that Memphis, which was formerly the celebrated capital of the whole kingdom, Heliopolis, Sais, and other important eities, are now mere heaps of ruins. The granite obelisks at Alexandria are partly illegible through the corroding influence of the atmosphere. On the contrary, in Upper Egypt, the monuments, unaffected by the inundations of the Nile, and the tombs, exhibit no signs of decay after the lapse of many centuries. The black bricks made out of the mud of the Nile, and dried in the sun, some of which have been exposed to the open air for thousands of years, as is proved 
by their bearing the name of Ramses Miamun, who is supposed to have reigned in the fourteenth century before the birth of our Lord, still retain their original hardness and firm position in the temples, pyramids, and tombs for which they have been used, together with all their architectural ornaments.

Máterials thus worn down by the chemical agency spoken of is called débris, a word which signifies a wreck, or waste of anything, and is therefore very appropriately employed to designate the wreck or waste of the cliffs under the slow but certain powers of the chemistry of nature. Débris generally collects at the base of the cliffs, by the decomposition of which it has been formed, and does so generally in the form of conical heaps, the upper point of the cone resting against the side of the rock. Sometimes, and particularly in the stupendous mountains of South America, great masses of this "waste" slide down into the valleys like huge avalanches, overwhelming every object in their course. It is at the base of these mighty mountains, that the "waste" rises sometimes to the enormous height of two thousand feet - the accumulated result of the action of water, gas, and air, for innumerable centurics. But these heaps, vast as they are, are only the visible monuments of the power and ex- 
tent of these destroying agents, and as such only represent a very small amount of the débris actually produced. The greater part

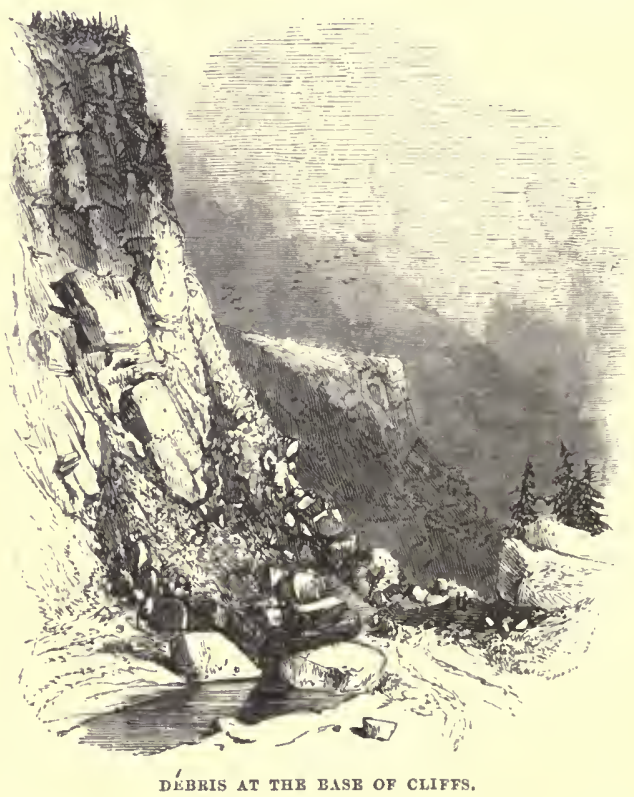

of it is swept down by rain and borne away to be deposited in the last resting-place of the rivers, whether that be lake or occan into which it ultimately falls. The granitie summits of Mont Blane, and of the adjoining range, exposing a vast surface to the atmosphere, are of 
course peculiarly exposed to the destroying powers in question. Glaciers and avalanches sweep down from their sides the crumbling particles, in the form of mud, pebbles, and detritus, or crushed rubbish, and thus supply the impetuous river Arne, which descends from - these lofty regions. "Scarcely," says Sir C. Lyell, "has the Rhone passed out of the Lake of Geneva before its pure waters are filled with sand and sediment by the Arne. The Rhone afterwards receives vast contributions of transported matter from the Alps of Dauphigny, and the volcanic mountains of central France; and when at length it enters the Mediterranean, it discolours the blue waters of that sca with a whitish sediment for the distance of between six and seven miles." The Red River of Louisiana is so full of the disintegrated particles derived from a region of red porphyry rocks through which it flows, as to have received its name from the fact; the river deposits its sediment on its banks in regular layers of red. Many other rivers are coloured blue, black, yellow, and brown from similar causes. The very names of the Ganges and Nile are so associated with the fertilizing influence of the mud they convey, as scarcely to make it necessary to allude to them in illustration of this subject. But it may be mentioned as affording us somewhat of an illus- 
tration of the amount of effect possible to be thus produced, that it has been calculated that the former of these rivers, in the course of a single year, carries down many millions of tons of mud-that is, of disintegrated rock. The sediment thus carried down is spread out upon the bottom of the seas, into which it is discharged, there forming a layer of yearly increasing thickness.

The more wild and rugged the scenery of nature, the more certainly and rapidly do these agents, first the chemical forces, and next the mechanical, combine to carry on the work of disintegration, and, if we may so call it, decay. In the gorgeous scenery of the Andes, where rise bare and precipitous hills of porphyry, pinnacles, and fortresses of rock, more wild and grand than painter yet conceived, and where violent conflicts of the elements are not unfrequent, it may be imagined that this process goes on with unusual rapidity. The following passage from the journal of Mr. Darwin conveys the impression with peculiar force :-

"The rivers which flow in these valleys (of the Cordilleras) onght rather to be called mountain torrentș. Their inclination is very great, and their water the colour of mud. The roar which the Maypu made, as it rushed over the great rounded fragments, was like that of the 
sea. Amidst the din of rushing waters, the noise from the stones, as they rattled one over another, was most distinctly audible even from a distance. This rattling noise, night and day, may be heard along the whole course of the torrent. The sound spoke eloquently to the geologist; the thousands and thousands of stones, which, striking against each other, made the one dull uniform sound, were all hurrying in one direction. It was like thinking on time, where the minute that now glides past is irrecoverable. So was it with these stones; the ocean is their eternity, and each note of that wild music told of one more step towards their destiny.

"It is not possible for the mind to comprehend, except by a slow process, any effect which is produced by a cause repeated so often that the multiplier itself conveys an idea not more definite than the savage implies when he points to the hairs of his head. As often as I have seen beds of mud, sand, and, shingle, accumulated to the thickness of many thousand feet, I have felt inclined to exclaim, that causes, such as the present rivers and the present beaches, could never have ground down and produced such masses. But, on the other hand, when listening to the rattling noise of these torrents, and calling to mind that whole races 
of animals have passed away from the face of the earth, and that, during this whole period, night and day, these stones have gone rattling onwards in their course, I have thought to myself, Can any mountains, any continent, withstand such waste?"

The material washed down by rivers after it has been disintegrated by chemical forces, and deposited under water either in the sea or in a lake, is called alluvium, when in the course of natural events it is at length raised above the surface of the water, as when, by some circumstance, the course of the river becomes altered, and the matter it formerly carried towards the sea becomes exposed. It constitutes, in fact, what may be called the mineral soil of many valleys, such as that we are contemplating, lying just underneath the vegetable soil formed ehiefly by the decay of vegetable matters. It consists of sand, gravel, stones, and fine sediment or mud, most of which may be often traced back to their source in the mountains or hills in which the rivers took origin, simply by analyzing them, and finding out their respective eomposition. We may thus, frequently, with some certainty, on taking up a stone from the bed of the torrent, and examining it at home, were we to find it composed of lime, declare that it was broken off and carried from 
ROCKS AND HILLS CRUMBLING DOWN. 91

some rock of the same substance, perhaps many miles from the spot where we obtained the specimen.

Enough has now been said to exhibit the powerful, although silent influences which, under the direction and constant control of the Allwise Creator, are incessantly at work in altering and destroying some of the most apparently unchanged and unchangeable objects which surround us. It has been seen that the rocks and hills are slowly crumbling away, and the forces which perform this duty have been shown to consist only of water, air, and carbonic acid. While mountain, rock, and valley, lose by the touch of water and gas, can the softer soil resist their influence? or are these alone affected by the powers of chemistry and the movements of time? 


\section{CHAPTER III.}

CHEMISTRY OF THE SOIL.

The law of change, illustrated in the last chapter cxclusively by its influences upon the sterner features of our landscape, the rocks and mountains, prevails even in the soft and tender layer of brown earth, which we find on the surface of the field. Herc, it is true, are less obvious processes of chemical change, eren than in the instances we have been considering; but they nevertheless exist, for the whole mass of vegetable mould is a body of substances contimually decomposing and altering in nature. This, therefore, also becomes an interesting subject of inquiry to the student of the chemistry of creation.

The soil which covers so extensive a portion of the earth's surface consists of materials which differ essentially in different localitics, but which may be described in general terms, as comprising the following constituents-the disintegrated particles of rocks, sand, clay, and calcareous matters, and the decomposing remains 
of animal and vegetable bodies. The soil is that reservoir from whence men and animals indirectly, and vegetables more directly, derive their sustenance. From hence proceed, by virtue of the beautiful laws of vital chemistry, the pleasant fruit for man's refreshment, the valuable grain for his support, the medicinal herb for the relief of his sufferings, the root for the colouring of his garments, and that large list of useful products, which manifest by their very number and variety, the benevolence and wisdom of God. While the depths of the earth supply man with materials for his utensils, for his luxury, or for his bodily comfort, the soil yields to all the animate creation, as well to the meanest animal as to man, as well to the humble violet as to the lofty tree, almost all that they require for the support of life. The phrase, then, "Mother-earth," is, even in a literal sense, correct.

We have in the last chapter drawn the very necessary distinction between the "mineral" and the "vegetable" soil. The chemical processes concerned in the formation of these two important layers of material are very different. The mineral soil consists of the waste of rocks, \&c.; the "vegetable" of the débris, or waste of plants, with organic remains superadded. And though in nature the one 
cannot be distinctly separated from the other, because both are mixed in a great measure together, it should not be lost sight of that the natural processes which produce the alluvium, and those which form vegetable soil or " mould," are quite different, and must not be confounded together. The subject, therefore, of the present chapter, is the chemistry of vegetable soil, or mould, and the method of its formation.

Let us travel back in thought to the time when the scenery we are now beholding exhibited a very different aspect. Yonder ziver now rolling down a channel, some twenty miles long, and emptying itself into the sea, was then an impetuous torrent, not a third of its present length. Those green and fertile plains which form the smooth bottom of the ralley, were then submerged beneath the waters; and from the spot on which we now stand, the eye, as it looked across to the rocks and hills on the other side, would have seen only tossing waves, in the place of waving corn. In a word, this valley did not then exist, it was a beautiful bay, the waters of the sea washing the foot of the hills and rocks, which now hem it in; and at its upper end the torrent, formed by the water-shed of the distant mountains inland, and of the hills around, poured into the sea, bringing down mud, gravel, and stones incessantly. 
Time went on; the waters of the sea gradually went back, leaving more and more of the bottom of the bay exposed, and the river had, of course, now to flow through a longer channel in order to reach the sea. As the waters retired, they left a large part of the upper end of the bay, where the river had emptied itself at first, uncovered; and here the river had left its alluvium or sediment, spread out in a triangular form, or like the Greek letter $\Delta$, the point representing the mouth of the river, and the broad part or base, the spreading out of the sediment, at first under the waters.

At this time nearly all the soil contained within this triangular piece, or, as it is called by geologists, Delta, was "mineral soil ;" and was obtained by the river, from the "waste" of the hills and rocks. The sea appeared to retire, leaving the bottom of the valley, for such it now became, covered with the mineral soil, brought down by the river. At first, this soil presented the appearance of dried mud; and we should have looked in vain for the soft brown layer, which now covers the whole valley, from one end to the other. This brown layer consists of vegetable soil, and the vegetable soil had not then been formed, for the waters had only recently departed, leaving the ground dry.

The seeds of plants carried by the wind, or 
dropped by birds, fell upon the alluvium; soon they put forth roots and leaves and flourished in great luxuriance, for this soil is very rich in the mineral ingredients and metallic oxides which plants require for their nutrition. More and more plants tenanted the once bare and naked surface, and it soon looked green and flourishing. Grasses and herbs crowded upon it; and where but a short time before the turbid waters of the river rolled down, now, in green glory waved a number of humble plants, whose vigour of growth sufficiently indicated how acceptable the situation they oceupied was to them. So it went on for a Spring, Summer, and Autumn. But Winter came, and slew all these, for they fell withered and dead, beneath his icy touch, and showers of dead leaves, from the forest on the hills hard by, covered them over as in a tomb. As soon as they were dead, the powers of chemistry began to act upon them. Water and oxygen caused their dead parts to rot or decompose, to become softened, reduced to powder, and at length to become altered into that very brown mould, which we now find on digging into the surface.

The layer thus formed was, of course, very thin at first. But year after year, as it saw fresh plants spring up, flourish, die, and decay, added to its thickness; and so in course of time 
a considerable layer was formed, several inches in depth, mainly consisting of the material formed by the decay of successive generations of plants. Such is briefly the history of the vegetable soil of this valley.

In examining the chemical history of this substance, it may be profitable to select an anecdote of forest life, in regions where sun, and air, and rain, together with other co-operating causes, act more powerfully than in our temperate climate.

The inhabitants of the vast primeval forests of the New World are frequently startled by the crash of falling timber, shaking even the solid ground under foot. Proceeding in the direction of the noise, it is found to have arisen from the downfall of some vast vegetable monarch, which, after centuries of increasing strength and grandeur, has at length fallen a victim to the exhaustive influences of time and old age, and lies on a heap of humbler forest-trees, which it has dashed to the ground in its descent. No sooner has it fallen than a number of agents set to work to effect its complete destruction. The rain-drops from heaven saturate it, the burning. solar ray darts down upon and heats it, and favoured by the temperature, the air begins to act chemically upon the prostrate trunk. 
Insects come, and bore long galleries through its sides; ants and beetles also drill their holes through and through, and others cat away its bark. Thus rain and air get access to the very heart of the tree. By-and-bye, all the insects have taken their departure. The sun, wind, and rain, have been, nevertheless, incessantly acting upon it; and now a tribe of painted fungi, of the most curious forms and splendid colours, sit upon the crumbling mass. Another portion of time glides away. Where is the prostrate tree?

The smiling sward, the up-springing flower, the unruffled aspect of surrounding vegetation, answer, "Not here-not here." Even so. The place which for centuries it covered with the grateful shadow of its broad branches, which it protected from the fierce, pelting of the tropical storm, and fiercer rays of a tropic's sun, has forgotten even its existence. "The place thereof knows it no more."

Is it so? Is the tree not there? Surely it is ; but its elements have all long since passed into another form, and some may at this moment actually form a portion of the ungrateful regetation, which by its thick and clustering growth, and undisturbed appearance, seemed to have denied even its existence. The tree has crumbled into dust; and the dust has blended with 
the earth, and can no longer be distinguished therefrom. How has this great change been effected? By what means has the hard and unyielding woody fibre of this giant tree been broken up, and left a mass of powder? Chemistry gives the reply, and informs us, that it is by successive chemical decompositions, that the loftiest inhabitant of the woods has fallen, and entered the common home of all living things, where, the great and the small, even among plants, rest together.

When woody fibre is moistened, and freely exposed to the action of the atmosphere, it immediately begins to undergo chemical decomposition. There is an interchange of ingredients between it and the air. There is also a certain amount of heat evolved. The fibre alters its external characters, changes colour, and loses tenacity: in common language, it is said to be "rotting." The process goes on, the colour deepens, until at length it becomes brown, and the mass is so friable as to crumble to pieces in the hand.

The chemistry of this change is not difficult. The organic compounds of the tree decompose, and their elements, carbon, oxygen, hydrogen, and nitrogen, become re-arranged in a more simple form. The hydrogen of the wood combines with oxygen, and is gradually given off 
as water. The nitrogen and hydrogen combine to form ammonia in small quantities. The carbon unites with oxygen and forms carbonic acid, which is slowly given off. These processes continue, until the form and substance of the wood are no longer recognisable; and the remainder is now called humus. Its chemical composition, although very variable, consists, in general terms, of carbon, with a little oxygen and hydrogen, and some insoluble earthy matters, formerly entering into the composition of vegetable tissue. The carbonic acid given off in this process of decay, either escapes into the air, or, dissolved by water, it supplies the roots of plants with a small portion of their food. Sometimes, when air is excluded, or partly so, as in the centre of a hay-stack, chemical changes go on so rapidly as to produce sufficient heat to set fire to the stack, if the hay has been stacked in too moist a state. Hence means are employed to ventilate the interior of ricks by boring large holes into them. Heaps of tow, hemp, cotton, \&c., take fire spontancously in a similar manner.

The most familiar example we could sclect of a decay of woody fibre, is the rotting of straw, and the formation of vegetable manure. Those to whom the busy farm-yard has at any time been an interesting scene, will readily be ablc 
to follow the changes which the fibre undergoes, after having left the stable, and being cast upon the dung-heap.* The decomposition goes on at so rapid a rate, that the temperature of the mass rises very considerably; and we know familiarly, that the heat thus produced, is turned to good account by horticulturists, for the formation of their hot-beds. As a tolerably equable source of moist heat, it is almost unequalled for such purposes. The long and glittering stems of the straw break up, lose their golden lustre, and are gradually reduced to an earthy, brown mass. The change is now complete, and in the crumbling condition in which it is now found, it is transferred again to the fields, the scenes of its bygone youth, vigour, and ripe age.

Thus is vegetable mould, strictly so called, chemically produced. It must, therefore, be regarded as a layer of material, in which, as we have said, continual processes of decomposition are going forward. A large amount of oxygen is absorbed from the air, and a continual return is made by the disengagement of carbonic acid gas. Vegetable mould in this condition is, we

* In consequence of the volatile nature of the carbonate of ammonia, formed in the decay of manure, this proceeding is a very wasteful one, since this substance is found to constitute a great part of the efficacy of such manure. 
may repeat, called humus. When decay has proceeded to a certain length, the constituents have become so entirely altered and reconstructed, that this decomposition no longer takes place. No more oxygen is absorbed, and no more carbonic acid is discharged. In this condition mould is analogous to peat, which may be defined to be vegetable fibre which has undergone comparatively complete decay, only the decay proceeds on somewhat different principles to that of ordinary vegetable mould, or humus.

This ultimate cessation of changes, however, never in reality takes place in nature, because every Autumn witnesses a fresh accession of decomposing material to the soil, in the shape of withered roots, stems, and leaves. The mould of our gardens, fields, and woods, is consequently always in process of change; absorbing oxygen, emitting carbonic acid, restoring the carbon of plants to the soil, and fulfilling its most important office, in causing the separation of the mineral ingredients, previously contained in the decaying plants, by the thorough disorganization of structure and tissue which takes place.

An important question here arises-Of what use is the decaying woody fibre to vegetation? Is the fibre thus comminuted, and reduced to 
powder, that it may again enter into the organism of plants? The gardener who prizes his well-rotted leaf soil for his floral nurslings, the agriculturist who spreads his fields with steaming loads of his farm-yard produce, and the majority of persons unacquainted with the chemistry of agriculture, will perhaps smile at our even venturing to question the exceeding great value of vegetable mould. When they behold the rich blossoms and luxuriant stems of the conservatory, and the soil groaning under a heavy harvest, and all this fertility following the application of vegetable manure, they appear to have a natural and unquestionable argument in its favour. Nor is its utility to be denied. The question is-On what does the fertilising property depend?

One of the principal ingredients of plants is the element carbon. Carbon is also the principal ingredient of regetable mould. Is the mould then the true source of the carbon, or solid part of vegetables? It was long thought to be so. Liebig, with his usual happy method of demonstration, has now clearly proved that this longreceived opinion is an error. While we shall return to this subject on a future occasion, when it will be more appropriately introduced, we may here mention that the fact is now well ascertained, that pure vegetable mould is, when em- 
ployed alone, almost useless for the purposes of vegetation. The principal uses of vegetable mould are to supply a small portion of carbonic acid to the delicate rootlets of young plants, and to restore the different salts and mineral ingredients of plants back again to the soil. The inorganic matters necessary to the life of plants are thus given back to the surface; they consist chiefly of the alkalis, phosphates, silica, sulphur, iron, lime, magnesia, \&c. Peat is a soil full of carbon; and yet, because of the absence of the latter ingredients, peat is the most barren of soils for all ordinary purpoșes; in fact, plants potted in pure peat, from which all soluble and insolublo salts, and other matter, are washed away, will languish and die. The different data upon which this interesting and important conclusion rests, will be found under the chemistry of the atmosphere.

While such is the process of decay adapted to the production of the vegetable soil, there is a remarkable variety of the same process, which has a most momentous bearing upon the welfare of mankind. This is the decay preceding the formation of coal. In the Mackenzie River we may be said to be permitted to see a modern type of the process, by which, in former times, the formation of this invaluable material was accomplished. Vast quantities of timber are 
brought down annually by this stream into the Slave Lake. The trees which have been torn down by the impetuous current, generally retain a considerable mass of earth and stones entangled in their roots; they, therefore, readily sink, and by so doing form considerable shoals, which time converts into wooden islands. "Then," says Dr. Richardson, "a thicket of small willows covers the newly-formed island, as soon as it appears above water, and their fibrous roots serve to bind the whole together firmly. The trunks of the trees gradually decay, until they are converted into a blackish brown substance, resembling peat, but which still retains more or less of the fibrous structure of wood." If we now suppose this island sunk to the bottom of the river, covered over with many beds of mud, and then left for a long period to perfect the chemical changes already begun, we have a complete idea of this interesting process.

The chemistry of it is as follows. In contact with but little air, and a large mass of water, the changes which take place are necessarily somewhat different from those occurring in woody fibre exposed to the air. Under these circumstances, a decomposition somewhat analogous to putrefaction or fermentation takes place in the wood. Its elements undergo rearrangement, the ultimate effect of which; com- 
bined with pressure, is to reduce it to a black substance, possessed of almost mineral characters. The decomposed mass becomes gradually covered with a deposit of sediment: the great pressure of which, when accumulated into beds of clay, or sand of some thickness, gives the hardness and density of a true mineral to this substance. It thus becomes stored up, it may be, for future employment in the service of man.*

It is interesting to remark the manner by which it has pleased the Great Architect of the world to order matters so, that out of the same material, two products so totally different in uses and structure as vegetable soil and coal, should be formed. Woody fibre is the material in both cases; the result how different! Thus, the decay of plants and leaves on the surface, in the course of a single year, restores to the soil all the materials it had been deprived of in their production; and this is effected by one sort of chemical decay. But the decomposition by which coal has been produced, the object in

* The leaves of ferns, reeds, and other plants, are frequently found between layers of shale or slaty elay, beautifully perfeet, but quite converted into coal! And in many kinds of eoal by means of very thin sections, and by the employment of the microseope, the eells of a vegetable strueture become visible; thus affording us a distinet proof that coal is really a vegetable substance, and produced by vegetable decay. 
view being different, is so ordered as to result in the formation of an admirable fuel, for the convenience of man. Decay in this case certainly takes place, but in so peculiar a manner, as to effect an alteration in the wood, which almost preventing further change, yet supplies an inestimable economical product, the very source of greatness and power to nations, of comfort, and even of existence, to large masses of mankind.

This peculiar decomposition in the production of coal is a beautiful example of the chemistry of creation. And in connexion with the subject, it is interesting to notice the wonderful manner in which the masses of coal have been arranged, in the great storehouse of the earth, for the use and convenience of man. "What," says Dr. Fownes, "can be more striking than the aspect of an English coal-field, where ironore of excellent kind lies interstratified with the fuel necessary to reduce it? Where the limestone used as a flux, and even the very grit and fire-clay to build the furnace, are all to be found in one and the same series, often within a few yards of each other?" If, in fact, the ore and the fuel were not thus nearly placed together, this invaluable metal, iron, would become of so high a price, as to render it comparatively unavailable for the general purposes of man. 
Surely here is wisdom in design, here is forethought, and pre-arrangement of events; and this is the work of God.

Before passing from this subject, we may mention that the origin of a jewel, the most precious in the eyes of the wealthy, and the most valuable in some of the arts, is probably ascribable to a process somewhat similar to that of the decay first mentioned. The diamond is, as is very generally known, erystalline carbon. It may be, therefore, burned, like charcoal, in oxygen gas. Diamonds are frequently found, whose lustre is greatly dimmed by some impurities within. When such "flawed " brilliants are burned, there generally remains a little heap of ashes behind. Under the microscope these ashes are found to possess traces of organized tissues, like the celled tissue of leaves or wood, in a skeleton state. It has been supposed, therefore, that the diamond has been produced under peeuliar eireumstanees by the decay of woody fibre proceeding to its extreme limit, when crystallized carbon became at length separated.

This would seem the most probable explanation to which seience can at present point for a solution of the difficulty in which chemists find themselves when called upon to account for its origin. Diamonds cannot be artificially 
produced at a high temperature, or by any form or variety of chemical experiment. It would appear probable they were first liquid, and crystallized from that condition. Amber, also, has been considered by some to be a product of decaying vegetable matter; it is found in abundance on the coast of Prussia, partly in beds of fossil coal, partly on the shore, and at the bottom of the sea. Others suppose it to be simply a fossil resin. 


\section{CHAPTER IV.}

\section{CHEMISTRY OF THE INTERIOR.}

WE have seen that on the surface the powers of the chemistry of creation are never at rest; that the repose which prevails is apparent, not real, and that there is a ceaseless law of change influeneing all the objects which have been presented to our notice. Must we suppose that the earth's chemistries are only on the surface, and that all within is quiescent? Could by some power a chasm be rent through the crust on which we stand, and we look down into the fearful gulf below, we should doubtless find that there was no scene of quiet, no symptom of repose. It might be thought that, without such a means of ascertaining what was going on in the interior of the earth, there was little for the student of nature's chemistry to investigate upon this subject. But we shall proceed to show that in various ways a very large and very interesting amount of information is afforded us, as to the chemical processes 
in operation in regions to which no mortal eye can penetrate. And evidence will be adduced to show, that in all probability the interior of this great planet resembles rather some immense laboratory, where enormous chemical decompositions are continually carried on, amid the fury of intense fires, than the silent and dark abyss we are commonly disposed to regard it.

What matter of thought is here? Deep under those smiling fields, beneath that peaceful hamlet, lie stores of raging elements, fiercely contending together. All around us here exhibits to us the forces of chemistry only in their gentler operations. The chemical phenomena of the landscape takes place without tumult, and altogether imperceptibly to the senses. But there we may conceive the wild artillery of nature constantly roaring, while masses of matter of enormous magnitude are now resolved into this, now into that chemical compound, the changes being accompanied with proportionate evolutions of light, heat, and electricity. How solemn these reflections! How solemn the remembrance of the predicted end of the present heavens and earth-they are "reserved unto fire!" How easily might God cause the great earth to open, and let loose upon the fair creation outside all the terrible powers which, at his command, lie bound within! All that can be learned of 
the state of matters within our globe, goes to assure us that the deep chemistry of the earth is on a scale of grandeur to which we are entire strangers on the surface of the planet, and seems. to bid us remember upon how frail and uncertain a tenure our lease of this position is held.

Yet its workings are, and must remain, in a great measure concealed from our eyes. The fairy tales of the East represent the world below as a scene of enchanting beauty, a palace adorned with bright and glittering jewels, and with minerals of wondrous structure, and dazzling lustre. If so, such beauties are unknown to us. All the idea we are able to form of its contents must be drawn from the emitted products with which we are familiar; and these, singular as some of them are, do not justify the conceptions that might be formed of any romantic regions of beauty below the earth's surface. That it is a region of disquiet, a scene of tumultuous agitations, of mighty conflicts between opposed powers of a material kind, we have sufficient evidence to show. For the interior of the planet is for ever reacting upon its exterior, as we have evidence in the earthquake, the volcano, \&c., and by the magnitude and extent of these phenomena we may form some conception of the force of the powers within. But these terrible manifestations of 
chemical force lend no countenance to the fanciful creations of fable.*

Let us now set before the reader some of those natural phenomena which seem to help us to some sort of acquaintance with the chemistry of the interior. And we may first allude to the remarkable facts which have been discovered relative to the temperature of the crust of the earth. If a thermometer is taken with us as we descend into a mine, and carefully examined, it will indicate a gradual rise of temperature proportionate to the depth of the descent. If we were to make the descent in winter, the increase would be very sensible even to the surface of the body. The actual increase has been ascertained by a number of experiments made in different countries, and amounts pretty constantly to one degree of Fahrenheit's seale, for every fifty or sixty feet in depth. A thermometer placed in a hole cut in the solid rock, at the vast depth of 1,380 feet, was observed to register on the average $68^{\circ}$, while at the same time the mean temperature of the surface was only $50^{\circ}$. It is a familiar fact also

* Fable has peopled the deep abyss with men, animals, and plants, and has conjectured even the existence of two planets, which have been called Pluto and Proserpine, to give light to this charming world within the world! Leslie and Halley affirmed that it was a hollow sphere, made up of stories like a house. 
that miners working at great depths in the earth, enjoy a kind of perpetual summer, which is almost entirely unaffected by the condition of the surface, even though the earth be clad in the cold but glittering raiment of the sharpest winter. There is a mine in Cornwall, one of the levels of which is so hot, that although a stream of cold water is purposely allowed to flow through it, in order to reduce the temperature, the miners are compelled to work nearly naked, and will bathe in water at $80^{\circ}$ to cool themselves! In another mine in the same county, which has been carried to the immense depth of 320 fathoms, the temperature is hotter than on the surface in the warmest summer day; for while a very hot day in July will raise the thermometer to $82^{\circ}$, this instrument in the mine rises to nearly 100 . The Artesian wells illustrate the same fact. These wells are formed by boring to the depth of many hundred feet in the earth. It has been found by experience, that the waters of such wells are hotter than ordinary well water, and exhibit a regular increase of heat in proportion to the increased depth of the borings. It has been a speculation whether, in fact, water could not be thus obtained sufficiently hot for economical purposes. The celebrated Artesian well at Grenelle, near Paris, has been sunk, after a labour of seven 
years and two months, to the depth of nearly 1,800 feet. The temperature of this beautifully pure and abundant spring is $82^{\circ}$, being about $30^{\circ}$ higher than the average temperature of the surface. The same fact was noticed in sinking the Artesian well at Southampton. At the depth of 520 feet the water which flowed into it was from $61^{\circ}$ to $62^{\circ}$. The atmosphere of the well at 50 feet was $54^{\circ}$; at 160 feet, $60^{\circ}$; and at 543 feet, $65^{\circ}$; showing a rise of temperature with the descent. The phenomena of hot-springs, volcanic eruptions, and earthquakes, all seem to indicate a high temperature in the world within. The heat of substances ejected from volcanoes cannot be less than $1000^{\circ} \mathrm{Fahr}$.

Now, if the same increase of temperature continued as we descended, supposing we could bore to the depth of rather less than two miles, water would rise up through the tube at the boiling point, or $212 \circ$ of Fahrenheit. Upon a similar calculation, the increase of 10 for about every fifty feet of depth, we should arrive at the point of red heat on penetrating to the depth of nine miles : at about forty miles' depth all substances with which we are acquainted would melt, and presuming that the same law of increase prevailed, it is not difficult to reach a point in the imagination when the temperature would be great beyond all powers of expression 
by figures or language. There are three methods of explaining this curious fact. Very probably all three together are actually necessary in order to explain the whole phenomena of the temperature of the crust of the earth. The first supposes it to be chiefly due to the absorption of heat from the sun. The second supposes that it is due to great chemical changes taking place in the substances forming the crust of the earth. And the third conceives the existence of a vast central body of fire in the interior of the earth. It is certain that from each of these causes separately heat may be communicated to the crust of our globe.

The heat-rays of the sun accompany the beams of light, and striking upon the surface of the earth, become absorbed by it. A large portion of them are radiated back again into the air, but another portion become conducted from particle to particle of the rocks and other materials of the earth's crust, and thus penetrate some distance into it. Of course the parts of the earth nearest the equator, where most of the solar influence is felt, reccive most heat, and there it penetrates farthest into the crust of the earth. The regions near the poles receive least, and there of course the heat of the sun penetrates but a very short distance into the crust. Although much heat is lost by radiation 
at night, yet the whole is not thus dissipated, for when once the ground is heated, it parts with its heat very slowly, in consequence of its bad.conducting powers. Hence the earth retains permanently a certain amount of heat in its crust, which was originally derived from the sun. At a depth varying from 40 to 100 feet below the surface there is a stratum at which the temperature appears to be invariable, and corresponding with the mean annual temperature of the surface. The diurnal variations of temperature are not perceived below two or three feet. At Paris the stratum of invariable temperature is ninety feet below the surface; in the tropics three or four feet; in temperate regions generally fifty to sixty feet. This constant temperature is highly advantageous to both the animal and vegetable creation. If the earth were a metal ball, it would be so hot during the day in summer, as to scorch all substances on its surface, while during the night it would cool down so rapidly as to freeze everything with the severest cold. In a word, it would have no constant temperature of its own, like that which it now possesses.

What we have to consider is, whether the increasing heat felt in descending into the earth is due to this cause alone? Down to a certain depth, which varies according to climate, the 
rise of temperature is undoubtedly principally ascribable to this cause. But when we reflect how bad a conductor is rock or earth, and how very steadily on the average the temperature is found to rise as we descend, instead of diminishing, as it should do the farther we get from the supposed source of the heat, and also how little the influence of climate seems to affect it, we must probably come to the conclusion that the heat of which we speak cannot be by any means altogether explained by referring its source to the sun.

Sir Charles Lyell, the eminent geologist, and others, appear disposed to believe that this heat is due to great chemical decompositions taking place constantly in the crust of our planet. This forms the second theory in our list. School-boys are in the habit of performing a little chemical experiment, which will illustrate this idea very well. They take certain chemical ingredients, among which are sulphur and iron, and bury them a little way in the earth. The substances act on each other, and become heated, so as even to take fire and burn. We can conceive, then, that chemical decompositions on a larger scale may produce immense supplies of heat in the earth's crust, which may be conducted by it throughout its substance. 
Without doubt such decompositions are continually taking place in the earth's crust. The mineral called iron pyrites, which is a sulphuret of iron, on exposure to moisture decomposes with rapidity, and eliminates a large amount of heat. It is well known that immense masses of this ore exist in the earth; and if we can imagine that a current of water flowed upon or through them, we may easily recognise a source of much heat in the changes which would succeed. A French chemist, M. F. Leblanc, examined the air of the galleries of a mine of iron pyrites in a district in Brittany, and found, strange to say, that the air only contained from 17 to 18 per cent. oxygen, and in some parts only 10 per cent., without the deficiency being replaced by carbonic acid. This singular effect is attributable to the pyrites walls of the mine absorbing this gas from the air. This constant chemical process could not go on without the evolution of a large amount of heat. We may conceive, therefore, that a part of the earth's heat is derived from this source also. Yet it seems impossible to suppose that it is entirely due to this cause.

Upon the third view, the earth's heat is due to a great central body of fire. Probable though this may be, when we remember the phenomena of volcanoes emitting burning lava, of hotsprings and earthquakes, it is only as yet 
to be considered in the light of a theory, the proof of which has not been placed within the reach of man.

Some remarkable experiments have been recently made by Mr. Grove, and also by Dr. Robinson of Armagh, which throw light upon what we may conjecture to be the state of matters in those intensely-heated regions which appear to exist in the interior of the earth. Mr. Grove has succeeded in decomposing water into its constituent gases, oxygen and hydrogen, merely by dropping upon it fused globules of melted platinum, heated to great intensity, in the flame of the oxy-hydrogen lamp. Dr. Robinson has also shown, that as the temperature of water is increased up to $212^{\circ}$, the chemical affinity of its elements is lessened, and eventually destroyed. Applying these highly important experiments to the matter before us, we may gather from them the startling fact, that a greatly increased temperature, such as that we may conceive to exist in the deep region beneath us, might not only prevent the chemical union of different bodies, but actually destroy it, if it existed in such bodies as might be exposed to its influence. Hence the elements may be conceived to intermingle one with another in the interior of the earth, where this ineonceivably great heat reigns, without any tendency to unite! Oxygen and hydrogen, car- 
bon, iron, phosphorus, and the metals generally, may move their particles in indifference to each other, being separated by the intense force of heat which overcomes their tendency to unite.

Should, however, any portion of them by any cause become cooled, to a certain extent, then instantly the powers of chemical affinity reassert their dominion, and violent chemical combinations immediately take place, which may develop themselves on the surface either in the upheaving might of an eartliquake, or the red torrent of the volcano. It is apparently a certain fact that the internal temperature of the earth does not affect the temperature of the earth's surface, nor of the ocean, overlying earth's deep cavities.

That tremendous natural phenomenon, the Earthquake, has been mentioned as apparently giving countenance to the idea, that the interior of the earth resembles a great chemical laboratory. Let us now advert to some particulars concerning it, and in so doing briefly mention the external phenomena which accompany these appalling catastrophes. A violent explosion is often heard, such as is produced by the firing of a mine, although the occurrence of this is uncertain; then follow a series of concussions and vibrations, the bosom of the earth heaves up like a sleep-disturbed giant, thunderings like legions of artillery roll beneath the feet, and deep chasms 
open up, ejecting torrents of mud or sulphureous winds. Clouds of black sinoke, fountains of boiling liquids, gusts of deadly gases, jets of steam, and up-springing flames, form its dreadful accompaniments, and spread desolation and despair around, while thousands of overwhelmed men and animals rend the air with their cries. Shoals of poisoned fish are cast upon the uneasy shore, and myriads of reptiles and vermin die suffocated by the streams of carbonic acid and other gases which issue from the earth.

These terrible phenomena plainly indicate the violence of the strugglings of the chemistry of the interior. Hence the up-heaving movements of the solid earth, reeling, we might suppose, under the accumulated pressure of elastic vapours, originating from sudden or it may be more gradual chemical decompositions within. The clouds of steam, the emissions of different gases, the concussions, and the out-bursting flames,-these are all indicative of the existence of chemical phenomena, probably not materially different from the experiments of the laboratory, except in quantity, duration, and force. It would be vain to attempt to define the nature or mode of origin of the elastic vapour, or vapours, the enormous pressure of "which is supposed to be equal to the production of such tremendous physical phenomena. In the 
absence of all positive knowledge on the subject, and comparing them with the lesser phenomena, we are ourselves able to produce by various combinations of different substances, that view of their nature seems most probable which regards them as of a purely chemical origin and character.

Recently a theory has been put forth, which advocates the idea that earthquakes are of an electrical origin, being the result of electric discharges in the earth, passing violently through beds of non-conducting substances. It has hence been thought quite possible to prevent them, if a metallic or other good conducting communication could be effected through the temporary or permanent non-conducting strata, so that the electric currents might find a ready passage. It is singular that this idea has already been carried into execution. The Chevalier Vivenzio, at the latter end of the last century, being self-convinced that earthquakes were the result of electric currents, the free passage of which was thus impeded, proposed to fix metallic rods, terminating in a number of points, like a brush, in the ground, to as great a depth as possible. But a better method was subsequently devised. In Naples there is a pyramid erected before a chirch, under which is a deep well, with several mouths opening about the 
base. This was made that the water, being a good conductor, might form a free electric communication between the strata through which the well is sunk, and thus acting on the principle of a lightning conductor, draw off the fluid. In the city of Udine, wells and other excavations have been made for the same purpose, and also great numbers in Nola in the kingdom of Naples. The success of these experiments at Naples and Udine does not appear, but at Nola it seems that since they have been undertaken the city has not been damaged by earthquakes. Whether we are to attribute it to this or other causes, appears more than questionable; the experiment, however, deserves repetition.

The idea is very prevalent that we know nothing of the effects of earthquakes in England; and that while other countries are shaken to their foundation, our land, excepting on rare occasions, is altogether unmoved by the great powers lying below. But this idea is erroneous. Scientific observers have been stationed at a particular place in Perthshire, and have obtained evidence that in every year a greater or less number of shocks of earthquakes have been felt even in Great Britain. By means of ingenious instruments of various kinds, sixty distinct shocks were observed be- 
tween July 1841 and June 1842. Twelve of these occurred in one day in July. The shocks are found to be most frequent in autumn and winter; and it has been noticed that very wet weather not unfrequently precedes their occurrence.

It is a very singular fact, that the instruments called magnetometers employed in studying the phenomena of terrestrial magnetism, indicate with great delicacy also the occurrence of earthquakes. Those employed at Dublin indicated from ten to twenty shocks in one year.

Another evidence of subterranean movements is the Volcano. Every stage of volcanic vivlence is attended with peculiar chemical phenomena. At first, when the vast artillery of nature opens fire, glowing ashes shoot up into the heavens, then a molten flood of lava is pressed up into the crater, and rolls down in devastating terrors upon the smiling country below. These are accompanied with the pouring forth of clouds of steam, and occasionally electric flashes dart across the lurid flames. At a later period, steam, sulphuretted hydrogen. and carbonic acid gases, are the only symptoms of chemical activity, and lastly, when the fire is almost extinct, carbonic acid gas alone rises from the once fire-glowing crater. Vapours of hydrochloric and sulphurous acids, together with pure nitrogen gas and ammonia, have also been 
deteeted among the gaseous exhalations of these fountains of fire. The celebrated volcano of Jorullo rises out of a plain, the remarkable aspect of which communicates a vivid idea of the activity of ehemical forees going on beneath the surface. This scene is represented in the accompanying engraving.

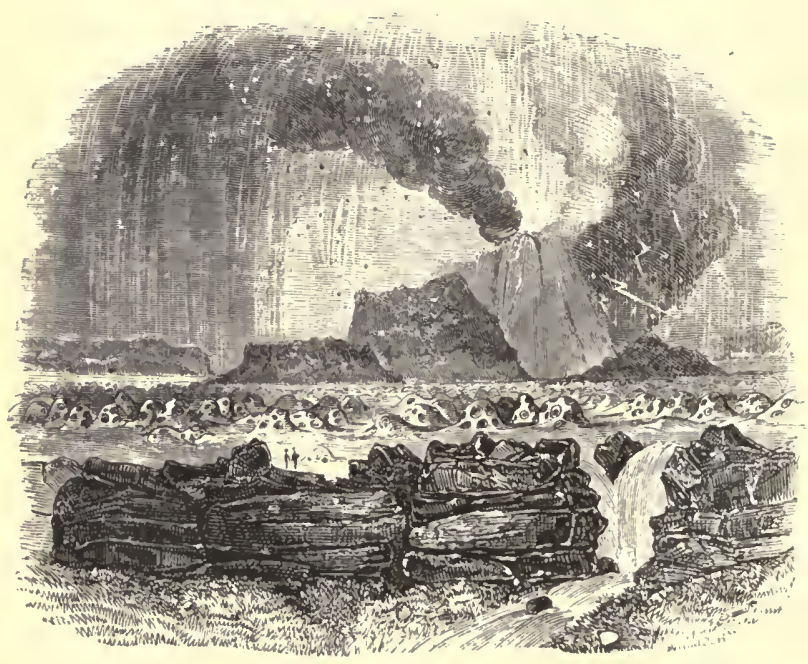

VOLCANO OF JORULLO.

Philosophy fails to inform us as to the real causes of the volcano. But upon chemically analysing the lava, and on a consideration of the nature of the gases discharged, conjee- 
tures of various kinds have been made. Into these we shall not enter. Dr. Daubeny says the lava itself and the gases, together with the intense heat of the substances discharged from the crater, leave little doubt that the phenomena of the volcano are only an external indication of the contests of the powers of chemistry, in which oxygen plays an important part, deep in the earth. There can be little question that the eruption of a volcano acts like the opening of a safety-valve, and relieves the accumulating pressure of contending elements within, which, if the volcano-vent were closed, would result in the production of dreadful earthquakes, more destructive and desolating probably than any. volcanic eruption.

In addition to these violent indications of chemical activity, we are presented with some which are not less interesting in their nature, although less tumultuous in operation. One of the most common is the effusion of carbonic acid gas, in very large quantities, from cracks and fissures in the ground. In many volcanic districts this phenomenon exists in a remarkable degree. Frequently, also, it rises, largely dissolved by the waters of springs in such localities. The gas being invisible, and, excepting when undiluted, destitute of odour, its presence is not so easily detected as that of 
other gases. When volcanic fires are dying out, large emissions of it take place. When Vesuvius has ceased to emit lava, there escape immense volumes of carbonic acid from the crater, and these entering the atmosphere are well known by the Italian people under the title of the Moffettes. These streams of gas are sometimes dangerous to life, if a person is exposed to their full influence. So largely does carbonic acid escape from the ground in the far-famed Grotto del Cane, near Naples, as to cause it to be fatal to animals which, by accident or design, are exposed sufficiently long to its efferts. All the dogs for miles around dread the spot, for it is a common experiment to put them into the cave until they are insensible, and then to bring them to life again by throwing them into a pool of water. The celebrated Upas valleys owe their deadly reputation to a similar cause. These valleys are described as about half a mile in circumference, full of the skeletons of men and animals, and teeming with sources of carbonic acid. They are narrow, flat, and desolate-the very valleys of the shadow of death; for there universal death holds its reign. Heaps of dead insects and birds lie around,- - sad proofs of the deadly nature of the gas.* The fatal air rises to the

* Although there has been mueh fable about the Upas Valleys, the deadly effects of which were attributed to the poisonous 
height of about eighteen feet from the ground. The only plant which flourishes there is the tall and fearfully-poisonous Pohon Upas-tree, which grows luxuriantly amid a scene of the gloomiest description. This gas is in other' districts so abundantly evolved from the earth as to be heard issuing with a hissing noise from cracks in the limestone; and it often proves fatal to birds which unconsciously come within its influence.

Carbonic acid appears, however, under circumstances where volcanic agency plays no part. Effusions of this gas take place in the vicinity of extensive layers of wood-coal, principally, however, in the form of an aqueous solution; in other words, as carbonated springs. The gas may often be seen bubbling around the edges; and the pleasant waters of some of these springs make them a valuable possession to the inhabitants.

From these considerations we learn, that the effusion of this gas is an indication of two classes of chemical activities-first, of volcanic decompositions; and, secondly, of those more gradual changes which time produces in the constituents of the coal-layers or measures. Both these

nature of the trees, it must not, therefore, be supposed that the whole matter is fabulous. The statement above given has been abundantly confirmed by modern travellers. 
decompositions possess interest. It appears more than probable that the true source of this gas, in the first casc, in volcanic districts, is that simple decomposition which heat effects upon limestone, whereby a portion of its carbonic acid is discharged, - a decomposition precisely similar to that we effect in burning limestone, the gas of which has so often proved fatal to the incautious traveller. 'The intense heat of an eruption must affect all adjoining rocks; and it is presumed that the calcareous or limestone rocks, heated by this means, expel their carbonic acid, and produce the phenomenon in question. We have the authority of Dr. Daubeny for this supposition. There is less difficulty in discovering the source and mode of production of the gas in the latter case. In the chemical decompositions which accompany the formation of brown coal, carbonic acid is extracted from the substance of the wood. The same process appears to be continually taking place at great depths in all the layers of wood coal, sometimes rendering mines unavailable from its abundance in the form of what miners call "choke-damp." Water percolating through the soil to these strata, and meeting with the gas, dissolves it, and rises to the surface as an acidulous carbonated spring.

But, from whatsoever source proceeding, this 
gas -itself in all cases an undoubted evidence of chemical decompositions at a depth below the surface-is the cause of important chemical changes in the crust of the earth. Feeble as the agency may appear, the gas, being a weak acid, exerts in reality a most powerfully decomposing and disintegrating effect upon the different strata through which it is compelled to permeate in its passage to the surface. Strata, which would otherwise remain solid and intact for centuries, are ready to crumble to pieces in consequence. Dissolving out, by its solution in water, many of the elements of the rocks, it eventually occasions them to become quite soft, or even (as in the case of limestone rocks) it may produce those great caverns and long galleries, of which different countries present us with such curious and magnificent specimens.* When the solution thus obtained reaches the surface, it there loses its carbonic acid, and deposits its calcareous matter (carbonate of lime) in the form of a white, solid, stony mass, called "travertin." A remarkable example of water fully charged with carbonic

* At Fredericshall, in Norway, is a cavern 11,000 feet deep. The most celebrated cave is at the village of Adelsberg, in Austria. The mere vestibule, called the Dome, to this magnificent cavern, is upwards of 100 feet high, and more than 300 feet deep. The entire extent of the cavern cannot be ascertaincd; it is known to be, very great. Yet all appears to be due to the action of water and carbonic acid! 
acid, and holding a large quantity of calcareous matter thus obtained, occurs in a lake existing in the Campagna of Rome, called the Lacus Albula, or the Lake of the Solfatara. The water is so impregnated as to assume a bluish, milky aspect. The ancient Romans ereeted their baths

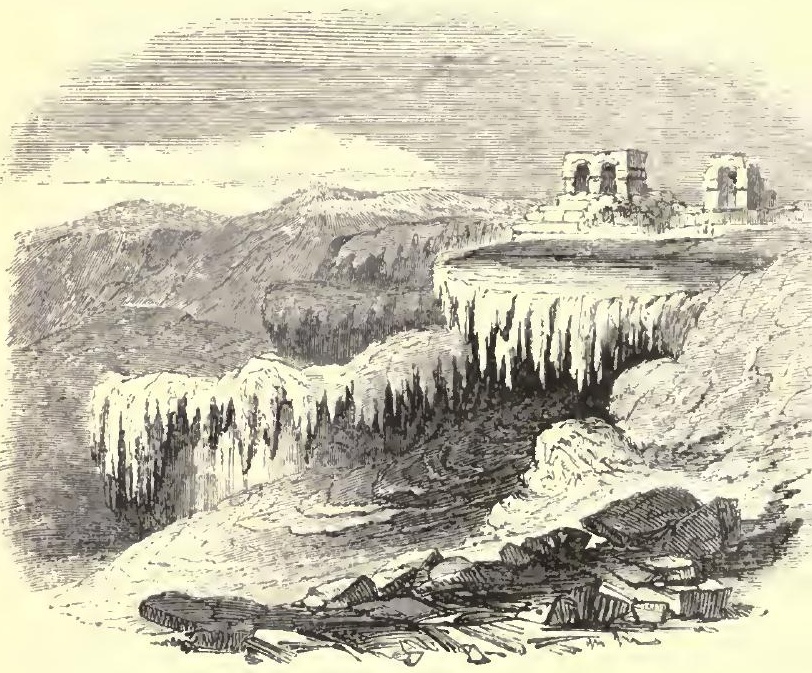

PETRIFYING SPRINGS.

here, which werc eelebrated for the eure of disorders of the skin. The temperature of the water is about twenty degrees higher than the average or mean temperature of the air. "Reeds, lichens, confervæ, and a vast mass of aquatic 
vegetation," says Sir H. Davy, "here find a rich repast, and grow in the utmost luxuriance, forming a number of floating islands on its surface." In certain districts of Asia Minor, the springs are so charged with calcareous matter as to deposit it in extraordinary quantities. It is said by a traveller into those regions, that, in order to make stone fences round the gardens and vineyards of Hicrapolis, it was only necessary to conduct the water of such springs into narrow channels, and they soon became filled up with stone! Even high roads are thus easily laid down by other than human skill. When such springs run over an eminence, they present the curious appearance of a frozen cascade.

An equally singular exhalation, also indicative of decompositions deep in the earth, is that of light carburetted hydrogen, or "coal-gas," called by miners the "fire-damp." Being invisible, like carbonic acid, it is only to be detected by its peculiar odour, and its inflammability. When once a light is applied to these streams of gas, they instantly inflame, and often continue burning for years, until the supply ceases. In the village of Fredonia, in the State of New York, gas thus naturally produced is collected and used to light the streets with! and also for heating and culinary purposes. At the edge of the river above the rapids, at the 
Falls of Niagara, a burning spring exists. The gas makes its way in countless bubbles through the clear transparent waters of the Niagara. On the application of a candle it takes fire and plays about with a lambent flickering flame, which seldom touches the water, the gas being at first too pure to be inflammable, and only obtaining sufficient oxygen after mingling with the atmosphere at the height of several inches above the surface of the stream. This gas rises out of a bed of limestone rock, probably from the decomposition of some bituminous matter below it. The Chinese collect it in such quantities, by means of bamboo tubes, from wells, where it is produced naturally, as to apply it on the large scale for heating evaporating pans. One such well is said to heat more than 300 pans. The production of the gas in this, as in some other instances, appears connected with saline springs. It is related that, while boring for salt near Lake Erie, the borer suddenly fell, after penetrating to the depth of 197 feet. Salt-water sprang up for several hours; after which, a considerable quantity of inflainmable gas burst forth from the same aperture, and, being ignited by a fire in the vicinity, eonsumed all within its reach. A similar eruption of this gas was related to the writer, as having occurred in a magnificent saltmine near Northwich, in Cheshire. On a hole 
being made into the floor of the mine, suddenty up burst a jet of gas, which caught fire, and streamed fourteen feet high, until it was put out by the terrified miners. The hollow sound of the floor of the mine had led them to suspect some cavity beneath; and on their boring into it, the escape of gas was the unlooked-for result.

In many of the coal districts of the north; this gas is frequently found issuing in jets from the ground; and it is almost surprising that a product of so much value should be allowed to discharge itself and become lost in the atmosphere.

At the late meeting of the British Association at Birmingham, an interesting account of a continued spontaneous evolution of gas from the ground was communicated, which may be transferred to these pages. "In a field by the side of a lane near the village of Charlemont, in Staffordshire, certain patches of ground had been noticed, which, without any apparent cause, were destitute of vegetation. The person who first paid attention to the cause of these barren spots was the tenant of a neighbouring cottage, at which there is a cold bath, noted in the vicinity for its sanative properties. From certain circumstances he was led to believe that something permeated the earth in these spots, and having dug a hole he inserted a gas- 
pipe, and on applying a light to the mouth of the pipe, he found, to his great surprise, that a large flame issued from it. It was not long before he conceived the idea of applying it to domestic purposes, and, in pursuing his experiments, he found that it was not necessary to convey it-from the place where it was first discovered, at a distance of about 150 yards from his house, as in driving a pipe some inches into the ground, under the floor of his cottage, he procured a continuous flow of the gas. There are, at the present time, seven burners in the cottage, which enable the owners to dispense with fire and candles! The next cottage is also supplied with two. It appears to make no difference to the supply of gas if allowed to burn for wceks together. The flame is always of the same colour. In windy weather the flame is unstcady: when there is a blast of wind outside the flames of gas rise several inches, but as each blast dics away, they return to their original size. The escape of gas is larger in wet weather than in dry; but whether the gas is produced near the surface or not, has not yet been satisfactorily ascertained. The place where it issues from the earth is quite a mile from any coal-pit, and is outside the eastern edge of the Staffordshire basin. Upon analysis it turned out that the gas was chiefly composed of light carburetted 
hydrogen. It also contained a little carbonic acid and nitrogen. It burns with a pale bluish white flame, emitting considerable light and heat. As it issues from the pipe it has a moist or slightly musty smell, as of sticks partially decomposed; but, after it has been kept a litile time, it becomes quite inodorous. It does not appear that the employment of it entails any evil consequences to the health of the family." When it escapes into mines, it forms the awful and dangerous gas too well known as "firedamp." This gas becomes explosive only when mixed with a certain quantity of air; if then a flame is applied to the mixture, it explodes with all the violence of gunpowder, and with great noise. Still more recently the inflammable gas rising from a bog has been made to drive a steam-engine, by being carried under the boiler.

In consequence of the awful accidents which have occurred, owing to the escape of this gas into coal mines, and to its subsequent explosion by coming in contact with the lighted candle of the miner, Sir H. Davy undertook the task of endeavouring to discover some remedy for these calamities. His labours were ultimately rewarded by the discovery of the invaluable safety lamp, with which his name will be connected through all time. It may be interesting to 
state the principles upon which the success of this simple and beautiful invention depends. The lamp is, in reality, only a common oil-lamp, surrounded by a wire gauze. It may be trimmed by a small bent wire which projects

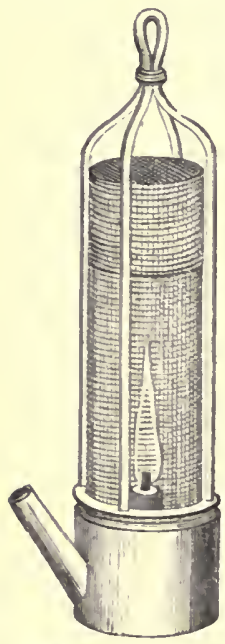

THB SAFBTY LANP. from the bottom of the lamp. So completely is it shut in, that the supply of air for its combustion can nowhere come to it but through the wire gauze. Now, when this lamp is put into an atmosphere consisting of fire-damp and air, it does not cause it to kindle and explode, as a common candle would do; but, strange to say, the light of the wick goes out, and the interior of the gauze cylinder becomes filled with a pale blue lambent flame, caused by the fire-damp and air taking fire within it, and burning without violence. On being taken out of such a mixture, the wick again catches fire, and the blue flame disappears. If, when the lamp is plunged in a glass jar filled with this explosive compound, we were to strip off its gauze protection, the whole would instantly explode, and shiver the ressel to fragments. It is therefore 
the wire gauze alone which protects the miner when he gropes his way, with lamp in hand, into a part of the mine where fire-damp may have collected.

The common explanation of this is as follows: The explosive mixture will not take fire unless the ignited body applied to it is at a white heat. The flame of the wick is, it is true, at a white heat, and would therefore cause it to ignite and explode immediately; but before this flame could pass to the fire-damp it must pass through the wire gauze, and in so doing, it becomes very much cooled by the conducting powers of the metallic wire of which the gauze is made. The consequence is, that it would be no longer at a white heat, and that the fire-damp therefore would not take light. The reason, then, why the safety-lamp is a safe light, is that the cooling properties of the wire gauze prevent the passage of the flame at a sufficiently high temperature to set fire to the explosive gas. If the reader will take a piece of wire gauze, and hold it over the flame of a candle, he will find that for a little time the flame will not pass through, and that he can, in fact, look down into the centre of the flame, which is hollow (fig. 2). After a time, however, the wire becomes so heated, that the flame does pass through, and then presents the appearance represented at fig. 1 in the cut. 
This seldom or never happens in the miner's lamp if it is carefully managed. It has been recently surggested that this can searcely be considered the true explanation of this fact: and it is supposed, on the contrary, that the

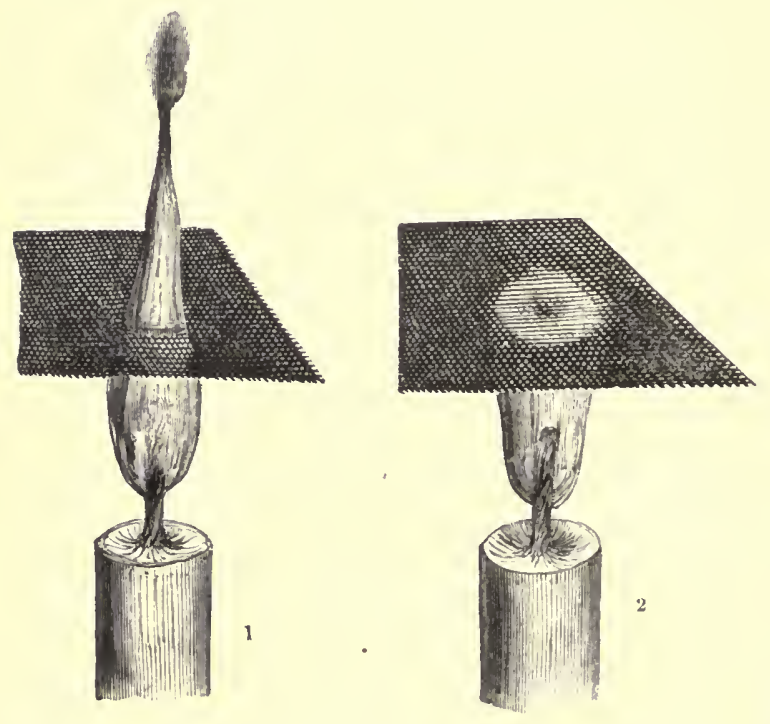

particles of the gas forming the flame are in a state of active repulsion over its surface, and thus refuse to pass through the wire gauze.

A portion of the chemistry involved in the production of this gas may be explained. A progressive continuance of the decomposition, 
which has been already described as taking place in wood coal, results in the formation of common bituminous coal. As this process continues, carburetted hydrogen and other inflammable gases are constantly evolved, and if able to reach the surface, appear in the jets just mentioned. If not able thus to discharge itself, the gas remains pent up in the coal mines until some unfortunate blow of the miner's pick-axe strikes the place, and the gas issues forth with great violence, and in alarming quantities. Such a stream of gas is called a "blower" by the miners. While, however, it remains extremely probable that in every instance bituminous matters form the source of this gas, it is not so clear by what series of links the necessary decompositions are effected.

In addition to the evidences afforded us by these gases of the really active operation of deep-seated chemical forces, we may enumerate sulphuretted hydrogen, sulphurous and hydrochloric acid fumes, sulphur itself, and ammonia, as occasionally emitted from the earth's crust in different countries, and under differing conditions. The causes leading to their extrication it is not possible to ascertain with certainty.

The highly remarkable phenomenon of mud volcanos; that is, volcanos which instead of lava, pour down enormous streams of mud, 
frequently without giving the least intimation beforehand, are probably also of chemical origin. The mud it appears difficult to account for, but the cause of the overflow is probably the elastic pressure of gases acting beneath the surface. They are commonly at first preceded by violent explosions and flames, but after-

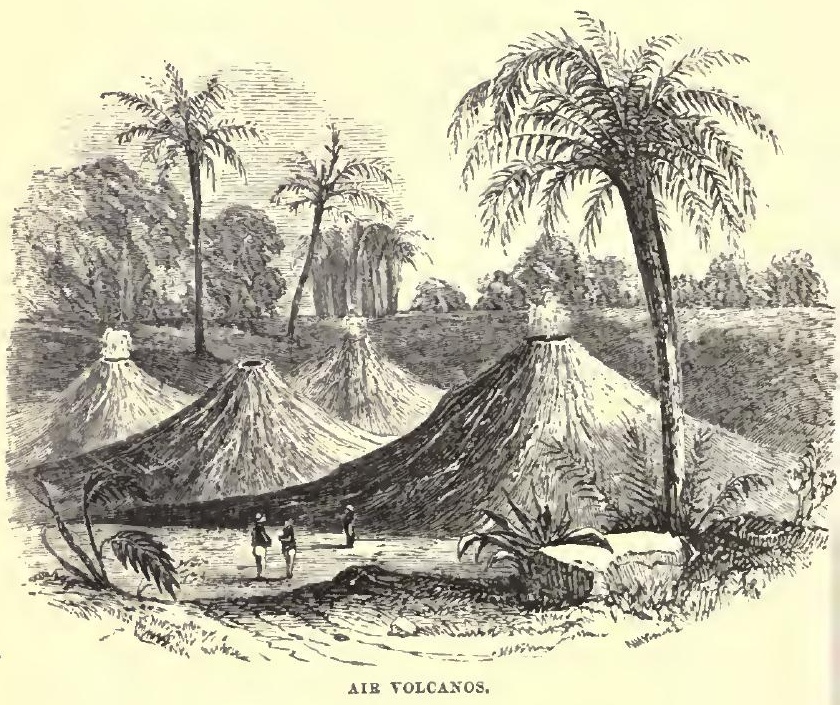

wards the mud is cold, so that its source is probably at no great distance from the surface. The eruption of the mud voleano of Galungung in 1822 was among the most fatal catastrophes of this kind ever recorded. Without warning, 
an immense volume of mud filled the crater, and streamed down in a great torrent upon the valleys and plains beneath. In its course it filled up the river courses, covered over hollows from forty to fifty feet deep, and turned a fertile area of land, forty miles square, into a desert. This extraordinary eruption destroyed hundreds of thousands of coffee-trees, many acres of ricefields, and, besides a vast number of inferior animals, cverwhelmed not fewer than from ten to eleven thousand human beings. In certain parts of South America are volcanos which only emit water and gas. They are called air-volcanos. In all probability the "air" consists chiefly of carbonic acid. The cut represents some of these.

We can give a somewhat more satisfactory account of another natural phenomenon, in the production of which the powers of the chemistry of the interior are intimately concerned-the springs of rock-oil, or petroleum, or naphtha, which are found in certain districts. It has been found by experiment, that when pit-coal is distilled with water, a certain quantity of an oily liquid is obtained, which resembles in all respects the mineral oil obtained from these springs. Hence it is reasonably concluded, that the production of this fluid is due when it occurs in nature, to the action of heat upon beds of coal under the surface, causing the petroleum 
to be, as it were, distilled, by a very slow process, into the layers of earth lying just above them, where this substance is generally found.

In a coal pit near Alfreton, in Derbyshire, a valuable spring of mineral oil has very recently made its appearance. The quantity thrown up varies from 150 to 30 gallons a-day. The pit in which the spring occurs is said to be the deepest in that part of the country. Some years since, a large spring of salt-water appeared in the same pit, and has sinee flowed uninterruptedly. The spring of mineral oil has accompanied the salt spring since its appearance. The oil as it issues is of a dark tarry colour; but, on being distilled, yields a volatile liquid, which has been used as a substitute for ether and chloroform in the painless method of operating; and also a nearly colourless oil, which forms a very valuable source of light when used in a proper lamp. It appears probable that this mineral oil may become useful for the purposes of illumination. Mr. Mansfield has proposed an apparatus for impregnating atmospheric air with the vapour of one of the products of distillation of mineral oils, so as to produce, simply by passing the air through the liquid, an illuminating gas. Mineral oil springs are found in great abundancic on the north-west shores of the Caspian Sea, on sinking wells to the depth of about thirty feet, 
whence it is collected by the inhabitants. In Italy they are also common; and the city of Milan is illuminated with the product of such springs. The surface of the sea near the Cape de Verde Islands has been occasionally seen covered with a film of mineral oil, which had probably exuded from the bed beneath.

At the foot of volcanic mountains we have often indications of great changes taking place within the earth's crust in the appearance of different sorts of springs. Frequently the waters of some are quite sour, being charged with sulphuric acid, and sometimes are of the colour of yellowish milk, from the presence of the powder of sulphur, abundantly diffused through the waters. Sometimes, also, there are springs, the waters of which contain a quantity of dissolved silex, which petrifies the abjects upon which the spray falls. All our chalybeate, sulphureous, and other medicinal waters, indicate the occurrence of constant chemical changes in the earth's crust.

In further illustration of the subject of this chapter, an instance of a highly interesting nature may be selected, which gives us a most lively and pleasing picture of the importance to man of several of the chemical phenomena occurring in regions to which he has no possibility of access. The substance commonly 
called borax is a product of these deep chemical processes. It is largely employed in glazing earthenware, in soldering metals, in medieine, and in the operations of fluxing and assaying. A part of what is used in commerce is obtained from the waters of certain lakes in Thibet and Persia; it is also imported from India under the name of "tincal;" but its most important and singular source is in what are called the " Boracie Lagoons of Tuscany."

The scene where these lagoons are situated is one of peculiar wildness. Conceive a region in the heart of bleak and solitary mountains, where the earth seems to be pouring out boiling water, where clouds of hot vapour come bursting from its surface, drenching the visitor to the skin, and impregnating the whole surrounding atmosphere with a strong sulphureous smell. The heat is intolerable; the rugged surface of the ground seems ready at every moment to break up and disclose some awful pit beneath, whence the boiling springs and clouds of steam arise. The ground trembles and shakes bencath the feet, and loud concussions are both heard and felt without cessation in the vicinity of the spot. The surface of the earth is covered with beautiful crystals of sulphur and other minerals. Need we wonder that the poor and ignorant peasantry regarded 
REMARKABLE NATURAL BAROMETER. 147

such a spot as the very mouth of hell, and never passed it without an agony of terror, nor without counting their beads, and praying for protection-to the Virgin!

The "lagoons" consist of rude circular basins, partly excavated, partly built, which are situated exactly over some of the fissures in the ground, from which the bursts of vapour rise. These basins are ranged one above the other, so that the overflow from the highest runs in succession down to the lowest; and they are filled with water by allowing a rivulet to run into the uppermost of them. The hot vapours rising by their natural conduits from that disturbed region below where the chemical phenomena combining in their production take place, bring with them the borax, which, on entering the water of the lagoons, becomes condensed and dissolved by it. After the water has passed through all the basins, it is evaporated in an ingenious manner by pans, which are heated by the vapours rising from the earth. It is then crystallized, dried, and sent to the market.

It is very curious that the inhabitants of the surrounding districts judge of the state of the weather by the quantity of vapour which they observe to rise from these lagoons. If there is an unusually large quantity, it betokens wet; if less than usual, it foretells fine weather. And 
the peasantry strictly watch this remarkable natural barometer, and by its indications regulate their own agricultural proceedings. We may conceive that it is connected with the varying pressure of the air. When the pressure is less than usual, the escape of the vapours is rendered easier, and more difficult when its weight is increased. The increase or diminution in the amount of the united vapours forms thus, in reality, a barometer that serves to indicate the weight of the superincumbent air. Such is certainly the case in regard to our coal mines, in which it is found that fire-damp escapes more abundantly when the barometer is low than when high.

It is probable that yet more important applications of the active chemical phenomena of this singular district will be made. "It appears," writes a gentleman * who paid an official visit to the spot, "that the powers and riches of these extraordinary districts remain yet to be fully developed. They exhibit an immense number of mighty steamengines, furnished by nature at no cost, and applicable to the production of an infinite variety of objects. In the progress of time, this vast machinery of heat and force will probably become the moving central point of * Dr. Bowring. 
extensive manufacturing establishments. The steam which has been so ingeniously applied to the evaporation and concentration of boracic acid will probably hereafter, instead of wasting itself in the air, be employed to move large engines, which will be directed to the infinite variety of production which engages the attention of labouring and intelligent artizans; and thus, in course of time, there can be little doubt that these lagoons, which were fled from as objects of danger and terror by uninstructed man, will gather round them a large intelligent population, and become sources of prosperity to innumerable individuals."

At all periods the earth's crust has" been incessantly under the influence of the powers of chemistry within; and, consequently, the character of its constituents has been constantly undergoing remarkable changes. The peculiar process, called by geologists the metamorphism of rocks, is a striking illustration of this. In various parts of the earth's crust there is evidence of a heated mass of rock having been pushed up from below completely through the overlying beds. Such rocks are called Eruptive. Their temperature at the time when they broke through the overlying or sedimentary beds must have been very great; probably not less than 1,000 Fahrenheit. The result of the application 
of this intense heat to the sedimentary strata has been in many cases to produce the most remarkable alterations in their chemieal composition, or in the arrangement of their particles. Thus, rocks have been metamorphosed into substances very different to their original constitution. The celebrated Carrara marble, which, from its unsullied purity of composition, has for ages afforded the principal supply of marble to the seulptor and architect, appears to have undergone this peculiar change; and beds, representing the original limestone previous to its metamorphosis, have been discovered. It appears to have been melted under high pressure, so as not to have lost its carbonic acid, and afterwards to have cooled down and crystallised. The common blue slate used for roofing is another instance of a substance altered by the same process. Every volcanic cruption produces, only in a more limited degree, ehemical and molecular changes upon the substances with which the heated matter comes in contact.

But, in addition to the chemical alterations effected by the contact of a heated mass, most important decompositions have taken place, and are still proceeding, from the discharge of vapours from the interior. Vapours of sulphuric acid passing upwards from the interior have acted upon large masses of lime-roek, and ex- 
pelling the carbonic acid, have transformed it into gypsum or sulphate of lime. Sublimations of metals and other elements are also found in fissures in the crust of the earth, driven upwards by forces acting from below. Veins of various minerals appear to have been thus produced. We see the powers of chemistry thus acting far below the surface, and we learn again how small is our every-day perception of the mighty works which are going on beneath us. It is highly satisfactory to be able to add that the connexion of chemistry with all these processes taking place in the earth's crust, and producing changes upon the masses of rock there existing, have been practically exhibited in the laboratory by Mitscherlich. By a careful series of chemical investigations, some of the most important simple minerals - felspar, mica, blende, \&c., garnets, and rubies-have been artificially produced, thus completely establishing the correctness of the principles upon which geologists are accustomed to explain the phenomena of which we have spoken.

To the student of nature's chemistries few countries present an aspect so attractive as does the waste and desolate country of Iceland. There may be seen in operation those mighty forces which in more peaceful soils are kept in bondage below the surface. Professor Bun- 
sen has communicated a most valuable and important memoir on the chemical history of this formidable land, from which some interesting extracts may be presented. The physical character of this remarkable country forms an important element in its chemical listory. A little observation of the several peculiarities distinguishing it will convinee us that an intimate connexion exists between the phenomena, the fame of which filled the ears of our childhood, of the boiling springs, geysers, fumeroles, \&e., and the active volcanoes of the island. While rolcanic dykes and fissures abound in the crust of the earth, and volcanos are continually emitting their molten contents from their lofty summits, inaccessible fields of snow cover the mountains, and reveal at great distances the limits of the regions of glaciers, which penetrate with their huge masses of ice for a length of many miles, even to the lower range of the plateaux. A tenth part of Iceland is covered with these glaciers; and it appears that, in consequence of their presence, an excessive abundance of water is deposited from the atmosphere, which, in its progress downwards, appears as springs. Vast masses of water break through the fissures and arches of the glaciers, or rush in cascades down the icy walls of the mountain slopes, not unfre- 
quently converting a district of many miles into a bottomless mass of moving mud. Innumerable inland seas, vast marshes, and swarnps, make this barren and desolatc country appear even more terrible to the eye of the traveller. This abundance of water, finding its way into the deep declivities along the gently inclining strata of rocks, seems to nourish the various systems of springs. The volcanic fissures thus become the channels of these subterranean waters, and cause them to diverge into those deep ravines where a process of heating and evaporation must unavoidably be induced from the action of the heat of the volcanic soil. The water then, elevated by the combined force of elastic vapour and hydrostatic pressure, rushes forth in boiling springs.

This connexion between atmospheric deposition of water in the form of rain, snow, \&c., and the deep volcanic phenomena of the country, is highly interesting. It is proved by the fact that the gas nitrogen is found rising from the hot springs. Nitrogen is not a product of volcanic activity, and it is therefore probable that this gas had its origin in the solution by rain of the gases of the atmosphere previous to its penetrating into the bosom of the soil. The proportion also in which it is found is just what we should expect, knowing the solubility 
of this gas in water. In all probability, therefore, the boiling column of the mighty Geyser itself is formed of particles of water which fell as rain-drops on the mountain slope!

Having thus traced the origin of the springs, let us seek in the depths of the earth, in this singular region, the explanation of its varied chemical phenomena. Exhalations of sulphurous acid, sulphuretted hydrogen, sulphurous and aqueous vapours, burst in certain districts in wildest confusion from the hot soil, and spread themselves far over the steaming fields, the soil of which must be traversed with caution by the traveller who would avoid the danger of being drowned in the hot mud. On the declivities of the mountains these exhalations burst, foaming and hissing, in the form of vast columns of vapour from the fissures and clefts of the rocks, giving rise to sounds like thunder. In the valleys, the traveller meets with pools of boiling mud, in which a horrible bluish-black clayey paste rises in huge bubbles, which, on bursting, often throw the boiling mud to a height of upwards of fifteen feet. These phenomena constitute a picture of the wildest devastation, only to be surpassed in horror by the dread waste of the dark rocky masses by which the scene is enclosed.

The most important of the strata of rocks 
concerned in the chemical phenomena of Iceland is a rock called Palagonite. The constituents of this rock are, silica, iron, alumina, lime, magnesia, potash, soda, and water. 'These ingredients, united in one substance, and exposed to the volcanic gases which are continually penetrating the earth, become acted upon in a variety of ways, and form with the latter and each other a number of different combinations. The gases thus permeating the strata beneath the surface, consist, as is generally the case, of sulphurous acid, sulphuretted hydrogen, carbonic acid, and hydrochloric acid. The palagonite becomes, by the chemical decompositions thus set up, converted into beds of ferruginous clay, interpenetrated by beds of gypsum or sulphate of lime. Around the smoking orifices of the fumeroles, thick crystalline crusts of sulphur are deposited. The source of this sulphur appears to be the mutual decomposition of the volcanic gases, sulphurous acid, and sulphuretted hydrogen, the result of which decomposition is the deposition of sulphur. The existence of the latter gas in the column of gaseous emanations rising from one of the highest craters of Mount Hecla, was not sensible to test paper; but was detected.in a very peculiar manner. This gas, when burnt in contact with air, undergoes a peculiar process of 
combustion, of which the prineipal product is sulphuric acid. But this combustion is rendered visible to the eye in a striking degree. On holding a lighted eigar near the stream of gas from the volcano, although all other tests failed to indicate the presence of sulphuretted hydrogen in it, it was by so doing instantly rendered sensible. A dense eloud of vapour instantaneously emanated from the burning body, and diffused itself, like the smoke which in Arabian fable poured from the fisherman's bottle until it assumed the form and magnitude of a geni, far over the ravine and the plain of the fumeroles. At almost all the hot springs, this remarkable phenomenon could be produced. Even the light vapour which rises from the clear bluish-green water of the basin of the large crater was converted, on the approximation of a burning body, into a dense cloud of vapour, whieh would envelope the whole mirror of the water, spreading in all directions, and almost leading the astonished traveller to anticipate the appearance of some giant form in its wreathing folds. By the constant passage of the volcanic gases through the palagonite, a number of chemical phenomena are continually proceeding; and the changes thus produced are manifest on the surface in saline incrustations and mineral productions of various kinds. 
Perhaps one of the most interesting features in the chemistry of this wonderful country is the formation of its geysers. Professor Bunsen explains the whole process in a beautifully clear and simple manner. In the mutual reaction of carbonic acid, sulphuretted hydrogen, and heated water, and the palagonite, are combined all the conditions required by nature to convert, in the course of centuries, simple boiling springs into geysers, whose clear, vapoury, and foaming columns of water shall burst from the summits of their self-created craters, either continuously, or at periods of a few minutes, hours, or days. The explanation of this remarkable fact is as follows. The water of these boiling springs contains a dissolved hydrate of silicia, which on its evaporation is deposited around the mouth of the spring, on the margin projecting beyond the level of the water. Of course, in the basin of the spring, and below its surface, no evaporation takes place, and therefore no incrustation can occur. Imagine, then, this process of inerustation around the edge of the spring to continue for years, the natural result would be that the margin would become higher and higher, forming a rocky tube of silicious matter. As the margin rises, the water, of course, rises also, being always a little below the latter. The 
consequence is, that the spring, by this continued process of deposition, increases in height, until, reaching a certain altitude, it becomes converted into a regular geyser. Surrounding the tube formed in this simple manner, is a hillock of silicious matter, formed by the overflowing of the water of the spring. 'These tubes are fed with water from the mountains above them, which becomes heated in the volcanic subterranean channels along which it is conducted. This high temperature converts a part of it into vapour, and the result is that the water, elevated by its expansive force, foaming, and hissing, rises up through the tube which the incrusting waters have reared; and rushes boiling out of the mouth of the spring. Iceland abounds in these springs.

But the Great Geyser, as is well known, is an intermittent spring. Its phenomena are different from the smaller geysers or hot springs. Instead of continually discharging a boiling stream of water, as the other springs, an interval of time occurs in its eruptions. The cause of this has been generally explained to be, the existence under ground of great caldrons, in which steam accumulated, until its elastic force drove up the water through the geyser tube, after which it subsided again. But this explanation is incorrect: the mouth of the Great 
Geyser tube is so wide; that although the water at the bottom is heated, and partly converted into vapour, yet the loss of heat at the surface by evaporation and radiation is so great, that the whole volume of water in the tube, is not brought up to the boiling point excepting at stated times. When this is the case, then, it appears that a powerful volume of vapour accumulates at the lower part of the tube, which, acquiring fresh elastic force, at "length lifts the immense body of water above it into the air, driving it in a roaring, rushing column 28 feet in circumference, and 100 in altitude; after this the spring becomes quiet again, until its column is again heated up to the boiling point.

As the incrustation continues, the sides of the tube rise, higher and higher, until they and the surrounding ground attain a height which puts an end to these singular phenomena. As soon as the supply of heat from below and the cooling at the surface are so far in equilibrium that the temperature of the mass of water is not anywhere able to reach the boiling point, the action of the spring ceases spontaneously. Large reservoirs filled with hot stagnating or running water are thus formed. Old geysers abound in various districts, appearing in the form of large reservoirs filled with hot water, in the depths of which the old mouths may still be seen. These 
springs are extremely beautiful, and in one region of this wild country, in particular, their aspect is highly interesting. In the depths of the elear unruffled blue waters in this district, from which still rises a light vapour, the dark outlines of what once formed the mouth of a geyser may be faintly traced amid the fantastic forms of the white stalactite walls of the basins.

The silicious deposit, the grand agent in producing all the splendid phenomena in question, is produced by the decomposition effected in the palagonite rock by hot water, carbonic acid, and sulphuretted hydrogen. Altogether, viewing the whole of the geyser phenomena, in connexion with the lapse of time necessary to the formation of one of these vaporous fountains, and contrasting the magnitude of the result with the apparent feebleness of the cause, we cannot fail to be struck with the view it presents to us of the grandeur, force, and beauty of the ehemistry of nature in this wild and wonderful region.

There is something deeply interesting in contemplating these great chemical phenomena of nature, whether we consider their intrinsic importance to man and to the created scheme, the magnitude of the scale on which they are carried on, or the depth from the surface where their seat is. They show us that the inner 
regions of the globe are regions of active life, and by no means the dark and unstirred abysses of our usual imaginings. It is satisfactory to add the testimony of one of the most learned philosophers of the day upon this point. "Geological phenomena of all kinds," writes Baron Humboldt, "indicate alternating periods of activity and repose. The repose we are now enjoying is only apparent. The shocks which the surface experiences under every variety of climate, and along with every description of rock, Sweden rising in its level,* and the appearance of new eruptive islands, bear no testimony to quiescence in the internal life of our globe."

But these phenomena impress upon us considerations of more moment cven than those of science. How precarious is the position of the

* The northern provinces only of Norway and Sweden are rising; the southern are subsiding." This gradual elevation of a whole region is a most wonderful circumstance. It has been ascertained by certain grooves being cut in the rocks on the sea-coast, marking the ordinary level of the water at a proper state of the tide on a calm day. Fourteen years afterwards, the spot was visited, and, under precisely the same circumstances, the level was taken, and it was found to be four or five inches lower than before. The fishermen also state that they now find they cannot sail through many channels easily passed in their younger days. Many sunken rocks have also become visible. If this rising goes on, in course of time, sea-port towns will become inland! 
human family when we remember these pentup powers, which are scarce restrained from convulsing and tearing asunder the firm and massive crust on which we rest in such unthinking security! How entirely hopeless an attempt to escape, were it to please God to break the yoke he has imposed upon them, and set them free! Happy are they who are able, in the humble confidence of children redeemed by Christ, to commit the kceping of body and spirit to Him as to a "faithful Creator." 



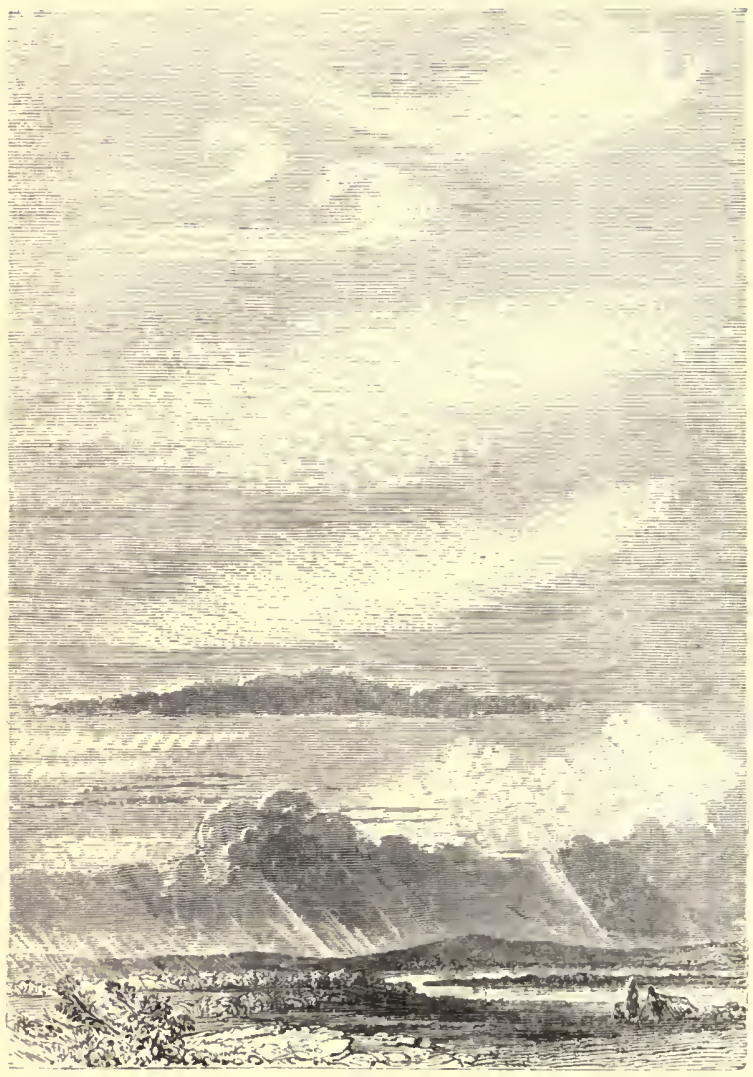

THE AIR.

VARIOLS FORMS OF CLOLDS. 


\section{PART II.-THE AIR.}

"THE FIRMAMEXT' SHOWETH HIS IIAXDIWORK."

\section{CHAPTER I.}

ITS PHYSICAL CONSTITUTION.

We who have been for so long a time with our thoughts directed earthward, must now turn them toward the sky, and look into the chemical mysteries of the blue heaven above us. Can chemistry inform us, then, upon the changes which take place in the invisible sea of matter which on every side surrounds us? We might suppose it conld not, for we can scarcely appreciate by any of our senses the presence of this amazingly thin and transparent fluid-the air. Yet the chemistry of creation, thanks to the well-directed labours of talented men, so far as it relates to the air, is more exact and complete in its information, than in any other of its departments. It is expedient, however, before we listen to the wonders of 
aërial chemistry, that some particulars should be mentioned as to the physical constitution of our air.

There are only one or two other planets of our system beside the earth which are considered to be provided with an atmosphere, or enrelope of gas. We cannot recognise in other systems of worlds a similar provision, though doubtless it may exist in some altered form without our being able to pereeive it. What is called "space" is considered to be destitute of any fluid like our air, or indeed like any gras with which we are aequainted. Our globe is revolving on its own axis, at the immense rate of, at the equator, upwards of 1,000 miles an hour. It is also moving in its orbit at a speed exceeding 68,490 miles in the homr. Now if such be the ease, if there is a rast cirrempty space above us, constantly attracting, or endeavouring to attract, our air into it, and if, in addition, the rapid motion of the earth has a tendency to scatter its airy garment to the ends of heaven, as it undoubtedly has by virtue of the centrifugal foree, by what power is it that the atmosphere nerertheless still closely clings to our globe? And the same inquiry is applicable to such other planets as may be thus provided. The atmosphere travels with us, as with them, at an enormous velocity, 
through a void and air-less region; yet no particle of it leaves us. Why is this?

The reason is that the earth exerts upon the atmosphere, as well as upon every gaseous fluid, or solid body over its surface, the influence of the attraction of gravitation. This force, which pervades the whole created universe, and enchains worlds and systems lying beyond the ken of unassisted mortal eye, holds this elastic and delicate robe, and binds it fast about the earth. As we travel, it travels. As we revolve, it revolves with us. In fact, could the globe for the space of one hour continue its revolution on its own axis, while the air stood still, the resistance offered by the air to the passage of the earth would be such as to produce, to all appearance, such a tremendous blast, as would not only level trees and houses, but would lift men' and animals, and every moveable thing. into the air, hurling them in a common destruction against the first mountain range that might present itself. Simple and interesting as the fact is, it is greatly lost sight of in our thoughts. We are apt to imagine that the earth moves through the air, not that it carrics the air together with it. Were it otherwise only for a little while, the fair landscape at our feet would be turned into such a scene of desolation and destruction as the eye of 
man has never rested on. It will be necessary to revert to the foree of gravitation exereised on the air, with the view to explain a part of the phenomenon of the trade winds, on another occasion.

Looking upwards into "this vaulted firmament," we seek in vain by the eye to fathom its actual depth. Lying at the bottom of this sea of air, we endeavour, without success, to obtain a measure by which some just conception thereof may be formed. As it rolls its thin waves above us, bearing at an immense altitude, apparently, those clouds which scem set there to tell us how immeasurably deep is the aërial ocean, and as we vainly seck some limit where the surface of the air might be supposed to lie, tlie inquiry presents itself, Has the atmosphere any actual limit? There is a great conflict of opinions upon this question. In the estimation of many talented persons, it is illimitable, or at least is supposed to extend greatly beyond what others consider to be its bounds. This also is the popular opinion, for most persons, uninformed on the science, would give answer that the air extended as far as the sun, moon, and stars. The learned Bishop Wilkins, who was a man of great talent, but of somewhat eccentric turn of mind, in a little treatise written by him, urged the importance of endeavouring to make 
a journey up to the moon. This was by no means a mere joke. He advocated the important results of a commercial intercourse with the lunar inhabitants, and evidently thought the only difficulty in the way was a proper flying machine! Some one objected to the learned bishop the little difficulty of there being no baiting-houses or taverns by the way. To which the bishop briskly replied, that his objector ought to have been the last person to raise that obstacle, as few were more famous than he for building castles in the air! Such schemes have been far from uncommon, and on the first discovery of the balloon, there were great hopes that man would rise to regions to which every human being has hitherto been a stranger.

'The belief' of the illimitableness of the air is now gencrally considered to have been proved to be erroneous. Had these would-be aërial travellers made the attempt at navigating the thin air, they would soon have found their sad mistake, and have discovered that an impassable gulf is fixed between us and all the heavenly bodies, and this gulf is the air-void region lying beyond the boundaries of our atmosphere. The investigations of philosophers make it appear probable that the extreme limit of the atmosphere does not reach beyond forty-five or fifty miles; 
but it is right to add, that others extend its limits much more, even as far as from one to two hundred miles. Dr. Wollaston, in a valuable paper upon the Finite Extent of the Atmosphere,* enters into an elaborate discussion of the subject, and proves that if the atmosphere were illimitable it must necessarily pervade all space, and accumulate around the sun, moon, and planets. Now, astronomical observations are clear in demonstrating that no atmosphere, or at any rate none similar to our own, surrounds most of the larger planets, which ought to collect a considerable mass of this gascous matter around them, in consequence of their size. From such and similar reasonings we are led to conclude that our air has a real limit. The fact also rests upon deductions of ehemical importance. The laws of the great atomic theory forbid that infinite divisibility of matter implied in the supposition of such extreme rarefaction of air as is demanded by the theory that it has no bounds. It is held, for instance, as certain, that we cannot subdivide matter beyond a certain point; at this point, its particles are called atoms, and these atoms have a certain size and weight. Applying the same reasoning to the air, it is considered that there is a point at which it cannot be expanded further; and this * Philosophical Transactions, 1822. 
point is supposed to be the true limit of the air. The air has consequently a true surface or level, like that of a fluid.

Could we take our stand upon the surface of our fair satellite the moon, as she "walks in brightness," and look toward the earth, supposing that the atmosphere enveloping it were coloured throughout, so as to be visible to our eyes, it would be scen to be of the form of an oblate spheroid, the lesser axis of which would pass through the poles of the earth. In short, its outline must correspond pretty nearly to that of the globe which it envelopes, supposing it to be of equal thickness in every region. This, liuwever, is not the ease, since it is more dense near the poles, and more rare near the equator. But the effect of this would be simply to exaggerate the oblately spheroidal outline of the air. It has been conjeetured by M. Biot, and others, that beyond the limits of our own air there exists a 'sort of ether, which pervades all space. In confirmation of this hypothesis, it has been supposed by some astronomers that it is only on such grounds that the retardation of the motion of certain comets is to be explained, the cause lying in the resistance to their motion offered by such a medium. If such a fluid exist at all, it must possess elasticity and tenuity in a degree, probably, as far 
superior to that in which these properties are possessed by our atmosphere, as the air transcends quicksilver in the same properties.

The condition of things on the surface of the air is, allowing that it has bounds, one of a very peculiar kind. At a certain limit the air is supposed to have lost its elasticity; and the. balance between the forees of elasticity and the earth's attraction may be considered as the real limit of the atmosphere. This equilibrium is supposed, as has been stated, to have its situation at a height of from forty-five to fifty miles.

It is very certain that an extreme degree of rarefaction may take place at an elevation up to which it is quite within the power of man to attain. Travellers on the high lands of South America relate that they experienced the most distressing symptoms in consequence of the extreme tenuity of the air; these were, great difficulty of respiration, uneasy symptoms in the head, and loss of 'muscular power. Mr. Darwin informs us, that he himself experienced this sensation, which is called by the natives, the puna ; they recommend onions as a remedy, perhaps with some benefit, as Dr. Pereira tells us that raw onions are occasionally useful as an expectorant. Strangers who come to reside in some of the villages situated at the elevation of from 10,000 to 12,000 feet above the level of the sea, do not get orer the sensation for almost 
a year. The natives of the Himalayas ascribe the difficulty of breathing experienced in the higher alpine passes, 15,000 to 16,900 feet above the sea, to the exhalations of poisonous plants. It is, in reality, due simply to the rarefaction of the air. Gay Lussac ascended in a balloon to the enormous altitude of nearly 22,000 feet above the earth. In these lofty regions the gas of his balloon expanded so much as to require the relief of the safety valve; and he himself underwent the most acute sufferings from the intensity of the cold, and extreme rarity of the air. Even birds flying over the summits of lofty mountains, are said to labour incredibly when they reach the highest points; and pigeons dropped from balloons at great heights, fall like stones to the earth. All these facts sliow us, that as far as man is concerned, the limits of the atmosphere are about three miles; for beyond this his respiratory system would cease to act. And if such is the tenuity of the air at the distance of a few miles, what extreme thinness must be attained just at its verge; such perhaps as is attained in the imperfect vacuum of the airpump; which is known to be almost immediately fatal to animal life.

In the study of this fact we are forcibly impressed with the truth that an impassable barrier exists, which shuts in the world from 
the rest of the heavenly bodies, so that we who "would pass from hence to them, cannot;" but whether other beings from them to us may pass or not, cannot be so clearly demonstrated.

It is one of the curious and interesting discoveries of modern metcorology, that the airy ocean is agitated like that of water by tides. These are, apparently, of two kinds, the first being the result of the lieat of the sun's rays, the second being due to the attraction of the moon. The atmosphere is heated, to some extent, by the transmission of the heat-rays from the sun through it, but chiefly by contact with the earth heated by the sun. Air, when heated, expands, and becomes lighter, and consequently rises; by this law the occurrence of the aërial tides is easily and simply explicable. It is perhaps necessary to mention, that the manner in which the fact is observed, is by carefully noting, at different periods of the day, the height at which the mereurial column stands in the barometer tube. Between the tropies, the ebb and flow, as it might be expected, of the atmosphere, is one of the most remarkable natural phenomena. The periodic rise and fall of the barometer in these regions is, in fact, due to the ebb and flow of the atmospheric tides. The variations occur daily in the following order, according to Humboldt:-Twice a day the baro- 
meter indicates the highest pressure, or, as we might' say, the flow of the tide, at 9 , or $9 \frac{1}{4}, A . M$. and 10 , or $10 \frac{3}{4}$, P.M. ; and twice a day the lowest at 4 , or $4 \frac{1}{4}$, P.M., and 4 , A.M., or nearly the hottest and coldest hours in the round of the twenty-four. It is highly remarkable that this periodic rise and fall in the atmospheric ocean, takes place in the torrid zone of America, without sensible disturbance by elevation, winds, storms, or rain, or earthquakes. Such, in fact, is the regularity of this phenomenon, that the hour may almost be told by looking at the column of mereury instead of the clock! It has also been observed, that in Europe the same phenomenon takes place, but is affected to a great extent by the season. In winter, the highest pressure takes place about 9, A.M., and the lowest about 3, P.M., after which the prcssure again increases up to 9 in the evening. In the summer, these periods are slightly different. It is, howe ver, very difficult to distinguish the occurrence of these aërial tides, in consequence of innumerable accidental causes, which disturb their indications.

The explanation of the phenomenon arises out of what has been said as to its periods. At the hottest part of the day, the air expanding ascends, and passes over into neighbouring regions, and the barometer at the same time falls. This is the "ebb" of the tide. At the coldest 
part, the pressure of the superineumbent masses of cool air, keeps the column up at its highest point; and this we have called the "flow" of the tide.

With reference to the attraction of the moon upon the air, it may be well to extract the following sentences from the admirable address of Sir R. H. Inglis, at the mecting of the British Association, in 1847 :- "The doctrine of the influence of the moon and of the sun on the tides was no sooner established, than it became eminently probable, that an influence exerted so strongly upon a fluid so heavy as water, could not but have the lighter, and all but imponderable fluid of air under its grasp. It is now clear, as the result of the observations at St. Helena, by my friend, Colonel Sabine, that as on the waters, so on the atmosphere, there is a corresponding influence exerted by the same causes. There are tides in the air as in the sea; the extent is, of course, determinable only by the most careful observations with the most delicate instruments. since the minuteness of the effect, both in itself, and in comparison with the disturbances which are occasioned in the equilibrium of the atmosphere from other causes, must always present great difficulty in the way of ascertaining the truth, and had, in fact, till Colonel Sabine's researches, 
prevented any decisive testimony of the fact being obtained by direct observation. But the hourly observations of the barometer, made for some years past at the Meteorological and Magnetical Observatory, at St. Helena, have now placed beyond a doubt the existence of a Lunar Atmospheric Tide. It appears that on each day the barometer at St. Helena stands, on an average, four thousandths of an inch higher at the two periods when the moon is on the meridian, above or below the pole, than when she is six hours distant from the meridian on either side; the progression between this maximum and minimum being, moreover, continuous and uninterrupted; thus furnishing a new element in the attainment of physical truth ; and to quote the expression of a distinguished foreigner, 'We are thus making astronomical observations with the barometer!' that is, we are reasoning from the position of the mercury in a barometer which we can touch, as to the position of the heavenly bodies, which, unseen by us, are influencing its visible fall and rise. 'It is no exaggeration to say, - and here I use the words of my friend, the Rev. Dr. Robinson,-', that we could, even if our satellite were incapable of reflecting light, have determined its existence; nay, more, have approximated to its eccentricity, and period." 
A phenomenon yet more extraordinary is that of Atmospheric Waves. As yet the discoveries made on this singular subjeet are very incomplete; but Mr. Birt, who has made them his peeuliar study, is zealously engaged in prosecuting the research. It cannot now be doubted, that though invisible to us, there occur, at certain periods of the year, phenomena in the atmosphere, which are clearly analogous to waves. Not mere undulations of a slight extent, like those of the surface of the sea, but great wave-like movements, pervading the whole depth of the atmosphere, and occupying several days in their duration. The most remarkable of these is a vast wave, which has for several years been observed about the middle of the month of November. It lasts, with some modifications, for about sixteen days; that is, it begins, rises higher and higher, until it reaches its highest point; then subsides again, and the atmosphere returns to its usual condition, in the space of a fortnight, or sixteen days. Sometimes it has been observed to set in with a gale of wind, and to end with one also. We are not yet in full possession of a sufficient number of facts to enable us to determine its cause or causes, with aecuracy.

It has been remarked, as a curious coincidence, that the period at which this great November 
wave is at its highest point in our country, is precisely that given by American travellers, for the occurrence of that most remarkable meteorological phenomenon-the Indian Summer. In America, at this period, generally from the 12 th to the 17 th of November, after a foretaste of the severities of winter has been felt, a sudden change of temperature takes place, a delicious warmth is felt, the sky is without a cloud, not a breath of air is stirring, and the whole atmosphere is filled with a glowing transparent haze. In three days this is all gone, and winter comes on quickly afterwards. In Switzerland, the same phenomenon has been remarked from time immemorial. About the 11th of this month, the fête of St. Martin is celebrated, and the inhabitants call the delightful four or five days' return of summer weather at that time, after, to all appearance, the summer has ended, l'Été de St. Martin, or St. Martin's summer. Whether these interesting facts are more than mere coincidences, whether the great wave has anything to do with them or not, it is not at present possible to ascertain.

Some curiosity will, doubtless, be felt to know how, seeing that the phenomenon cannot be rendered visible to our eyes, its existence has been ascertained. It is true, we cannot see this wave, but its presence may be felt by 
means of the very simple instrument-the barometer; - to some mention of the phenomena and construction of which we are now conducted. Light and thin though the particles of the atmosphere are individually, they lave in the mass a sensible weight, and exert a pressure altogether enormous upon the whole surface of the earth. This pressure is not felt by our bodies, because it is equally distributed botl within and without. It might even be very much increased, if very gradually, and yet we should not become sensible of its increase, on this account. But were it possible to disturb this equilibrium, by suddenly exhausting the air from any part of the frame, the lungs, for instance, then immediately the pressure of the air would be painfully felt, and if the exhaustion were carried on to any great extent, the sides of the chest would be crushed together by the weight of the external air. The entire amount of its pressure on our globe may be conceived by stating, that could we place at one end of a balance a hollow sphere of mercury, 8,000 miles in diameter, and about 30 inches in thickness, it would exactly counterpoise our atmosphere, could it be appended to the other extremity. Upon each square inch of surface at the level of the sea, the air presses with a weight of about $15 \mathrm{lbs}$. 
The principle of the barometer is very simple. It is an instrument, which, by virtue of its peculiar construetion, weighs or balances'a column of air, forty or fifty miles high, and of the diameter of the barometer tube. Suppose the diameter of this tube to be equal to that of a goose quill. Now, suppose that we could take a piece out of the air of the size of that quill, which extended from its summit to the level of the sea, and weigh it; and that we then filled the tube of the barometer with mercury, up to the height of 30 inches, and weighed it; we should find the weight of this short column of mercury, and the forty or fifty mile-long column of air, precisely equal! This may be easily put to the test. We are able actually to weigh the one against the other, in the following manner. Let us, by means of the blow-pipe, melt one end of a tube of glass about 33 inches long until it is quite closed at that end, and then fill

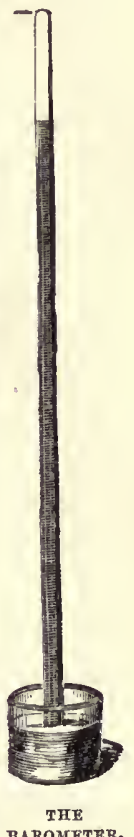

BAROMETER. it with mercury, and putting the open end into a saucer with a little mercury in it, let us invert it. Yet the mercury does not run out. The reason is, the tall, thin column of air, of which 
we have spoken, presses upon the surface of the mereury in the cup, and counterbalances it, so preventing its running out. Should the weight of this column of air be by any means diminished, the fact will be immediately exhibited by the mereury falling; should it be increased, it will rise. In other words, when the weight of the column is greater, it counterbalances more, and when lower, less mereury in the tube. An ascending current of air rarified, and therefore made lighter by heat, causes the ebb of the daily aërial tide in the tropies beforementioned; and this ebb is duly registered by the mercury in the tube, standing at a lower mark.

Elevation produces a similar depression, the barometer falling gradually for every step of ascent gained;* and if it were possible to rise to the very surface of the atmosphere, not a drop of the mereury would remain in the tube. This fact is of the utmost importance in the admeasurement of heights, and proper formulæ exist by which it is easy to ascertain, after certain corrections are made, the amount of perpendicular elevation possessed by a mountain, or other eminence. On the contrary,

* The ingenious instrument ealled the anezoid barometer, a pocket weather-register, eonsisting of an exhausted reeeiver with a moveable lid and index, has proved very useful in these investigations. 
were we to descend with the barometer into the earth, so increasing the weight of the column of air pressing upon the mercury, it would rise exactly in proportion as we descended. So also any cause acting in the upper regions of the air to increase the weight of the column, would produce the same effect. Thus the great November wave renders its passage obvious even to the eye, for by reading the height of the barometer, we are able to perceive its gradual rise to its crest, and its gradual recession again.

It is generally said that it is the pressure merely of the air which causes the rise of the mercury in the tube of the barometer. Recent researches of Professor Dove and Coloncl Sabine are tending gradually to develop a very dif"ferent view of this matter. The air constantly contains water in a vaporous and invisible state, which, as well as the gases forming air, properly so called, presses upon the mercury in the cistern of the barometer. When the air is warmer the pressure of this watery vapour is greater than when it is cold and dry. Hence, during the summer, the pressure of the vapour has an important influence in keeping up the level of the mercury; during winter, on the contrary, its pressure is least, but then the pressure of the gases is greater than in summer. When, 
therefore, we state that the pressure of the atmosphere is 15lbs. on a square inch, we must not forget that a part of this is due to the pressure of the watery vapour in the air, though only a small part in comparison with that caused by the gascous constituents of the air.

Proportionally to the decrease of temperature, the elastic force of the vapour, or, in other words, its pressure on the barometer, will be diminished. In the late Antaretic Expedition, the effect of a decrease of temperature on the barometral pressure was particularly striking. From the tropic of Capricorn, southward, a gradual diminution in the height of the mercurial column was observed as the latitude increased. At Kerguelen's Island the mean height of the barometer was 29.497. In S. lat. $66^{\circ}, 29.078$; and in lat. $74^{\circ}$, it was only 28.928 . Thus the * mean position of the mercury in the higher latitudes of the antaretic regions, was nearly an inch lower than in other parts of the world. Similar results have been observed in Siberia.

The manner of estimating the pressure of the watery vapour, independently of the gaseous atmosphere, is by calculations based upon an ingenious little instrument called Daniell's DewPoint Hygrometer, which will be noticed on another occasion.

Although insensible to ourselves, the pressure of the air is of great consequenee to our well- 
being, and is also highly necessary to that of every living thing, and to the preservation of natural things in their present condition. To ourselves, it is important in various ways. It prevents that excessive evaporation from the surface of our bodies, which would otherwise exhaust and destroy us. It also determines, in an important manner, the proper density of the volume of air which is requisite for our comfortable breathing: hence the laborious respiration of persons at high elevations. It is important also to us in an economical point of view : it is found, for instance, that if we by any method diminish the pressure on the surface of liquids, as, for example, by exhausting a part of the air from a close vessel, that they will boil at a much lower temperature than when - the full pressure of the atmosphere is allowed to exert itself upon them. In sugar refineries this is taken advantage of, by boiling down the sugar in pans, out of which the air is pumped by a steam engine; in this way all risk of burning is avoided. Again, if the pressure is increased, the boiling point rises' also, and it will be more difficult to bring liquids up to this point. As a curious result of the diminished pressure lowering the boiling point, it may be mentioned, that much inconvenience is occasionally felt by travellers on high mountain regions. Darwin relates a humorous anecdote 
of this nature; he was at that time travelling in the Andes:- "Our potatoes, after remaining for some hours in the boiling water, were nearly as hard as ever. The pot was left on the fire all night, and next morning it was boiled again, but yet the potatoes were not cooked. I found out this by overhearing my two companions discussing the cause; they had come to the simple conclusion, that the potatoes were bewitched: or that the pot, which was a new one, did not choose to boil them." The monks of St. Bernard, living as they do at an elevation of 8,600 feet, are sorely distressed at the same phenomenon, and are compelled to subsist almost entirely on fried, roasted, and baked food in consequence of the water boiling at so many degrees under the usual boiling point, $212^{\circ}$, as to render its heat insufficient to render wholesome the food which they procure. It seems a great pity no kind traveller should have carried a Papin's digester to them; for as that is a close vessel, fitted with a pressure valve, they could easily remedy the inconvenience under which they labour, by substituting an artificial pressure in place of the deficient atmospheric weight.

It is easily conceived, that since the density of the air is directly proportionate to its pressure, how important it must be for the 
feathered tribes, that the air should be sufficiently dense to offer resistance to the play of their pinions; so also, though in a less degree, to insects. Some birds, taken up on one occasion by an aëronaut in a balloon to a great height, and set at liberty, refused to leave the machine, and clung to its sides in great terror, being apparently sensible that the air was too thin to trust the weight of their bodies to. To fishes, the atmospheric pressure is also of vital consequence. If this pressure were removed the result would be, that the air now dissolved by water, would immediately rise from it, and the inhabitants of our lakes, rivers, and seas, would die in consequence. To plants, it is also of great moment; it restrains that excessive loss of fluids which would follow if it was in

- any degree removed; for just as a diminished pressure lowers the boiling point,* so it increases the facility with which the evaporation of fluids takes place. In various ways atmospheric pressure exerts a beneficial influence upon their growth and functions, and upon the motion of the vegetable juices.

If we place a piece of solid ice under the exhausted receiver of an air-pump, and take care that the experiment is conducted in a room

* Water in the imperfect vacuum of an air-pump, will boil at the low temperature of $67^{\circ} !$ 
below freezing point, so as to insure its not melting, we should find in a little while that all the ice had disappeared; the reason would be, that it had evaporated away. From this we may learn, that if the atmospheric pressure were removed, not only would liquids evaporate, but, in all probability, many solids also. From all these considerations, we may learn the wisdom and beautiful adaptation to existing circumstances, exhibited even in the apparently less important particular of atmospheric pressure.

There is yet another circumstance to be noticed in reference to the physical constitution of the atmosphere, and that is, the temperature of its higher regions. It has been mentioned that in proportion as we rise from the earth, the density of the air becomes continually less and less. The balloon of the aëronaut, after rising to a certain height, can rise no longer. It then remains stationary, for above it the air is so thin as to be unable to support it, with its car and weights, even in spite of its buoyant contents of hydrogen gas. This effect is due to the elasticity of the air. In proportion as the pressure on its particles diminishes, their tendency is to separate farther and farther from each other; or, in other words, the air expands. By calculation it has been found that this expansion of the air, as we ascend takes place in 
what is called a geometrical progression. For instance, if at the level of the sea a certain quantity of air occupied one square foot of space, at a little more than two miles and-a-half it would fill a space of two square feet; at about five miles, four; at eight miles, eight; at ten miles, sixteen; at thirteen miles and-a-half, thirty-two; and at sixteen miles, sixty-four cubic feet. Hence we very soon reach a limit by means of the balloon beyond which we cannot pass. The limit appears to be about 22,000 feet; that, at least, is the highest point yet attained in aërial navigation.

Now, it is a remarkable fact that one of the consequences of this expansion is a diminution of temperature. It has been found by experiment that this is due to the fact of expanded air having a greater capacity for heat than compressed air. It seems,-although it must be carefully remembered the subject is still very obscure,-it seems as if expanded air contained more room for heat than compressed air : for it is found that we may, as it were, squeeze out heat from air by a well-fitting syringe, by forcing it violently down; and a peculiar syringe is constructed, with a piece of German tinder at the bottom, which, when forcibly worked once or twice, produces so much heat by compressing the air, as to set fire to the tinder! 
On the contrary, if we cause air to expand, as in the air-pump, we can produce a great degree of cold, because the expanded air absorbs heat into itself from all surrounding bodies. By the

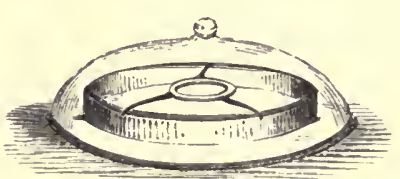
little contrivance represented in the cut we may readily manufacture a small quantity of ice. A little water must be put into a watch-glass, supported by a triangle of wire, over a saucer of strong sulphuric acid, or oil of vitriol, placed over the plate of an air-pump, and covered by a flattened receiver; the pump, being then worked, the water will in a few minutes be converted into a solid mass of ice! Sir John Leslie actually formed an apparatus for making ice artificially on a large scale by the adaptation of this principle; and large ice-making machines have been sent out to India with this view. The facility with which we can now procure the beautiful lake-ice of America, renders these contrivances no longer interesting except as curiosities.*

It is partly in consequence of this increased

* Recently a machine has been patented in America for making iee by the expansion of previously compressed air. It is a kind of steam-engine, and at every stroke produces a shower of snow! The idea is, however, not altogether new. 
capacity for heat that the upper regions of the atmosphere are so intensely cold. Part of the effect is likewise due to the loss by radiation into space. This loss of temperature as we ascend must be familiar to every visitor of mountain scenery. Frequently it is picturesquely painted by the snowy cap which envelops the summits of the loftiest mountains; and where the mountains are of the most elevated description, at a certain height there is a distinct line, visible from afar, and forming a very peculiar feature of landscape, which is well known as " the line of perpetual snow." It is, in fact, in most cases, an almost straight line between the fringe of hardy and scanty vegetation, and a snowy covering which clothes the mountains from its summit to that point. This appearance sufficiently indicates, by a sort of natural thermometer, the temperature of the air at such elevations. The line varies in height in different countries; and although highest in hottest countries, as at the equator, as a general rule, and becoming lower as we approach the poles, when it enters the earth, this law is by no means without its exceptions, some of which are of a very singular character.

Of these exceptions, one of the most remarkable that have recently presented themselves is the account given by a missionary of a supposed 
snow-covered mountain in Eastern Africa. 'This discovery is mentioned in the following extract from his journal:*_" The mountains of Jagga gradually rose more distinctly to our sight. At about ten o'clock I observed something remarkably white on the top of a high mountain, and first supposed that it was a very white cloud, in which supposition my guide also confirmed me; but having gone a few paces further, I could no longer rest satisfied with that explanation; and while I was asking my guide a second time whether that white thing was indeed a cloud, and scarcely listening to his answer that yonder was not a cloud, but what that white cloud was he did not know, but supposed it was coldness, the

* The cut exhibits the variations with great accuracy. In its composition, the great and admirable work, Johnson's Physical Atlas, has been followed.

REFEREXCE TO CCT OPPOSITE.

1. Erebus.

2. Sarmiento, Tierra del Fuego.

3. Nose Peak, Tierra del Fuego.

4. Mount Stokes, Patagonia.

5. Yanteles, Andes of Chile.

6. Osorno, Andes of Chile.

7. Egmont, New Zealand.

- 8. Vol de Peuquenes, Chile.

9. Gualatieri, Western Cordillera.

10. No. de Sorata.

11. E. Cordillera.

12. Chimborazo, Quito.

13. Cotopaxi.

14. Purace.

15. Tolima.

16. Sierra Nevada de Marida.

17. Abba Jaret, Abyssinia.

18. Popoeatepetl.

19. Sierra Nevada.
20. Etna.

21. Pyrenees.

22. Ben Nevis.

23. Mageröe.

24. Sulitelma, interior of Norway.

25. Osterjokul.

26. Interior of Nurway.

27. Northern Lral.

28. Kamtsehatka.

29. Oonalashka.

30. Altai.

31. Mont Blane.

32. Elbrouz, Caueasus.

33. Kastuek, Caưcasus.

31. Ararat.

35. Bolor.

36. Hindoo Koosh.

37. Dhawalagiri, Himalaya. 


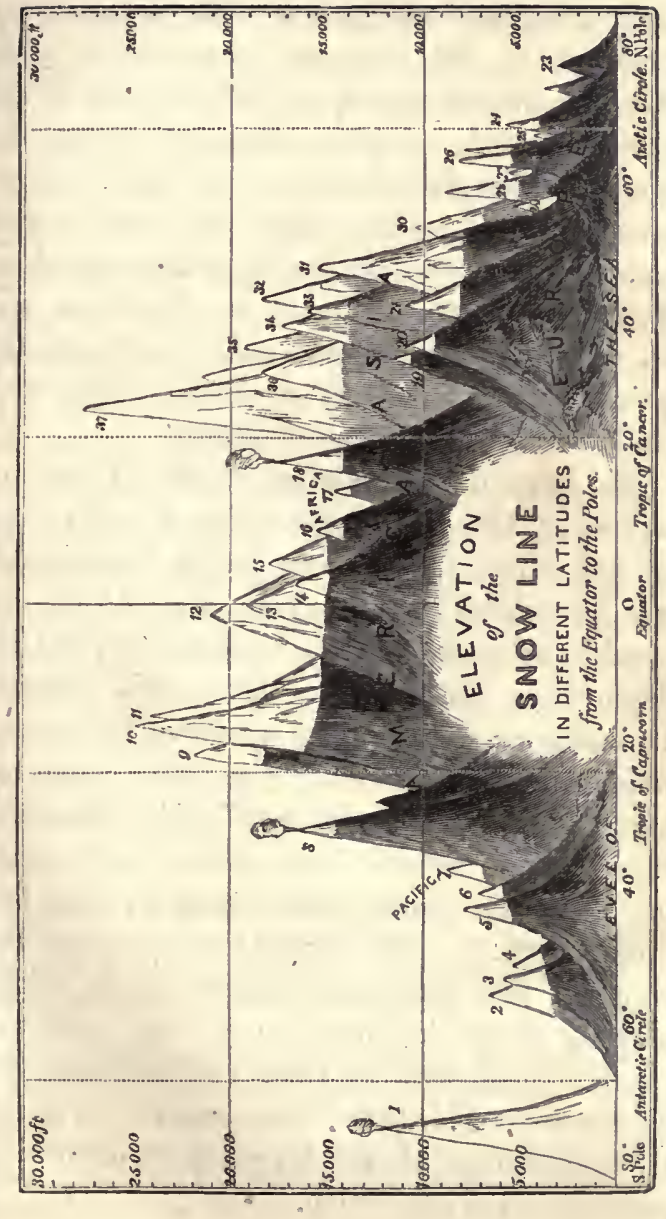

Q. 
most delightful reeognition took place in my mind of an old European guest called snow. All the strange stories we had so often heard about the gold and silver mountain Kilima dja àro, in Jagga, supposed to be inaccessible on aecount of evil spirits, which had killed a great many of those who had attempted to ascend it, were now at once rendered intelligible to me, as, of course, the extreme cold, to which the poor natives are perfeet strangers, would soon chill and kill the half-naked visitors.'

Further on this gentleman, Mr. Rebmann, writes,_-"May 12, at about five o'clock, P.M., we had to ford another river, ealled Gona, which was eonsiderably larger than the Loomi, its breadth being from thirty to forty feet, and its depth three feet, with a most rapid stream. Its water was cold enough to prove its source, which evidently is nothing else than the eternal snow of the Kilima dja āro." Mr. Rebmann adds to these remarks some particulars respecting a large exploring party sent by the late king of the country to "examine into the nature of that strange white guest in the neighbouring mountain, when only one man was spared, though with his hands and feet destroyed by excessive cold, to tell his despotic sovereign the sad tidings of all his companions having perished in the expedition." . 
Although loosely stated, the account of this mountain is considered by many to be accurate, and if so, it undoubtedly forms one of the most remarkable exceptions to the general rule, with regard to the temperature of high air in the tropics. It is but right to add, that it has been much disputed whether the white cloud on the mountain really was snow. The white and glistening appearance has been supposed to have been caused by something else, because by ordinary calculations a mountain in East Africa to be covered with perpetual snow must approach 16,000 feet in height; and it is by no means clear that Kilima dja āro approaches this degree of altitude. The mean height of the line of perpetual snow is at the equator 15,200 feet.*

We say that the air is transparent, $\uparrow$ and without colour; why then, it may be asked, as we gaze upwards, do our eyes rest in every direction upon a vault of so intense and beau-

* Since the above was written, intelligence of a more de finite character as to the nature of this mountain has reached England. It now appears to be without a doubt that its summit is capped with perpetual snow.

† Mr. Darwin says that while ascending the Bell mountain in Central Chile "the evening was fine, and the atmosphere so clear that the masts of the vessels at anchor in the bay of Valparaiso, although no less than twenty-six geographical miles distant, could be distinguished clearly as little black streaks." 
tiful a blue? The truth is, the air is not perfectly transparent when seen in bulk; and the cause of the blue colour is the reflection of the rays of light from its particles, and from those of the watery vapour it contains. As we ascend, the colour deepens in intensity, in consequence of the dark space beyond our atmosphere being seen through it more distinctly, and at the great elevations which have been attained by means of the balloon it almost approaches a black. On the summit of high mountains it is often seen to be of an intense Prussian blue. M. de Saussure made some singular observations upon this subject, and formed a scale of the shades of colour as we ascend. In Colcridge's sublime lines, entitled the Alpine Hymn, this fact is alluded to in speaking of the "Sovran Blanc."

" Around thee and above

Deep is the air, and dark, substantial black, An ebon mass. Methinks thou piercest it As with a wedge."

Sometimes, apparently in consequence of the presence of a large quantity of water in the air, the blueness becomes very remarkable. The following letter describes a most curious example of the occurrence of this phenomenon at Bermuda:-"On the 10th of August, 1831, the weather,"' observes the writer, "was remarkably fair; but as evening drew near, a change 
took place. The sky began to lower, and put on an awful and glnomy appearance. The clouds collected voluminously, and very heavily, in every direction over the island, indicating a prodigious fall of rain. At this time I do not recollect any threatening of a storm of wind, save a moderately-hollow sound of the sea dashing against the shore, but by no means equalling that which we frequently witness at this season of the year, when a storm is impending, or has passed by us. Thunder and lightning began to be severe, and the weather more threatening. Next morning, the 11th, I rose early for the purpose of writing, and soon discovered the light was so dim that I could not proceed. I removed to another room, and finding my situation not improved, I said in the presence of one of my family, I apprehended a sudden failure of sight. I was then asked if I had not observed a very peculiar appearance of the sun's rays the day before. I had not; but had perceived the floor of the room to look blue, especially where the, sun shone on it: indeed, every object in the room appeared of a sickly blue colour. The next day, the 12th, a mail-boat was put under weigh, for the first time, with a party on board. The day was so mild and tranquil, we could only reach a few miles: the sails, which were 
new and pure white, nevertheless appeared to be stained of a bluish colour, and the sea was of a dingy yellow. On the first arrival from the West Indies, we heard of the devastation at Barbados; but with us there were no subsequent unusual appearances; on the contrary, we had very fair weather, although 1 heard this singular blue colour was observed even to the coast." This letter was read by Sir D. Brewster, at the tenth meeting of the British Association; and in alluding to the cause of the phenomena, he expressed the conviction that the blue colour was produced by the interposition of water, in the form of vapour, between the sun and the observer.

It has been ascertained by M. Arago, that the light thus reflected from the sky is in the peculiar condition known by chemists as polarised, exhibiting different effects from that of the direet rays of the sun. Upon one of the peculiar phenomena exhibited by the polarised light of the sky as the sun ehanges its position during the day, Professor Wheatstone has constructed what he ealls the Polar clock or dial. It is impossible in this place to enter into an explanation of the principles upon which this beautiful invention depends, as it would be unintelligible without a full discussion of the difficult subject of polarisation of light; but it 
may be stated, that by its means the time may be most accurately ascertained, simply by directing the instrument to the North Pole of the sky. It is found that it will indicate the time even before sunrise and after sunset; in fact, as long as the rays of surlight are reflected from the atmosphere.

The beautiful and gorgeous colouring of clouds depends upon the decomposing effect of their watery particles upon the rays of the sun. In tropical countries there is a peculiarly beautiful appearance in the atmosphere which we do not meet with in temperate zones. Baron Humboldt frequently alludes to it as a sort of thin haze or vapour, which, without changing the transparency of the air, renders its tints more harmonious, and softens its effects. This appearance was also noticed by $\mathrm{Mr}$. Darwin. "The atmosphere," he says, speaking of Bahia in Brazil, "seen through a short space of half or three quarters of a mile, was perfectly lucid, but at a greater distance all colours were blended into a most beautiful haze, of a pale French grey mixed with a little blue, The condition of the atmosphere between the morning and about noon, when the effect was most evident, had undergone little change, excepting in dryness."

The atmosphere contains a large amount of 
electricity, which acts in various ways an important part toward both organic life and inorganic matter. The whole vegetable and animal world are largely influenced by this electricity, and it is doubtless intimately conneeted with their life and well-being. It is also greatly concerned in the formation of clouds, rain, and similar phenomena. When developed in intensity, as in the explosions accompanying tempests, it effects various ehemical decompositions in matters present in the air. It has been considered that ammonia may sometimes be produced by its influence. It also occasionally produces small portions of nitric acid. A peculiar ingredient, called Ozone, is constantly produeed by it. Its services are very variable. Friction of currents of air against each other, evaporation and chemical decompositions taking place on the earth's surface, all produce it. It is generally, when the air is clear, of the positive kind. This varies, however, with the variations in its sources. The earth, on the contrary, is always eharged with negative electricity.

With these remarks on the physical constitution of the atmosphere and its connected phenomena, we may pass on to what is more peculiarly our province, and speak next of the Chemistry of the Air. 


\section{CHAPTER II.}

CHEMICAL CONSTITUTION OF THE AIR.

DIFFICULTIES which appeared quite insurmountable had long beset the investigations of chemists upon the composition of the air. Long after the revival of experimental chemistry the most erroneous impressions were afloat; and chemists, in their discordant analyses, only increased the confusion by the vast discrepancies which occurred between the results of one analyst and those of another. Until the middle of the eighteenth century, the opinion was very prevalent that the atmosphere formed one of the four elementary bodies, - that it was, in fact, a simple, undecomposable gas. It was reserved for the talented Dr. Priestley to dispel this error. He discovered the existence of a new gas which formed one of the constituents of air. In this gas it was found that combustion took place with extraordinary intensity; even ironwire, heated red-hot and plunged into it, caught fire, and burnt away! Other combustibles gave out showers of the most brilliant sparks, and produced the most intense heat, when placed in 
the jar containing it : a lighted taper having been blown out, instantly rekindled when put into it, and blazed with much greater brilliancy than in air. These extraordinary characters soon gave the gas great celebrity.

Soon afterwards another gas was found also to form a part of the composition of air. This gas was the direct contrast of the other. Instead of increasing the brilliancy of flume, it extinguished it as effectually as so much water.* Like the other, it was inodorous and invisible;

* A very interesting application of this property of nitrogen gas, mixed with earbonic acid gas, has been recently made by Mr. Gurney. By some accident, a large and rahable coal mine took fire. After vain attempts to queneh the devouring element, the galleries were rehctantly abandoned, and the miners withdrew with their instruments. There seemed no way of quenching the immense body of fire raging underground, but by the enormously expensive one of turning a 'stream of water into the mine, so as to fill it! When the idea was suggested that it might be extinguished just as effectually ly means of gas as of water, arrangements were then made for conducting the air of a furnace-whieh consists largely of nitrogen and earbonic acid-after eooling it by passing it through water, down to the workings; and a steam-jet placed over the mouth of the pit, was caused to act so as to produce a powerful draught. By this means a stream of nitrogen, carbonic aeid, and other gases was drawn from an apparatus speeially contrived for this purpose, passed down the descending shaft, poured itself upon the body of fire, and being sueked upwards by the steam-jet, returned again up the ascending shaft. In a few hours the fire was wholly quenehed! and after a certain time pure air was 
but while the first exhibited the utmost avidity for combination, this was resolutely indifferent to every substance. Animals were intoxicated when immersed in the first; they were suffocated on immersion into this. Such were the opposing qualities which at the time of their discovery were found to exist in the important gases, oxygen and nitrogen.

The celebrated chemists, Scheele and Lavoisier, both arrived, and each independently of the other, and of Dr. Priestley, at the same conclusions, and stated the composition of the atmosphere in terms, which, considering the great imperfection of their method of analysis, were wonderfully near the truth. Thus the bare fact was shaped out-air is not a simple or elementary fluid; its constituents are oxygen and nitrogen; and these are mixed together in a certain proportion.

blown through the mine; the next day it was inspected, all was found safe, and the workings were resumed. From this may be learnt the value of even a moderate knowledge of chemistry. Mr. Phillips's "Fire Annihilator," which is a machine for pouring out a stream of gas upon a fire, and putting it out by excluding the combustibles from the access of the oxygen of the air, acts upon similar principles to this plan of Mr. Gurney's ; but the gases evolved are different, consisting of the products of the combustion inside the apparatus of sulphuric acid, chlorate of potash, and sugar, together with some portion of steam. 
It will be readily conjectured that the ultimate process of obtaining an accurate statement of the composition of air, that is to say, one of sufficient aecuracy to satisfy the chemical philosopher, was yet to be long deferred. The investigation was one of unusual difficulty. The methods of analysis were to the last degree rude and imperfect, and the consequence was that the results were invariably discrepant, and more or less distant from the truth. The principle upon which they were conducted was in every instance the same,--the methods were very dissimilar. The chemical energy of the gas oxygen has already been mentioned, and offers a striking contrast to the inertness of nitrogen. This was taken advantage of by chemists. It was easy to select substances which seized upon oxygen with avidity, while the nitrogen was left wholly uninfluenced by their presence. These substances were of many kinds. To enumerate a few-we find employed, sulphuret of potassium, phosphorus, lead turnings moistened, spongy platinum, and the gas hydrogen. When the first three of these substances are exposed to air, they immediately begin to oxidate, that is, to absorb its oxygen, leaving all the nitrogen behind. 'The experiments with spongy platinum and hydrogen were differently conducted to those with the former substances. 
That a definite idea may be formed of this singular process, by which we learn this important part of the chemical constitution of the air, the method of conducting the experiment with the substance Phosphorus, may be shortly stated. A portion of air should be confined in a glass tube, over distilled water, in which a small piece of phosphorus, fixed to the end of a wire, should be placed. The tube should be graduated into a number of divisions, by which the height, of the contained water may be ascertained. After the lapse of some hours, the water inside the vessel will be found at a higher mark than before. 'I'his indicates that a certain amount of

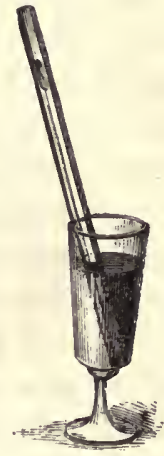

BUDIOMETER, air, equal to the amount of increase in the height of the water, has been abstracted. After a time, the water ceases to rise, and then the process is complete. On removing the jar and putting a lighted taper into the remaining air, it will be found to go out directly, and a small animal would be suffocated by it. These are not the characteristic effects of oxygen; the residue is therefore nitrogen, the oxygen having entirely disappeared. The calculation is now easy, - the water indicates the amount of oxygen 
removed, and nearly all the rest is nitrogen. Such was the simple analysis which was long considered best for the determination of this point. This process was called Eudiometry, which signifies the measuring of the beneficial principle (oxygen) of the air.

But in this plan the solvent power of water for oxygen, the uncertainty whether the whole of this gas had been completely removed, with several other causes of crror, interfered with the result; and we may, in the recollection of these errors, satisfactorily point to the real source of those analytical inaccuracies which had long perplexed chemical science.

To place this subject on a sounder basis was felt to be a national subject by Messrs. Dumas and Boussingault, two of the most eminent chemists of the French school. They resolved to attempt to remove the stigma from ehemistry, and to determine finally the true chemical constitution of the atmosphere. Impressed with this idea, they conceived a method of analysis of perhaps unparalleled ingenuity and accuracy, in the employment of which every conceivable source of error appears to have been guarded against. The following account of it is derived from their own published memoir, in a recent volume of the Annales de Chimie et de Physique.

The air selected for analysis was collceted in 
several large glass flasks, which were first entirely exhausted of air by means of a very powerful and perfect air-pump, the vacuum being properly tested before the vessels were used. On arriving at the proper locality, the mouths of these vessels were opened, the air immediately rushed in and filled them; they were then closed and conveyed to the laboratory, and the analysis of the air was commenced. One of these flasks was connected with the tube of the analysing apparatus; and at the opposite end of the apparatus was attached a similar flask, only perfectly vacuous. By this means it was intended that the air of the first flask should be drawn through the apparatus, into the second. The flasks and whole apparatus were now carefully weighed. The stopcock of the vacuous flask, and that of the one filled with air, were then opened, thus causing the air from the one to pass on to the other, through several liquids, in which its watery vapour and other impurities were arrested, and finally over metallic copper, finely powdered, and heated to redness, a substance which has the remarkable property of instantly arresting and absorbing every particle of oxygen from the air as it is passing over it. Thus at length nitrogen only remained, and passed on into the flask. After the process was completed the apparatus was 
again weighed. By this means the amount of oxygen in the whole quantity of air that had passed through was accurately ascertained, as by uniting with the copper it gave additional weight to the apparatus, consequently all that was necessary to ascertain the precise quantity of oxygen in the flask of air was to find out how muel the copper had inereased in weight; all the grains of increase represented grains of oxygen.

The result of a large number of experiments, although occasionally some striking variations were noticed,* gave an average which exhibits the composition of the air in the following proportions :

One hundred parts of air consist of, by weightOxygen . . : : $\cdot 23 \cdot 1-10$ th
Nitrogen . . . . $769-10$ ths $100^{\circ}$

This question was therefore at length satisfactorily decided. But it had often been much disputed by philosophers whether air was universally of a similar composition. Is it the same in the loftiest regions as it is on the level ground, on Mount Blane, or Chimborazo, as on the sea-shore? The late Dr. Dalton held the

* According to analyses made by M. Lewy, it appears probable that the quantity of oxygen varies slightly in different seasons of the year, bver sea and over land. 
contrary opinion. He believed that the oxygen and nitrogen of the air were always in the proportions just stated in the lower regions; but that as we ascended higher and higher, in consequence of the superior heaviness or density of oxygen over nitrogen, the proportion of it became smaller; the oxygen being supposed to gravitate more towards the earth than its companion nitrogen. The analysis of air from these regions would therefore indicate, if this supposition be correct, the presence of less oxygen and more nitrogen, in a certain amount of air. This subject is one of great interest. Some curious and inexplicable phenomena connected with the variable quantities of these gases, appear to countenance it. Dr. Dalton also conceived that he had actually proved the fact, by analysing a portion of air from the summit of Snowdon, which certainly contained less oxygen than a similar quantity taken from the neighbourhood of Manchester.

But when all the facts are inquired into, it seems almost certain that such is not the case. Gay Lussac, by means of the balloon, brought down air in a vessel from the height of between three and four miles. On being analysed it was found to be in no respect different from the air of the lower strata of the atmosphere. A distinguished French chemist also spent a 
considerable time on the high Alps, in analysing the air of those altitudes; but he found that air taken from the summit of Faulhorn was of the precise composition of air at Paris. The air contained in particles of snow was also examined, being expected to furnish a fair sample of the qualities of air in those lofty regions of the atmosphere where snow is formed. In all these cases the results were similar, and it appears therefore to be fairly established that the composition of the atmosphere, so far as regards elevation, is perfectly uniform.

Chemistry perhaps surprises us in few things so much as in revealing to us the fact that the composition of the atmosphere, as regards these ingredients, is also invariable as respects locality. Experiments have been conducted upon the chemical constitution of the air of Ecypt, of the deadly breezes on the coast of Africa, of England, France, the lofty Alps, of Santa Fé de Bogota, of North America, and a number of other localities, and it hạs been hitherto impossible to detect the smallest difference in its composition. What is even more remarkable,the very air which was spreading the most fatal pestilence, the air of a great and crowded eity, and the air of a thronged hospital-ward, were identical in their composition, so far as their proportions of oxygen and nitrogen went. Che- 
mical analysis cannot as yet render appreciable the smallest essential difference between the hot and dusty air of town, and the balmy breathings of a country wind laden with the odour of a thousand flowers. We shall have, on another occasion, to show that a real difference does always exist.

Is air, then, a chemical compound, that its constancy of composition is so remarkable? Few in the present day appear disposed to consider the constitution of the atmosphere in this light. In fact, the admirable analyses of Dumas and Boussingault have presented positive evidence to the contrary, of the most incontrovertible character. But it is still sufficiently singular that the composition of the air is apparently as constant and unvarying as if it were fixed by the unchanging laws of chemical combination. Air is therefore simply a mixture of gases, not held together by the force of chemical union.

The purely physical constitution of the air was not ordained without a satisfactory object in view. Whether we are sufficiently acquainted with this subject to pronounce positively the purposes for which it was thus ordained, may be matter of question; but it is unquestionable that a wise end was attained in its creation and constitution upon simple physical principles, and not upon the more complicated principles 
of chemical combination. It might be thought it was thus formed, possibly with a view to facilitate the innumerable decompositions into which the gases of the air so largely enter. When we remember with what extreme difficulty a true chemical compound of oxygen and nitrogen gases is decomposed, the dissolution of union only taking place under the force of violent chemical reactions, we believe there is sufficient cause for admiration that the wisdom of the Creator has otherwise ordered the composition of the air, in having formed it a mere mechanical mixture of these gases.

If we should stop for a moment to consider the enormous loss of oxygen which the atinosphere incessantly endures, thousands of tons of this gas being withdrawn from it year by year, and yet that by all attainable evidence* we are assured that the composition of the air has not altered from age to age, the reflection comes upon the mind with overwhelining force, How is this loss repaired? What ean be that exhaustless spring which pours back the exact equivalent of these abstracted quantities into our beautiful air? Had not some means of its restoration been preordained, there can be no

* The air contained in a jar, buried in the destruction of Pompeii, when analysed, showed no eliemieal difference from air analysed at the same time on the surface of the earth. 
question that a most serious deficiency of this gas would have been sensible at this period of the earth's history. The Chemistry of Creation, however, informs us that a never-failing spring of oxygen exists, and its copious streams, by a nice adjustment, replace by far the greater part of the loss. In this green grass, in the leaves of these unpretending herbs, and in those of the clustering wood, we shall hereafter find are hid those springs of this precious ingredient of our air, without which desolation and death might at no distant time gradually overwhelm our globe.

From the preceding remarks, it must not be supposed that the atmosphere is purely a mixture of two gases. Such we may indeed truly consider as the composition of air, but by no means that of our atmosphere. Oxygen and hydrogen in chemical union form water, but pure water would ill satisfy the wants of the countless inhabitants of the ocean. So, while we may justly regard oxygen and nitrogen in the given proportions as air, the atmosphere would be totally unfitted to fulfil its present functions, were there no other gaseous ingredients present in it. Indeed, the salts and dissolved gases of the great deep do not stand in anything like the same relation of importance to the tribes which people it, as does the admix- 
ture of foreign gases in the air to both man and vegetation. Possibly, had the atmosphere been created for man alone, and could he have existed on a different description of food to the present, it might have been unnecessary to have cast any other ingredients into its composition. But the earth was to be adorned with plants, and these were destined to supply man with a pure, agreeable, and nutritious food. Vegetation cannot exist in a pure atmosphere of oxygen and nitrogen for any length of time, much less thrive, blossom, and produce fruit. A provision, therefore, was necessary for its wants. Yet here another difficulty presents itself. The gas which proves most nutritious to regetation is one which is deadly in its effects on the animal tribes! This gas is Carbonic Acid. The room capable of containing one hundred cubic feet of air, if filled by a mixture of ninety cubic feet of air and only ten of this gas, would be speedily fatal to any human occupant. How was this difficulty to be surmounted? How was vegetation to live, and man not to die? By the most beautiful adjustment this problem has been solved, for it is found that a proportion of carbonic acid gas, which appears disproportionably small, and is in reality so minute as to be altogether without effect upon the human constitution, yet at the same time sufficiently great 
to meet and satisfy all the requirements of the most profuse vegetation, has been widely mixed with the other gaseous constituents of the atmosphere. The quantity of carbonic acid present in the atmosphere is variable. Represented by figures, it may be thus stated:-

In 10,000 volumes of air :

The maximum of carbonic acid is 6 volumes.

The minimum a little more than 3 volumes.

Other observers place it a little higher, and consider it present in the proportion of one to one thousand volumes, or about one-tenth per cent.

Carbonic acid, however, is a remarkably heavy gas: so heavy, that it may actually be poured like water out of one vessel into another, as may easily be proved by filling a jar with this gas, procured by action on a little chalk with hydrochloric acid and water, and holding it in the position represented

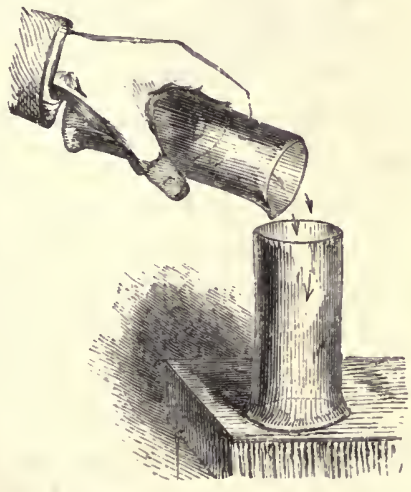
over the mouth of another jar containing a lighted taper, which will be immediately extinguished. If at the temperature of $60^{\circ}$, and 
barometric pressure 30 inches, one hundred cubic inches of air weigh 30 grains, under similar circumstances one hundred cubic inches of carbonic acid will weigh more than 47 grains. Its tendency, therefore, is to collect and aceumulate near the surface of the ground. This may be seen by any one who will pay a visit to a large brewery. Standing by the side of one of the large fermenting vats, and in such a position that it may be seen against the light, he will perceive trembling transparent floods of this gas pouring over the top and down the sides of the vessel. The same appearance is also frequently visible in a glass of soda-water, which is charged with carbonic acid. This gas, as has before been noticed, is poured into the air in enormous quantities. Why does it not obey the laws of gravity, and remain near the ground? What is there to hinder its falling down and overwhelming the human race and the whole animal world with its deadly floods? The answer is, the power of diffusion. What, then, is the "power of diffusion?" This question must be answered by an experiment.

If a glass jar or bottle were filled with carbonic acid, and the mouth stopped by a plug of plaster of Paris, and left, in a little time the vessel would be found only to contain common air. The heavy carbonic acid would have 
entirely disappeared. As there is but one way of escape through the neck, and even this passage is, apparently, very accurately closed, it is evident, whatever the power, it was sufficient to enable this naturally heavy gas to rise up and leave the vessel, and the naturally lighter air has descended and filled it. A pleasing way of performing this experiment is to fill one jar with the lightest of all known gases, hydrogen, and another with the heavy carbonic acid gas, and to connect them by two perforated corks and an intervening tube, as represented, and then to place them in the position

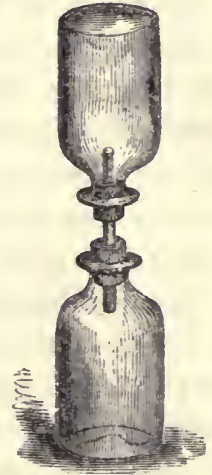
shown, that containing the hydrogen being uppermost. In a little while the heavy carbonic acid gas will rise to the top of the upper jar, and the light hydrogen will descend, and sink into the lowest jar, until the two jars contain a uniform mixture of both gases. The force which produces this remarkable phenomenon is the diffusive power of gases, the beautiful laws of which were discovered and developed by the eminent chemist, Professor T. Graham. By virtue of this remarkable force, the heaviest gases rise up into the air, though less rapidly 
than the lighter, and, more singular still, actually with as much foree as if they were rushing up into a vacuum! Thus they have power to rise to the very highest regions of our atmosphere, and to spread to its remotest limits.

It would be diffieult to select a more striking illustration of the wisdom and design displayed in assigning laws to the atmosphere, and to gaseous fluids in general, than is thus presented to us. The uniformity of the atmosphere is mainly due to the incessant influence of this dispersive force. Diffusion is, as it were, the messenger between man and vegetation, for it conveys to the one the carbonic acid produced, and brings back to the other the oxygen restored. By this means, also, is gradually effected the dispersion of all gases, no matter whether dense or rare. While the heaviest vapours are thus made to rise and spread far and wide, the lighter ones are also caused to descend and intermix with air far more dense than themselves. These are facts which experiment has amply proved.

De Saussure found the heavy gas of which we have spoken (carbonic acid) present in the thin air of the Alpine summits, and even in greater abundance than in the air of the lowlands far beneath-an effeet duc, without doubt, to the influence of vegetation; thus clearly 
proving that the mere circumstance of elevation is no obstacle to the force which impels the gas upwards.

The same diffusive force scatters gases abroad laterally as well as in the perpendicular direction. A French chemist; M. F. Leblanc, instituted a series of experiments upon the amount of carbonic acid present in confined air, and his results show, in the most complete manner, that by these ever-active agencies the air of our chambers is renewed and preserved from an excess of carbonic acid, and our habitations, with all their comforts and warmth, are made, as far as regards their amount of carbonic acid, to enjoy a degree of purity of air not so very far inferior to the open spaces in which they may be placed, as might have been anticipated.

We owe to diffusion more than this. The balmy air which every now and then comes to us, odorous with the simple perfume of the violet or hedge-row, or with the peculiar fragrance of the new-mown hay, would be deprived of all its scented properties, and would be felt without pleasure and inhaled without delight, were it not for the power of diffusion. As, while we stand thus discoursing on nature's chemistry, we drink in the pure fragrance of such flowers as lie scattered around, and perceive such freshness and delightful property in the air, let us remem- 
ber that, did not diffusive force lend wings to the fragrant vapours poured out from the flowers, none of these pleasures would be experienced. We see, then, in this force a most powerful agent of intimate, although imperceptible, intermixture of the various gaseous and vaporous ingredients of the atmosphere, whether regular or accidental.

Accurate investigations have made us acquainted with a less expeeted gaseous ingredient in the atmosphere than the last,-light carburetted hydrogen, or, as it is often improperly called, "coal gas." The amount of this gas is not so considerable as that of the former, but it is said to be very generally present, in variable quantities, in the atmosphere. The part it fulfils in the economy of the atmosphere is not well defined. It does not appear to undergo any great degree of inerease or of diminution, and we are therefore disposed to believe that chemical relations between it and other bodies actually exist, since it can be clearly shown that large quantities of this gas are continually discharged into the air. In short, it is eonecivable, on the supposition that those analyses which state its constant presence in the air are correct, that some force exists, as in the case of carbonic acid, to decompose the gas, and put a check to any excess in its quantity. It arises from rarious sources, among 
which are the natural gaseous springs before alluded to. It is also a product of the decay of vegetable tissues, and is largely thrown into the air from the countless economical processes connected with human operations.

Who that has looked with grateful surprise on his fields a few days since parched and brown, now re-clothed with raiment of freshest green, the herbage springing up with that vigour and luxuriance peculiar to the growth of the tender blade, when the "clear shining of the sun follows rain," would suppose that this sudden verdure owed anything to Ammonia? Still less would one be disposed to admit that our pastures are deeply indebted to a gaseous constituent of the air, so minute in its amount, as we shall learn, as to have long eluded the search of the most eminent chemists. Ammonia had long been suspected to exist in the air. Philosophers, aware of the numerous sources from whence this volatile compound was disengaged, felt persuaded of its presence in the atmosphere, but.were unable to confirm their suspicions. At length, Liebig conceived the happy idea of trying whether it might not be found in rain-water. Since ammonia is very soluble in water, it seemed rational to suppose that if it really existed in the air, it would be found in the waters of a shower. A consider- 
able quantity was collected and evaporated down carefully. After this operation had been long continued, at lengtl brownish crystals appeared in the fluid. The chemist's search was about to be crowned with success; and to his great gratification on analysing these crystals, they proved to be the long-looked for ammonia in the form of an ammoniacal salt.

Quite recently, by a series of accurate experiments, M. Fresenius has determined that $1,000,000$ parts of atmospheric air contain, during the day, 0.098 parts of ammonia; a quantity equivalent to $0 \cdot 283$ parts of carbonate of ammonia. During the night, singular to state, the proportion is greater; for the same amount of air contains then $0 \cdot 169$ parts of ammonia, or the equiralent of 0.474 parts of the carbonate. It is not easy to trace the cause of this excess during the night. This discovery of the positive existence of ammonia in the air proves of high importance, as we shall immediately perceive. Ammonia is a compound substance, formed of, by volume, three of hydrogen, and one of mitrogen gases. Now it was long known that nitrogen was absolutely neccssary to plants in order to supply them with material for the formation of several vegetable products containing nitrogen, such as albumen, gluten, and fruits and seeds gene- 
rally. But it was exceedingly difficult to ascertain its true source. There exists now little doubt that its chief source, when not supplied artificially, is in the ammonia of the atmosphere. Minute, therefore, although the quantity of this ingredient be in the air, it has an importance which can scarcely be exaggerated, when we consider the uses it fulfils. "The quantity of food required by animals," writes Liebig, "for their nourishment, increases or diminishes in the same proportion as it contains more or less nitrogen." In other words, that kind of food, as a general rule, is the most nutritious, which contains the greatest proportion of nitrogen in its composition.* This element consequently becomes most essential to the existence of animals; and it is supplied to herbivorous and graminivorous animals chiefly by plants, in the food they derive from the vegetable kingdom. Plants, as we have seen, obtain their nitrogen chiefly from the minute quantity of ammonia contained in the air ; and hence it is manifest that the health and vigour, and even the very existence of the whole animal world, is most intimately con-

* Bread is well called the staff of life. The gluten it contains is a nitrogenised compound. It is well known that upon bread alone life can be supported for a very.long period; a fact due, in great part, to the circumstance of its containing this nitrogenous substance, together witlı earths and salts. 
nected with, and even dependent upon, the existence of a gaseous ingredient of the air, so small in quantity as to have long escaped the detection of the most accurate experimenters.

Man, it is true, is an omnivorous creature. His food consists of both kinds, animal and vegetable. It may be said, all the nitrngen he requires he ean obtain in the greatest abundance from the flesh he consumes as food; and no doubt the greater part of those tissues of the human body abounding in nitrogen, such as muscle, \&c., are nourished from this source. But the difficulty is only put a step back by this consideration; for we must then inquire from whence do these animals used as food, and themselves feeding exelusively upon plants, obtain their nitrogen? This discovery furnishes us with a sufficient answer,-it is from the vegetable kingdom; and plants derive it ehiefly from the ammonia of the atmosphere. It is thus by an interesting and beautiful series of links that this important process-the supply of nitrogen-is carried on. Ammonia, a minute component of the atmosphere, containing the essential element for the animal kingdom, is essential to vegetation; a regetable diet is essential to the animals we use for food; and a mixed diet is, without doubt, essential to the healthy 
existence of a man. Thus it is literally true, that a large portion of our muscles and flesh was once present in the air as a gas!* Such, then, is the importance of an atmospheric ingredient, the whole amount of which, in upwards of eleven thousand cubic feet of air, has been estimated to be about one grain!

The ordinary sources of ammonia in the atmosphere are readily recognisable. It was a curious fact, incidentally noticed in the experiments which detected ammonia in rain-water, that the ammonia thus procured always possessed the "offensive smell of perspiration and animal excrement;" and this plainly indicates one of the most abundant sources of this valuable atmospheric constituent. Whencver organic bodies containing nitrogen undergo putrefaction, ammonia is abundantly evolved. As the last product of this process, it streams up from large cities where heaps of decomposing animal matter pollute the pure air of heaven. It has also been stated to escape from volcanos in the form of a sulphate. A grotto exists near Naples in which ammoniacal gas is discharged in large quantities, apparently from some volcanic strata. Combustion, and many economical and manu-

* The remarkable results of M. Regnault show that in some cases animals appropriate the nitrogen of the air and increase in weight simply by the process of respiration.-Vide p. 340. 
facturing processes, are also abundant sources of this ingredient. In London it is said to be often seen in the form of an ammoniacal salt, in little star-like spots upon dirty windows, which serves to show that it exists in greater measure in the air of populous cities than elsewhere.

The principal means by which atmospheric ammonia is rendered available for the purposes of vegetation, is by its being dissolved in rainwater. It is curious, however, to notice that some manures, which the agriculturist's experience has taught him the value of without revealing its cause, owe some part of their efficacy to the peculiar property* they possess of absorbing ammonia from the air. Gypsum, or sulphate of lime, is a valuable manure, yet it is very insoluble in water; therefore, merely as sulphate of lime, it is not possible that it can directly contribute, to any large amount, to the fertility of our fields. Burnt clay, and pure vegetable mould, are also considered to be of little value as direct fertilizers. It is therefore thought by many chemists, that their principal function is to withdraw ammonia from the air and supply it to vegetables. This is effeeted in a remarkable manner, which may be illustrated by an experiment. If a piece of freshly-burnt charcoal is put, after cooling, into a glass vessel

* Professor Liebig. 
full of the vapour of ammonia, and standing over mercury, it will be presently noticed that the mercury rises up into the jar, and a considerable quantity of ammonia has disappeared. The charcoal has undergone no change, neither has the mercury ; on "what principles, therefore, are we to account for the disappearance of the ammonia? The explanation is to be found in a very peculiar property of gases, allotted to them, it may be, for this very purpose we have been speaking of:

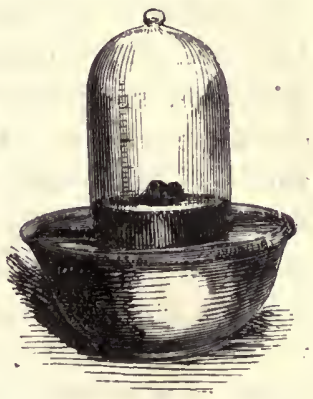
By virtue of this property, ammonia, like other gases, is capable of becoming condensed on the surface of bodies, or absorbed into their substance; some possessing a greater aptitude than others for -effecting this process. Charcoal, burnt clay, gypsum, and vegetable mould, all possess this property in a high degree. Dr. Daubeny considers that the use of gypsum arises in part from its property of fixing amunonia, and in part from its being itself directly serviceable to certain species of plants, by supplying them with a salt which they require for their development.

Thus endowed, these substances form appro- 
priate manures. Minute though the quantity of ammonia present in the air may be, by a slow process of this kind, it is extracted, and the first shower causes it to be brought into solution in a form in which it is readily appropriated by the roots of plants.* The Chinese, those original and practised agriculturists, says Sir J. F. Davis, will often pull down the plaster of their kitehens, deeming the trouble, labour, and expense of replacing it, amply repaid by the rich stoek of manure obtained in the old plaster. It has been supposed that the old plaster contains ammonia, and that we have in this proceeding the artificial application of a principle which, in nature, is in constant operation on a larger seale; but the quantities of ammonia absorbed are smaller. A recent writer in the Paris Hortieultural Review mentions the following curious particulars illustrative of the value of powdered eharcoal as a manure:- "About a year ago I made a bargain for a rose-bush of magnificent growth, and full of buds. I waited for them to blow, and expected roses worthy of such a noble plant, and of the praises bestowed upon it by

* In addition to the ammonia obtained by plants from the air, it appears that, according to the researches of Professor Mulder, a slow proeess of formation of this substance takes place in the soil during the putrefaction of bodies not containing nitrogen in their composition; the nitrogen appearing to be derived from that of the atmosphere. 
the vendor. At length when it bloomed, all my hopes were blasted. The flowers, were of a faded colour. I therefore resolved to sacrifice it to some experiments which I had in view. I then covered the earth in the pot in which my rose-bush, was, about half an inch deep with pulverized charcoal; some days after I was astonished to see the roses which bloomed of as fine a lively rose colour as I could wish! When the rose-bush had done flowering I took off the charcoal and put fresh earth about the roots. You may conceive that I waited for the next spring impatiently to see the result of this experiment. When it bloomed the roses were, as at first, pale and discoloured; but, by applying the charcoal as before, the roses soon resumed their rosy red colour. I tried the powdered charcoal likewise, in large quantities, upon my petunias, and found that both the white and the violet flowers were equally sensible to its action. It always gave great vigour to the red or violet colours of flowers, and the white petunias became veined with red or violet tints; the violets became covered with irregular spots of a bluish or almost black tint. Many persons who admired them thought that they were new varieties from the seed. Yellow flowers are insensible to the influence of charcoal."

These singular and simple experiments de- 
serve repetition. Since charcoal itself is quite insoluble, its effects are, in all probability, due to the ammonia it condenses from the air. It must, however, be added, that it is highly desirable that experiments of a satisfactory kind, as to extent and character, should be made upon this subjeet.

It will now be useful to sum up the normal constituents of the atmosphere from the preceding observations. The atmosphere consists primarily of two gases, four-fifths being nitrogen, and one-fifth uxygen; but, in addition, and to adapt it for the purposes of vegetation and ultimately for the supply of the very conditions of human and animal existence, it contains, in small proportions, two ingredients, the use of which is well ascertained; and a third, upon which some question still remains. The two first are carbonic acid and ammonia; the last is earburetted hydrogen. The following table will represent in a inore satisfactory manner what the chemist could find if he were to be at the pains to analyse ten thousand volumes' of dry air :-

\begin{tabular}{|c|c|}
\hline Nitrogen . . . . . & . \\
\hline Oxygen. & . \\
\hline Carbonic acid. . . & . \\
\hline Carluuretted hydrogen . & \\
\hline
\end{tabular}


It is, however, always to be remembered, that variations of considerable extent may take place in these results; but these do not affect this table, representing, as it does, the average composition of the atmosphere, deduced from an extensive series of carefully-performed experiments.

Professor Schmid, of the University of Jena, has recently calculated the entire weight of the atmosphere, omitting its watery vapour and carburetted hydrogen, and he places it at $1,371977,266659,000,000 \mathrm{lbs}$. Of this sum the relative proportions of nitrogen, oxygen, and carbon, in pounds, are stated as follows:-

\section{1,057245,681687,000,000 lbs. nitrogen.}

$$
313634,003159,000,000 \text {, oxygen. }
$$

$1097,581813,000,000$, , carbonic acid.

Total . . $\overline{1,371977,266659,000,000 \mathrm{lbs}}$.

In reality the weight of the air must considerably exceed this.

From this it is apparent that the air which floats around us, and in which we live and breathe, is by no means a simple fluid. In its regular constitution we find there are no less than five different ingredients, oxygen and nitrogen, however, infinitely predominating above the rest. It is only the light of science that has detected this fact. The evidence of 
our senses fails to render us any account of the ingredients forming the atmosphere, mingled together in the proportions in which we find them. Pure air is without odour or taste, and is so transparent that the exhausted receiver of an air-pump presents the same appearance to the eye as it did when full of air.

While, then, we remain in this pleasant country spot, far from the busy hum of men, and listen to the important facts detailed upon the chemical history of the gentle breeze, let us not forget that we owe all that we know on this subjeet to the long-continued and persevering labours of the experimental chemist in his often dark and smoke-filled laboratory. 


\section{CHAPTER III.}

OCCASIONAL INGREDIENTS IN THE AIR.

AT the extreme end of the valley upon which we are supposed to be looking lies a flat, marshy district, over which in the dewy evenings we may often see suspended a dense cloud of vapour. The whole area of this district is not above three or four square miles, yet its inhabitants are more frequently in ill health, and the annual proportional mortality is greater there than in any other portion of the plain beneath us. Were we to question them, they would inform us that when in the hot weather of autumn a current of air blew across the marsh, they might certainly expect attacks of ague to ensue. Their very countenances betray their ill-health, and the long and sallow faces of some are so peculiar, that we may well exclaim, What can be the cause of this unhealthiness? The inhabitants say it is the marsh air. When the same sort of district and effects occur in 
Italy, the inhabitants attribute it to the malaria, or bad air.

No doubt they are eorrect. The air of such districts contains something in addition to those ingredients which in the last chapter we found to constitute the eomposition of the atmosphere generally. Nitrogen, oxygen, carbonic acid, carburetted hydrogen, and ammonia, although representing the ordinary ingredients of the atmosphere, are not, therefore, its only constituents in particular cases. Dr. Prout says, "The atmosphere may be conceived to contain a little of everything that is capable of assuming the gaseous form." We shall learn, however, further on, that there are active chemical processes taking place in the air itself, which in a short time remove such "occasional ingredients" from its eontents.

What is known upon the chemistry of Malaria at present is but unsatisfactory. When regetable matter is left to rot, with a limited supply of water, and at an elevated temperature, it begins to give rise to certain products of its decomposition which escape into the air, and constitute what is called malaria. Chemistry is in great ignorance upon the nature of these products; but the most eurious facts exist, by which, although we can neither determine their nature nor analyse their eonstitution, we are 
yet able positively to affix certain general characters to them. The poison infused into the air appears to be ponderous: this is shown by the fact that it accumulates near the earth, since it is safer to sleep on the top of a house than at the bottom; persons occupying the lower stories have been attacked with ague, while those on the upper have escaped the complaint. It does not appear to be altogether gaseous, for the Italians are in the habit of wearing gauze veils as an efficient protection from it, the infiltered air being thus divested, as they state, of its injurious powers. It is invisible, inodorous, and gives no indication of its presence by any chemical quality whatsoever. A variety of conjectures have been made upon its nature, and some have even supposed that it consisted of minute.animalcules. Probably one of the most happy of the explanations given is that which refers it to the existence in the atmosphere of certain minute organic particles buoyant with every wind, coming into existence as a product of the putrefactive process in vegetation, and capable when inhaled by the lungs and received thus into the circulation, of inducing that peculiar form of disease by which its effects are characterised. But after all it must be confessed, the explanation itself wants to be explained.

The subject of Epidemic Disorders-that is, 
of disorders affecting at one time large numbers of persons-of all kinds, is equally enveloped in obscurity. A few facts are known, but these are of a sadly insufficient character. Among these is the important and interesting modern discovery, that some diseases, originally local, if they acquired sufficient intensity in the spot where they originate, may proceed, and, gathering additional strength in their progress, eventually become true epidemies-diseases of the people. "Like living things," observes the Registrar-General, "epidemics do not cease with the eircumstances in which they are produced; they wander to other places, and descend to remoter times." Thus the accumulating filth of a wretched metropolitan alley may be the hot-bed of a disease not confined to the miscrable locality, but extending to the broader squares of the wealthy, to the palace doors, and perhaps inner chambers, of the great and noble, and perhaps descending to posterity. As malaria appears to be an atmospheric impurity resulting from vegetable decomposition, so infectious and epidemic disorders would seem in most cases to arise from the putrefaction chiefly of animal substances, or in some instances from that of both animal and regetable materials.

Reasons exist, to which it is not necessary 
here to refer, for believing that these disorders of large masses of people are produced by some peculiar organic poison, not gascous, nor vaporous. It is at least very certain that such organic particles as are detrimental to the health, float in the atmosphere of every great city, and may often be perceived by the senses in the offensive air of the habitations of its poor and dirty inhabitants. Such particles cannot exist in the air without undergoing chemical change, and it is passible that by their existence in this state of change, they may set in motion a series of events which terminates in the appearance of the disease we are alluding to. A simple experiment will prove the truth of the assertion that an atmosphere of organic matters is undoubtedly mixed with our air. It is a property of strong sulphuric acid to char or blacken most substances of this kind; now, if a saucer, partly filled with this acid, is exposed for a little period to the air, its colour will alter, and ultimately deepen almost to black, in consequence of a large portion of organic matter having fallen into it from the air, and undergone the charring process; and this will take place even in the open air of the country.

As we look down upon yon distant village, it is not necessary to call in the aid of chemistry to inform us that even its compara- 
tively pure atmosphere is charged with impurities of various kinds. A pale bluish haze rests upon it, and slightly tinges the air for some distance; and when a breeze blows along the valley, it may be seen wafted for a mile or two from the village. The larger the eity, the more dense this cloud of impuritics, which is by no means all made up of smoke, although its opacity is chiefly due to that ingredient in its composition. In London it is extremely rare that even in the length of a street the air is perfectly transparent; objects distant only a few hundred yards are perceptibly enveloped in a mantle of bluish haze. Some highly interesting obscrvations upon this subject have been made by Dr. Smith, and read by him before the British Association in 1848. Of these we shall present an abstract. The town has always been found to differ from the country. This general feeling is more conclusive than any experiment that can be made in a laboratory. The various manufactures of large towns, the necessary con- ditions to which the inhabitants are subjected, and the deteriorating influenecs of man himself, all exert a powerful effect upon the state of purity, or otherwise, of the surrounding atmosphere. Dr. Smith caused a portion of air to be passed continually through a certain quantity of water for three months. $\mathrm{He}$ was thus able 
to detect a certain amount of chemical matter in the air. A part of this was sulphuric acid, with some chlorine, and an organic substance resembling impure albumen. Such matters are constantly being poured into the air, partly from the lungs of men and animals, and from manufacturing processes. On these substances becoming condeused upon cold bodies and in a warm atmosphere, the albuminous matter very soon putrifies and emits disagreeable odours. The oxygen of the atmosphere: acts upon it, and it gives rise in its decomposition to carbonic acid, ammonia, sulphuretted hydrogen, and probably other gases. The matter condensing on cold walls in crowded assembly ruoms may be collected by means of a little tube called a pipette. If allowed to stand it thickens, and on examination under the micrescope is found to contain numbers of minute confervx, between the stalks of which a number of greenish globules are seen constantly moving about, accompanied by still more minute animated particles, presenting a very interesting and beautiful spectacle. If this animal exhalation is allowed to accumulate on various objects by its frequent condensation on their surface, and subsequent drying up, it forms a gummy organic plaster, which may often be found upon the neglected furniture of dirty houses. In - moist 
weather it decomposes, and produces that peculiarly disagreeable organic smell which no words can describe, but which is only too familiar to our senses in the abodes of misery and poverty. In contrasting this condensed animal exhalation with dew collected in the open air, the most remarkable difference is found to exist. The dew remained beautifully clear and limpir, even when boiled down; the odour was not remarkable; and when the small portion of solid matter which remained dissolved in it was exposed to heat, the smell was that of vegetable matter, with very little trace of any nitrogenised substance. It was also rather agreeable than otherwise.

From these researches it is quite manifest that organic matters are always present in the air of towns. Occasionally, in close unhealthy neighbourhoods, it may even be perceived by the sense of smell, and that it is not more evident to us when entering a large eity from the open country, and fresh air, is due chiefly to the circumstance of our beeoming by degrees accustomed to it during the time occupied in our journey. Could a Highlander be suddenly transported from his heather-covered hills, and set in the midst of a densely-populated alley in London, he would instantly be sensible of the existence of a great degree of impurity in his 
new atmosphere. Persons from the Highlands of Scotland frequently experience this on entering Glasgow, the air of which impresses the same feeling as that of a forge or glass-house; occasionally they are unable to bear its excessive impurities. It has been found that such matters are never absent from the air, and that, let it rain ever so much, or long, in a large city, with every shower a quantity of organie ingredients will be brought down. This matter is capable of promoting animalcular life to some extent, and small specimens may be seen moving solitarily in it. If allowed to stand in a bottle this may be more clearly detected. Vogel and Dr. Southwood Smith have both found organic inatters present in the atmosphere.

Difficult, and intricate as the whole question is, this general fact appears to flow out of the preeeding remarks-that whatever be the extraordinary causes of epidemies and plagues of an aërial kind, the sources of the commoner disorders belonging to this class are discoverable in the putrefying filth which the negligence of our poorer fellow-countrymen suffers to accumulate in death-productive heaps on the walls of and round about their dwellings. Notling, in fact, can be more confidently affirmed than that filth and fever stand in the relation of cause and effect; and that poverty, although the first, is 
not the only victim in the case. There is no doubt, therefore, that the negligence of all classes of society, rich and poor, entails the most terrible calamities on both. The poor man may not, with impunity, live on in a state of disgusting and unnecessary filth and dirt. Neither, on the other hand, may the rich, with impunity, neglect the sanitary and physical condition of the poor that crowd around his mansion. It has been well ordered thus, that no man may be so much occupied with his own things, but that each should look upon his brother's; and where, in a simple scientific view of the question, this is the case, there the best possible human security exists against the invasion of the most formidable and desolating diseases.

While upon this subject, it may be interesting to mention some particulars upon the supposed nature of what is considered by many to be a disease of aërial origin-Asiatic cholera. In so doing, we shall merely state a few faets, or content ourselves with simply alluding to different theories. For some years Dr. Prout had been investigating the chemistry of the atmosphere, and for more than six weeks before this awful malady made its appearance in the metropolis, in 1832, he had been engaged almost every day in endeavouring to determine, with the greatest possible accuracy, the weight 
of a given quantity of air. On the 9 th of February, 1832, the weight of the quantity of air suddenly rose above the usual amount to a slight but still very appreciable extent. Again and again was the experiment made, and the same result obtained, so that there was no possibility of an error. At the same time, the wind, which had previously been blowing from the west, veered round to the east. These appeared a part of the preparation for the tremendous drama shortly to be played out, for precisely at that time the first case of epidemic cholera appeared in London, and from that period the pestilence expanded until it enveloped the whole of the mighty city in its embrace.

It is remarkable that the disease chiefly prevails in damp situations, and in ill-ventilated. filthy neighbourhoods. The earliest cases, on its recent visitation in the metropolis and its. vicinity, occurred on board the Justitia convict-ship, at Woolwich, which was moored opposite the mouth of a sewer. It raged most, also, in the low damp districts of the metropolis. The returns of mortality exhibited a striking aspect in the week ending Saturday, July 21, 1849. ' In this week, on the south side of the river Thames, the deaths from cholera amounted to four hundred and forty-three. In the same week, in the north districts-Mary- 
lebone, Pancras, Islington, Hackney, and Hampstead--all more or less elevated-the deaths from this disease amounted only to seven.

The Thames presents the large evaporating surface to the inhabitants of London of about 2,245 acres. Mr. Glaisher calculates that each acre evaporates $1,857 \cdot 6$ gallons daily; consequently, 4,170,000 gallons are raised from this part of the Thames on an average daily throughout the year! Thus about 18,000 tons of water are daily thrown into the atmosphere of London, and become intimately mixed therewith. The contents of sinks and drains are disgorged by the great sewers into the waters, and are agitated with the mud, from which vapours are constantly given off in enormous quantitics. During the prevalence of cholera, the mean night temperature of this river from May 27 to September 15, 1849, was 64! Hence, evaporation was largely taking place into the air of the slecping city. It is a fact well worthy of attention, that after the temperature of the river has risen above $60^{\circ}$, diarrhœea and dysentery become prevalent, disappearing as the temperature again subsides. This appears to show a connexion between the atmospheric moisture and impuritics and the prevalence of disease, in a very marked manner.

Cholera has been regarded by some as a 
disease due to a deficiency in the amount of the electricity of the air. Some curious statements have been made. At St. Petersburgh it was found that a large magnet had wholly lost its power so long as cholera ravaged the city; but, as the disease took its departure, the magnet gradually recovered its sustaining effect, and when the disease had entirely gone it was as strong as before. It has also been noticed that the electric telegraph refused to act during its prevalence. The most recent communication on this point is contained in a letter addressed by M. Andraud to the President of the Academy of Sciences (France), of which we give the following extracts. The machine used in the observations was a powerful electric machine, capable, at ordinary times, of giving out sparks in profusion on being gently put into action. "From the time the epidemic became general," writes M. Andraud, "I was no longer able, un any single occasion, to produce a corresponding effect. During the months of April and May (1849), sparks could only be procured after violent action.$\therefore$ These fluctuations were then observed to coincide most exactly with the fluctuations of the cholera! Nevertheless, I was afraid lest the irregularities of the electric machine should have been occasioned by the hygrometric state of the atmosphere. I waited 
with impatience the arrival of fine weather, to enable me to continue my observations; but, far from the previous indieations of the machine showing any signs of diminution, they only became stronger; for although with the improved weather an augmentation of eleetricity might have been expeeted, in a few days the signs of its presence eeased altogether. On the $4 \mathrm{th}$, 5th, and 6 th of June, it was only possible to obtain a slight erepitation; and on the 7 th the machine became dumb. This singular decrease in the eleetric element fatally accorded with a eonsentaneous increase of the cholera. On the 8th feeble sparks reappeared, and inereased in number and intensity. In the course of the day a thunderstorm announeed to plague-stricken Paris that electrieity had onee more entered in its dominion. On the $9 \mathrm{th}$, at the slightest touch, the machine gave forth sparks in abundance. Meantime the cholera was rapidly subsiding."

During the whole year 1849, M. Quételet has proved, by eareful observation, that the electrical intensity of the atmosphere has been about onc-half of that observed in former years; and that from January, in this year,* it regularly diminished up to a certain period, when it

* Mr. Glaisher makes a somewhat similar obscrvation for the quarter ending Sept. 1849. 
continued stationary. The following is M. Quételet's table of the mean electrical intensity of the air, for the years from 1844 to 1848 , both inclusive, and the means of the same months in the year 1849 :-

\begin{tabular}{|c|c|c|c|c|c|}
\hline & $\begin{array}{r}\text { 3feans of } \\
1844-1848 .\end{array}$ & $\begin{array}{c}\text { Means } \\
\text { of } 1849 \text {. }\end{array}$ & & $\begin{array}{r}\text { Mreans of } \\
1844-1848\end{array}$ & $\begin{array}{r}\text { Means } \\
\text { of } 1849 \text {. }\end{array}$ \\
\hline January & . $53^{\circ}$. & . $39^{\circ}$ & June . & - $18^{\circ}$. & $.13^{\circ}$ \\
\hline February & . 47 . & . 36 & July . & . 19. & $\cdot 14$ \\
\hline March & . 38 . & .27 & August . & . 21 . & . 21 \\
\hline April . & . 27 . & .20 & September & - 24 . & . 24 \\
\hline May . & 21 . & .16 & & & \\
\hline
\end{tabular}

Other scientific observers have detected the same peculjarities. We are unable to say, however, that a deficiency in the electric intensity of this atmosphere can be the cause of this mysterious disease; it must rather be looked upon as an àcomplishment of the phenomena which produce cholera, and in all probability partly concerned in their operation.

In addition to the presence of organic particles, or, in other words, particles arising from the decomposition of animal and vegetable matters, it is certain that impurities of an inorganic kind are often to be found in the air. In large cities the rain which falls is always found to contain coal ashes, soot, and sulphates and chlorides of different kinds-the latter probably derived from the former-thus proving the large amount of impurity present in such at- 
mospheres. A quantity of ammonia sufficient to render rain quite alkaline is occasionally present. The most curious illustration of the existence of such impurities in the air has been noticed at Manchester. The rain which falls in that city, owing to the enormous amount of mineral ingredients poured by its immense chimneys in to the air, is found to be harder, that is, to be more charged with mineral and saline ingredients, even than the water from the neighbouring hills, which it is now intended to use instead.

Occasionally an adulteration of a more sensible character is infused into the atmosphere, increases to an enormous extent, and fills the air with haze. A remarkable event of this kind took place in 1782. The phenomenon of which we are about to speak is commonly called "Dry Fog," to distinguish it from the ordinary humid mist called fog. The vast space between Lapland and Africa was shrouded over, during the years 1782 and 1783, with a dry fog unequalled in intensity. It was in the form of a pale blue haze, and was so thick at noon-day that the sun looked of a blood-red colour through it. It was not affected by rain, and it extended alike over countries, like our own, of "distempered climate," and others where the air is usually serene and clear. Voyaging was dangerous even in the Medi- 
terranean by reason of it; and it was just as thick on the summit of the highest Alps! Its properties were peculiar. It was said to have a strong disagreeable odour, and in some places a viscid acrid liquid is said to have been deposited by it. The greatest alarm prevailed; men's hearts failed them for fear. More terrible visitations were expected. Public prayers were earnestly made to avert the apparently impending doom of all Europe; and such an agitated state of the public mind was probably never known. A tremendous volcanic eruption in Iceland burnt up seventeen villages, and ejected such a mass of matter as would defy the united efforts of the whole human race to remove, each man taking away as much as he could carry. Awful thunderstorms visited the continent, desolated France, and destroyed a large number of human beings and cattle in England. It was a time of terror, of tumult, and of universal excitement. The summer of 1783 saw at length its termination; violent electric phenomena, with storms of wind and rain, dispersed it, and before the autumn all was gone; the plague was removed. During the whole period that it had lasted a severe epidemic catarrh-something similar, probably, to influenza-affected men and animals.

These remarkable years were singular as 
regards "dry fog," principally in the enormous extent of its distribution-a circumstance of which history is unable to. offer a parallel example. Dry fogs of a local, or more limited extent, had been before known. Jussieu relates, that "the influenza of the spring of 1733 appeared in France immediately after offensive fogs, more dense than the darkness of Egypt!" In the autumn of 1775, in France influenza appeared with violence, and was ushered in by thick noisome fogs, having been preceded by diseases among the lower animals. About the 7th of October, 1775, Scotland appears to have been visited by the same fog, for we learn that in certain districts a continual dark fog, possessing a particularly smoky smell, made its appearance, and lasted for five weeks. During its continuance the sun could not be seen to shine. During the year that the potato disease was most extensive in its ravages, it was noticed in some parts of the country, that clouds of "dry fog" preceded its appearance in some fields.

It has been remarked by some, who have sought for the causes of these singular occurrences, that they often occur together with volcanic disturbances. In 1782 , besides the tremendous eruption already mentioned, there occurred several earthquakes in Calabria, and 
other symptoms of disquietness in the deep regions of the globe. In the years noted in history for the appearance of dry fogs, in 526, 1721, 1822, and 1834, several volcanoes were in great activity. The meteorologist, M. Kœmtz, reasoning upon, this subject, has ascribed the occurrence of the dry fog of 1782 to the enormous volumes of smoke produced by the devastations of the burning lava in Iceland, as it descended on its fiery errand: hence he conceives the smoky odour of dry fogs. Several others of these phenomena he attributes to the smoke emanating from the peat-burnings of Westphalia and Germany. A very prevalent opinion, in 1782, was that the tail of a comet had become mixed up with our atmosphere. The learned author of the Bridgewater Treatise on Chemistry (Dr. Prout), appears disposed to ascribe the fatal effects of dry fog to the presence of a very minute quantity of one of the most deleterious gases known to chemistry, Seleniuretted Hydrogen. This gas, since the metallic element Selenium is a volcanic product, he conceives to have been discharged by the volcanic eruptions, and to have become widely dispersed, in a state of extreme dilution, through the air. Berzelius, who first discovered this gas, had a painful experience of its virulent powers; allowing 
a minute bubble, not larger than a pin's head, to pass up his nostril, he immediately lost the sense of smell for five or six hours, and suffered for fifteen days afterwards from a most severe catarrh, in all respects the same as that of influenza. The same effects, on another occasion, followed the escape of only a bubble or two into his laboratory, and he again suffered from cough and catarrh.

M. Kømtz's explanation can scarcely be considered correct. Dry fog is doubtless something more than smoke. When its remarkable accompaniments, volcanic disturbance and severe epidemic attacks, are remembered, it will be evident that some other cause than that specified must be called in to account for this phenomenon. It has been considered of electrical origin.

It is difficult to assign to any of the causes alluded to, the existence of a remarkable phenomenon which took place in Norember, 1819, at Montreal. On a Sunday morning the whole atmosphere in this city appeared as if covered with a thick haze of a dingy orange colour, during which rain fell of a thick and dark inky appearance, and apparently impregnated with some black substance like soot. The weather then cleared up, but on the following Tuesday, at twelve o'clock, a heavy damp vapour enve- 
loped the whole city, which was so dense that the inhabitants were compelled to use artificial lights. The appearance was grand in the extreme. About three o'clock a slight shock of an earthquake was felt, accompanied with a noise like the roll of distant artillery. At twenty minutes past three, when the darkness reached its greatest depth, the whole eity was instantaneously illuminated by the most vivid flash of lightning ever witnessed in Montreal, immediately followed by a peal of thunder so loud and near as to shake the strongest buildings to their foundations, accompanied by a shower of black rain. Very recently a shower of black rain took place in Ireland, which, together with the alarming phenomenon here described, must evidently have had its origin in the existence in the air of impurities of some anomalous kind.

Occasionally light particles of a more easily explained origin make their appearance in the air. "On the afternoon of June 11, 1847," writes Dr. D. P. Thomson, "the wooded part of Morayshire appeared to smoke, and for a time fears were entertained that the fir plantations were on fire. A smart breeze suddenly got up from the north, and above the wood there appeared to rise about fifty columns of sometling resembling smoke, which wreathed about like water-spouts. The atmosphere now 
calmed, and the mystery was solved; for what seemed smoke was in reality the pollen of the woods." Insects, fish, lichens, infusorial animalcules, volcanic ashes, sand, earth, and many other substances, occasionally enter into the air by the attraction of rapidly revolving currents, and are dropped often at a great distance from the places whence they were snatched.

One of the most remarkable discoveries of late years, upon the chemistry of the accidental ingredients of the atmosphere, is that of Professor Schönbein, in the body which he has called Ozone. This is a compound of oxygen and hydrogen, analogous to, though in some respects differing from, that substance so long known to .chemists under the name of Peroxide of Hydrogen, to which reference was made in the illustration of one of the fundamental laws of chemical combination. The latter has been considered chiefly as a curiosity by chemists. It is a limpid transparent fluid, precisely resembling water in its appearance, and remarkable for its bleaching properties. It also possesses several very curious chemical peculiarities. It is composed of exactly twice as much oxygen to the same amount of hydrogen, as in water. Such also appears to be the composition of ozone : yet, strange to say, it seems that ozone and the peroxide of hydrogen are 
not similar in their properties, and it is Professor Schönbein's opinion that they are not the same substance. Like peroxide of hydrogen, ozone bleaches powerfully. It appears to be produced even in the ordinary process of combustion; it is also formed during the passage: of a galvanic current through water, and probably in many other artificial ways. In nature, ozone is often produced in a large measure during electrical, changes in the air. During the night, when plants rest from their daily functions, they emit this remarkable principle; and it is said that a part of the peculiar smell perceived in the early day when the

\section{"saturated earth}

A waits the morning beam, to give to light,

Raised through ten thousand different plastic tubes, The balmy treasures of the former day,"

is due to the existence of a portion of this principle in the atmosphere. It appears probable, also, that organic matter about to decay has the property of developing ozone, which then acts upon it.

We are not yet able to state with precision what purposes are served by this highly interesting substance, ozone. Without doubt they are important. Since it is a substance which readily yields up its excess of oxygen, and then becomes simply an oxide of hydrogen, , or, in other words, water, it may be the means 
of supplying this gas to various bodies, and so acting a lighly essential part in nature as an ox:dizing agent. Perhaps we may point to a homely application of its bleaching properties, in the linen which may be seen spread out on many a grassy field and way-side hedge to whiten. Formerly all our calicos were taken to the green plains of Holland, in the spring, there spread out, and allowed to lie until whitened; the goods were then sent lome in the autumn.* It is certain that the chemical rays of the sun have a bleaching effect; but it may be reasonably supposed, that, as ozone is also a powerful bleaching agent, its elimination at night by plants may lielp forward, possibly, to a large extent, this process.

Some connexion between the presence of ozone in the air and the existence of epidemie diseases, such as the influenza, cholera, \&e., has lately been imagined. In a recent communication to the Athenceum paper, Mr. R. Hunt has propounded a view of this connexion which deserves our consideration. He writes as follows:- "Ozone is constantly produced in the atmosphere, under every cireumstance, which determines either electrical or chemical

* In two or three days, at a Lancashire bleachwork, as much linen is bleached as would carpet a large field all over. This is effected by the chemistry of art. 
changes; and its amount appears to vary in an exact ratio with the electrical intensity. We may produce it in a room, by exciting an ordinary electrical machine, when it is detected by its very peculiar smell; we obtain it during the decomposition of water by the voltaic battery, in combination with the liberated oxygen; and Schonbein has proved that ozone is formed in every process of combustion.

"The use of this agent in the atmosphere will, I-think, be obvious after a very brief consideration of the conditions which prevail during the mutations of organized bodies. All living animals and vegetables are constantly throwing off from their bodies organic matter in a condition the most fitted for recombination with the chemical elements of the air. The gaseous exhalations from all dead matter are also constantly combined with organic particles in a state of extreme division. Thus the atmosphere is constantly receiving exhalations from the earth and its inhabitants, which, without a provision for their removal, would speedily become far more injurious to all forms of life than carbonic acid ...

"Ozone combines with, and changes in the most rapid manner, all animal matters, except albumen in its fresh state. I am, therefore, disposed to consider it as the great natural 
agent employed to convert all these deleterious exhalations which the air receives, into-innocuous matter. An atmosphere artificially charged with ozone, immediately deprives the most putrid solid or fluid bodies of all disagreeable smell, and sulphuretted hydrogen is instantly decomposed by it ...

"It has been proved that the electrical intensity of the atmosphere has, during the year (1849), been diminished in a remarkable manner. As this is the great cause, ever active in producing ozone, we might, à priori, infer a relatively diminished quantity of this chemical agent; and experiment has proved, that during the last three inonths (June, July, and August, 1849), an appreciable quantity of ozone could not be detected by the ordinary methods, in the air of London... Certain it is, that we have for several months had to endure an atmosphere of low electrical intensity, deficient in ozone, an agent which would remove or alter pestilential miasma. Vegetation has exhibited, and is exhibiting, peculiar abnormal indications dependent upon solar influences, of which we are absolutely ignorant; consequently, the atmosphere has been receiving an excess of organic poison from the thousand and one sources which the congregation of masses of men in towns gives rise to, and has remained unchanged, to do its work of destruction upon humanity.... 
" Each time that cholera has disappeared from amongst us, it has been rapidly followed by influenza. At the meeting of the British Association at. Swansea, Dr. Moffatt communicated the remarkable fact, that the prevalence of influenza and the spread of catarrhal affections were invariably connected with an excess of ozone in the atmosphere."

From these considerations it may be gathered that, upon this theory, the presence of cholera is connected with the absence or deficiency of ozone; while the presence of influenza and epidemic catarrhs, is due to the excessive presence of ozone in the air. Also, that a certain amount of ozone is necessary in order to sustain the entire salubrity of the atmosphere, in consequence of its promoting the property of destroying noxious occasional ingredients in the air. It has been noticed that Birmingham and Berlin have generally escaped the severity of the infliction of cholera; and this has been attributed to the metal manufactories of these towns, which are abundant sources of ozone. But in the recent epidemic, Birmingham was visited with it, though only to a moderate extent. A great mystery still hangs, over the cause and nature of this as well as of all pestilences, but light may be expected to be thrown on the subject as: we advance in knowledge. Known or unknown, we must not fail to ac- 
knowledge a Divine Hand in these visitations,for the remedying of which there is little help in man,-nor to inquire wherefore they are sent.

From the property possessed by ozone of decomposing iodide of potassium, in such a manner as to strike a blue tint when a solution of starch is added, it is to be easily detected in the air. Perhaps some of our readers may feel inclined to repeat the following plan for detecting it in the air. The directions are:- "Slips of paper are to be smeared with the following composition: a drachm of common wHITE starch is mixed with an ounce of boiling water, and the solution boiled until it is of the consistence of that used in the laundry; then twelve grains of iodide of potassium are to be added, and the whole well mixed together. The presence of ozone is indicated by the decomposition of the potassium salt, and the formation of a blue iodide of starch." We may look forward with interest to the fresh discoveries of chemistry upon the uses of this occasional ingredient of the air.

Sulphuretted hydrogen gas is one of the most common occasional ingredients in the air of towns. It is pereeptible by its peculiar odour like that of rotten eggs, and is rendered provokingly sensible by effects on white paint, the white lead of which it decomposes and turns black. It is emitted from sewers and drains in large quantities. A house in Paris fresh 
painted with white lead was turned black in a single night by clearing, out the drains, and so setting free a large quantity of sulphuretted hydrogen. In his day, Sir Kenelm Digby complained much of the odours of the streets, and declared that silver could not be kept clean, an effect due to the agency of this gas. It is often combined with or accompanied by ammonia, which neutralizes its bad effects in some degree. It is also probably oxidized and decomposed by the effects of ozone.

In addition to these occasional ingredients, it has been supposed by various writers, that, in the wrords of Dr. Prout, before quoted, "the, atmosphere contains a little of everything that is capable of assuming the gaseous shape." In a recent work on science the same statement is repeated in the following words: "A thousand results daily and hourly accumulating as truths around us, prove that the solid metals, the gross earths, and the constituents of animal and vegetable life, all pass away invisible to us, and become 'thin air.' We know that, floating around us, these volatilized bodies exist in some form or other." The same idea prevailed in the minds of the ancients, ${ }^{*}$ and is repeated in the following expression of Shakspeare-

"We must all part into this sea of air."

* Quodcumque fluit de rebus, id omne

Aëris in magnum fertur mare--Lucretius, De Rer. Natur. 
It has been apparently forgotten, however, that the air contains, in a condition highly favourable to its activity, two principles of the utmost energy in decomposition, the gas oxygen and ozone. In all probability no such accidental impurities can long exist in the gaseous form mixed with the ordinary constituents of the air. Even in water, which appears less favourably circumstanced for such a result, a natural process of purification takes place; how much nore rapidly, then, in a medium constituted, like our atmosphere, of very large proportions of an element which is ready for immediate union, without laving to be first set free by a preliminary decomposition, and is furnished also with a very easily decomposed substance rich in oxygen-in ozone, which is ever active in fulfilling a similar office. There can be, in fuct, little doubt that the oxygen of the air and that of ozone are sufficient to reduce all, or almost all these occasional ingredients, by successive steps, to simpler and simpler forms, until at length they are deposited in a solid state, and thus are removed from the thin folds of our earth's mantle, or are converted into beneficial constituents of the air. Bodies which are impure have generally a tendeney to volatilize; in so doing they become exposed to oxygen, the great purifier, and become pure. 
It is by this means that that accumulation of particles of every kind, which would otherwise load the air, and interfere to a serious extent with its purity and functions, is obviated. But, particularly, these principles appear to have the power to destroy those noxious organic particles which are evolved in certain diseases. The fresh air is the worst enemy of putrid fevers; oxygen, whether derived from this element in the air or from the decomposition of ozone, combines with the fetid exhalations, neutralizes their effects, and reduces them to powerless and innocuous forms of matter. Thus oxygen, in a variety of ways, assists to preserve the purity of the air, and its freedom from accidental ingredients for any length of time. It sets up putrefactive processes, when life has ceased, both in vegetable and animal bodies; these are the first powers of destruction, which are to be succeeded by others, and these again by others, until all is destroyed. It is on this account that the complete exclusion of air prevents the putrefactive process from commeneing. Meat is preserved for years untainted in close vessels.

When decomposition sets in, the tissues of the animal frame become resolved into gaseous and watery elements. The atmosphere seizes again upon these, and takes quickly from them 
their capacity for doing mischief. Such as may be beneficial in their relation to created beings, are simply taken up and distributed far and wide for the service of creation. There is a singular gradation observable in this process of decomposition, which well descrves our attention. The process of destruction is slow, and advances from one step to another. The air attacking a compound of complex constitution, reduces it to one of more simple nature, and so on, until the simplest is arrived at, and this is innocuous. The change is at length complete; the body is literally dissolved either into gas or water; its fluids and solids are dispersed, and the bleaching bones and earthy materials of the skeleton, alone remain to indicate that the framework of an active and animated being had once rested on the earth.

A singular exception to the general rule in the decomposition of the body after death exists, as we are told by Mr. Willis, in the borlies of those which are deposited in the raults of St. Michan's church in Dublin. 'These vaults are perfectly dry, and are occupied with the remains of bodies which have been deposited there for centuries. From a published account of these vaults we make the following extracts:- "The bodies of those long departed appear in all their awful solitariness at full 
length, the coffins having mouldered to pieces! but from those, and even the more recently entombed, not the least cadaverous smell is discernible, and all the bodies exhibit a similar appearance, being dry, and of a dark colour. The floor, walls, and atmosphere of the vaults of St. Michan's are perfectly dry, the flooring is even covered with dust, and the walls are composed of a stone which is peculiarly calculated to resist moisture. This combination of circumstances contributes to aid nature in rendering the atmosphere of these gloomy regions more dry than the atmosphere we enjoy. In one vault are shown the remains of a man who died at the advanced age of one hundred and eleven; the body has now been thirty years in this mansion of death, and although there is scarcely a remnant of the coffin, the body is as completely preserved as if it had been embalmed, with the exception of the hair." It is more probable that the stones forming these vaults are strongly hygrometric, than that they resist moisture. They probably withdraw all the moisture from the air, and thus render the customary decomposition impossible.

The durability of animal and vegetable substances in Upper Egypt, in consequence of the peculiar dryness of the air, is quite extraordinary. In the most ancient tombs are to be 
found sarcophagi, chests, chairs, tools, and other things made of wood, grains of corn, dried fruits, almonds, dates, nuts, and grapes, plaited reeds, papyrus, and a number of limen articles, all in a state of perfect preservation. Mummies that have lain there for centuries have been discovered with the hair, skin, and features entire.

Hence we learn, that though accidental impurities undoubtedly find a temporary lodgment in the air, they instantly, if of a kind admitting decomposition by oxygen, begin to alter, and if of an unchangeable kind, they are at no distant period removed from it. Thus the chemistry of nature, rightly interpreted, teaches us that the atmosphere is not only the grand receptacle, but also the laboratory for the decomposition of a large number of the constituents of the animal and vegetable frame, and of sueh other ingredients of a foreign kind as find their way into it. All "flesh" and all "grass" part with a majority of the elements which compose them into this great reservoir, in the form of the simple compounds, carbonic acid, water, and ammonia, but not therefore to be irrecoverably lost. The atmosphere is a faithful conservatory for these constituents. They may be scattered to the four corners of heaven, but they shall reach their proper destination in the end. The 
THE ATMOSPHERE-EARTH'S TREASURY. 267

watery vapour, the ammonia, the earbonic acid take wings, and soar, it may be, to vast elevations from the earth, as though they would never more eome into active duty on its surface. But in process of time they must return again, and take their allotted place in the operations of the universe. Millions of animals may die, leaving their putrefying carcases to rot in the wilderness, or in the jungle, or in the depths of the eaves of the earth; and it might be thought that all the valuable constructive materials which entered into their composition were for ever removed from usefulness. But it is not so. Every wind that sweeps over these remains bear away the volatile portions round about the world. The gentle rain comes down and washes the soluble parts away, supplying a fertilizing fluid to the roots of distant plants. The interehange of ingredients never ceases. Millions of animals feed upon the vegetation nourished by the decay of former myriads. Their time is then completed; their period of utility is ended: they die. The air again reeeives their elements, and again with eontinually sueceeding generations do these enter into aetivity in the economy of the world. 


\section{CHAPTER IV.}

THE WATERS OF THE AIR.

"Waters devour and swallow up the earth; waters quench and kill the flames of fire; they mount up aloft into the air, and seem to ehallenge a seignory and dominion in the heavens also; while by a thick ceiling and floor, as it were, of elouls eaused by the dim vapours arising from them, that vital spirit which giveth life unto all things, is debarred, stopped, and choked."

ONE would almost think when Pliny wrote this passage, that he must have had a sort of hydrophobia, a dread of that fluid, the absence of which would turn our fair landscape into a desert, and this fruitful plain into a waste and barren wilderness. How differently old Gower writes in the quaint but refreshing lines,-

"The moyst droppes of the reyne

Descenden in to the midale erth, And tempreth it to seed and erth, And doth to springe gras and floure."

Surely the smiling grass and soft turf acknowledge anything rather than that "waters devour 
and swallow up the earth." We might say rather, in the words of an old poet of nature,* that

" The earth waxeth proud withal

For sweet dews that on it fall."

In all the various forms assumed by this beautifully-constituted fluid, as dew, mist, rain, hail, and snow, we are presented with remarkable illustrations of the importance of such an ingredient in our air, and of the wisdom of that great and glorious Being who employs the simplest means to accomplish the greatest amount and variety of beneficial results. No one questions the fact, that the rivers, lakes, seas, and oceans, are the great reservoirs of water for the use of the globe; but few remember that not only is the atmosphere a reservoir of water also, but that it is the chief medium through which, on the large scale, the contents of-the rivers and seas become available for the necessities of the land. Such is, however, perhaps as important a function of the air as any that has been assigned to it; - an office, the cessation of which would render the earth waterless, would dry up our rivers, and confine both animal and vegetable life to the immediate vicinity of the sea-shore.

We can easily prove the existence of water

$$
\text { * Chaucer. }
$$


in a gaseous form in the air. On putting a few lumps of ice into a tumbler, the surface of which is carefully wiped clean, and carrying the glass into a sitting-room, it will be immediately found to be covered with a dense cloud of dew, which will form again and again, even after the first deposit has been wiped off. The amount present in the air varies greatly, but a eertain portion is never absent, and the amount is usually greater in warm than in cold air. It arises from the evaporation of water on the earth. The atmosphere on the summit of lofty mountains is oecasionally remarkable for the absence of watery vapour. On the lofty passes of the Cordilleras this degree of dryness produces some curious effects. Articles of foor become perfectly dry and hard, wood-work shrinks; and if a mule dies it is preserved from putrefaction, as this process does not take place in the absence of water for a length of time. The atmosphere in such a condition is remarkably clear and transparent. Electricity also is developed on the slightest friction; articles of flannel clothing, when rubbed in the dark, glisten with the electric fire, and the hairy coats of animals crackle and emit sparks.

The state in which watery vapour exists in the air is closely analogous to that of the other gases, and it is influenced equally with them, 
within certain limits, by the laws of diffusion. There is, however, this great distinction, that watery vapour is liable to become condensed and liquefied at common temperatures. Carbonic acid gas* is likewise a liquefiable gas, but it is only under the influence of cold and extreme pressure. Watery vapour, on the contrary, is readily made to assume the liquid condition. When this takes place, that is, when the vapour passes from the vaporous into the liquid state, the phenomenon called "dew" is produced. The philosophical explanation of the formation of dew is simple. 'There exists for watery vapour a state of density which it cannot pass without losing its gaseous condition, and becoming liquid. This state is conveniently expressed by the term, "the maximum density" of the vapour. The point on the thermometer at which watery vapour attains its maximum density is dependent upon the temperature of the air, increasing as the temperature increases, and sinking as the temperature falls. Consequently, if the temperature of the evening were $50^{\circ}$, the point of the maximum density of watery vapour would be lower, and the facility with

* Whether oxygen and hydrogen may become liquefied in future experiments is uncertain; at present it seems little probable. Professor Faraday's laborious researches have fisiled to show the least tendency of this kind. 
which it would be deposited in the liquid form, as dew, would be greater than if the temperature were $70^{\circ}$. Now, when any substance or surface becomes cooled down, whether naturally or artificially, to a little below the point of maximum density of watery vapour, the latter immediately loses the form of vapour, and becomes condensed in minute drops upon the cold surface; the point at which this takes place is ealled the "Dew-point." The late Professor Daniell invented an interesting little

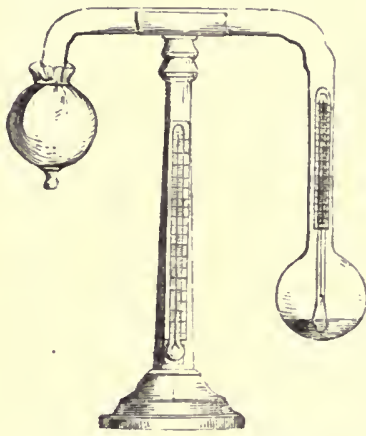

DAYIELL'S HYGROYETER. instrument, of considerable importance in hygrometric pursuits, entitled the "Dew - point hy" grometer." It consists of a bent glass tube, terminating in two bulbs, one of which is half filled with ether, the whole being vacuous as respects atmospherie air. In the ether bulb is a delicate thermometer; a piece of muslin wetted with ether covers the empty bulb outside. The eold produced by the evaporation of this ether condenses the ether vapour inside the tube, and rapidly lowers the temperature of the ether bulb 
until dew appears on its surface. When this takes place, by looking at the little thermometer inside, the dew-point is easily read off.

In nature, the deposition of dew takes place under the following circumstances:- So soon as the sun sinks beneath the horizon, the earth, no longer absorbing the rays of heat from that source, begins rapidly to lose by radiation its temperature acquired during the day. This cooling process continues until the surface of the ground and the bed of air overlying it has reached the dew-point, and then almost every object becomes covered with a deposit of dew.

It is singular that gardeners have adopted from experience, as a shelter for their flowers, a plan which theory has subsequently shown to be based upon purely scientific principles. It is noticed, for instance, that it is chiefly on clear calm evenings that dew is deposited, and rarely on cloudy evenings. The cause of this is, that the clouds prevent the loss of heat by radiation from the earth, and consequently it is kept so warm that the dew-point is never reached. It has been found by the gardeners that a slight screen will effectually preserve their plants from severe cold, the radiation of heat being in this simple manner effectually prevented. Bodies which are good radiators, such as the hairy foliage of some plants, since they lose heat more 
rapidly than substances having smooth surfaces, are always first and most abundantly covered with dew. In the history of Gideon's fleece, the most striking miracle, as we speak, of the two performed was not that it should be full of water, while all the ground around was dry, but that it alone should be dry, while the surface of the earth around was wet with dew; for a fleece is a good radiator of heat, and would naturally cool before other bodies, and become saturated with dew sooner than many other substances, but unless shaded, all the ground around would be more or less wet with dew, especially in the East, where the dews are much more profuse than in our country. It was consequently a complete reversal of the ordinary laws of nature, that the fleece alone should be dry; and, as if to mark the more special interference of God in this case, it is sufficiently striking that the saered text with reference to it contains the expression, "God did so."

Dew does not in reality present the least chemical difference from pure water. It is, in fact, the purest form in which water is found.* Rain water is more or less charged with impurities;

* Very minute traces of nitric and muriatic acids have been stated as discoverable in dew occasionally. In hoar frost, which is frozen dew, none have been found. It is therefore probable such impurities were accidental. 
and even the distilled water of the chemist contains them in a very minute degree, but dew may be considered as perfectly pure water, when it forms on a clean surface. Hence its brilliant appearance and the splendid colours it displays at that pleasant time, the charms of which are told in the solemn and beautiful lines of Milton,-

\section{"Sacred light began to dawn}

In Eden on the humid flowers that breathed

Their morning incense, when all things that breathed

From earth's great altar send up silent praise

To the Creator, and his nostrils fill

With grateful smell."

Strange properties have been ascribed to it. The ancient alchemists seemed to regard it with a singular veneration, as if it were something more than mere water, and used to employ it in their attempts to dissolve gold. The ladies of antiquity also attributed to dew the magical power of preserving their beauty, and collected it, as we are told, by exposing fleeces to the night air, and wringing them out in the morning. It is not uncommon to hear country people jesting with young people too much attached to their beds, by telling them that if they washed their faces in the morning dew they would never want any other cosmetic. The ancients used to imagine that dew dropped from the stars. How superior to 
all these false ideas is the simple and accurate expression of the Scriptures, contained in the beautiful words, "My doctrine shall drop as the rain, my speech shall distil as the dew."* For if we liken the bedewed surfaces to the "condenser," we see the foree and correctness of the expression. The aneients imagined universally that the dew fell, and the same erroneous idea prevailed almost to the end of the last century! Yet for more than three thousand years the true account of its formation, namely, from a vaporous to a condensed state, lay forgotten in the Bible! How satisfactory are such ineidental evidences of the Divine origin of the Sacred Word.

If the earth continues to lose heat by radiation, even after the formation of dew, it may be reduced as low as $32^{\circ}$, the freezing point, or even lower. The dew then freezes, its limpid particles become set fast in solid beads and crystals of various forms; thus hoar-frost is produced. The extraordinary beauty of the crystallizations thus formed must have been universally noticed.

There is something eminently interesting in noticing the occasional glimpses of an adjusting principle which we may eatch in a survey of the kingdom of nature. The depo-

\footnotetext{
* Deut. xxxii. 2.
} 
sition of dew is an illustration in point. The heaviest dews, other circumstances being favour-

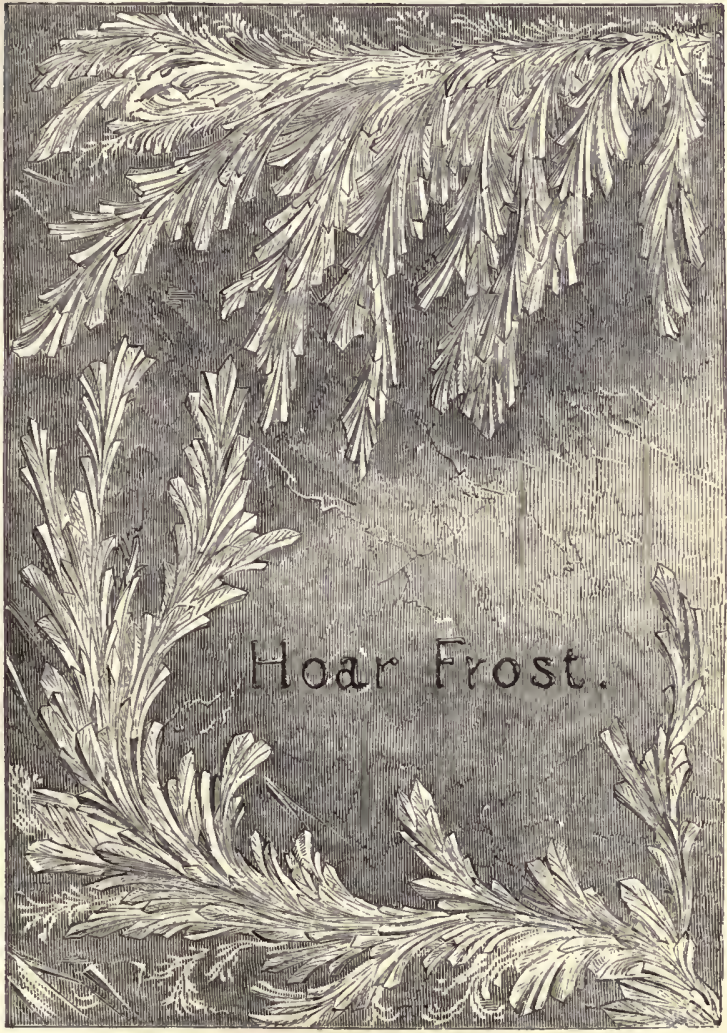

able, succeed the hottest, clearest, and driest days. Hence the dew is most abundant when 
it is most necessary. In hot climates the dews are most profuse; and the morning sun rises in its strength upon a landscape which the gentle hand of night has cooled, refreshed, and invigorated with a sea of dew-drops. Thus, though no rain-carrying cloud may cross the blue air during the day, to shed its supplies of refreshing waters upon a parched earth, the clear and brilliant evenings witness, in the phenomenon we have been considering, a grateful and efficient compensation; and the thirsty vegetation, satisfied with its evening portions, is enabled without injury to endure the rays of the burning luminary all the day long.

Dew, in common with all water shed upon the ground, has important duties to fulfil. Besides quenching the thirst of plants, dew is largely instrumental in facilitating the evaporation of some important bodies. Thus, when it is evaporated by the heat of the sun, it is the vehicle by means of which ammonia escapes into the air, and becomes subservient to the wants, not only of the isolated spots in which it was probably first produced, but to those of vegetation at large. Hence, as has been before observed, the farmer's carefully-stored heap of manure becomes robbed of half its ammonia, which escapes with the evaporating water, and 
helps to fertilize his neighbours' fields as well as his own, by rising into the air and diffusing therein. That is, where science has not come to his aid, and put a stop to the appropriation by a shower of dilute acid, or a sprinkling of powdered gypsum, by means of which the evaporation of ammonia is prevented, in consequence of its being compelled to assume a new and less volatile form. A certain amount of moisture is almost essential to the escape of odour from many bodies. The cause of this appears to be, that the vapour forms a sort of vehicle for the escape of volatile organic matter; and also, that moisture favours the decomposition of bodies, so that as they decompose the vapour is given out. Much of that pleasure which we ourselves derive from the perfume of plants, depends on the assistance to its vaporization rendered by dew. "Who," writes the late Professor Fownes, "does not inhale with rapture the perfumes of a flower-garden, when the dews of night, or the refreshing summer shower, have awakened the thousand sweet odours of its fair inhabitants? The breath of the hawthorn and of the rose have been always one of the most favourite themes of the poet's song; and yet this endless succession of pure and simple pleasures is but a mere consequence of the law which bids a vapour, arising by its own 
elasticity from a volatile substance, mingle itself . with the surrounding air, and extend its influence until its effects become so enfeebled by dilution, as to be imperceptible to the sense."

The presence of moisture also favours the escape of disagreeable odours; and it may be noticed, that in damp weather, the exhalations from reservoirs of putrid matter are more abundant than at other times. It appears, also, that alkalies favour the escape of vapours and organic exhalations into the air.

We must, however, now proceed to inquire how it happens that dew, or water in its other form, becomes thus dissipated and lost in air? By the way-side, a week ago, was a pool, some six or twelve inches deep, a place for ducks to sport in, and for thirsty cattle to drink. Where is it now? The parched, cracked mud at its bottom is all laid bare. It is eertain that it has not sunk into the earth, for the subsoil is a heavy clay; it has all become dissipated into the air, in the form of vapour: in other words, it has evaporated. A saucer full of water placed on a sunny window-sill, becomes emptied by this invisible foree before night.

It is found that water and all liquids evaporate, or pass off invisibly into the air, even at low 
temperatures. Ice evaporates in the open air, even when the temperature is below the freezing point. This process goes on until the vapour has attained what has been before called its maximum density; evaporation then ceases, and if its temperature becomes suddenly lowered, the vapour condenses into the form of a liquid. It is remarkable, that while the presence of air checks the rapidity with which evaporation takes place, it does not interfere with its amount. Thus, if we could empty a sitting-room of air, and put a basin of water into it, the vapour of the water would rise almost instantly, and fill the apartment, until it became as dense as it can be in this form; yet, if we put the same basin of water into the room full of dry air, precisely the same quantity of vapour would rise from it, and fill the room just as in the former case, as if there were no air present, - only it would occupy a longer time in so doing. Hence we may perceive, that liquids evaporate with a certain degree of force. In short, when a drop of water spilled on a slab disappears, it does so because it is able to pass into the invisible condition of a vapour, in spite of the pressure of the air on its surface. It has as much the power to resolve itself into fine particles which elude our notice, as if no air were present.

It has already been mentioned, that watery 
vapour is never absent from the air. When, owing to some reduction of temperature, this vapour passes its point of greatest density, it becomes visible to the eye in the form of a mist, or fog. The fogs of London have long acquired, owing to their density, a proverbial celebrity. "There happened," writes the amusing John Evelyn, "this weeke, so thicke a mist and fog, that people lost their waye in the streetes, it being so intense, that no light of candles, or torches, yielded any, or but very little direction. It began about four in the afternoon, and was quite gone by eight, without any winde to disperse it." On the twentyfourth of February, 1832, an intensely thick fog prevailed in the metropolis, and was so thick at mid-day, that it was impossible to discern objects or persons distinctly; and at night, the streets being illuminated in consequence of some public rejoicings, boys went about the streets with torches, looking, as they said, for the illumination! On these two occasions, the fog appears to have attained an unusual degree of opacity.

The cause of fog is considered to be the intermingling of a cold and a warm current of air, each pretty fully charged with watery vapour: upon both thus mingling together, so great a reduction in the temperature of the 
warmer current takes place, that its excess of moisture is immediately rendered visible as fog, and is rapidly deposited. There has been much question in the minds of the learned, as to the exact nature of this phenomenon. The greatest number of philosophers believe the watery particles to be vesicular, or like so many minute hollow spheres of water; in fact, like miniature soap-bubbles. These vesicles are supposed to have repulsive tendencies towards one another. M. de Saussure, who paid more than ordinary attention to this subject, saw in fogs which he examined on the Alps, vesicles float before him as large as peas, the coating of which was inconceivably thin. This view has been recently doubted, and in a communication read before the Royal Society, Dr. Waller has attempted to prove that the watery particles of fog are not vesicular, but are minute spherules, or solid beads of water alone. Fog is probably composed both of vesicular and solid particles of water.

Whatever be their physical constitution, a large aggregate of such particles in the higher regions of the air produces the phenomenon of Clouds. All that exquisite and inexhaustible variety of effect, which the artist loves to imitate, and the eye to rest upon; all those glowing pictures of mansions in the skies, of 
fantastic landscapes, of fleeey snow-drifts, of overhanging mountains, and rocks gilded by a declining sun, are the results of the play of light upon a mass of little particles of water. The various forms of clouds have been arranged under three principal classes: The Cirrus, or curl-cloud; the Cumulus, or heaped-cloud; and the Stratus, or fall-cloud. These three classes of clouds, with their various combinations and varieties, are represented in the frontispiece to this Part. However considered, the phenomena of clouds are such as to fill us with wonder. Held up mysteriously in the air, their ample folds retain and convey to parched lands at a distance, or to regions of high mountains and cliffs, thousands of tons of the refreshing draught. They are the water-bearers of the skies. Iaden with fresh-distilled liquid, at first perfectly soft, and free from mineral or earthy ingredients, and borne upon the wings of the broad wind, they "turn about fulfilling God's commands;" they descend, water and make fertile the earth, softening it, and making the green pasture to sing with joy.

Our considerations of the "clouds dropping down the rain," and thus watering the desolate places of the earth, call us to an explanation of the latter phenomenon, namely, Rain. It is supposed to be thus produced: the watery 
particles of the clouds appear to lose their mutual repulsion, and several unite into one, probably in consequence of some change in their electric relations, a drop is thus formed, and its gravity causes it at once to fall towards the earth. As the drop falls, being formed in higher strata, it is colder than the air through which it traverses in its passage to the earth; it therefore condenses mure and more vapour around it, and thus increases in size until it finally reaches the earth. Even the altitude of an observatory will make a difference in the size of a rain-drop, for it is constantly remarked that rain-gauges at the summit of such a place never indicate so great a fall of rain as others placed at the basement, the drops in falling this height undergoing an increase of size which became sensible by means of this instrument. Other explanations of the increase of rain near the ground are given. Perhaps this is the most simple and correct.

Although it is not difficult to assign the ultimate cause of rain to a change of temperature, or to define the process by which vapour becomes rain, it must be confessed that great obscurity still rests upon the laws which influence its occurrence, and upon the actual nature of the phenomenon. Rain occasionally falls from a sky clear as crystal, and altogether 
undimmed by a eloud. Such a phenomenon does not appear to have been ever noticed in our own country; but an observer who was at Constantinople relates that he was out in a pretty heavy shower which lasted for ten minutes, while the sky was serene and cloudless! In the island of Mauritius this phenomenon is very common in the seasons when the southeast winds blow. About evening time, while the weather is most beautiful, and the stars shine with the utmost brilliancy of lustre, a very fine rain occasionally descends; and Sir J. C. Ross relates that in the South Atlantic, it rained upon one occasion for upwards of an hour, while the sky was altogether free from clouds !

The wet season of tropical countries, a season of almost unintermittent rain of the heaviest kind, is a very remarkable and regular phenomenon; but is explicable on simple principles. At such periods the great atmospheric currents, which in these countries are of great steadi. ness and duration, receive an altered direction, and the condensation of an enormous volume of watery vapour, and its precipitation in the form of rain, take place as a result of the accompanying intermixture of hot and cold streams of air.

Important chemical functions are discharged by rain. There are regions where, for five or six 
months in the year not a drop of rain falls, nor is scarce a cloud to be seen on the molten surface of the sky, yet many trees preserve all their beauty and freshness of aspect. We are not, however, therefore to suppose that the office of rain to vegetation is either trifling or unimportant. In these peculiar circumstances, it has been suggested that the appendages of the stem, or the leaves themselves, are gifted with a peculiar function of withdrawing watery vapour from the air, and thus sustaining existence when it would otherwise be impracticable. But it must also not be forgotten that the soil itself has the property, in a remarkable manner, of absurbing watery vapour from the air, and no soil possesses this property more remarkably 'than that which is formed of decayed vegetable tissues, and other matters called humus.- Hence in the tropics, where such a soil is rapidly produced, owing to the rapid decomposition caused by the elevated temperature, plants do not suffer as much as might be the case in time of drought, were the soil not possessed of this property. We may perceive, however, in the picture of the effects of drought presented to us by travellers in tropical regions, something of the value and importance of rain to the earth. The grass becomes burnt up, withered, and dead. The leaves of the forest-trees hang 
soft and drooping, and the gigantic flowers become flaccid, scentless, and faded. The earth is cracked and parched, animals and birds faint, and men die for thirst.

In the generality of plants, the supply of fluids is drawn exclusively, or nearly so, from the delicate spongioles of the roots, which, with their multitude of delicate cells, drink in from the earth the newly-dropped rain, and transmit the fluid to the stem.* The water, thus supplied, enters into the circulating system of the plant, and undergoes decomposition to meet its wants, while the excess flies off through the stomata, or mouths of the leaves, or escapes, with a rich load of odour, from the waxen cells of the flower.

As the medium by which a number of solu-1 ble substances of importance to the well-being of plants are conveyed to them, the importance of rain to the vegetable economy appears still more evident. Falling in the manner described, rain is in the most favourable condition for dis. solving any ingredients of a soluble kind pre-

* At times when no rain falls, and no free water is present in the soil, which is merely damp, or charged with condensed vapour upon water, plants obtain their fluid from.water in this condition. It appears from some observations and caleulations of Dr. Schleiden, that the greater part of the water used by plants does not come from rain, but from the vapour silently condensed by the soil from the air. 
sent in the air through which it passes. Its minute state of division, and the consequent exposure of a vast amount of surface to the soluble matters or gases present in the air, renders it a most efficient and valuable medium for bringing down the hoarded treasures of the air to the needy and expectant soil. When the chemist in his manipulations wishes to obtain a saturated solution of a gas, he effects it by a process as nearly as possible similar to that by which in nature the same result is produced; he violently agitates the liquid so as to reduce it to a mass of drops, exposed on all sides to the gas intended to be dissolved. Where machines intended to charge water with gases, and partly to dissolve the latter in the water, as in the manufacture of soda water, are employed, the same effect is produced by a revolving agitator driven at such a speed as to beat the water into a fine mist. Now, M. Schubler has calculated that upon a field of 26,910 square feet, the annual fall of rain is about $2,520,000 \mathrm{lbs}$. In this large amount of rain-water is contained much ammonia, on the lowest calculation about $80 \mathrm{lbs}$. All this ammonia existed previously in a gaseous form in the air, having been brought down in a dissolved state by rain, and in this simple but beautiful manner rendered valuable to vegetation; to which, had it remained in the gaseous 
form, it would otherivise have been little valuable.

Carbonic acid gas is also largely soluble in water. At the ordinary temperature and barometric pressure, water will take up about its own volume; a cubic foot will dissolve a cubic foot of the gas. Carbonic acid exists in air in still larger and less variable proportions than ammonia. If the rain dissolves the one, it must dissolve the other gas. There cannot be a doubt, therefore, that the descending drops all contain, in addition to a solution of ammonia, a notable amount of dissolved carbonic acid. This solution, coming in contact with the roots of plants, is absorbed by them, conveyed into the digestive organs of the vegetable economy, and being decomposed there, contributes toward the formation of the solid portions of the vegetable structure. It appears, from some experiments by Mr. Mallet, that rain-water, when fresh fallen, frequently also contains one-fifth of its volume of oxygen.

The beneficial duties of rain to vegetation do not end here. When the emigrants of a new colony set about clearing whole forest districts, and destroy, by burning, the timber they cannot store or transport, there are found, in the ashes, large quantities of alkalies and other mineral ingredients. These once existed 
in the structures of the trees, particularly in the leaves and young branches, and rain was the chief instrument by which they were introduced. Being produced in the soil by virtue of processes which have already come under notice, they assume a soluble form, become dissolved in the rain-water as it trickles down from the surface to the roots, and are then absorbed and appropriated by the spongioles of the plant. It is curious that a shower produces a stream of water actually containing more salts and earthy matter than the water which trickles slowly through the ground. Rain, by softening the ground, renders the matters therein contained more soluble. 'The frosts of winter break up the ground, and the succeeding rains of spring supply the roots of plants with an abundance of soluble matter, then so important to them.

As a mere mechanical agency, rain is also of great service to plants. Any one who has seen the accumulation of dust and dirt which the turmoil and bustle of human society causes to rise and be deposited on all vegetation within its reach, and has again noticed the fresh and cheerful aspect of the vegetable creation when a newfallen shower has been succeeded by a clear sky, will perceive the importance of this function also to the well-being of vegetation. The particles 
of dirt thus deposited, if not removed by some means, would most seriously interfere with the respiration of the plants. The stomata or mouths of the leaves would become clogged up and unfitted for the discharge of their peculiar functions, and the most injurious consequences to the health of the plant would ensue. But the shower comes down, and, in a few minutes, all is clean again; every function is restored to its due activity, and the scene assumes a freshness of colouring quite peculiar to such seasons. The remark does not seem to have been previously made; but, it may be suggested, is not the glossy coating of evergreen shrubs intended to facilitate this process, rendered all the more necessary by the length of time the leaves endure?

As it restores cleanliness and freshness of garb to the vegetable world, so rain also exercises a most beneficial influence upon the condition of the atmosphere. It carries with it the mass of carbonaceous particles which, owing to the bad construction of our fire-places, are cast forth into the air. It also brings down that invisible, though not always inodorous cloud of organic matters which float in the atmosphere of populous places, and very probably renders, in many cases, these otherwise dangerous ingredients of the air of towns com- 
paratively innocuous. That organic matter exists in rain-water, no one who has made the experiment of keeping it for a day or two will be disposed to deny. Its rapid putrefaction is sufficiently indicative of the presence of such impurities in it. Muriatic acid, salts, and earthy matters, are very commonly found in rainwater. It may be justly remarked that the purifying influence of rain in this respect is of a limited degree, and of local application principally, but it is not therefore to be considered as unimportant. In fact, it may very reasonably be doubted whether our large towns would be able to exhibit such low rates of mortality as many of them in average seasons do, were it not for the frequent heavy showers, the occurrence of which too often forms the subject of complaint against our unstable climate. The dirty and defiled condition of our public edifices in England, especially in the metropolis, the inky waters which roll down the most splendid of our architectural façades, obscuring the labour of the sculptor, and greatly defacing the artistic beauties of the structure, show, in a striking manner, the mass of impurities contained in the air, and the necessity for some effectual means of ridding it from them. The rain which falls through the smoke-filled air of our towns, contains a large quantity of soot in a mixed state, 
not in solution. Dust comes down with the purest rain, consisting chiefly of coal-ashes, which is apparently the source of the sulphates and chlorides found in rain. It is sometimes acid with sulphurie acid.

Though, doubtless, the presence of these matters in the atmosphere is in a lesser degree injurious to human respiration, it is far more so to vegetable life; for neither the most healthy previous condition, nor the most careful tending, will preserve plants in health in our large cities. It appears, therefore, that we have a cause of thankfulness, at least in some respects, even for the proverbial fickleness of our climate, since its copious showers are the appointed means for counteracting that measure of mischief which might otherwise arise.

Let us follow the rain-drops in their descent into the earth. Whatever soluble matter is met with by the rain at the surface of the soil, it carries with it as it sinks downward into the earth. All the umpleasant results of organic decay on the surface that are soluble, are conveyed downwards by it, and the water, thus polluted, sinks to the underground reservoirs, from whence man draws his supply of this indispensable fluid. What results might we not therefore anticipate on an examination of water drawn from such receptacles; and what a polluted 
condition might we not expect the soil to be in which forms the filter through which this decaying organic matter penetrates! Yet, when we come to examine into these matters, "we do not find them;" in the words of Dr. Smith, "present that exaggerated character which we might suppose." It is surprising, on the contrary, to find that organic matters, properly so called, are scarcely, in reality, found in these wells; and, more singular still, the wells nearest to a source of organic matter frequently contain less than others farther removed from the apparent probability of contamination.

This seems highly paradoxical; but it admits of being very beautifully and simply explained. The analysis of the waters of the wells in towns shows that they contain a quantity of nitrates. Liebig found nitrates in twelve wells in Giessen. Dr. Smith found the same compounds in thirty wells in Manchester. The wells of London all contain nitric acid in various forms of combination. In an old well at Clerkenwell 148 grains of solid matter were found in a gallon of water; there was much nitrate of lime among other eartlyy salts. In a natural state, this water ought not to have contained more than about 20 grains to the gallon. In a well near Tottenham-court-road, 130 grains of sulphates, chlorides, and nitrates, were contained in a gallon of 
water; the water itself a highly nauseous and disgusting fluid. Water taken from wells in the country generally contains organic matter; thus presenting a striking contrast to those of the towns, where much more organic matter exists on the surface of the soil, but where the wellwater contains chiefly nitrates, not organic matter, properly so talled.

We are therefore led to inquire into the source of this nitric acid in combination. How is it formed, and why formed in the town and not in the country also? The following experiments, performed by Dr. Smith, will show that it is actually formed by the simple process of filtration. A jar, open at both ends, was filled with sand, and some putrid yeast, which contained no nitric acid, was mixed with pure water and poured on the sand, allowing it to filter through. Nitric acid was found abundantly in the fluid which dropped from this filter. It must have arisen without question, then, from the combination of the nitrogen of the yeast with oxygen, in its passage through the sand. Putrefied meat, treated in the same way, gave the same result. A bottle of strong sulphuretted hydrogen water was poured upon the-sand-filter, yet the liquid which dropped through only contained sulphuric acid. Water, from a certain pump, exhaled strongly a smell of sulphuretted 
hydrogen which filled the neighbouring houses; yet, when filtered, such water had no smell at all, and was commonly drunk by the inhabitants. The sulphur of the sulphuretted hydrogen had been converted into sulphuric acid, and thus the water was purified.

We may learn from these most interesting discoveries a highly important fact, namely, that there is a most active process of oxidation, or union with oxygen, constantly taking place in the soil. Nitrogenous matters are carried down into the soil, there filtering through various loose materials, - upon the surface of which oxygen is supposed to be condensed, like ammonia by charcoal, undergo oxidation, and nitric acid is the result, which then combines with the various salts and bases it meets with, forming nitrates. What is very curious, is, that the more organic matter is on the surface, the more certainly will nitric acid be thus formed; it seems as if a certain excess of organic matter favoured the process of its conversion into nitric acid. The sulphur and nitrogen of organic matter being thus oxidized and rendered comparatively harmless, it appears probable that its carbon is also oxidized, and forms in many instances the sparkling carbonic acid gas which we so familiarly know to abound in most spring water. 
Thus there is in 'nature a grand process of filtration incessantly continued, the fulfilment of which is intimately connected with the health and well-being of the inhabitants of both city and field. By this means a most powerful oxidation of all injurious matters is constantly taking place, and the perfect purification of the most impure substances is effected. The ditch-water of our fields differs widely in purity from the water of a subsoil drain. The first will be highly charged with animalcules and organic matter; the second contains but very little. The oxygen thus united to these matters alters their constitution in the most complete manner. They are not left behind in the soil, for it has been found that the sand used in large water-works for filtering, after being used for weeks, and thus becoming the instrument of effecting the oxidation of an immense body of organic matter, is not impure in a high degree, only containing about one and a half per cent. of organic and volatile matter. Hence both the soil itself remains comparatively free from contamination, and the matters passing through it are, nevertheless, perfeetly purified. What a beautiful portion of the elemistry of rain is this! What an illustration of the perfection of the arrangements of God, to behold the muddy and polluted waters sink into the 
earth, there, by Nature's chemistry, become perfectly ridded of their dangerous contents, and rise pure and sparkling to the surface again, now admirably adapted for all the purposes of man and animals!

When rain-drops in their course toward the earth become exposed to a degree of temperature below freezing point, or $32^{\circ}$ of Fahrenheit's thermometer, they become congealed into solid masses, and in this condition are known as Hail. It has been considered by some that hail is produced by the rapid descent of the rain-drops when first formed, causing a rapid superficial evaporation, the cold produced by which freezes the rest of the globule. Hail is also produced from a nucleus of snow, which gathers weight as it descends. As the frozen drop falls, condensing continually more watery vapour around it, which, becoming also frozen, adds to its size, it proceeds with accelerated rapidity until it reaches the earth, striking on its surface frequently with considerable violence. It is supposed by others that the origin of hail is attributable to the sudden encounter of two masses of cloud of very unequal temperature. Hailstones of a very large size are fréquently found in summer hailstorms; and the force with which they fall is proportionate to their size. Hailstones of the size of a.goose's egg have occa- 
sionally been picked up in the Orkneys. Fable tells that there once fell near Seringapatam a hailstone as large as an elephant! At a late meeting of the British Association, Dr. Robinson stated, that an instance was on record of a mass of ice having fallen from the air, fifteen feet across! It has been caleulated that the rapidity with which hailstones of a large size fall, equals fifty miles an hour, their destruetive force being correspondingly great. The mischief done by hail at times can scarcely be estimated. Many thousands of pounds would not cover the damage of the tremendous hailstorm of 1846 ; and in vine countries their ruinous effects are felt still more severely. Seasons are on record when the whole vintage of large domains in Southern France, and elsewhere, have been annihilated. On the 14th of January, 1849, at a certain town in the Deccan in India, there was a hailstorm, during which some of the stones were from two to two and a half inches diameter, and weighed from 'one to two ounces each. Hailstones present various crystalline appearances on examination. A hailstorm is frequently accompanied by violent electrical phenomena.

Snow is formed under eircumstances corresponding to those accompanying the formation of rain, but instead of condensing into drops, it crystallizes from a previously vaporous 
form into a multitude of minute separate forms, often possessing the greatest variety.

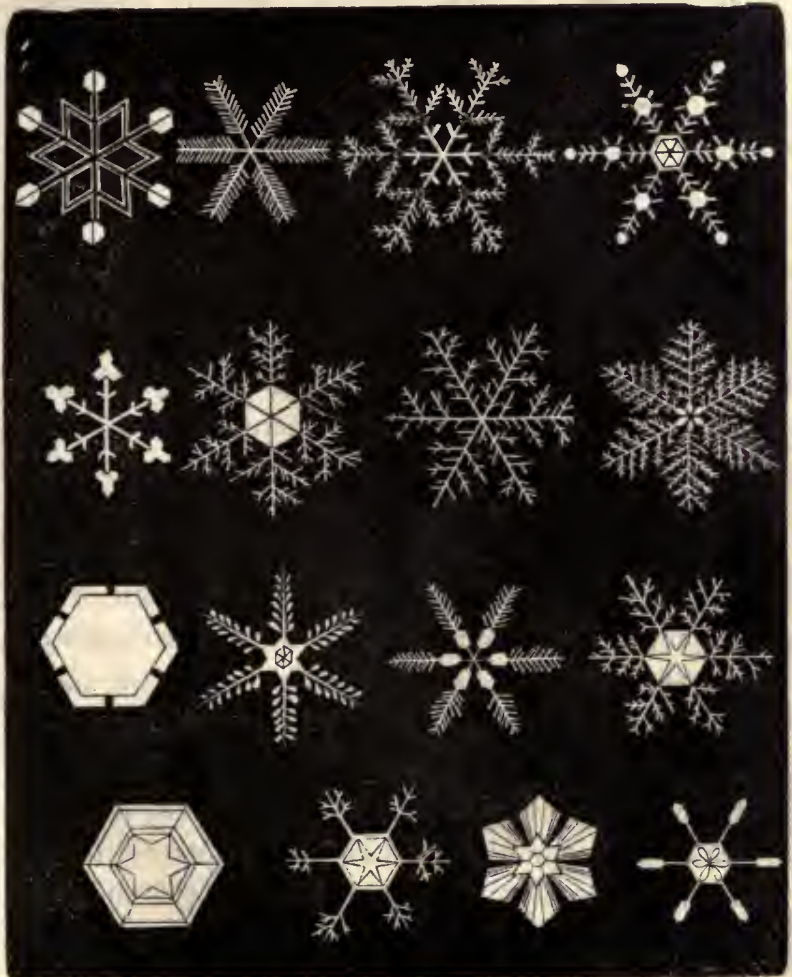

SNOW CRYSTALS.

and singularity of appearance. After undergoing this change of condition, the snow begins 
gradually to descend, forming in its course small flakes, which, uniting with others in fantastic groups, at last reach the earth. Elegant varieties of form are occasionally discoverable in the structure of a snow-flake even in our own temperate regions, but in the Aretic regions their beauty assumes the most remarkable character. The celebrated Arctic traveller, Scoresby, has described a great number of different crystalline forms, some of which resemble objects of which the imagination would scarcely dream of their assimilating to in form. Thus, among others, there are beautiful varieties which resemble stars, others wheels, pyramids, very complex mathematical figures, rosettes, leaves, spines, feathers, and others equally curious. These are represented in the adjoining cut. Strange to think, a few degrees less heat evolve these beauties of form and aspect out of a drop of water! Strange also to remember that a few degrees more heat reduce them all to the transparent mobile fluid out of which they sprang! It has been supposed that snow favourably influences vegetation, from its containing a solution of atmospheric oxygen; but in this respect it cannot be much superior to rain; and it is difficult to imagine that plants must be indebted to snow for a principle which in the adult state all the day long they 
ELECTRICAL ORIGIN OF RAIN, DEW, ETC. 303

reject from their leaves! Most probably the non-conducting properties : of snow, by preventing the dangers of excessive cold to plants, are those to which its serviceable reputation is chiefly due. It is, however, very certain, that snow contains proportionably more ammonia, and probably more carbonic acid, than rainwater.

There can be no doubt now, that electricity plays a most important part in. these aqueous phenomena of the atmosphere. Humboldt writes - "In fogs, and at the beginning of falls of snow, I have, in the course of a long series of observations, seen the previous permanently vitreous" (or positive) "electricity, change suddenly into the resinous" (or negative) "electricity; and these alternate repeatedly, as well in the plains of the frigid zone as under the tropics in the Paramos or Alpine wilderness of the Cordilleras, between ten and twelve thousand feet high. The alternate transition was in all respects similar to that which the electrometer had shown shortly before during the continuance of a thunderstorm." Mr. G. A. Rowell, in a communication. laid before the British Association in 1847, states his conviction, that most of the phenomena of evaporation, rain, hail, and even of the winds of temperate regions, are due to electricity. He 
considers that the minute particles of watery vapour are each, even in their most condensed state, completely enveloped in a coating of electricity, and are thus rendered sufficiently buoyant to be carried away by the wind. When expanded by heat, their specific gravity being reduced, and their capacity for elcctricity being increased by the increase of surface, they are then buoyed up into the air by their electrical coatings. When these particles are condensed, they are supposed to become surcharged with electricity by the contraction of their surface; and if this takes place near the earth, the surcharge escapes, and the particle falls as dew; but if the particles are condensed when they are above the influence of the electrical attraction of the earth, they are still buoyed up by electricity, and on the escape of the surcharge the particles attract each other and produce clouds and rain.

Connected with the theory of the influence of electric changes upon and in the production of rain, hail, \&c., is the proposition which has been seriously entertained of sending up copper balloons in the vine districts of France, by which means the electricity of the atmosphere might be conducted harmlessly to the earth, and the formation of the terrific hailstones which devastate those districts be avoided. 
SINGULAR EFFECTS OF FIRES, ETC. 305

In the year 1788 the devastation committed by a hailstorm amounted to twenty-five millions of francs! It becomes, therefore, assuredly a serious question whether means for averting those wide-spread calamities might not be successfully adopted.

- Propositions proceeding upon similar principles have also been made for bringing down

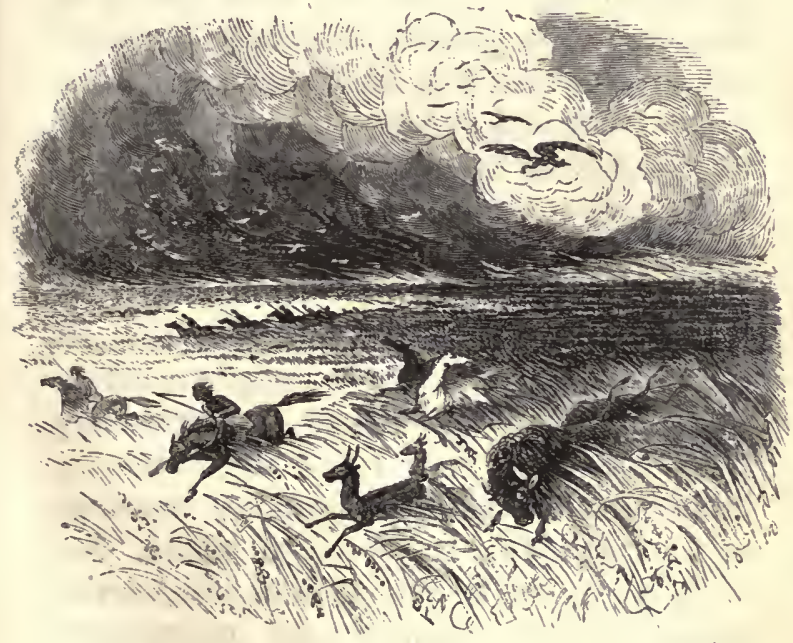

PRAIRIE ON PIBB.

artificial rains! It is well known that the Indians of Paraguay, when their crops are threatened by drought, adopt the expedient of 
setting fire to vast plains of grass, and as the result, expect storms of rain and even thunder; nor are they, as it is said, often disappointed. A similar effect has been also obscrved to follow the occasional conflagrations which take place in the American prairies and woods. It is conceivable that in these cases great electrical disturbances are occasioned which end in the production of rain. It has been noticed at Manchester, the weather has become constantly and progressively more and more rainy as the city has increased in size, and in the number of its vast manufactories; so that now the number of rainy days is very large indeed.* M. Arago, the French astronomer, appears disposed to account for this singular fact by supposing that the enormous chimneys of the cotton-mills, and other factories, withdraw a large amount of electricity from the atmosphere, and thus bring about this effect. The effects of volcanos in producing rain by their eruption are sometimes very remarkable. It has been related, that when a volcano bursts out in South America during a dry season, it not unfrequently changes it to a wet one. Great fires in different localities have been said to be often

* A person mueh exasperated with Manehester weather, said to another that it rained every day there. "No," replied the other, "it only rains six days out of every seven!" 
followed by violent rain, with thunder and lightning.

Mr. Rowell proposes to bring down artificial rain by raising electrical conductors to the clouds by means of balloons. The following extract from a letter quoted by him appears to lend some probability of success to his proposition:- " It has several times happened," observes the writer, "that when my electrical kite has been raised immediately under a distended, light, fleecy cloud, at a moderate elevation, and a free current of sparks has passed from the apparatus for some ten or twelve minutes, I have suddenly found myself bedewed with a descent of fine misty rain, and, on looking up, I have seen the cloud upon which I was operating surprisingly reduced in magnitude!" "Electrical kites," observes Mr. Rowell, "cannot reach the clouds, and can only be raised in windy weather, when the clouds must be every instant passing away from the influence of such apparatus; and if they have such effects, what may we not anticipate from the use of conductors which would reach the clouds, and could be raised in calm weather?"*

* Mr. Espy, an American writer, proposes to create artificial rains in time of drought by setting fire to large bodies of combustible substances. 
Whether such plans will ever succeed or not, can scarcely be foretold. As yet, great obscurity hangs over much that concerns the various conditions of the "waters of the air," and we may still address to philosophy the sacred words-"Dost thou know the balancings of the clouds-the wondrous works of him that is perfect in knowledge?"* It may please the Author and Giver of all wisdom to diselose to human research much of that which now eludes our grasp with reference to this as to other subjects. Until then, as regards rain from heaven, it is his will to keep us the daily pensioners of his bounty. Let us seek to cherish that humble and dependent spirit which accepts with gratitude and love all the dispensations of his wise and gracious providence, knowing that to them that love him all things are working together for good.

* Job xxxvii. 16. 


\section{CHAPTER V.}

MOVEMENTS OF THE AIR.

UPON the blue horizon of the scene we are contemplating, something resembling a white cloud may be seen gently gliding along the distant waters. By the aid of a telescope we make out this white object to be a vessel under sail. In a little time it is lost to view; it appeared to sink into the vacancy between the water-edge of the horizon and the sky which it almost appears to touch. 'Turning our eyes toward the sky, we pereeive the light and fleecy clouds, which seem at a great depth in the firmament, to be also borne smoothly and slowly along. The smoke of a cottage chimney beneath us does not rise straight into the air, but is slightly bent to one side, and stretches out slantingly upwards for some distance. The browsing of a sheep hard by has shaken a full ripe thistle.

"A whitening shower of vegetable down Amusive floats,"

and is carried silent and smoothly over the field, until it is lost to sight.

All these indicate movements in the air, 
although where we are now placed they are so soft and gentle that we do not feel them. But some of the movements may be actually seen. If we look attentively at certain objects, as on a hillock, upon which the heat of the sun has been directed all day long, we shall perceive a number of minute undulations in the air just above it. This is rendered still more apparent if a telescope is employed, and so interferes with the direction of the rays of light as to make the objects appear distorted and indistinct. Upon the sea-shore this effect is sometimes curiously manifested, and at a little distance off we may observe the whole shoreline marked by the waving and trembling stratum of air rising above it up to a certain height. The cause of these tremulous movements is undoubtedly the heat of the sun, since on a cold or cloudy day they are not perceptible. The grand cause, indeed, of most of the movements of the air is the solar ray, and the mode in which it acts is explicable in a simple manner.

It is generally said that the air only receives heat from its contact with the earth, and absorbs but a very minute portion of the heat rays of the sunbeam as they pass through it. Recent experiments have shown this idea to be in some measure erroneous. In a series of experiments conducted by Professor Forbes, it has been found 
that the absorption of the solar rays by the strata of air to which we have access is considerable in amount, even for moderate thicknesses. By calculation it has been found that about one-third of the solar heat is lost by the transmission of the rays through our atmosphere. The watery vapour present in the air absorbs these rays in a remarkable degree. We are thus shaded, as it were, at all times from the full influence of the solar heat. While, however, this is true, it is also certain that the atmosphere receives a much larger portion of heat from its contact with the heated earth. In consequence of this the particles of air expand, become specifically lighter, and are rendered sufficiently buoyant to rise upwards, their places being immediately supplied by cooler particles of air drawn from the vicinity. If, therefore, we suppose a particular spot or tract of land to be heated by the sun, while a neighbouring part remains comparatively cool, the immediate result is that an upward current rises from that spot and ascends into the higher regions of the air. But as it rises, its place below must be occupied by an equal bulk of air which is necessarily derived from the sides. A current is thus immediately established, an ascending stream in the one case, and a horizontal flow of greater or less force in the second. 
It is related by an observer, that if in a still day the atmosphere of London, or some equally great city, were to be carefully observed in calm weather, it would be found that in the morning, streams of fresh air are flowing in from the country round about the metropolis down all its suburban streets, to supply the place of the current which, heated by the vast city, rises up into the air from its centre. Prevailing currents or other accidental circumstances, so constantly interfere with this phenomenon, as to make it difficult to verify the observation. A common fire-place furnishes us with an excellent home-illustration of the same laws. A hot ascending current pours up through the chimney, and to take its place a cold horizontal stream sets from under the door, or from openings in the floor made for its accommodation. In tropical climates this law produces the interesting and vastly-important natural phenomenon of Land and Sea breezes. During the day, under the powerful rays of a vertical sun, the land becomes greatly heated, much more so than the sea; an ascending current consequently arises from the land, and to supply the place thus partially vacated, a body of cool air flows in from seaward, producing the sensible effect of a fresh breeze blowing from the sea, from about nine in the morning until two or three o'clock in the 
afternoon. The sun then beginning to lose its power, the land also begins to cool, and towards

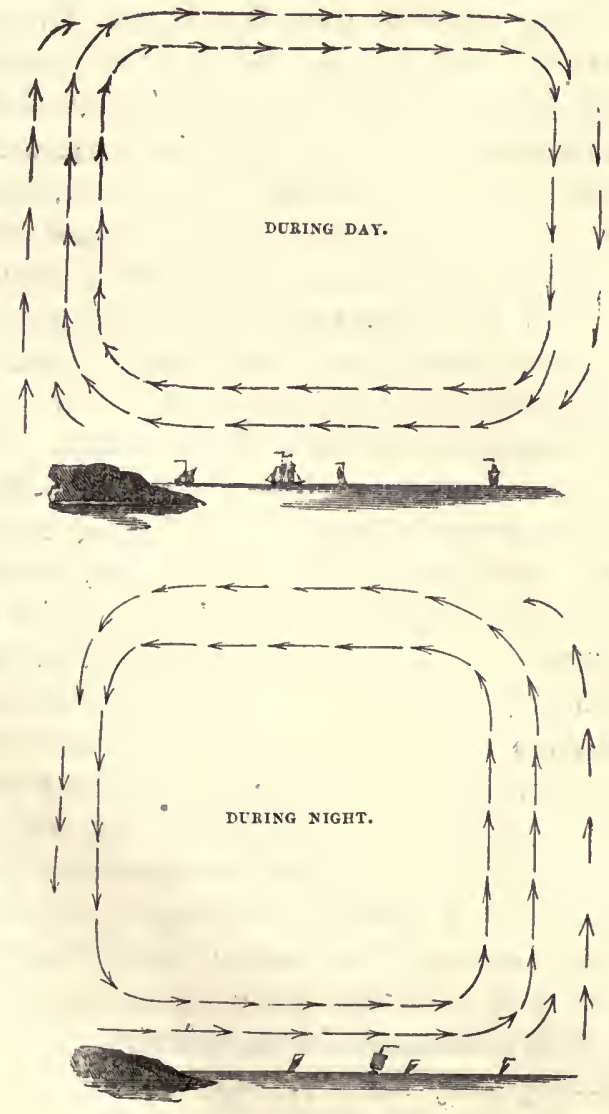


evening, and during the night, the land being a better radiator of heat than the water, it becomes colder than the sea. The heated column, therefore, now rises from the sea, and the cold horizontal flow is from the land, the sensible result being a fresh breeze to seawards. WThen the heated column, in either case, reaches a certain height in the air, it turns over, blows along the upper regions, and then comes down to supply the place of the descending current. This will be readily understood by reference to the figures, which rudely represent the state of things during the day and at night.

A modifieation of the same phenomenon which has been frequently observed in mountainous regions, is the bill and valley brecze, and it arises precisely from the same cause, namely, inequality of temperature setting in motion an asecnding and compensating current. Mr. Darwin makes particular mention of a powerful one observed by him in his travels in Mexico.

Winds, due to a similar cause, whose periodical occurrence was familiar to the ancients under the title of the Etesian winds, take place on land, when one district being more heated by the solar rays than another, the cold current of air flows from and across others, to supply the place of the ascending hot current.

Incomparably the most important and grand- 
est atmospheric movement is that of the Trade Winds; and we shall find in this phenomenon another illustration on the large scale of the fact of inequality of temperature producing movements in large masses of air. There are particular regions of the globe whose temperature is in the most violent contrast, as those of the equator and the poles. Here, therefore, we have all the conditions necessary for the production of motion in the air. Under the beams of a tropical sun, the equatorial regions become heated to a high degree and over a vast area. The result is, that an enormous body of air rises from these regions, the place of which must be supplied from cooler parts. Hence, if the earth were not in revolution on its own axis, a cold current would flow from both poles directly to the equator, there rise with the ascending heated current, and turning over, it would proceed to the poles in the higher strata, and would again descend to pursue the same course. This is clearly indicated in the accompanying diagram.

But the earth revolves on its axis. In so doing it carries its atmosphere with it. The equatorial regions being further from the central axis of the earth, are in more rapid motion than the polar, just as the rim of a wheel moves faster in the same time than any part of the 
axle, and therefore the equatorial atmosphere has a more rapid movement through space than that of the poles. If now we suppose a current

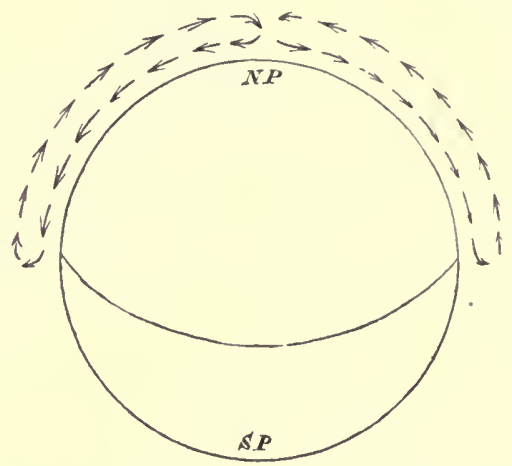

to be dragged across the surface of the earth, from the slowly revolving poles to the rapidly revolving surface of the equator, it is necessarily unable to proceed at once at the same rate as the latter, and the consequence is, that the swiftly moving regions of the earth brush against a mass of air having a slower motion than themselves. Hence there are two forces to be considered in the production of the trade winds1st, the ascent of a heated equatorial column of air, and 2 nd, the resistance offered by a slowly moving current of air proceeding in a horizontal. direction from the poles to the equator. If the earth were stationary, the under current would 
perpetually blow directly from the poles to the equator; but in consequence of its revolution, the direction of the current is bent aside, and the wind becomes an easterly wind with a direction from the north, or from the south in south latitude, instead of a strictly north or south wind. Since the earth revolves from west to east, a current of air having a less velocity than the surface over which it was being drawn, would be felt by one standing on the earth as a wind from the east. As we approach the equator its northerly direction gradually ceases, and it is felt as an east wind, and thus forms the more proper trade wind, a current blowing from east to west within the tropics. Thus the high temperature of the equator sets in motion, and the revolution of the globe modifies, the direction of the trade winds.

The effect of the earth's motion in producing what is felt to be a wind, by its brushing against a body of slowly moving air, may be rendered somewhat more intelligible by reference to an every-day illustration. The outside traveller on a railroad carriage, going at the rate of thirty or forty miles the hour, experiences apparently a very powerful current of air blowing in his face, so long as the machine continues in motion. Yet he may notice the distant smoke curling up from the cottage 
chimney, and rising into the air in an almost perpendicular column; the leaves on the tall poplars beyond are still, and the few flecey clouds which rest on the blue sky lave no sensible motion. The atmosphere, then, is calm and motionless. The apparent wind is the result of the resistance a swiftly moving body experiences in passing through the air. The current is, in fact, the difference between the motion of the carriage and that of the air through which it passes. In like manner the mariner placed on the watery surface of our swiftly rotating globe is whirled along insensible to himself at a greater velocity than the bed of air which lies above him, and the sensible effect is that he perceives a strong and equable wind in the opposite direction.

Having thus hastily traced the lower current to the equator, let us now follow the ascending column. Upon rising to a certain altitude, it is there to some extent cooled, by parting with its heat into space by radiation, and its upward progress is necessarily arrested; the current is then deflected, and flows towards the poles in a grand stream. As it proceeds it still loses heat, and at about the 30 th degree of latitude, it is so cold as to descend and change places with the lower current from the poles. Proceeding onwards still it receives heat from its contact 
with the earth, and again rises to form the upper current, being displaced by the cold and heavy air flowing from the poles. There is thus a sort of atmospheric chain formed, which

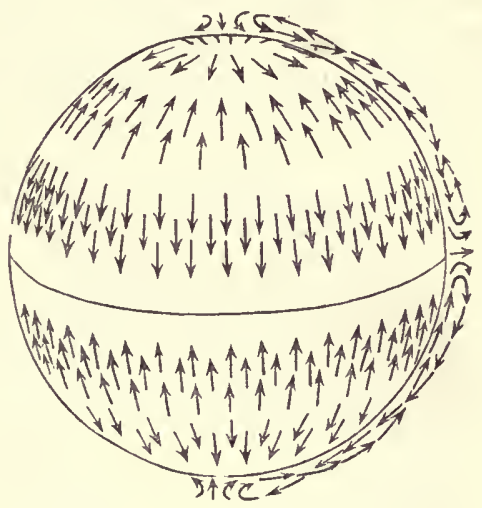

will be more clearly understood by reference to the cut. At all places, however, above the latitude of 300 , in consequence of the variations in the amount of heat received from the earth, these currents are very irregular.

Now, this upper current, having a different velocity, in consequence of its origin at the swiftly rotating equator, to that of the more northerly or southerly. slower moving regions which it has now reached, takes on the apparent character of a wind from west to east, and thus appears as a westerly wind. And when the 
upper current descends to take the place of the lower, at about the 30 th degree of latitude, it is actually felt as a violent westerly gale. At the poles, and within the polar circles, there is a constant steady polar gale toward the equator on every side. The effect of the earth's motion in altering the direction of these currents, is exhibited in the accompanying eut.

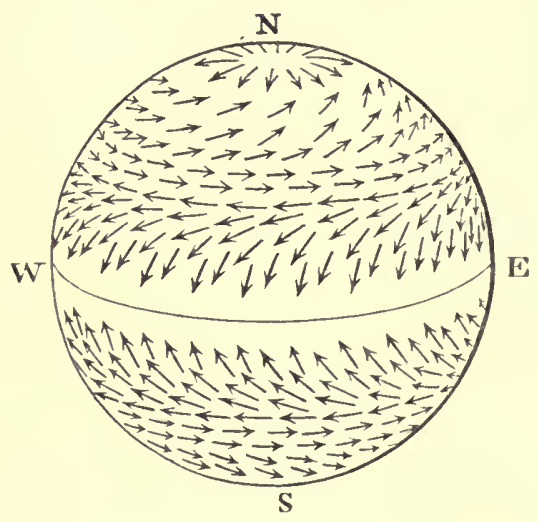

The upper current was long suspected to exist, before its existence was positively known. $A$ curious accident at length decided it. In 1822 an immense voleano burst open in the island of St. Vincent, and romited to an enormous altitude showers of stone and ashes. Strange to say, although the trade wind blows so strongly in the opposite direction, that a cireuit of one 
hundred miles is necessary to enable vessels to reach Barbadoes from St. Vincent, a quantity of volcanic ashes fell on the island of Barbadoes, which undoubtedly had their origin in the eruption at St. Vincent. The only explanation of this singular event was upon the supposed existence of this upper or back current. The power of the volcano had projected these ashes entirely through the lower current into the upper, and after being carried by it, they were dropped in Barbadoes. Another curious confirmation of its existence is recorded by Messrs. Humboldt and Bonpland. They set out on an expedition to ascend the Peak of Teneriffe; at its base the trade wind was blowing strongly in its customary direction, but upon reaching the summit they found they had actually penetrated through the lower stratum of air and got into the upper, and they now felt a strong wind blowing in a precisely opposite direction!

A variety of local winds, receiving their peculiar modifications from the circumstances in which they originate, are to be found treated of in works upon meteorology. Many of these, together with those here mentioned, appear to be easily explained upon the great principle of the inequalities of temperature. But many circumstances render it at least probable that other causes of motion in air exist beside, or perlaps 
superadded to, those of heat and cold. Mr. Rowell, whose views on the formation of rain, and aqueous meteors generally, were mentioned on a previous page, has also put forth some curious speculations touching the origin of irregular winds generally. He conceives that as water in its vaporous condition occupics, when suspended in the air, much more space than when it falls as a rain-drop, it must in the act of its falling cause a vacuum in the air which must be filled up by a rush of air from the surrounding districts. He supports his views by various calculations as to the average vacuum per square mile caused by some heavy storms of rain. He also mentions that in the autumn of 1846, while France and other parts of the Continent were deluged with rain, storms of wind swept over England from the northwest and west.

It has also been thought that electricity, in its various modifications, was in some manner connected with the irregular movements of the air. And it has been remarked as particularly observable, that in the regions where the magnetic influence* of the earth is at the lowest

* Although the phenomena of magnetism differ in several curious particulars from those of the principle we commonly call electricity, such as that developed by friction, both are believed to be only the manifestations of one and the same cause. 
intensity, as in the midst of the Southern Atlantic, storms seldom or never occur: while in those where its intensity is greatest, hurricanes and violent tempests are extremely common. If importance is attached to the views of the electrical origin of most meteorological phenomena, it may be readily conceded, also, that alterations in respect of the electricity of the air may have some direct or indirect influence in setting in motion irregular currents of air. Upon these points there exists at present much ignorance; but in consequence of the greatly-increased amount of attention now paid to the science of storms, it is to be hoped that much of our present obscurity will in a little time be dissipated.

One of the most remarkable and beneficial discoveries hitherto made by meteorological science is what is called the rotatory theory of storms. By this is meant the remarkable fact that hurricanes, typhoons, and it is probable other violent storms in all regions of the world, have a revolving motion. They do not blow, that is to say, in a straight line from a point many hundreds of miles distant, but they are vast eddies in the air which whirl round like the eddies of a stream of water, or like the water let out of a basin by a plug at the bottom. Besides this revolving movement, these storms 
have also a movement from place to place, and it is highly remarkable that this movement of translation also takes place not in a straight line, but in a curved direction.

It is possible that when all the phenomena of these storms are fully developed, the mariner will be able to direct the course of his vessel in such a manner as to escape beyond their destructive influence. Very recently, the captain of a vessel, by availing himself of the knowledge of this fact, saved his ship, and escaped without damage from a violent storm, which might otherwise have endangered not only property but life. Of all the glories of science, none equals that of a well-directed and successful attempt at diminishing the risk of human life. Yet while we owe much to the labours of those who have discovered its important truths, let it not be forgotten that we owe all to that Great Being, who from time to time permits his creatures to obtain a view of those mighty governing prineiples with which $\mathrm{He}$ orders and directs the course of natural events.

Should the inquiry be made as to the immediate connexion between the ehemistry of nature and the movements of the air, the reply must be that the connexion is most intimate. The irregular eapricious winds which constantly agitate the air of temperate regions, fulfil a 
most important office in nature's chemistries. Porverful as is the influence of the diffusive force of gases in dispersing abroad the noxious emanations of any particular district or region, it may be reasonably doubted whether this force is anything like sufficient of itself to preserve the purity of a densely-populated region. $I_{t}$ is true we might not be sensible of any ill effects from even a thrêe days' calm in our own temperate climate, although such a state of the air seldom endures for more than a few hours. But this could not long continue without originating very serious evils. If we imagine a crowd of human beings placed in a hall, however great its magnitude, and the air of such a building entirely without motion, it is easy to foresee the result. The impure emanations from the lungs and bodies of so many human beings would accumulate in this motionless mass of air to such an extent as to render it in a lesser or greater period of time altogether irrespirable, and death would be the consequence of continuing under its influence.

Such also would be the condition of a great city over whose hundreds of thousands of inhabitants hung an atmosphere totally without motion, without a breeze to fan the cheek or a storm to intermix the various parts of air and impurities together. Under such circumstances 
a city werc as surely doomed to destruction as though the windows of heaven were opened, and her living multitudes engulfed in a deluge of waters.

It is, however, impossible for such a condition as a dead calm to exist in the atmosphere of any region. It is true that to the senses there may be no apparent motion in the air, and every leaf of the forest may hang idly and unstirred on the branches. But there are invisible morements incessantly occurring in the stillest air. Not only by day, but even in

"The stillness of a moonshine heaven,"

these insensible commotions are constantly taking place. Not only in the open air, but in the closest shut apartment, the airy particles are never at rest. This is easily proved. Let the windows be closed up with shutters all but a little hole through which a pencil of sunlight may stream. Standing at a little distance, wc may pereeive that the whole track of the sunbeam is as it were animated. Particles of dust are seen incessantly rising, falling, moving now in this now in that direction, thus plainly indicating that the air in which they float is moved without ceasing.

A part of these insensible and imperceptible motions of the air are due to its elasticity and 
to the facility with which its particles, like those of all gases, move over or between each other, at the application of the least force. If we do but gently breathe upon the thick and numberless particles forming

"The gay motes that people the sunbeams,"

they are instantly thrown into the most violent commotion, and the disturbance does not cease, in consequence of the small amount of friction, for a very long period.

Part also are due to the effect of heat upon air. A body heated, whether naturally or artificially, instantly causes motion in the particles of air by which it is surrounded. If, for example, a cannon ball were heated to redness and placed on a tripod, as in the cut, it would cause the surrounding air to be in rapid motion. A stream of hot air, upon the principles before alluded to, would rise up, and a stream of colder air would be continually called to occupy its place. In this manner a current would be set up which would somewhat re-

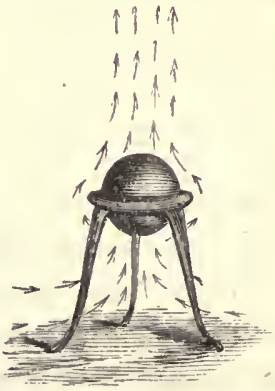
semble, could its direction be rendered visible, the appearance shown in the cut. Therefore 
every object upon which the sun shines, every tree, rock, and hill before us, that feels the genial influence of its rays, is an instrument for communicating motion to the air, and, in a degree by no means to be despised, assisting to preserve the intermixture and purity of the atmosphere.

The effect of these imperceptible movements is perhaps slight for a given time, but in their constant operation, at times when no breath of air stirs around us, they contribute largely to preserve the air of our apartments and cities in a condition fit for respiration, or at least more fit by far than if they did not exist. When we reflect how soon by their agency and that of diffusion a cloud of smoke is dispersed, until not a trace remains; how soon an offensive gas is wafted away, or a volume of dust dispersed, we shall be better able to appreciate this unscen instrumentality.

Proportionately to its increased force is the purifying influence of wind. The last-named movements are able to dissipate impurities only to a small extent, and within a very limited area. Wind, on the contrary, is a body of air in movement sufficiently powerful to sweep away every accumulation of foreign ingredients in the atmosphere generated by accident, or by the influence of congregated masses of mankind. How 
often do we, who live in temperate latitudes, vainly and thoughtlessly bemoan the inconstancy of the wind! And yet there is unquestionable wisdom manifest in the appointment of this very phenomenon. The masses of human society, proportionably to the area occupied by them in temperate regions, both naturally and by artificial processes, vitiate the air considerably more than do those of tropical countries. Contrast, for example, the purest atmosphere of England with that of an American prairie, and while no chemical difference in the quantities of ingredients might be detected by our limited analysis, yet it is positively certain, as a mere inference from known facts, that the air of a country containing upwards of sixteen millions of inhabitants within a very limited area, possessing besides immense manufactories, and consuming enormous masses of fuel per annum, must be less pure than that of a region where the eye in vain for hundreds of miles seeks even the traces of a human habitation. What, then, were the condition of England, we may ask, but for her variable winds?

In all probability, were there a constant current from any quarter, it would not accomplish anything like the amount of intermixture which is effected by the shifting winds of which we so 
undeservedly complain. During the prevalence of cholera, this was actually noticed by the meteorological observers at Greenwich. On many days when a strong breeze was blowing on the top of the Observatory and over Blackheath, there was not the slightest motion in the air near the banks of the Thames; and this remarkable calm continued for some days together. On September 11 and 12, however, the whole mass of air at all places was in motion, and for the first time for nearly three weeks the hills at Hampstead and Highgate were seen clearly from Greenwich. These capricious currents carry away the smoke of cities, and roll the masses of aërial impurities hither and thither until they become diluted indefinitely, and ultimately entirely lost. Again they return, bearing from the fields and woodlands the pure air, in the words of Spenser, so-

"Gently attempered and disposed so well,

That still it breatles forth sweet spirit and wholesome smell."

Thus by their ceaseless changes they so agitate and intermingle the atmosphere of our country, as to preserve in it a degree of purity and freshness which could in no other way be attained. In tropical countries the population is not so large in proportion to the area oceupied, and manufacturing processes are scarcely 
known among them. Hence they produce in proportion little carbonic acid, and a steady constant current in any direction would be amply sufficient to remove the comparatively small amount of foreign ingredients thrown into the air. These thoughts deserve to be remembered when we are disposed to declaim against the fickleness of our climate, for it appears that though it may prove a "partial evil," it accomplishes an "universal good:" Yet when the changeful wind is accompanied frequently by moisture and wetness, without a positive rapid precipitation of rain, our complaints of the fickleness of our climate and of its effects upon the atmosphere of our towns are more remarkable. When the day is dull and wet the smoke of the city rises only a little distance above the chimneys, and is then poured down into the streets, enveloping men and houses in a dark and gloomy mantle of offensive gases and vapour. The carbon contained in the smoke absorbs the moisture of the air, and becoming too heavy to seek, as in dry days, the upper air, falls slowly down to the ground. The mineral substances of smoke fall with it, and these, added to the empyreumatic odours developed in combination, truly render a wet or damp day in our towns in the last degree disagrecable. A heavy shower, on the contrary, carries down 
these matters at once, and the air is all the clearer afterwards.

It will be necessary, in a future page, to advert to the use of the Trade Winds in earrying forward and preserving the purity of the atmosphere on the whole. They also subserve another and scarcely less important functionthat of preserving in a sort of equilibrium the temperature of the atmosphere, and to some extent of the regions over which their influence is felt. The tropies are thus the perpetual sources of enormous floods of warm air, which, rising up and flowing over, proceed ultimately to the poles, and in all probability exert a very considerable modifying influenee over the severity of the arctic regions, as well as over those which they traverse on their way thither.

How wonderful is the unity and dependence of creation! The movement even of a breath of air is not without its purpose and its end. Let this soft and scarcely sensible eurrent, which as we talk of these things here salutes our cheek, when we are reminded of all the marvels of its origin, and of the intentions for which" it has been put in motion, waft our praises to Him whose divine power and love reveals itself even in a summer wind! 


\section{CHAPTER VI.}

THE ATMOSPHERE AND ANIMALS.

Coxsiderixg that all animate and inanimate bodies alike are immersed in a sea of gaseous fluids, which possess affinities of a powerful kind for the different elements of the organic and inorganic kingdoms, it will not surprise the reader to learn that important chemical functions are perpetually discharged by the balmy and apparently inert air which fans his brow or cools his cheek. To these chemical relations of the air we are now to draw attention, and in so doing we shall first direct the consideration to the chemistry of one of the most important functions of the animal frame-namely, the function of breathing, or respiration.

When we expire the air we had previously taken into the lungs - no matter whether from the mountain-ridge, or in the less healthful, atmosphere of a crowded town-an important alteration in its chemical composition has taken place. We are not conscious of this fact; but it is one which may be readily proved by the 
simplest means. If a vessel is filled with water in which some fresh-burnt lime has been slaked, and the water decanted off elear-which is now what is commonly called lime-water-and if then, taking a glass tube, we breath some of the air we are expiring from the lungs through it, we shall have rapid evidence that a change of some kind has taken place in this air in the altered appearance of the pre-

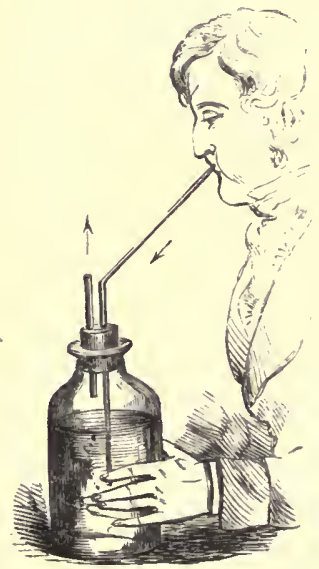
viously clear and pellueid fluid. It now becomes quickly turbid and milky, and eventually deposits a whitish sediment. Air, in its ordinary condition, would not produce this decomposition, whatever it may be; for the liquid remains unclouded, though a large volume of air be passed through it by a bellows. Therefore the air we take into the lungs has this striking difference from that we expire from them, that while it produces no alteration in the colour or composition of limewater, the latter decomposes it and renders it turbid. It will be interesting now to inquire

-What is the nature of this difference? 
The white precipitate is carbonate of lime, an earth formed by the union of carbonic acid gas with lime. From analyses already given of the atmospheric composition, carbonic acid has been found to be invariably present in air, and therefore it might be said this precipitate indicates nothing more than what might have been expected. And it is true that lime-water, after being exposed for any length of time to the air, is decomposed, and carbonate of lime falls to the bottom of the vessel. But in the simple experiments above mentioned this difficulty disappears, for it will be found that the bellows must be moved all day long to get a sensible precipitation, whereas a single expiration of air from the lungs will instantly render the fluid turbid. Although, therefore, it is certain that a minute portion of carbonic acid exists in all air, it is, on the other hand, cqually certain that there is an enormous disproportion in the quantities contained in ordinary and in expired air. In the one the amount is merely fractional; in the other it is present to a large per centage. The air which has done duty in the lungs receives a large amount of carbonic acid gas as it leaves them.

Let us now enter upon another range of thought. In cases of disease it is very often considered necessary to open. a vein, and to 
withdraw variable quantities of the blood circulating in the system. The fluid thus derived is always of a dark colour, and sometimes is almost black. But, occasionally, disease calls for the opening of an artery, and then the most striking difference is perceptible in the appearance of the blood; for it is of a vivid bright-scarlet hue. If the dark venous blood is exposed for some little time to the fresh air, it loses its dark colour, and assumes the lighter aspect of arterial blood: but it still differs from arterial blood in many important particulars. This change is directly attributable to the influence of air, for it would not take place in a vacuum. If a moist piece of bladder were laid over the fluid, it would not prevent the change from dark to red; and it is known to physiologists, that when dark blood becomes circulated in an organised living structure over a large surface, upon which alternate currents of fresh air play, the mere circumstance that air is not brought into direct contact with blood does not interfere with its chemical effects on that fluid. Direct contact with air is therefore not necessary to effect the ehange, since it will take place very readily through the medium of an interposed animal membrane. This is, in part, due to the laws of the interpenetration or diffusion of gases, and in part to the remarkable forces called 
endosmose and exosmose, which enable the solution of a gas to pass through a moist membrane with considerable facility.

The requisite conditions, then, for the chemical changes of respiration to take place between the air and the blood are, access of fresh air, and the circulation of dark blood on one side of a moist animal membrane. In the lungs these conditions exist to their fullest degree. There, perpetual influxes of fresh air play upon an enorinous surface of animal membrane, which is covered with a dense mesh of blood-vessels, all carrying dark blood. To these organs the streams of blood from the remotest parts of the body are directed by the propulsive energies of the heart. At the same time, muscular arrangements, externally and internally disposed with miraculous skill, and kept in action by an untiring power, continually partly fill and empty these organs, which are subdivided into innumerable tubes, tcrminated by minute cells, producing the ordinary phenomena of inspiration and expiration, or, in other words, of breathing. By this means, a measured quantity of air is admitted to the chest, and then expelled again, and so on alternately, about eighteen times in cach minutc. The pure air is thus received, and the impure is discharged.

At this stage, two facts about respiration are 
brought prominently under our view.-1st. There is a discharge of carbonic acid gas from the lungs.-2nd. In the lungs, a remarkable alteration takes place in the blood. And we must proceed immediately to add to them a third, of nearly equal importance; namely, That while earbonic acid gas is discharged from the lungs, a quantity of the oxygen of the inspired air is received by them, and disappears in the process of respiration. Thus, to put the changes in clear terms, from the measure of air which goes into the lungs, a certain measure of oxygen is abstracted, the place of which is supplied by the addition of carbonic acid. We are naturally, therefore, led to suppose that these three chemical phenomena-the change of the blood, the absorption of oxygen, and the discharge of carbonic acid gas in respirationare in some measure connected with each other. Their connexion is as follows :-

The blood-in circulating along the arteries, through the fine capillary vessels, to the veins which carry it back to the heart, and in the performance of its various duties, as the source of nutrient and regenerative matter, to every portion of the animal frame-besides parting with many other ingredients, loses a large amount of oxygen which, in its condition as arterial blood, it had previously contained. In so doing, it 
acquires carbonic acid and other principles, and changes colour from the bright scarlet to the dark hue. In short, from being "arterial" it becomes "venous" blond. Blood upon which this change has passed may now be considered as unfit to fulfil the functions previously devolving upon it. To render it again serviceable for the purposes of the animal economy, it must be altered, and restored to the pure and healthful state of arterial blood. It is a well-known fact, that venous blood cannot circulate for any length of time without producing the most serious and even fatal consequences. Some chemical agency, therefore, must interfere to restore its lost wholesomeness, or the functions of the animal economy would soon cease, never to be recommenced. After performing its round, the blood is directed into the lungs, and poured through millions of fine tubes which line the walls of the air-cells. Here the blood comes into contact with the air inhaled into these organs. Exposed on such a vast surface to atmospheric influence, the dark fluid loses the carbonic acid with "which it was laden, and receives from the air a fresh, and exactly equivalent, supply of oxygen gas; and now it turns from dark red to scarlet, and from the deleterious character of venous to the healthful composition of arterial fluid. This done, it is removed from the lungs 
as quickly as possible, in order that its newly aequired properties may not be lost, by means of several large blood-vessels, singularly straight and simple, with a view to faeilitate this object, and re-enters the heart, which, by its incessant toilings, despatches it on its life-giving errand throughout the frame.

The most recent results on the chemistry of respiration discloses the following faets :-*

1. Warm-blooded animals exhale nitrogen in proportion of from $\frac{1}{100}$ to $\frac{1}{50}$ of the oxygen consumed in breathing. 2. Animals fed on farinaceous food exhale a measure of carbonic acid exactly equal to the oxygen inspired; but if fed on animal food, they absorb oxygen sometimes equal to four parts in ten of that inspired; and if on leguminous food, they absorb a quantity intermediate between that in the two former eases. 3. The eonsumption of oxygen is directly proportionate to the surface of the body, and inversely to its bulk, so that a sparrow is found to consume ten times more oxygen in a given time than a fowl. This arises probably from the cooling effect of the greater surface. Lastly, in their winter-sleep, or hybernation, animals in some cases actually inerease in weight, though without food, living only upon the air, and appropriating its oxygen and nitrogen.

$$
\text { * M. Regnault. }
$$


Such is a large part of the chemistry of respiration. Professor Schönbein throws out the hint that ozone may perform an important part in the chemistry of respiration. Other philosophers have engaged themselves with the question-By what agency are these processes carried on? but hitherto only to arrive at conflicting results, and to indulge in unsatisfactory speculations.

Let us now put the following inquiry:-If a thermometer were placed under the tongue of an Arctic seaman, and the degree marked by the instrument compared with that indicated by another placed in the mouth of a Hindoo, or any other inhabitant of the burning tropics, would there be any difference between the two points? In the one case, an icy air seventy or eighty degrees below the temperature natural to the body, would surround the individual; in the other, a scorching heat, many degrees above that temperature, might envelope him. Yet, notwithstanding this extreme degree of contrast in external circumstances, there would be actually no difference, or but a very trifling one, between the degree of heat. indicated in each case!.

This wonderful truth informs us of two things-1st. That the animal frame has an internal source of heat, unaffected by external 
cold; and, 2nd. That it has a power of refrigeration, or of redueing its temperature, by which it is enabled to prevent its natural temperature rising beyond a certain point. The latter function, upon which we shall not further speak, is due to the cold produeed by the enormous evaporation which takes place from the surface of the body, and the extent and rapidity of which are proportioned to the external heat. The former and more mysterious power is known to physiologists under the title Animal Heat.

It is found that whenever the element carbon undergoes, in any of its combinations, the process of oxidation or union with oxygen, the change is invariably aecompanied by the evolution of more or less heat. It is no matter where the combustible material is burnt, that is, is united with oxygen; whether in a furnace of iron, or in the animal frame, the same quantity will give out the same amount of calorie. Reasoning upon this fact, ingenious speculators have been led to suggest that the organs of respiration are the heat-furnaces of the body, and that fuel supplied to them produces just as much heat in them as it would do if burnt in a fire-place or consumed in a lamp.

It has been seen above, that in the lungs a continual process of union of the constituents of the blood, earbon, hydrogen, with oxygen, takes place. Chemistry positively assures us 
that this cannot occur out of the body without the extrication of heat; therefore the union of blood-materials in the lungs with oxygen must produce heat. Again, in the minute vessels, called capillaries, which exist in almost every portion of the frame, oxidation takes place, for the arterial blood gives oxygen to the tissues, among which it circulates; here again, therefore, heat must be eliminated. Thus we see that the body possesses two sources, or rather two localities for the evolution of heat-the lungs and the capillaries; in other words, heat is evolved all over the frame, and particularly in the lungs. The perpetual ingress of cold air, and the enormous loss of heat by evaporation, demand that the lungs should be specially provided for; and this is considered to be effected by the perpetual oxidation taking place there. While, however, this is true to some extent, there can be little doubt that the animal frame possesses other sources of heat in addition to that of respiration derived from the process of oxidation.

The carbonic acid given out in respiration is a sufficient proof that carbon has been burnt somewhere, for when carbon burns in air it forms carbonic acid gas, and the above consideration indicates the locality where this heatproducing process takes place. Respiration is really and truly a process of combustion. The 
chief fuel consumed is the carbon and hydrogen contained in the materials of the blood; and therefore derived indirectly, or immediately, as the case may be, from the food. Calculations have been made as to the actual amount of fuel necessary to keep up the temperature of the human body for one day, and it appears, that of all economical furnaces the animal frame is that which evolves the most heat from the same amount of fuel; for an adult healthy man only consumes for the purposes of respiration about fourteen ounces of fuel-carbon every day!* A large quantity of hydrogen also is consumed in respiration, and produces a notable amount of that sum of heat, which, with the thermometer at 'Temperate,' is required to keep the body at $96^{\circ}$ or $97^{\circ}$ for one day.

The function of respiration, therefore, alone makes large demands upon the body for fuel. Man supplies this, together with the other demands for his nutrition, \&e., by the food he consumes. A large part of the food is fuel. Just as in winter we find it necessary to heap up our fires, and thereby to increase the consumption of fuel in order to keep up the temperature of our dwelling-houses to an agreeable point, so with man. In proportion to the

* No artifieial furnace whatever can eompare with these animal furnaces, for the most eeonomical consumes, aceording to Baron Liebig, not less than from ten to twenty times this amount of fuel in producing the same amount of heat. 
intensity of external cold must be the amount and heat-giving quality of the food he requires. Food differs largely in the amount of heat equal quantities will give out. Bodies into whose composition carbon and hydrogen enter largely, are those whose combustion will afford the most heat. He who basks in the heated air of the Tropics, requires but little combustible food compared with him who is condemned to the rigours of a Polar atmosphere. Hence the easily-satisfied Hindoo might conceive it utterly impossible for an Esquimaux or a Russian to devour his seven or eight pounds of flesh per diem, with the addition of train oil and tallow candles! Yet, if he were placed in similar external circumstances, he would probably find his appetite so sharpened as to compel him to adopt a somewhat similar habit of life. The great amount of heat lost by radiation from the body of the Esquimaux must be made up, or life will be forfeited. Respiration can make up a great part of it, but it requires a proportionate supply of heatgiving fuel, * and it is a familiar fact, that oils and fatty matters are substances which in their combustion eliminate a very large amount of

* We must however guard the reader against the error of supposing that all the enormous quantity of extra food consumed by an inhabitant of the Polar regions is burnt in the lungs in order to supply heat to the body. Far from it: calculations have been made, which show that if such were the 
heat in eonsequence of the large proportion of carbon and hydrogen entering into their composition. The appetite in a healthy man is the beautifully-adjusted measure by which the fuel-food requisite for the condition in which he is placed is determined. In the keen air of the north, it is much more loud in its calls than in the heated and depressing atmosphere of the Equator; and a careful attention to this natural index would enable men in these contrasted situations to regulate their supply of food accordingly; and would doubtless tend in some degree to the preservation of health of the body under these opposite circumstances. It has been remarked, that over-warm clothing and a keen appetite in temperate weather are incompatible with each other; and doubtless this curious fact is connected directly with respiration. When the body is covered with a number of non-conducting materials, its loss of heat is greatly lessened, and the eall upon respiration is therefore lessened in proportion: and this again tells back upon the appetite, and informs the system, so to speak, that less food is necessary for its wants. But reverse the condition;-let a man be elad in rags, and the intensity of his appetite increases proportion-

case the individual must inhale eight times as much oxygen as an ordinary adult, and his pulse must move at the rate of 500 beats a minute - which is clearly impossible. 
ably. Hence it is a purely scientific fact, that the poor and ill-clad creatures who tread our streets, suffer most severely from the calls of hunger, although the sensation may be, perhaps, blunted in many instances by the frequency of its exercise. In the case of the poor man, respiration, supplied with but scanty fuel, and called upon to do more than ordinary duty to keep an ill-covered body warm, draws its supply from the structures of the body, and is no doubt the primary cause of that large amount of diseases of debility whose victims are almost exclusively to be found among the poor of this world.

It is ascertained that, in addition to respiration as a source of heat, there are several other causes in the living animal body by which the temperature of the whole system is maintained. In digestion, which is in great part a chemical process, a considerable amount of heat is extricated. "Every mechanical movement of the body," observes Mr. R. Hunt, "occasions the development of heat; every exertion of the muscles produces sensible warmth; and indeed it can be shown by experiment that every expansion of muscular fibre is attended with the escape of caloric, and its contraction with the absorption of it. There is no operation of the mind-not even the most idle thought-which does not excite the latent caloric of the body; 
and frequently we find it manifested in a very remarkable manner by a suddenly awakened feeling. The poet, in the pleasure of creation, glows with the ardour of his mind; and the blush of the innocent is but the exhibition of the phenomenon under some nervous excitation produced by a spirit-disturbing thought. Thus we see that the processes of digestion and respiration are not the only sources of animal heat, but that many others exist to which much of the natural temperature of the body must be referred."*

Thus reminded of the importance of the air to man and the animal world at large, we can feel the full import and accuracy of the expression, the "breath of life;" for only while we breathe we live. There is more, therefore, than health in the soft airs which float around us." Upon them our very existence is every moment dependent. The breeze not only refreshes and cools the eheek, but gives strength, activity, and warmth to the entire frame. The learned Dr. Derham well said, "It is the air the whole animal world breathes and liveth by; not only the animals, inhabiting the earth and air, but those of the waters too. Without it most animals live scarce half a minute, and others that are the most accustomed to the want of it live without it many days."

* The Poetry of Science, p. 382. 
Yonder sleeping flock and those shade-seeking cattle are not less debtors to the air for life than is the cowherd on the river bank, or the shepherd under the elm. And in the animals the function of breathing differs but little from the same function as carried on in the human frame. In the animal world generally there is found the same general principle to prevail with respect to this function; that is, the air is drawn into a cavity upon the sides of which the vessels containing the blood ramify, and so the vital oxygen of the air becomes applied to the blood and is received into it, and so also the impurities and waste matters of the system, those at least which can be thrown off as gas or vapour, become discharged. There is a remarkable exception in the structure of insects. Here there is no organ like our lungs; but, strange to say, the air is

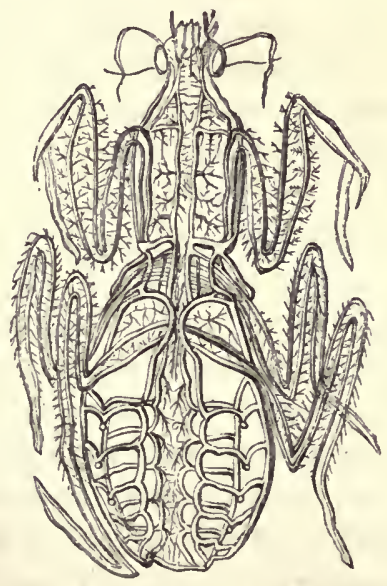

AIB-TUBES OF INSECTS. conveyed by a series 'of beautiful fine pipes all through the body, even to the extremities 
of the limbs! This of eourse answers the same purpose as the other arrangement, the blood-vessels of the insect ramifying over these air-tubes, or trachece, as they are seientifically called. The same objects are effected by this arrangement as by the other, namely, the oxygenization of the blood and the removal of its impurities. The breathing of those members of the zoological kingdom whose abode is in the waters will be noticed in the concluding part of this work.

Yet while fulfilling these important duties, the air has others of an opposite kind also to discharge with respeet to all animal bodies. The whole bodily frame is in process of incessant change, to a large degree, by the influence, direct or indirect, of the vastly important function of respiration, and by the oxidation which goes on to a greater or less extent through the skin all over the body. No part remains permanent. Its tissues are nourished by the blood, their waste parts are carried off into the air, or rejected in other ways as excrementitious, and new particles take their place. In a little time these again, having served their turn, become effete, and are cast out of the body. Yet these ceaseless changes do not affect the form of organs and their peculiar characters, unless, indeed, disease has been established in them. Curious truth! even the accidental impression 
of a long-forgotten injury, the honourable scar, or the effect of a severe laceration, remain in enduring memorial of the event upon the unchanging yet ever altered surface. Although undergoing perpetual alteration of their parts, the features with all their characteristics remain the same. Time may indeed brush the down off the young man's face, and blanch the ruddy hue of the maiden's cheek; it may pinch up the full features of youth into the withered lineaments of age; but a little mole on the skin defies the effects of time, and even of deathentering the tomb with the rest of the cold clay it had so long distinguished.

The atmosphere must be considered as one of the grand agents in the perpetual work of reparation and destruction. Its chemical energies are continually arrayed against the very existence of the human body. It is only by daily recruiting his strength that man is ablc even for his brief allotted period of life to offer a sufficient opposition to its effects to permit of his healthy existence. If his means of so doing fail, a destructive process immediately commences. The active lungs continue their incessant play, and the swift-flowing blood demands and receives from the tissues of the frame the fucl for which these organs call. The stored-up fat quickly disappears; the round contour of health vanishes; starvation begins. 
The body slowly consumes away; the muscular tissues shrink and soften, and the haggard face and incipient delirium assure us that the work of death is going on at the nervous centres. If no help arrives, if the poor starving one is left to be "burnt with hunger," death sooner or later ensues, and the expression of the sacred text, which strikingly coincides with the philosophy of starvation, is realized; for the unhappy person is burnt alive. This effect is unquestionably principally due to the oxidizing influence of the atmosphere.

Our "carthly tabernacle" is but a tent after all; a tent which each moment undergoes repair and waste. The structure which is the scene of such incessant conflicts between the powers of destruction and reproduction, is already doomed. The balance cannot always be kept in equilibrio; equalization of the forces cannot always be secured. The surplus accumulates; the reparative powers give way before the onward march of the destructive. The body wastes down, as we say with old age, and when not actually hurried into the grave by disease, dies at last of exhaustion. Well is it for him who is able to say with one of old, "I know that if the earthly house of this tabcrnacle be dissolved, I have a building of God, an house not made with hands, eternal in the heavens."* * 2 Cor. v. 1. 


\section{CHAPTER VII.}

THE ATMOSPHERE AND VEGETATION.

LET us now proceed to make inquiry as to the mutual relations subsisting between the air and the luxuriant vegetation which surrounds us. How and in what way are these blades of grass affected by the summer breathings which pass in wave-like movements over them? The direct connexion of animals with the chemistry of the atmosphere can, as a general rule, only be said properly to be immediately established when they first draw the breath of life, although undoubtedly they are indirectly the recipients of its beneficial influences in their previous condition of immaturity. In birds, however, and oviparous creatures generally, from the earliest dawn of the principle of life within the shell, this relation commences, only to cease with their death. The presence of the atmosphere is in like manner essential to the commencement of vegetative life. The seed can only begin to grow, or, in other words, to germinate, by 
virtue of its presence. Much, therefore, of the success of the florist, and, on a larger scale, of the agriculturist, depends upon this simple and often forgotten condition of things. The seed must have access to air. It is also necessary that it should be surrounded by a medium sufficiently but not too moist, and that a moderate degree of warmth should exist in the bed into which it is cast. It is a singular fact also, that while the luminous rays of light interfere with or even prevent this process, by some discoveries of $\mathrm{Mr}$. R. Hunt it appears necessary that the actinic or chemical rays of the solar light should reach the seed in order to its germination.

Placed in these favourable conditions, the seed absorbs moisture from the soil and oxygen from the air. A series of intricate chemical changes is immediately commenced, the gluten of the seed is altered, and its starch is converted into sugar for the nutriment of the young plant. Water and carbonic acid are also formed during this process, and in a short time the head of the young plant peeps above the soil.

Passing by the less important period of vegetable infancy, we are led on to that far more interesting time when the plant and the atmosphere enter into new relations with each other, 
on the fulfilment of which the most momentous results to all animate creation depend.

In a previous section of this work it was stated that plants derive but a small proportion of their solid constituents from the soil in which they grow. It has been before mentioned that the chief solid material of a plant is its carbon; also that plants live with their roots buried in a material (vegetable mould) extremely rich in carbon. Yet, on the question being put, Do plants derive their carbon from the mould? the answer has been, Certainly not. This must now be proved.

Experiment has shown that it is impossible for a plant to receive nutriment by its roots in any other but a soluble and perhaps a gaseous form. Be the nutrient material what it may, it must first be in one or other of these conditions, before it can be appropriated by the vegetable economy. The rootlets cannot take up solid matter; nor, if they could, could the plant grow upon such a dict. If the hungry fibres wandered in their search for food through a mass of dry sawdust, or threaded their way through a pile of stones, they would find none, -because they would find nothing dissolved in such a situation.

Applying this to our present subject, vegetable mould may be considered as almost in- 
soluble. If its solubility were represented by figures, one part of good mould would dissolve in 100,000 parts of water. The same might be said of many stones; in fact, some show a. considerably larger solubility. A plant, therefore, whose roots meandered through a mass of powdered stones, would be actually in a better condition, as regards its supply of soluble matter, than one planted in pure vegetable mould.

It becomes clear, then, that while analysis fully confirms the fact that the vegetable soil abounds in one of the elements of wood, or in carbon, yet, at the same time, we are taught, that it is in such a condition as to be utterly useless to vegetation for food. The source of wood in plants is, consequently, not in the soil. Its true source is the atmosphere. This may excite surprise, and even challenge belief, but it is based upon the most incontestable evidence afforded by vegetable physiology. The wood of plants is derived from the thin air which they breathe: thus air, or, more properly speaking, one of its ingredients, is actually the food of vegetation. The orchis-tribe, or, as they are commonly called, the "airplants," furnish us with a beautiful illustration of this fact. These plants, in their native haunts, are found upon the branches of lofty trees, seated as it were in state, and surrounded with groups of flowers and leaves, 
whose fantastic forms and gorgeous aspect make them objects of the most extraordinary character. The glowing colours and delicious fragrance of these plants have given them admission now to our conservatories. In the plant-stoves at

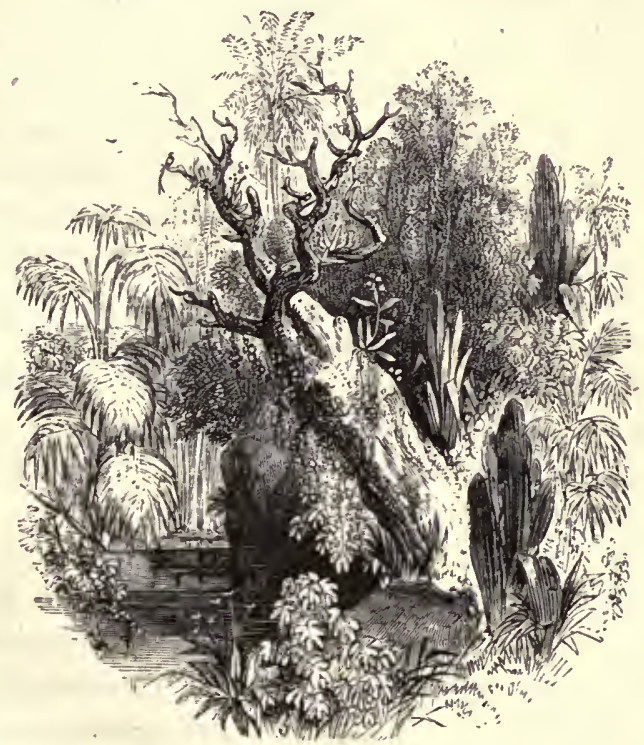

ORCHIDS GROWING ON A DEAD TRTXK.

Kew, orchids are to be seen growing upon pieces of dead wood, or out of a little moss in iron baskets, or out of oyster-shells, cocoa-nuts, and the like. Their long, naked, snake-like roots drop into the air from the topmost boughs on which 
the plant sits, but never reach the earth. The sunshine, the heavy dew, the occasional shower, and the balmy air, are all their dietary. There are, it is true, a number of terrestrial orchids, and they, as other plants, derive a part of their carbon from the carbonic acid of the soil. In addition to the orchids, the extraordinary plant called the "stag's horn" fern, is almost exclusively nourished upon the air. This plant is also to be seen at Kew, where in one of the tropical stoves it will be found growing upon a piece of wood! Its great leaves, in shape resembling antlers, hang down in a singular manner; and the whole plant presents us with a remarkable instance of a vegetable deriving little or nothing from the substance on which it grows, and yet flourishing in the greatest luxuriance upon a diet of water and air!

These plants are not strictly parasites, for they do not live upon the natural juices of the branches on which they grow; therefore their carbon could not have been derived from the boughs on which they rest. The question may then be put, If they do not derive their carbon from the air, from whence do they obtain it? Nor are orchids and these curious ferns solitary in this property of living in the air alone, for several other plants have the same faculty. The conclusion therefore cannot be resisted, that the air is the principal, if not 
the only, source of carbon in these instances; and if in these, most probably in all other plants.

Some other facts may be mentioned, on the authority of Dr. Schleiden, which in a striking manner set the same great fact with regard to other plants before us. He observes: "The oil-palms (Cocos nucifera, and Elais guineensis) grow in sea-sand. The culture of the latter is largely carricd 'on' on the west coast of Africa in moist damp sand, not enriched by manure. Between the years 1821-1830, England alone imported from the coast of Guinea $107,118,000 \mathrm{lbs}$. of palm-oil, and therewith about 76 million lbs. of carbon (contained in the chemical composition of this oil), drawn from a soil which in itself contained no carbon. . . According to Darwin, the richest maize harvests are obtained, from the interior of Chili and Peru, from the most sterile quicksands, which are never enriched by manure, and where only small streamlets from the Andes supply any water. . . The soil of the entire district of Brandenburg consists entirely of sea and downsand. It is still in many places composed of a loose and pure quicksand of 100 feet deep, and. so movable that it does not, as I have had opportunity of witnessing in the neighbourhood of Berlin, require any very high wind to change entirely the configuration of the surface. 
Young pines are found sometimes standing with their first branches buried in the soil, and after eight days with a naked stem, and the roots so exposed that one could creep through them! (Yet) this soil, as is seen in the Spriewald, so far as it is moistened by the rivers Sprie and Havel, produces vigorous pine vegetation, which most certainly cannot draw all its carbon from sources furnished by the soil, for it has never possessed it, nor has it been furnished to it by artificial processes."

It is remarked by Colonel Campbell that the einnamon tree flourishes best in a soil which consists chiefly of sand. He says: "The soil of the cinnamon garden, in the neighbourhood of Colombo, (as well as that near Galle and elsewhere, in which the cinnamon-tree is grown; and in many places it is produced naturally, is a remarkable instance of the silicious kind. The surface of the ground in many places, where the cinnamon plant flourishes, is white as snow: this is pure quartz sand. Below the surface a few inches, where the roots penetrate, the sand is of a grey colour. A specimen of this, dried thoroughly, was found to consist of $98 \cdot 5$ silicious sand.

1.0 regetable matter.

0.5 water. 
SOIL NOT CHIEF SOURCE OF CARBON. 361

If these facts are considered, it will become apparent, that the true source of the carbon of plants cannot be in the carbonaceous matter of the soil, seeing that vegetation is luxuriant even upon soils which contain little or none of this èlement.

The carbonic acid furnished to the air by the various processes of combustion, respiration, and putrefaction, and from volcanic craters, is the true source of the carbon of the vegetable world. The composition of this gas is one equivalent of carbon, united to two of oxygen gas. If we could remove the two proportions of oxygen, carbon is left. Wood is composed of carbon, together with the elements of water, oxygen, and hydrogen; it contains other principles, but it is sufficient for our present purpose, to consider wood to be chiefly carbon. If therefore any structure is supposed to have the power of decomposing carbonic acid, of rejecting its oxygen, and of appropriating its carbon, modelling it for the peculiar purpose of its organization, the atmospheric origin of wood is rendered perfectly feasible. All we have to do is to show that plants possess this decomposing power; that is, they really are able to destroy the union between carbon and oxygen in carbonic acid. If it should appear that plants are really endowed with this power, it is not diffcult to believe that they should be able to use 
the element which they set free, and by the powers of vitality to apply it to the different purposes of their economy.

The following experiment will doubtless be considered decisive as to the chemical influence

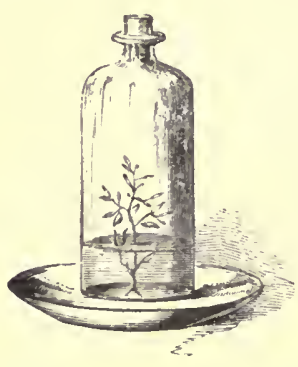

THE SPRIG OF MINT. of plants over carbonic acid. Dr. Priestley took a sprig of mint and put it into a glass ressel (see Fig.) which contained air mixed with a considerable quantity of carbonic acid. He then put it in a position where it was well exposed to the light, and left it for a little time. He subsequently analysed the air contained in the jar, and to his astonishment found that all the carbonic acid had disappeared, and the air within the vessel contained more oxygen than common air! De Saussure performed similar experiments; and he found that not only had carbonic acid disappeared, but that actually a notable amount of oxygen had been added to the air, and the plants under examination had also increased in weight. Boussingault performed a yet more conclusive experiment. He enclosed a vine-branch in a glass receiver exposed to sun-light, and containing air with a certain proportion of carbonic acid gas. The 
vine-branch was found to have absorbed and decomposed half the carbonic acid of this portion of air in a very, short time. These plants, in decomposing the carbonic acid, had appropriated its carbon and rejected the oxygen.

Before, however, this theory of the origin of wood can be considered to be satisfactorily confirmed, we should inquire whether the air really contains sufficient carbonic acid to supply the wants of the vegetable world. Humboldt says, that in some of the forests of the New World, monkeys might run a hundred miles in a straight line upon the tops of the trees! The amazing mass of carbon contained in such forests can therefore be scarcely represented by the ordinary powers of numbers. Is it possible that all this was derived from the air? Does, in fact, the atmosphere contain a sufficient amount of this element to account for the separation of so great a mass of it as exists in this single instance, not to take into consideration the entire vegetation of the rest of the globe? The carbonic acid of the atmosphere has been estimated at one-thousandth of its whole weight. The entire weight of the atmosphere is known; and calculating upon it, it has been found that the entire. weight of carbon contained at one time in the atmosphere is about three thousand and eighty-five billions of pounds. Calculations 
have been made as to the actual demand upon the atmosphere for carbonic acid, of the whole vegetation of the earth. If we suppose the actual surface covered by vegetation to be onc-fifth of the entire area of our globe, that will give a space of two millions of square miles, or of 43,124 millions of acres. Let us suppose that each acre derives every year 2,000 lbs. of carbon from the air; then the whole annual necessities of the vegetable world in a year amounts to about 300 billions of pounds of carbonic acid. How is this enormous annual drain to be supplied? Dr. Schleiden calculates that from tobacco smoking alone we have a supply of carbonic acid in a year equivalent to 1,000 millions of pounds. He bases this odd calculation on the following grounds. North America alone produces in a year enough tobacco, on its being burnt, to yield the immense sum of 340 millions of pounds! The other tobacco-growing districts supply the rest. Yet when we contrast the insignificant cloud of smoke rising from a single pipe-more, perhaps, from those used by Dr. Schleiden's continental countrymen than from our own-together with that rising from our furnaces and factories, how insignificant does even this enormous sum appear, compared with that which from combustion of fuel alone escapes into the air! When it is 
remembered that from a number of other sources carbonic acid is discharged into the atmosphere, little difficulty as to the existence and constant supply of a sufficiency of this gas in the atmosphere to account for all the wood upon the earth's surface will be experienced.

Such is the chemical history of the formation of wood from the air. Let us now inquire what becomes of the other element entering into the composition of carbonic acid gas-namely, oxygen. Is it condensed and solidified, so as to form a part of the vital structures of the plant? or is it again rejected, and again returned to the air? Upon the answer we are able to give to this question depends another important point,-Do plants purify, or do they vitiate the air? If they retain the oxygen of the carbonic acid they decompose, they rather tend to vitiate the air than otherwise, by removing one of its most essential ingredients. But if, on the contrary, they reject the oxygen, retaining only the carbon, they purify the air. in a double sense; for they not only remove from it a dangerous ingredient, but add to it a salutary one, in the element of oxygen.

The opinion popularly held is not altogether correct. It seems to be a general impression, that the presence of plants in a room, or to be long in the air of a conservatory, is unwhole- 
some; for it is said, the plants vitiate the air.* It is important to set the real state of this beautiful case of nature's chemistry before the reader, if only to assist him to a right knowledge of facts. To ascertain the point, the following experiment may be suggested to those who are sufficiently expert in mechanical and chemical manipulation to attempt it. Take any plant, the branches of which are sufficiently long and well-clothed with leaves (see cut), and insert it in a dish of mereury, bringing it up through the fluid into an inverted glass jar filled with air containing a slight excess of carbonic acid. $\dagger$ The apparatus may be easily arranged, as in the cut, and the whole must be exposed to sun-light. If now, in a few days' time, the air in the jar is examined, by merely introducing a lighted taper into it, it will be found that the flame is much more brilliant than in open air,- which is due to the presence of an increased amount of oxygen in the air of the jar. From this we learn, and the experiments of Boussingault, Saussure, and Priestley, have with due accuracy proved the fact, that plants in reality, while exposed to the sun, retain the

* Plants with a profusion of flowers undoubtedly vitiate the air, to some slight extent, until the fiowering season is over.

† Easily produced by pouring a little dilute hydrochlorie acid over a lump of ehalk or marhle, and then allowing the gas to escape into a jar, out of which it may be poured into this jar. 
carbon and give out the oxygen of carbonic acid - thus incontestably proving that their function is to purify the air of this gas, and to restore it to the element oxygen.

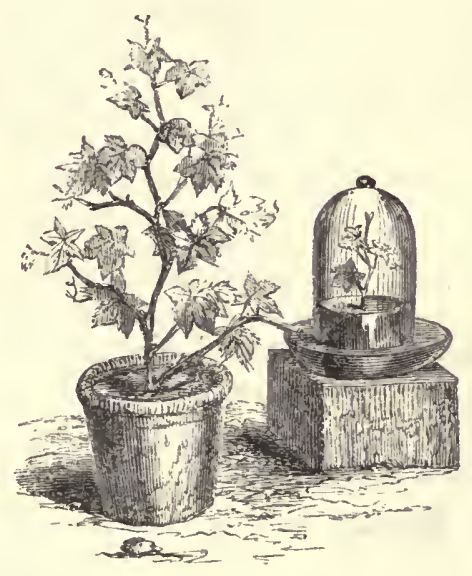

These grass-covered fields, and those leafcrowned forests, are not the mere ornaments of the scene we contemplate. They do not flourish for nought, or live in vain. The pure air which lightly floats along the meadow, and softly whispers the wood-leaves to sleep, parts not with them as it finds them. It comes bearing a deleterious ingredient; it departs leaving it in some degree behind, and bearing away a healthful exchange of a fresh supply of oxygen. Thus in bcautiful connexion are plants nourished and 
strengthened; and in this very process the air is purificd, and rendered more suitable for the existence of man and the animal world.

But this process only takes place under certain conditions. The popular belief about plants is less inaccurate at night. Plants cease almost entirely to decompose carbonic acid at night. When the sun sinks below the horizon, and the shades of evening lengthen out; when

\section{"twilight gray}

Has in her sober livery all things clad ;"

and when man, beast, and bird are seeking repose for the night, the vegetablc world sleeps too. The leaves cease their daily task, and pour out carbonic acid back into" the air unaltered. Whether a little carbonic acid is not decomposed during the night is not altogether decided, but it is certain that a very large proportion of the carbonic acid inhaled by plants during the night is given back to the air in its original state. At night plants actually absorb a certain measure of oxygen gas from the air, which is appropriated, on the return of day, to the formation of oils, acids, and other regetable ingredients.

We must refer to the influence of sun-light for the explanation of the cessation of this process at night. It has already been noticed that 
the rays of the sun exert a most important influence upon the vegetable kingdom. Perhaps there are few more pleasing subjects in the chemistry of creation than that of the influence of light upon plants. The whole of the three principles resident in the sunbeam, namely, the luminous, actinic, and calorific rays, produce highly interesting effects upon plants, and are, together, strictly necessary to the health, development, and perfection of the vegetable being. Let us briefly advert to the facts now knuwn upon this subject. It has already been stated, that, at the commencement of vegetable life, the actinic or chemical rays have been found to be indispensably necessary for the commencement of the process of germination. So soon as this process is ended, the plant having now raised its tender head into the light, it enters into a new connexion with the air, and with the sumbeam. During germination the seed absorbed oxygen from the air, under the influence of the powers of vital chemistry, and actinism combined. But when the first ray of unshaded sun-light falls upon the young leaf, its processes undergo an entire change. It now becomes green, in consequence of the action of the rays of light upon some of the ingredients present in the leaves. And now, almost to the end of its existence, it pours out oxygen gas all 
the day long, in return for the carbonic acid it absorbs. It also begins rapidly to form wood; and we shall soon find that all the parts of the plant have acquired the hardness and firmness peculiar to woody tissues. The next important period in the history of the plant is its flowering scason. The flowers, instead of decomposing carbonic acid, on the contrary, give out that gas, and absorb a considerable quantity of oxygen from the air. At the time of ripening, the fruit also absorbs oxygen from, and gives carbonic acid to, the air. In addition it is stated, that all the parts of a plant not having a green colour, such as the bark, absorb oxygen and eliminate carbonic acid gas.

These effects-the alternate decomposition of carbonic acid, and evolution of oxygen, with the contrary process of absorption of oxygen, and evolution of carbonic acid,-appear to be all dependent entirely upon the alternate presence or absence of the solar beams. The plant is influenced in succession by the chemical rays, by the luminous, and by the calorific or heatrays. The luminous or pure light-rays cause its leaves to decompose carbonic acid; and under their influence alone is the green colour, which is due to a substance named chlorophylle, produced. By the light-rays, therefore, 
wood is formed, and upon their stimulus depends the production of this refreshing green which mantles over forest and field. But the heat-rays are not less essential to the plant. It appears that it is to the influence of the heat-rays that we owe all those flower-beauties in the vegetable world, which form such charming objects to the eye. It has been found that by separating the heat-rays from light, by means of a coloured glass, neither the lightrays, nor the chemical rays, will enable the plant to put forth flowers or fruit. For this the heat-rays are essential, and, in some wonderful and mysterious manner, by their assistance, the plant becomes crowned with its chiefest ornament. The influence of the chemical rays in germination has been already noticed.

We may thus recognise three stages in vegetable life, in each of which one of the three principles resident in the sunbeam comes most prominently into operation. 1. In the infancy of vegetable life, Actinism. 2. In the youth of the plant, Light, properly so called. And 3. In its perfection, or flowering-time, Heat. It must not, however, be imagined that at no other period in the life of the vegetable being are these principles in active operation; this would be in the last degree erroneous. In 
every process it is probable that the whole three forces are concerned-in all the phenomena of growth, and in the various and complieated chemical process taking place in the plant. But, at the three periods mentioned, it would seem that each becomes, in succession, of the greatest and most prominent importance to the plant. In connexion with this most singular discovery, is one equally singular and beautiful. It appears, from researches which have been carried on with care for some years by Mr. R. Hunt, by means of an instrument called the actinograph, for measuring the intensity of the actinic power at different periods of the year, that the actinic rays are most active in spring, the lightrays in summer, and the heat-rays in autumn. Thus, by a beautiful adaptation, it is found that the various periods of the life of plants requiring the predominant influence of one or other of these principles, are admirably connected with those periods of the year when these principles are most actively exerted. Thus, in spring, the slumbering seeds require actinism to awaken vitality in them; and actinic power is then most prominent in the sunbeam. In summer, they need to have their tissues condensed and consolidated by the formation of wood, which is performed by the aid of light; and then the light-rays are most powerful. In autumn, the 
fruits of the orchard need to be ripened by the agency of heat; and at that season the heatrays are most predominant. It appears, indeed, that even during the day, the relative force of the three principles in the solar ray is modified. In the evening there is less aetinic force than in the morning; and at noon there is more luminous and calorific power. All these results are of deep interest, and are entirely of recent discovery. What wisdom is manifest in this long unsuspected but marvellous arrangement of vegetable functions and light! What views does it give us of the strict dependence of one part of this fair creation upon the other, and of the manner in which various phenomena have been linked in such close union by the Divine Creator! He only is as excellent in working, as $\mathrm{He}$ is Almighty in power!

From these considerations we may learn, first, the importance of light to the vegetable world; and, secondly, the importance of light in order to the preservation of the purity of the atmosphere." Without light, no plant could long exist; without light, little carbonic acid could be decomposed; and the air would be so much vitiated, as to become irrespirable to the animal world. In how many ways is this cheerful sun-light connected, directly and otherwise, 
with the health and joy of all creation! The Fungi are a tribe of plants which grow best in the dark; and they are actually deleterious in their influence on the air, absorbing oxygen, and exhaling carbonic acid. It is therefore certain that the influence of regetation, when in a healthy condition-for in decay its effects are deleterious - improves the health of a country, by its direet purifying influence upon the atmosphere.

Dr. Franklin, in a letter to Dr. Priestley, upon the subject of the then recent discoveries of the latter philosopher, says, "I hope this will give some cheek to the rage of destroying trees that grow near houses. I am certain, from long observation, that there is nothing unhealthy in the air of the woods; for we Americans have everywhere our country habitations in the midst of woods, and no people on earth enjoy better health."* Dr. Franklin's observations are true, where the amount of decaying vegetation does not produce a sufficient amount of malaria and carbonic acid to turn the balance on the other side; since, in this ease, the clearing a country of superfluous trees, becomes a positive gain to its sanitary condition. On the grand

* From recent statistical faets, it appears that the Americans do not "enjoy the best of health of any people :" the English are more long-lived, and necessarily more healthy. 
scale, however, vegetation is one of the indispensable provisions for the continuance of animal life on earth; and we find in the atmosphere the link which connects these kingdoms in a more intimate bond of mutual dependence than might at first sight appear.

There appears to be a beautiful provision, even in the succession of day and night, by which the temporary loss caused by the cessation of plants from their labours in our hemisphere is counterbalanced. For while in this hemisphere, at night, all nature is asleep, both animal and vegetable; in the other the sun shines, and the wide domain of plants pour out their daily streams of oxygen into the air. Thus, the purifying influence of vegetation upon the entire mass of air is never arrested all over the world, the time of rest in one region being that of activity in another. It has been suggested by Liebig, that those vasts movements of air, the Trade Winds, are also instrumental in preserving the general balance of purity in the entire atmosphere, by conveying from the tropics to the poles the pure air, rich in oxygen, ascending from the profuse vegetation of these burning regions, to the frozen north, where vegetation has scarcely a representative. Mingling with the ascending flow of warm air, this pure and highly oxygenated 
stream is borne on its wings to the higher regions; there, out of all danger of contamination, it is wafted by means of the "upper current," to the north; and descending, to form the "lower current," on its circuit back to the equator, carries with it health, life, and vigour, over every region through which it sweeps, until, robbed of some of its valuable properties, and becoming laden with the impurities of colder climes, it reaches the tropics, where its oxygen is restored, and becomes again involved in the great system of circulation. By this vast cireulatory scheme, which we might almost venture to designate the "respiration of the atmosphere," the earbonic acid, produced in such enormous volumes in northerly regions from the innumerable sourees already mentioned, is conveyed by the returning current to the equator; there, after fecding the luxuriant vegetation of the tropies, it becomes decomposed into its constituent elements, its oxygen mingles with the ascending eurrent, and, in process of time, returns by the course just indicated to enrich the air of temperate climates. The interchange thus effected is perpetual; it rests not day nor night. Hence, while this great current fills the canvas of the merchant's vessel, and was long considered as the exclusive agent of intereourse between the New and Old 
World, it is, at the same time, the great ventilating process, by the instrumentality of which the atmosphere of the teeming tropics, and less fertile regions of the north, is properly intermingled and purified.

It has been well said, it is " the earthgirdling atmosphere which makes the whole world kin." The air we inhale with pleasure as it breathes fresh over these heath-clad fields and hills, but a little while since bade farewell to the splendid vegetation of Brazil, or to the palm-trees of Ceylon; and it will leave us to be wafted among the forests of India, or the spice groves of the islands of the east. How strange the thought!- the gases gently rising, discoloured with smoke, from yonder cottage chimney, may soon become food to the vegetable inhabitants of warmer regions than our ownmay become appropriated by the sugar-cane, or sago-palm, or become part of the tea-shrub, and may actually return to us in the form of sugar, sago, or tea!

The atmosphere is connected with the wellbeing of vegetation in a remarkable manner also . by its influence on the soil. When land has been exhausted by successive crops, the remedy has been to let it lie "fallow," or, in other words, rest from bearing crops for a little time. The recovery of its lost ingredients is effected by the 
silent ageney of the atmosphere. The command to the Jews of old, to let the land enjoy her sabbaths, had, no doubt, a direct reference to this object. The air and rain, with the alternations of heat and cold, exert a powerful influence upon the reposing surface. The mineral ingredients previously insoluble, become gradually dissolved under their operation, and a store of them is collected for the uses of the next year's vegetation. The land having "rested," the seed is again committed to the ground, springs up, and luxuriantly flourishes upon this gathered hoard. So on, alternately: the atmospheric influences continuing to reproduce what man carries away as fast as it is ripened, in his corn, and other plants, and appropriates to his own use.

The atmosphere, in all these ways, influenees vegetation, and, indirectly also, animal life. Its influence extends to the preparation of the soil, is felt also in quickening the seed into life, in supplying it with food, and, finally, in reducing it when its course is ended-when its functions are all fulfilled-to the dust of the earth, and there preparing its ashes for the service of a future race.

We are told in the word of God," that " the 
heavens declare the glory of God, and the firmament," or atmosphere, "showeth his handywork;" and, perhaps, in no part of creation is the wisdom, beneficence, and power of God more remarkably conspicuous than in the constitution and laws of the atmosphere. In the dews of evening - in the heaven-descending shower-in the gentle breeze, nay, even in the tempest-and in all the physical phenomena of the air, we have tokens of the Divine wisdom, goodness, and power, apparent to every mind; but the wonders of its creation appear most on a survey of its chemical constitution. Here we are taught how wondrously are the animal and vegetable worlds mutually dependent for existence on the atmosphere; and, more singular still, how each depends also upon the other through this very medium. We learn, also, that the whole surface of the earth is more or less under the influence of the same chemical agents which connect the air with animals and plants. In short, we learn that the atmosphere not only surrounds all things, but is constantly exercising the most important effects upon their condition and character; yet all is harmoniously arranged-countless chemical processes are carried on without confusion, and innumerable ends are accomplished by the same 
means, but without disorder. Perhaps the facts which have been detailed in these chapters on the air, may help the reader to a deeper perception of the sacred truth to which allusion has been made-the "firmament showeth his handywork." 
. 


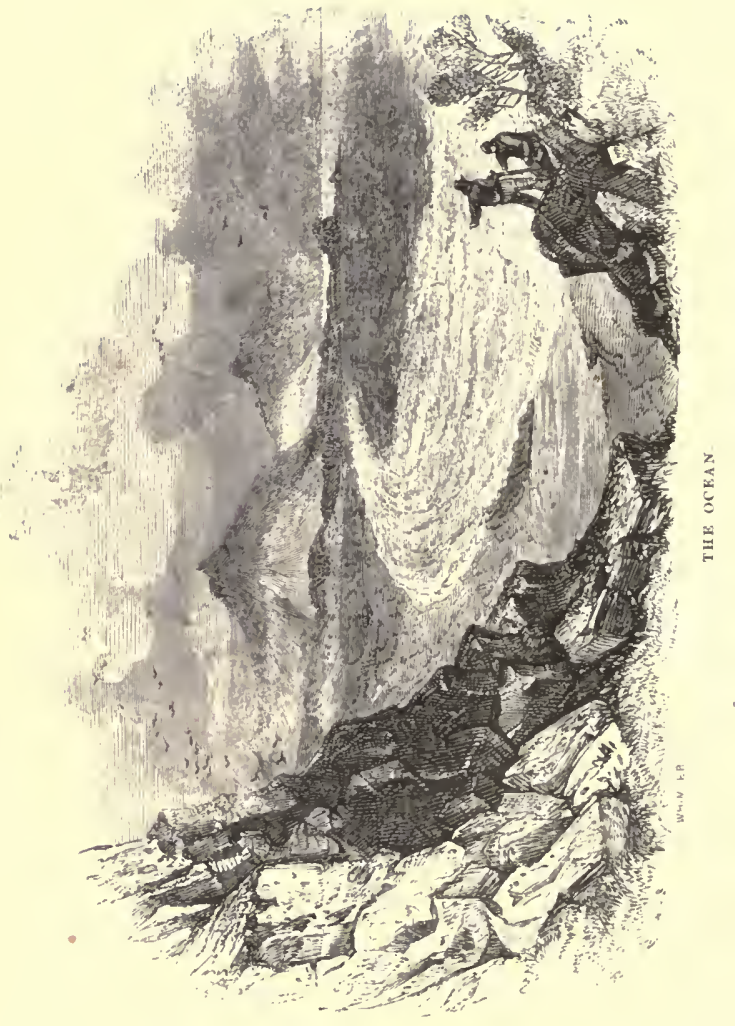




\section{PART III.-THE OCEAN.}

"TIIE SEA IS HIS-AND HE MADE IT."

\section{CHAPTER I.}

ITS PHYSICAL CONSTITUTION, ETC.

LET us transport ourselves to the sea-shore, to which the valley where we have lingered so long conducts us. What matter of thought and investigation lies before us in this restless and majestic element, whose waves cast themselves at our feet, shedding their salt spray over our persons! Are the principles of chemistry in movement throughout this mighty deep, as we have seen them on the earth and in the air, producing their slow but ceaseless changes of form and matter? This inquiry it is our present object to satisfy. It may, however, be premised that the chemistries of the ocean are few and simple, far more so than those of earth or air; but they are not less interesting nor less important. 
It has been seen that we know but little of the real depth of our "sea of air," for it must be admitted, after all, that our data for the determination of this question are not wholly satisfactory, but we know perhaps less of the profundity of the great waters. All that ean be learned is the depth down to which our researches have extended in the vain search for the bottom. The greatest depth yet obtained was by Sir J. C. Ross, in S. lat. $15^{\circ} 3^{\prime}$. 'The

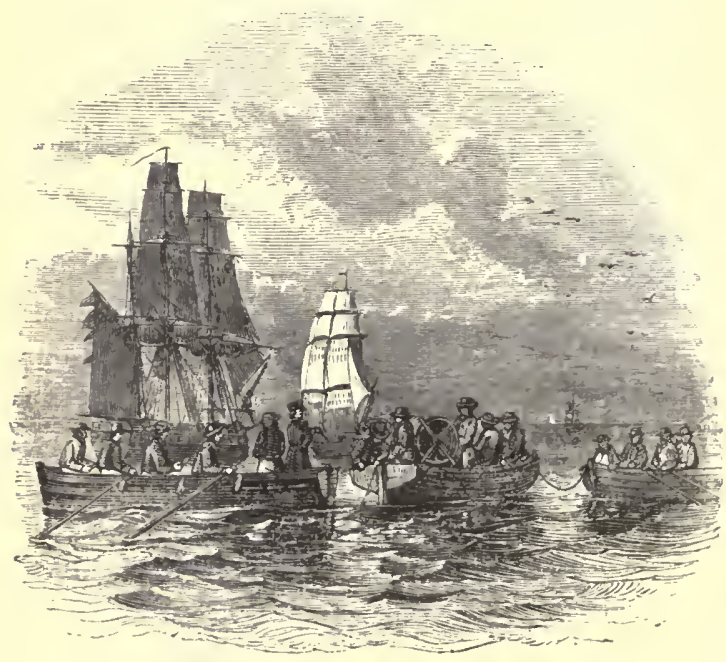

DLEP SOLNDIYGS.

weather being ealm and the water quite smooth, soundings were tried for with 4,600 fathoms of 
line, or 27,600 feet. The method of taking this deep sounding is represented in the cut. The depth of the ocean is, however, by no means uniform, in consequence of the inequalities of surface at the bottom. Could we suppose the ocean emptied, and the bottom exposed, we should behold a great cavity very different from that of our imaginings. Far from its surface being smooth and uniform, like the sides and bottom of some vast bowl, it would be seen that many of the varieties of hill and dale, of mountain, rock, valley, and level plain, which give variety to the aspect of nature on land, are repeated in the ocean, though doubtless a certain smoothness of aspect would be in general found to overspread these features, greater than we behold on land, in consequence of the levelling influence of currents, and of the deposit of sand and detritus.* That such is really the case, is evident from the facts observed in sounding by means of the lead. Shoals, for example, which extend for miles, and are surrounded on every side by deep water, where the lead cannot find a bottom, are manifestly mountains in the ocean, and would be seen as such were all the water removed. Sometimes the shore of a country falls with a very gentle

* Locke well and simply" says, "The sea is a collection of waters in the deep valleys of the earth." 
inclination; sometimes, and particularly near precipitous coasts, the bottom cannot be reached within a few hundred yards of the rocks. The one would appear as a gently-descending plain, the other as an abrupt, precipitous mountain of great elevation. It must not, however, be supposed that no limit exists to its profundity, or that, except in the imagination of poets, it is without a bottom. In all probability its depth is only a fourth or a fifth part of that assigned to the air; the greatest hollows being supposed not to be deeper than from twelve to thirteen miles, or thereabouts.

The pressure of the atmosphere is greatest on the surface of the earth. Not so with the ocean. We must not forget that on the surface of the earth we are at the bottom of the aërial sea; while, on the contrary, we are at the top, so to speak, of the sea of waters. Hence, as we descend into the ocean; the superincumbent pressure increases in proportion to the depth attained. How vast must this pressure become at the depth of eight or ten miles, when we reflect that the pressure even of such a light body as our air, equals on the earth $15 \mathrm{lbs}$. on the square ineh, water when perfectly pure being 815 times heavier than air! Experiments upon this subject have often been made. It has been common to sink bottles full 
of fresh 'water, closely corked, into the ocean, when it has been found that the corks have been driven in, while the fresh water has been replaced by salt, or the bottles have burst with the enormous pressure to which they were thas subjected. Picces of light porous wood have been weighted and sunk, and when brought up again have been found to be so condensed in their tissues, as to be incapable of floating any more, sinking like stones when thrown back into the water. In the experiments undertaken by various observers upon the temperature of the deep sea, by sinking thermometers, accidents repeatedly occur from the pressure of the waters above. What sailors term "waterlogged" occurs when a boat or vessel has been sunk beneath the surface so low as to cause the pressure of the superincumbent water to drive the particles of water into its interstices. Mr. Scoresby mentions that, during a whaling cruise in the Arctic regions, a whale, on being harpooned, dragged the boat under water, the crew escaping on to a piece of ice. When the fish returned for air to the surface, it was again struck, and then killed; it immediately began to sink. Fortunately, a grapnel was thrown over its tail, and its descent was thus arrested, though at imminent risk to the boat. On hauling up the line, it was found 
to have an extraordinary stress upon it, no fewer than twenty-five men being neeessary to raise it. After several hours of toil, the boat which had been sunk was recovered, and was now so heavy as to require a boat at each end to keep it from sinking. On being examined, the paint came off in large strips, and the wood was so penetrated with water by the enormous pressure of the depths to which it had been dragged, that a piece of it sank like iron in the water, and it would not even burn when apparently dry and placed on a fire.

Many interesting experiments have been carried on, both in our own country and on the continent, to prove what the Florentine academicians, in their celebrated experiment upon the compression of water in a sphere of gold, considered they had finally disprovedthe compressibility and elasticity of water. Although much less compressible than air, or gaseous bodies, it is still capable of diminution or increase in bulk, according as the pressure on its surface is greater or less. The experiment with the bottle of water sufficiently indicates this: but the fact has been aceurately ascertained by philosophers. By means of an ingeniously construeted apparatus, Mr. Perkins obtained a striking evidence of the compressibility of water, in the index of the instrument, 
after its having been lowiered deep into the sea, marking several inches lower than before it was sent down. At the depth of 20 fathoms, 20 cubic inches of sea-water only occupy the space of 19 at the surface.

In its profound depths, the ocean is darker than the darkest night. No twinkling of the stars gives variety to the dark expanse over head; and not even the brilliance of the noonday sun can enliven these gloomy regions. Silent and black, it might be conceived to be the abode of eternal night. It has been a question how deep it is possible for daylight to penetrate into the waters. In the clear regions of the tropics, where however the utmost brilliancy of natural light is attained, the bottom of the ocean, at a depth of many fathoms, may be distinctly seen, and navigators state that the zoophytes and marine plants may be very clearly beheld, and that they appear most delusively near to the surface. Shells are visible in parts of the Arctic Ocean at a depth of 80 fathoms. In the seas around the West India Islands the bottom is distinctly perceptible at 30 fathoms. Ordinarily, about 700 feet appears to be the extent to which light penetrates into the ocean.

The colour of the ocean has engaged much attention, although not in some instances with 
that amount of entire suecess which could be desired. Sometimes it is of a beautiful blue; this is its natural colour; at others it is emerald green. Sornetimes it appears streaked in brownish, or bright green, or olive-green patehes; sometimes it is even milky, and sometimes red, or of a reddish cast. Scoresby found, in the Aretic seas, that the green hue appeared to depend upon the presence of a vast number of semi-transparent spherical substances, with others resembling small portions of fine hair; and notieed further, that the whales delighted most to feed in these green patehes of water. Darwin, while cruising in the Beagle off the coast of Chili, found the vessel passing through a large area of water having a pale red colour. Obtaining a bucket-full of this singularly tinged fluid, and placing a drop or two under the microseope, he found it full of animalcules which darted about with great rapidity. A cubie inch contained more than a thousand of them, yet the surface tinged by their bodies extended for several miles. What an innumerable multitude must have been present in the whole!

The ordinary colours of the sea, however, depend undoubtedly in a great measure upon the influence of the water upon light, and not upon any colouring principle diffused or dis- 
solved in them. Perfectly pure water, like pure air, when seen in bulk, appears of a beautiful blue colour, but the least admixture of foreign matter destroys this effect, and renders the colour dirty and variously shaded. By taking a glass tube; two inches wide, and six feet six inches long, blackened internally with lamp-black and wax to within half an inch of the end, the latter being closed by a cork, and filling it with chemically pure water, putting at the bottom a few pieces of white porcelain, and now holding the tube vertically in a white plate-we can develop the naturally blue tint of water, and the column of it acquires a beautiful pure colour of this kind. Whercver water is clear and deep, it has the colour natural to it. Professor J. Forbes, in his travels in the Alpine regions, says: "During an expcdition which I made upon the ice in the month of September, during a snow-storm, I observed that the snow lying eighteen inches deep, exhibited a fine blue at a small depth (about six inches) wherever picreed by my stick. Nor could this possibly be due to any atmospheric reflection, for the sky was of a uniform leaden hue, and snow was falling at the time." Hence it is probable that blue is the colour of pure water. The exquisite blue colour of the glaciers 
and crevasses is highly remarkable.* The colour also of the bed upon which the water lies greatly influences the colour presented by the latter. At Capri, in the Gulf of Naples, are two grottos remarkable for the exquisite colour of the water seen in them: The sea at the Blue Grotto is most remarkably clear to a very great depth, so that the smallest objects inay be distinctly seen on the light bottom at a depth of several hundred feet. All the light that enters the grotto, the entrance of which is only a few feet above the level of the sea, in the precipitous rock opening on the surface of the water, must penetrate the whole depth of the sea, probably several hundred feet, before it can be reflected into the grotto from the clear bottom. The light acquires by this means so deep a blue colouration from the vast body of water through which it has passed, that the dark walls of the cavern are illuminated by a pure blue radiance, and the most differently coloured objects below the surface of the water are made to appear tinged with blue. In the Green Grotto the depth is less, and the yellow tint of the subjacent rocks alters the colour of the reflected light from blue to green. Some parts of the Mediterranean Sea are found to present

* Professor Bunsen notices the same appearances in the glaciers of the Jokull in Ieeland. 
a reddish or purplish hue; and in a bay on the west coast of Africa the waters always have almost the appearance of being tinged with blood: in both cases the effect is due to the colour of the bottom.

The- beautiful phosphorescence, familiar to residents on the sea-coast, and well known to fishermen, who term the sea brimy when its surface, on being agitated by the air or tide, flashes with phosphorescent light, is generally supposed to be principally due to phosphorescent animalcules. Sometimes the appearance is so marked as to form a most curious and splendid spectacle. Wavies of heaving fire rise and fall, flashing in the dark night with a lustre of indescribable brilliancy, and, as far as the eye can see, an ocean of fire appears to toss its waves, emitting a beautifully pure and pale light. Under the bows of the vessel, or in the water-line in her wake, ripples of flashing brilliancy play, and the path of the ship becomes marked with a long line of moving light. When water is taken from the surface it possesses the same luminous properties. Sometimes the luminosity has different tints; in tropical waters it is often white as snow, and the whole surface of the deep appears like a field covered with new-fallen snow. In the Gulf of Guinea the surface of the water sometimes appears of the most bril. 
liant white. The cause in this instance has been supposed to be vast numbers of small crustaceous animals, which have the singular property of emitting a white light.

Sornctimes it is of a ghastly blue, and the appearance then presented is more than ordinarily terrifying to the superstitious. Again, sometimes it is of a fiery red, or even scarlet, as though some marine monster's blood did

"The multitudinous sea inearnadine, Making the green one red."

Sometimes also the tint is green, and sometimes yellow.

In many cases this power of emitting light appears to be a vital property connected with the existence of marine beings. Dr. Macculloch, who laboriously investigated this curious and interesting subject, writes:- "I believe the power of producing light to be an universal property in the marine tribes. I have never found a species in which it did not exist." The luminosity of some fishes depends upon the minute phosphorescent creatures, Nereis noctiluca, attaching themsclves to the scales of fish, and thus illuminating the surface of the creature on which they rest. Many of these phosphorescent creatures are of extreme minuteness. The little being represented in the eut, Noctiluca miliaris, does not exeed 
the one-thousandth of an inch in diameter: Millions may be easily contained in a bucketful of sea-water. On examination under the microscope, it appears that they possess the power of squeezing out a phosphorescent fluid, which leaves a line of light in the water.

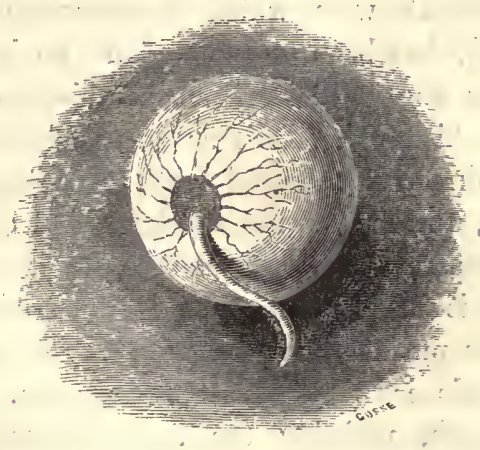

NOCTILECA MILIARIS. (MAGNIFIKD.)

In the British seas theșe little animalcules are often found congregated together in innumerable millions. : Dr. Pring, in a paper communicated to the British Association in 1849, details some interesting results of experiments upon these phosphorescent creatures. "Galvanism increased the luminosity; oxygen gas, and carbonic acid gas, also increased the light; but the latter most spcedily killed the animal; sulphuretted hy: drogen quickly destroyed the light; "nitrogen; nitrous oxide, and hydrogen, produced little or 
no effect on the luminosity. Strong mineral acids increased for a moment, but speedily afterwards destroyed the light; ether instantly destroyed the life of the animal; chloroform increased the light, and then destroyed the animal."

The light with which these creatures are endowed, has been considered to be in many instances the guide of the inhabitant of the deep to his prey. It is a remarkablc fact also, and is directly connected with the chemistry of the sea, that when the dead body of a fish is still comparatively fresh, and before it becomes putrid, it often possesses this luminosity, but not after putrefaction cominences. There is no doubt this is a chemical phenomenon. Soon after death, probably the first process of decomposition is the disengagement of phosphorus in the form of some luminous compound: as the process advances, this becomes decomposed, and putrefaction soon goes so far as to render the body unfit for food. Then the luminosity ceases. While the food is in a fit state for consumption, the beacon exists which directs the consumer to his prey; but as soon as, from natural changes, it becomes unfit for that purpose, the light is extinguished. Here surcly is something more than a merc law of inanimate matter. He who said, "Gather up the frag- 
ments that nothing be lost," has written the same lesson upon creation at large; and the instance in question may be taken as an interesting illustration both of the care of God over his creatures, and of that feature of his providence which will have nothing to be wasted.

The temperature of the atmosphere was observed to decrease as we ascend; that of the ocean, in temperate and tropical climates; observes a rule exactly the reverse; it decreases as we sink into it. The recent interesting researches of Professor Forbes during the survey of the Egean Sea, have developed a very singular fact in connexion with the temperature of the sea. Just as the progressive decrease of temperature in the air as we ascend is marked by zones of vegetation which become more and more northern; so as we descend into the sea, there are zones of temperature marked by the character of the marine animals which exist in them; and in the lower regions these animals consist of species, as strikingly resembling the northern species, as the higher vegetation in a lofty range of mountains resembles that of the northern regions. Even in the fourth region nearly fifty per cent. of species are identical with northern forms. Professor Forbes found a difference of temperature between the highest and lowest zone; 
the latter at the depth of 300 fathoms amounted in summer to from $26^{\circ}$ to $30^{\circ}$; the temperature of this zone was $55^{\circ}$, while that of the upper zone ranged from $76^{\circ}$ to 84 , during eight months in the year. It is highly interesting to find that the inhabitants of the deep are thus carefully accommodated and distributed, far out of sight of man, as is the case with the vegetable and zoological dwellers on the surface of the eartli.

The warmest part of the ocean is, in temperate and tropical regions, at its surface, and it is in its usual and mean condition somewhat warmer than the bed of air immediately resting upon it. This is the result of a very simple law connected with what is termed convection (or carrying) of heat in fluids. The warmer particles of water, expanded by heat, become lighter. than the surrounding particles of colder water, and consequently rise of the surface; while the cold particles sink, until they meet with a stratum of water of similar temperature and density to their own. It is thus that the fluid particles convey or carry heat. In the conduction of heat there is no movement of the particles of a substance, but heat flies from particle to particle. In the case of fluids, heat is actually carried by the particles from one position to another, and is thus very slowly diffused throughout a liquid; 
the coldest particles being at the bottom, and the warmest at or near the surface. There is, however, a remarkable apparent exception to this rule, at a particular degrec of heat, to which allusion will be immediately made. In the ocean, then, in these regions, the more deeply we can penetrate, the colder will the temperature of the water we obtain become. The fact of the coldness of the inferior beds of water was singularly illustrated by Messrs. Kotzebue and Dupetit Thouars. Water was procured by them from the abyss of the ocean, in the tropics, and found to be at the unusually low temperature of $35^{\circ}$, or only three degrees above freezing point! This, too, under the full influence of a tropical sun! This most curious discovery led philosophers to conceive the existence of inferior polar currents of water proceeding from the poles to the equator, just on the principle of the trade-winds.

Kotzebue and Sir James Ross have established the fact, that there is a depth in the ocean at which the water has a constant temperature of about $39^{\circ} 5^{\circ}$. This depth depends on the latitude. At the equator the stratum of invariable. temperature was as low as 7,200 fect, from thence it gradually rises till it comes to the surface in S. lat. $56^{\circ} 26^{\prime}$, where the water has the temperature of $39^{\circ} .5^{\prime}$ at all depths; 
it then gradually descends to S. lat. $70^{\circ}$, where it is 4,500 feet below the surface.

Proceeding northwards the same law still obtains. Sir J. Ross therefore proposes to divide the regions of oceanic temperature into threetwo polar and one equatorial. If we imagine the bed of water of invariable temperature to be represented by a curved line, we should find this line beginning at the depth of 4,500 feet in the southern polar region, rising nearer and nearer the surface until it reaches $\mathrm{S}$. lat. $56^{\circ} 26^{\prime}$, then sinking again to the depth of 7,200 feet at the equator; again rising in the corresponding $\mathrm{N}$. lat., and finally descending again to the depth of 4,500 feet in the northern polar region. This curve is determined by the state of temperature at the surface. Near and at the equator, the surface temperature is constantly at $80^{\circ}$; hence the depth of the line of water at $39^{\circ}$ is greatest here. At S. lat. $56^{\circ} 26^{\prime}$., the temperature of the surface is $39^{\circ}$. Such, also, is the temperature of the surface in the corresponding $\mathbf{N}$. lat. Toward the poles the surface is at the freezing point even in summer, and the line of cunstant temperature is consequently at a depth of 4,500 feet. Hence the water is warmer as we descend at all latitudes beluw $\mathrm{S}$. lat. $56^{\circ} 26^{\prime}$, and above the corresponding $N$. lat.; at these points it is of uniform 
temperature at all depths. At the equator it is colder as we descend until we reach the depth of 7,200 feet, after which the temperature does not alter with the depth. These results, which have been obtained with extreme care, are highly satisfactory, and appear to set at rest the vexed qucstion of ocean temperature.

It .might be thought that, as it was found that the internal temperature of the earth increased on descending into it, the effect of this increase of temperature would be experienced by the deep ocean; but Sir J. Ross is disposed to believe that the internal heat of the earth exercises little or no influence upon the mean temperature of the ocean.

Dr. Williams assigns as one cause of the existence of this stratum of uniform temperature, and which, in the two polar regions, appears as a bed of warm water underlying the cold surface, the effect of pressure upon water. He asserts that he has found, by experiment, that water acquires a considerable increase of temperature under great pressure; an effect apparently due to the extraction of the latent heat of its dissolved gases.

The temperature of the ocean, it is thus seen, is greatly influenced by its depth. Under ordinary circumstances, it appears that the water close by the shore. is colder than that far 
from land. Sailors might thus frequently be made aware of the existence of shoals or sandbanks without the aid of the lead, were it not that a number of circumstances of local origin interfere with the temperature of the water near land, and thus render what might otherwise prove a valuable sign, far too uncertain to be relied upon. It is supposed that the influence of the seasons is not felt by the ocean below the depth of 300 feet.

We must now advert to a remarkable fact in the physical history of the ocean, and of water generally. The particles of cold water, being the heaviest, descend, while the lighter warm particles remain on the surface. If we suppose this process to continue, the ultimate result would inevitably be that our lakes, and the shallower parts of our seas, would soon be covered with a dense solid layer of ice, which would increase until they became almost choked up with it. Such an altered condition of the waters would rapidly affect the climate; our summers would become cold and cheerless, our winters long and severe, and our climate would rapidly deteriorate, until it became of almost Aretic rigour. This result is obviated by a very singular law observed in water as it is gradually reduced in temperature. In cooling down to within eight degrees of freezing point, or $32^{\circ}$ 
of Fahrenheit's thermometer, it becomes gradually heavier and more heavy; but when it has reached this point $\left(40^{\circ} \mathrm{F}\right.$.), further cooling reverses the state of things, and the particles actually become specifically lighter! The descent of water cooled below $40^{\circ}$ is thus effectually arrested in the simplest manner. It is difficult to explain this curious phenomenon. It is supposed that, since the particles of ice, in consequence of their angular form, are lighter, in consequence of their occupying a larger space than the particles which form fluid water, the expansion of water below $40^{\circ}$ may be due to its particles being in a process of arrangement preparatory to their becoming visible erystalline, as they do below $32^{\circ}$. "Ground ice," as it is called, seldom is formed in still water, but not unfrequently in shallow running water. When ice is formed it is so light as to float on the surface of the water, and, in so doing, covers and protects water actually warmer than itself below, the propagation of cold from above downwards being extremely slow in fluids, and being, in the case of water, rendered additionally difficult by the refusal of the cooled particles to sink when their temperature is reduced to the point in question.

A curious fact is related by Krusensteirn, with reference to the temperature of a part of 
the sea which was sounded in his travels. It was found, in a series of experiments made in some places in the Gulf Stream, on letting down the lead to the depth of 600 feet, and raising it again, it was so hot* as not to allow being handled. The experiments were many times repeated with the same result, and the inference could not be denied, that below the cool surface of the blue waters was a bed of water not far off boiling point!

In consequence of the bad radiating properties of water, the temperature of the ocean is much less subject to variations than that of the air, and the variations which oceur are small in amount. The result of this is, that the air overlying the ocean is much more uniform in regard of temperature than that over the land. In parallels where the range of the thermometer suspended in air over land, amounts to twenty or thirty degrees, or even more, a thermometer suspended over the ocean's surface does not range more than five or six degrees. Thus the effect of the presence of the sea upon a climate is to equalize it; and this is remarkably the case in the climatology of small islands. In the Channel Islands, for example, in Guernsey

* This phenomenon was probably due to the existence either of some submarine voleano, or of some spring rising from the heated interior of the earth. 
and Jersey, this influence is most remarkable: frosts are of rare occurrence there, and of the shortest duration, and the extreme of heat is seldom experienced there. In the quarter ending December 31, 1849, the mean temperature of Guernsey was $49^{\circ} 2^{\prime}$, while that of Greenwich was $44^{\circ} 8^{\prime}$ a difference of about tive degrees. Thus summer and winter are not separated by the chasm which divides them in the climate of great continents, and the excessive degrees of temperature are almost unknown on either side of the thermometric scale. The influence of such a climate upon the floriculture and horticulture of these islands can scarcely be belicved. The most delicate and beautiful plants which in England must be carefully kept, during the winter, in our conservatories, and cherished with artificial warmth, are there exposed without injury all through that part of the year; and the markets in summer exhibit an appearance of exuberant fertility of soil scarcely to be expected even in districts much farther south than is their position. In all probability the equalizing influence of the ocean is felt universally, through every region of our globe, to a greater or less extent. The waters heated in warmer regions are directed by the various currents of the ocean to others, where the solar influence is far more 
feeble, and roll down the shores of countries lying in latitudes far remote. There can be little question that, were the present relation altered, that alteration would speedily be attended with a modification of climate, and, as a result, with important alterations in the number and varieties of the animals and plants occupying the surface of the present earth.

The ocean is the great reservoir from whence, raised by the process of evaporation, the earth derives its supply of water, and to which all springs and rivers carry back their contents. A system of circulation is thus established on the grandest scale. Water rises as vapour from the ocean, assumes the form of clouds, descends on land in the various conditions of rain, hail, snow, and dew; and becoming then collected in larger currents, sceks the ocean again, to undergo again the same series of changes. A small portion of the saline contents of the sea are thus made available to the necessities of plants on land, by uniting with the ascending vapour, and being precipitated in the descending shower. 


\section{CHAPTER II.}

CHEMISTRY OF THE OCEAN.

The waters of the ocean have been repeatedly analysed; and, though some differences of result have arisen, they have been principally of a trifling kind, and unimportant amount. Sea-water consists essentially of pure water, with the addition of various saline and earthy ingredients. The analysis of seawater presented none of the difficulties attending that of the atmosphere; for it was comparatively easy, on evaporating down a sufficient quantity, to obtain its constituents in so concentrated a form as to arrive at their number and nature, and to estimate their proportion. The result of analysis has been to show that upwards of three per cent. of saline matter exists in sea-water; and that common salt, or chloride of sodium, as it is chemically entitled, constitutes a large proportion of the whole saline matter present. As to its specific gravity, if pure water is represented as 1000 , sea-water is from 1026 to 1030 . The subjoined table pre- 
sents us with a tabular view of the most recent analysis of sea-water :-

\section{0 grains eontained -}

Water . . . . . .964745

Chloride of sodium . . . 27.059

Chloride of potassium . . . . $\quad .766$

Chloride of magnesium . . . 3666

Bromide of magnesium . . . $\quad 029$

Sulphate of magnesia . . . . 2296

Sulphate of lime . . . . . $1 * 106$

Carbonate of lime . . . . . $\quad .033$

Traees of iodine, ammoniaeal

salt, and organic matter.

$1000 \cdot 000^{*}$

From this it will be evident that sea-water is a fluid containing a much larger number of chemical constituents than have yet been discovered in the atmosphere. In all probability it is chiefly owing to the difficulty of the analysis that we are not yet able to detect many ingredients in the air, which may be present in minute quantities. While, however, the analysis of sea-water, carcfully conducted, will generally exhibit the presence of these ingredients, their proportion is subject to variation under different circumstances: the Mediterranean sea-water is considerably more

* In a reeent analysis by MIN. Malaguti, Durocher, and Sarzeaud, the presence of copper, lead, and silver has been deteeted in sea-water, and to a larger extent silver was found in the aslies of sea-weeds. 
highly charged with saline matter than the waters of the ocean outside the Straits; an effect which appears to be due to the immense evaporation taking place from its surface, which carries off an enormous volume of water in the form of vapour, to supply the place of which a strong current sets in from the main ocean, through the Straits of Gibraltar. In other inland seas, on the contrary, the amount of saline matter is diminished; and this is the general rule. The explanation of this appears to be, that such seas generally receive a very large addition of fresh-water from the coast around them, and from one or more great rivers which may flow into them. The Baltic Sea is thus remarkably contrasted with the Mediterranean; for while the latter has a high density, probably about 1029 or 1030 -pure water being 1000 - the waters of the former have a density very little higher than 1015. Near the mouths of great rivers, as is naturally to be expected, the quantity, of the saline contents of sea-water is much lessened; the fact being, that the waters of the ocean are in reality diluted by the intermixture of a large body of freshwater. It is said that the diluting influence of the great American river, Amazon, is distinctly perceptible for a distance of upwards of 300 miles from its mouth.

Professor Forchhammer has made some highly 
important investigations into the comparative analysis of sea-trater, and his results are interesting. The following extracts are from his report on this subject:- "In the ocean between Europe and America, the greatest quantity of saline matter is found in the tropical region, far from any land: in such places, 1000 parts of sea-water contain 36.5 parts of salts. This quantity diminishes on approaching the coast, on account of the masses of freshwater which the rivers throw into the sea: it diminishes, likewise, in the westernmost part of the Gulf Stream, where I only found it to be 35.9 in 1000 parts of the water. By the evaporation of the water of this warm eurrent, its quantity of saline matter increases towards the east, and reaches, in N. lat. $39^{\circ} 39^{\prime}$ and W. long. $55^{\circ} 16^{\prime}$, its former height of 36.5 . From thence it decreases slowly towards the north-east, and sea-water, at a distance of sixty to eighty miles from the western shores of England, contains only 35.7 parts of solid substanees; and the same quantity of salt is found all over the north-eastern part of the Atlantic, as far to the north as Iceland; always at such a distance from land that the influence of fresh-water from the land is aroided. From numerous observations made on the shores of Iceland and the Faröe islands, it is evident that the water of the Gulf Stream 
spreads over this part of the Atlantic Ocean; and thus we see that water of tropical currents will keep its character even in high northern latitudes.

"The water of different seas is much more uniform in its composition than is generally believed. In that respect my analyses agree with the newer analyses of atmospheric air, in showing that the differences are very slight indeed. Sea-water, it is true, may contain more or less salt; from a very small quantity, as in the interior part of the Baltic, to an amount of $37 \cdot 1$ parts in 1000 parts, which I found in water from Malta, and which is the greatest quantity I ever observed; but the relative proportion of its constituent saline parts changes very little. In the longitude of Greenland, and more than 100 miles to the south of the southernmost point of that large tract of land, sea-water contains only 35.0 in 1000 parts. In going from this point towards the north-west it decreases constantly; and in Davis' Straits, at a distance of about forty miles from the land, it only contains 32.5 parts of salt in 1000 parts of sea-water. This character seems to remain in the current which runs parallel to the shores of iNorth America; and at $\mathrm{N}$. lat. $43 \frac{1}{2}^{\circ}$ and W. long. $46 \frac{1}{3}^{\circ}$ the seawater contained only 33.8 parts of salt. Thus tropical and polar currents seem not only to be 
different in respect to their temperature, but also in the quantity of salt which they contain; from which it appears, that while the quantity of water carried away from the tropical sea, by evaporation, is greater than that which rain and the rivers give back to that sea, the reverse takes place in the polar seas, where evaporation is very small, and the condensation of vapour very great. The cireulation must on that account be such, that a part of the vapour which rises in tropical zones will be condensed in polar regions, and in the form of polar currents flow back again to warmer climates. Although my analyses are only made in water from the ocean between Europe and America, yet little doubt can be entertained that that part of the ocean which separates America from Asia is constituted in a similar manner; and that currents flowing from the poles are the rule, and eurrents flowing towards the poles are the exception."

The chief cause of these variations in the total quantities of saline matter present in the water of different seas, are-1st, the influence of evaporation, which concentrates the fluid by removing a portion of its watery particles; and 2 nd, the influx of fresh-water from the land, or from the atmosphere. In consequence of its saline contents, sea-water is more dense and heavy than fresh-water. This is occasionally 
turned to some advantage by navigators; for it is found that, in calm weather, the fresh-water overlies the salt, just as oil does in respect of water: by drawing water, therefore, from the surface, fresh-water may be obtained; whereas, if the hose of the pump penetrates some feet down, it may encounter a stratum of saltwater. The saline matter of the lower stratum mixes with the fresh-water by a force analagous to that with which gases mix with each otherthe force of diffusion. In the narrative of the voyages of the Adventure and Beagle, Captain Fitzroy remarks, in their expedition up the river Santa Cruz, in Patagonia, at.a particular point:- "The water was fresh over the surface, and sometimes it is quite fresh eren into the estuary; but in filling casks, or dipping anything into the stream for fresh-water, it is advisable not to dip deep, or to let the hose, if one is used, go many inches below the surface, since it often happens that the upper water is quite fresh, while that underneath is salt. This occurs more or less in all rivers which empty themselves into the sea: the fresh-water, specifically lighter, is always uppermost."*

* "Voyages of the Adventure and Beagle," vol. ii. p. 340. -In the Bakerian Lecture delivered by Prof. Graham before the Royal Society, in December, 1849, the diffusion of saline fluids into each other was admirably discussed. The unequal rate in which different salts diffuse upwards into the 
One remarkable feature of these investigations into the chemistry of the sea is too important to be passed by ; namely, the uniformity of chemical composition of sea-water, notwithstanding the circumstance of its varying saline quantities. This apparent paradox may be explained in the following manner: if a solution containing certain quantities of salts, six in number, the relative proportion of each of which is known, be dropped into, 1st, a pint of water; 2nd, a quart; and 3rd, a gallon, -and these waters are analyzed, we shall have the following results:-In the first we should find a considerable quantity of "saline matter, in the next less, and in the third still less; but the proportion of the salts in this saline matter would not vary in the lrast, just for the same reason that a drop of this saline solution has exactly the same chemical comprosition as the whole quantity. So in the great ocean: in parts it has more, in parts less, saline contents; but their number and proportion are pretty generally the same in all parts. If the saline matter were of a blue colour, we should find the sea deep blue at the tropics, paler toward the poles, and along all our crasts a pale blue hue would extend, reaching decper

fresh-water above, explains the discordant results foltainerl by different chemists in examining the water of of the: Dearl Sera.-Vide Athencerm, Jan. 12, 1850. 
into the sea near the mouth of every large river than elsewhere.

It is extremely difficult to account for this fact, in the present state of our knowledge on ocen-chemistry. Why are some soluble eonstituents which ought to find their way into the sca, we should say, at least as abundantly as some of the dissolved matters, missed when we come to look for them in analysis? Upon what principle can we account for the enormous presence of the metal sodium in combination, and the comparative absence of potassium, the compounds of which are equally soluble, or nearly so, with those of the other elements, and much more so than the compounds of magnesium and lime? Yet, in 1000 parts of sea-water, the proportion of the ehloride of magnesium to that of potassium is as 5 to 1 : even sulphate of lime, a compound comparatively insoluble, is present in equal proportions to chloride of potassium.

Some suggestions of a solution to the problem of the pretty constant composition of seawater may be offered. It is to be remembered that, by the laws of chemical combination, a heterogeneons mixture of all kinds of ingredients, if left to itself, would ultimately assume a certain definite composition, according to the nature of its contents, and their aflinities for one another. Were we, for example, to pour certuin qumtities of sulphuric, hydrochloric, 
nitric, and acetic acids into a vessel of water, and to add to the fluid various substances, such as iron, the alkalies, lime, magnesia, \&c., a number of chemical reactions would ensuc, and continue for a certain time; but ultimately the fluid would possess a certain definite composition, and several substances would lie at the bottom of the vessel in an insoluble form. What takes place in this vessel may be presumed in some degree to illustrate what occurs in the ocean at large; it is impossible for several chemical compounds, each of which has an affinity for the other, and a tendency to decompose and unite with it, to exist in it at one time. The result of the addition of such matters to it would be, that they would react upon each other, produce some soluble and some insoluble compounds, and the fluid part would be in that neutral condition in which we find sea-water; namely, as a fluid holding dissolved several compounds which have no disposition for mutual union. In the language of science, the water of the sea is a fluid holding "compatible" substances in solution.

A small part only of the difficulty is thus removable. It is plain, it may be urged, that sea-water could not consist of a compound medley of substances, since the laws of chemical affinity would produce the separation of many in an insoluble form, and the combination 
of the rest in a group, the parts of which are in chemical harmony with each other; but a fluid holding compatible substances in solution might have a very different constitution to that of the sea. This is true. Let us, however, recall what was remarked on a previous page, upon the gross composition of the earth, from which the ocean has derived its saline contents. It was there stated that the earth en masse is chiefly composed of seven elements-silicium, calcium, aluminum, magnesium, potassium, and sodium, in union with oxygen. Hence it is evident that the waters which wash the shores, and receive the drainage of a world thus framed, are not exposed, on the large scale, to that mixture of heterogeneous ingredients, which, upon a circumscribed view of the subject, we might be led to anticipate. With the earth's gross composition in view, the number and nature of the elements present in the waterworld might almost have been anticipated. Of the seven elements, or the six oxides, silica, as we are informed by chemistry, is not sensibly soluble, and alumina, occurring in nature chiefly in the form of clay, or locked up in the massive granite as a silicate of alumina, presents little probability of affording a solution. This reduces the list to the four elements which, in combination with chlorine, iodine, bromine, sul- 
phuric and carbonic acids, enter into the composition of sea-water. Of the four elements, thus united, calcium in a state of nature exists as a sulphate and carbonate. Sulphate of lime is soluble in 500 parts of water, and carbonate of lime is sparingly soluble in water containing carbonic acid-is, in fact, never absent from either river or spring water, constituting what is called the "hardness" of such waters. All the salts of soda and potash are highly soluble. Thus, from a review of the main constituents of our globe, it would appear natural to expect that the water which surrounds so large a portion of it, and is the greater reservoir for its water-shed, would contain sodium, potassium, calcium, and magnesium, in combination: and such is actually the case. Why chlorine and sulphuric acid are the principal bodies united to these elements, it is difficult to say. Sulphuric acid, it is true, in the form of sulphate of lime or gypsum, forms a large constituent of the earth's crust; but chlorine is chiefly known in nature as in union with the sodium of sea-water. 'The cause of its preponderance is, therefore, buried in obscurity.

When we come to ask, again, the cause of the constancy of the relative proportions of these ingredients in sea-water, a fresh per- 
plexity arises, for the solution to which reference must be made to the concluding chapter of this work.

There are probably few subjects upon which such erroneous opinions have been held, as upon the origin of the saline matter in the ocean. For a considerable time it was said, that the saline matter was derived from the solution, by the waters of the sea, of certain conjectural masses of rock-salt, which were supposed to exist at its bottom; and that the ocean became salt, as a dish of tea becomes sweet, by simply dissolving the soluble matters conveniently arranged at its bottum. Other views equally erroneous have been entertained. The presence of the saline matter is now accounted for, either on the supposition that, when God created our world, it pleased Him to create the ocean of its present composition, or upon the view already offered; namely, that the saline matter owes its origin in a manner equally exhibiting the Divine wisdom and power as upon the former supposition, to the ocean being the receptacle for the drainage and washing-out of the solid parts of the "earth.

Dr. Fownes observes: "I'he rain which falls upon the earth is due to condensation of aqueous vapour previously existing in the atmosphere, and which is supplied in great part by 
evaporation from the surface of the sea; the area of the latter, compared with that of the land, being very great,-necessarily so, perhaps, to furnish the requisite extent of evaporating surface. This water is, as is well known, perfectly fresh and pure, the saline constituents of the ocean having no sensible degree of rolatility at the temperature at which the vapour has been raised. No sooner, however, does it reach the earth, than it becomes contaminated with soluble substances which it meets while flowing on the surface of the ground, or percolating beneath. It is thus that the waters of springs and rivers invariably contain a greater or less amount of alkaline and earthy salts, which all eventually find their way into the sea, and there remain, since there is no channel for their return. The saline condition of sea-water is but an exaggeration of that of ordinary lakes and rivers; the materials are the same, and of necessity so; the ocean being, in fact, the great depository of all the soluble substances which, during many ages, have been separated by a process of washing from the land. The case of the sea is but a magnified representation of what occurs in every lake into which rivers flow, but from which there is no outlet except by evaporation. Such a lake is invariably a salt lake; it is impossible that it can be otherwise; 
and it is curious to observe that this condition disappears when an artificial outlet is provided for the water. It will be remembered that the saltness of the ocean is very far exceeded by that of several inland lakes of the kind described: that of Aral, near the Caspian, and the Dead Sea, in Judæa, are remarkable examples."*

Upon either supposition, we may not doubt that a wise and gracious end was accomplished in the constitution of the ocean being such as it now is. If it was, in the beginning, formed by the creative hand of God a mass of saline water, we are sure it was not so formed in vain; if, on the contrary, as seems natural to suppose, its saline contents are the result of the water drainage of the earth, we are not to regard it in the cold and gloomy aspect in which it is placed by the writer last quoted, as " rather an inevitable result of the present disposition of things, than a special arrangement expressly intended to fulfil certain objects." When God formed the world in the mass, and employed in its mighty fabric the elements to which we have alluded, had He not, who knows the end from the beginning, a gracious intention in so doing? The all-wise Creator suffers nothing to be done by chance; and if the ocean

* Fownes: Actonian Prize Essay, p. 17. 
was to be made salt by the lixiviation of the crust of the earth, ean we suppose that so important a result, one so vitally connected with the existence of all the inhabitants of the world of waters, would be permitted to the operation of accident? If, instead of employing limestone, it had pleased God to employ baryta in the important office of constructing the great mass of the earth's crust,-or if many other elements beside those enumerated had taken a larger share in this work, - the ocean, receiving the washings of the carth thus formed, would have been unfit for the residence of a single living creature. The saltness of the ocean is, therefore, a wonderful instance of the forethought and wisdom of the world's Creator, linked-as it, upon this view of its origin, inseparably is linked-with the number and nature of the elements employed in the construction of the chief solid matter of the globe. All nature is as one; for its various parts have been bound together by an Almighty hand.

Just as the power of diffusion tends to preserve the uniform composition of the air, so the same or a similar force tends to intermix the saline contents of the ocean with the enormous volumes of fresh water eontinually added to it. Without this, the ocean would in time become divided into an underlying constantly increasing 
stratum of salt-water, and an overlying stratum of fresh-water.

It is not clearly ascertained what are the precise objects in view in the saline constitution of the ocean. The presence of the salts is useful in checking evaporation to too large an extent; in causing sea-water to freeze at a lower temperature than fresh-water, at $28 \frac{1}{2}^{\circ} \mathrm{Fahr}$. instead of $32^{\circ}$, thus rendering it more difficult to solidify its surface than if it contained less saline matter; and is also useful in communicating to sea-water a greater buoyant power than fresh-water. It likewise renders its putrefaction less easy than if it were fresh. As we shall have again to remark, there exists a strict connexion between the functions of the tenants of the deep and this saline matter. If, therefore, we are to regard the presence of certain principles in the air satisfactorily accounted for by the recognition of their usefulness to animals and plants, the same reasoning may be applied to the ocean; and we may with justice regard its saline contents as specially adapted to the functions and purposes of its varied inhabitants.

In addition to the saline matter, a trace of. organic matter is generally obtained in the analyses of sea-water. This organic matter may be due to minute animalcules, or it may consist simply of some products of animal 
decomposition. Sometimes it exists in very large proportions in sea-water. M. de Tessan observed in the sea, near the Cape of Good Hope, a very singular instance of this kind. Innumerable minute spherical bodies filled the water, and thickened it to such a degree as to give rise to a faint crackling sound on its being agitated with the hand. Some of this water, when strained through a cloth, left half its bulk of this organic matter. In all probability this matter consisted chiefly of the bodies of animalcules. It was highly phosphorescent.

A very interesting question upon ocean chemistry is connected with this organic matter, and is now awaiting the decision of investigators into this neglected study. Among the several causes of the phosphorescence of the sea, it might have been mentioned that it appeared occasionally due to the presence of organic particles soon about to become putrid. It is considered by many, and among others by the celebrated microscopical observer, Ehrenberg, that the phosphorescence of the sea is at all times chiefly attributable to the existence of organic matter in this condition.

The following singular account of a large luminous spot in the sea, observed by Captain F. Eardley Wilmot, deserves attention. On his voyage home from the Cape of Good Hope, in 
the spring of this year, he observed one night a remarkable though not very uncommon appearance of the sea. This was a large and very luminous spot, which was clearly defined by a sharp edge. He thus describes the appearance, and also the steps which he took to obtain some of the water, for the purpose of bringing it home to England and submitting it to chemical examination: "The sea was covered with so brilliant a surface of silver light that we could see to read, and the shadows of the ropes were strongly marked. We sailed through it for about four hours! In one place it had an edge, and we sailed out of it for nearly half an hour, when we again entered it as abruptly, and finally left it, where the edge of the illuminated part was strongly defined. The water was taken up in a clean bucket, and put into a carefully-cleaned bottle, about $10^{\circ}$ north latitude." This bottle was submitted to Dr. Faraday for analysis, the result of which is given in the following note from this eminent chemist: "I have examined the water, and it is peculiar in some points. It contained much sulphuretted hydrogen, and also a portion of solid deposit, which was about one-half sulphur and the other half organic matter. There has, no doubt, been considerable change in the contents of the water, and I cannot now recognise organic 
forms; but the presence of the animal matter, the sulphur, and the sulphuretted hydrogen, all agree with the idea, that the water when taken up was rich in animals or animalcules." Nevertheless, in the absence of any evidence to prove the existence of luminous animals in this water, it is just as probable that it contained simple organic matter in the first stages of putrefaction.

Mr. Darwin states that after using his towing net during one night, he allowed it to become partially dry, and having oceasion twelve hours afterwards to employ it again, he found the whole surface sparkle as brightly as when first taken out of the water. It docs not appear probable in this case that the particles could have remained so long alive. On one oceasion, having kept a jelly-fish of the genus Diancea till it was dead, the water in which it was placed became luminous. Professor Ehrenberg, during a stay of five months at Tor, on the Red Sea, was frequently engaged in examining the sea-water, which was found to be very full of small slimy particles without any determinate form, often having the edges jagged, and which emitted light on stirring the water in which they were found. They covered the marine plants, corals, \&c., which consequently appeared luminous; every stroke of the oar caused them 
to sparkle; but he was never able to detect organization in any of these particles, and he could never satisfy himself that any of the microscopic animals which he found with them in the water gave out light. They did not unite and form large slimy masses, but were dispersed about in small flakes. On examining the water, after a violent storm at Heligoland, Ehrenberg found no infusorial animalcules in it; but quantities of morsels of gelatinous matter, often torn and ragged, which emitted light, and small gelatinous globules, with jagged edges occurred, similar to those which he obtained in the Red Sea. During his stay at Heligoland, he often observed as it were chains of luminous matter floating in the sea, which on examination proved to be the masses of luminous medusce, detached and torn by the violence of the sea. Darwin says, " The same torn and irregular particles of gelatinous matter described by Ehrenberg, seem in the southern as well as in the northern hemisphere to be the common cause of this phenomenon. The particles were so minute as easily to pass through fine gauze, yet many were distinctly visible by the naked eye. The water when placed in a tumbler and agitated, gave out sparks, but a small portion in a watch-glass scarcely ever was luminous. Observing," he adds, "that the water charged 
with gelatinous particles is in an impure state, and that the luminous appearance in all common cases is produced by the agitation of the fluid in contact with the atmosphere, I am inclined to consider that the phosphorescence is the result of the decomposition of the organic particles, by which process (one is tempted almost to call it a kind of respiration) the ocean becomes purified."

Recent discoveries render it highly probable that this view, which is also held by Professor Ehrenberg, is the correct one, and that while it is certain that many marine creatures possess the faculty of emitting light, yet that this phenomenon, when occurring over a large surface, is due to a sort of natural purification of the water, by exposing these organic matters to the influence of the air. Professor Schönbein, in his Report on Ozone (the remarkable principle frequently before mentioned), adopts a similar view, and explains the chemistry of the process in a highly-ingenious manner. The most ready method of procuring ozone is to put a piece of moist phosphorus into a bottle full of air. A peculiar chemical decomposition now takes place. The oxygen of the air unites with the water present, and oxidating it, produces ozone. The ozone then reacts upon the phosphorus, and in oxidating it produces the peculiar 
light called phosphorescence. It is remarkable that when phosphorus is put into perfectly dry air, free from all moisture, it shines no longer, or but very feebly, and ozone is not produced. Thus it appears that phosphorus possesses the peculiar property of causing the union of water and oxygen so as to form ozone, which then acts upon it. Bearing this singular action of phosphorus in mind, Professor Schönbein says,- "It is well known that the phosphorescence of the sea is intimately connected with the motion of its waters, or, to speak more properly, that the phenomenon is dependent upon the particles of these waters being brought into immediate contact with the atmosphere. When a ship moves about, or the wind happens to agitate the sea, the surface of the brine is continually renewed, and consequently new particles of organic matter are every moment brought into contact with the surrounding air." Just as the phosphorus has the property of producing ozone, which then oxidates it, and in so doing causes the emission of light, so it is supposed that this organic matter causes the oxygen of the air to unite with water to produce ozone, which when produced, oxidates and destroys it. Hence we are to consider the light given out by the waters of the ocean as the effect of a process of oxidation taking place 
on a most extensive seale, which process is carried on less by the free oxygen of the atmosphere than by that of the ozone produeed by this peculiar property of the organic particles in the sea-water.* The source of the organic matter in the waters of the ocean lies in the decomposition of innumerable marine animals daily dying in its depths, and also in the organie matters brought down and swept into the ocean by rivers.

It has been lately found by Professor Forchhammer, that in fresh-water also there is generally a considerable amount of organic matter. It is greatest in summer, and almost disappears as soon as the water freezes. Its quantity is diminished by rain, and also when the water has to run a long way in open channels. Whether the results of an examination into the organic constituents of sea-water will furnish a similar series of facts, cannot at present be stated.

In addition to the ingredients hitherto recognised as producing a portion of the saline contents of sea-water, another has been reeently discovered by Dr. Wilson. This is the remarkable element Fluorine. By some ingenious experiments upon the crust of the steam-boilers

* It is supposed by the discoverer of ozone, that the shining of rotten wood in the dark is due to its possessing the same power with regard to atmospheric oxygen as phosphorus. 
of steamers, he obtained conclusive evidence of the presence of this element, in the production of hydrofluoric acid vapour, which has the property of corroding glass almost instantly. By properly treating the crust thus obtained, he was able to etch several pictures on glass, which were exhibited at the scientific meeting before which his experiments were brought. In all probability, as fluorine has been found both in the waters of the German Ocean, of the Firth of Forth, in the teeth of the walrus, and in the ashes of marine plants, fluorine in minute portions is one of the regular constituents of sea-water. Professor Forchhammer states that he has examined many shells and marine products from various localities, and they all gave evidence of the presence of the same body, the quantity being always greater in sea than in land animals.

The shields of many infusorial animalcules found in sea-water are largely composed of silica; yet silica is not found as one of the mineral ingredients of sea-water. In all probability they are able to obtain it even when it exists merely in a state of mixture in water. Dr. Smith discovered silicious-coated animalcules in the water of the Thames only in those parts of it which receive the drainage of the metropolis, and he ingeniously conceives the silex to be derived from the decomposition of 
wheat, \&c., and to be conveyed into the river in the exuviæ of our sewers.

Recurring to the important occasional ingredients noticed as being present from time to time in the air, and considering the analysis given at the commencement of this chapter as the normal or standard representation of the chemical constitution of the sea, it may be asked, Are not "occasional ingredients" present likewise at times in the waters of the ocean? Darwin says he saw a considerable tract of the ocean on the coast of Mexico covered with a thin iridescent coat of oil. This is supposed to have arisen from the putrefaction of a whale. The sea, as has been before remarked, near the Cape de Verd islands, is not unfrequently seen covered with a film of rock oil. In the waters which bathe the coasts of volcanic regions, evidence exists to show that occasional ingredients, fatal to animal life, are added from time to time to the sea. Thus we are informed that at the eastern extremity of Java there is a lake containing sulphuric acid, a quarter of a mile long, from which a river of acid water issues, which supports no living ereature, nor can fish live in the sea near its confluence. It is one of the frequent phenomena of earthquakes, that the sea-water of the regions where they occur is covered with shoals of fish poisoned by the addition of some deleterious ingredients to 
the water. After a volcanic eruption in Iceland, the fish all deserted the sea coast, thus evidently showing that something had been added to the water unfavourable to their existence. It was one of the plagues visited upon the obduracy of the Egyptian monarch, that the fish that were in the river died, the waters having become poisonous to them by the remarkable change mentioned in the Scriptures. Beyond these facts, 'which have only a local bearing, ocean-chemistry is not empowered to speak. It is possible there may be a state of poisonous diffusion in the waters analogous to our malaria, or even to our epidemics; * but we can scarcely be said to be in possession of a single fact to justify this conclusion. Doubtless, the inhabitants of the deep are not exempt from disease and death; but no evidence exists to favour the supposition that the regions of the deep are desolated as those of the dry land by the infliction of epidemics.

There can be no question that a self-purifying property has been given to the ocean, little though its phenomena are as yet understood. Dr. Smith, in the Researches in the Air and Water of Towns, before quoted, has particu-

* It must not be considered that the brute creation are exempt from epidemics. Every agriculturist can add his testimony to the fact, that epidemic disorders, frequently of a most alarming character, appear among the lower animals. 
larly adverted to the self-purification taking place in fresh-water. The organic matter is precipitated as it is in fresh-water when it comes into contact with clay at the bottom of the sea or with the mud on its shore. It is thus rendered insoluble and innoxious. Another portion of it, which remains in solution, becomes acted on by the various living creatures peopling the waters; and what escapes both these processes is no doubt decomposed in the manner already alluded to by the influence of the air and ozone. 'In consequence of the continued deposit which is taking place over a great part of the ocean bed, the products of these decompositions, when insoluble, are buried at the bottom, and soon so entirely covered over with a layer of detritus, as effectually to protect the overlying waters from their influence. This purifying process is largely assisted by the mechanical action of the waves. The occasional ingredients locally present in the waters of certain coasts, are removed by the ordinary effect of chemical decomposition.

Would that, as the result of the intelligent and careful investigations of chemical philosophers, we were in possession of more and betterdefined information on the chemistry of the ocean than this chapter now contains! 


\section{CHAPTER III.}

MOVEMENTS OF THE WATERS.

THE restlessness of the ocean is a fact so familiar to us as to have passed almost into a proverb. The "troubled sea" is an expression, the frequency of the use of which sufficiently indicates that the movements of the waters are phenomena of the most familiar observation. As the tide continues flowing in, and threatens soon to cover the spot where we stand, it is impossible not to feel strongly impressed with the fact, that ceaseless motion appears to be a very law of the constitution of the magnificent element we behold. Yet, in reality, just as its particles are more dense, and less elastic than those of the air, the movements taking place in the waters are not nearly so extensive or so various as those which incessantly agitate the air around and above us, even when it appears in the most quiescent condition. The fact that every ripple which agitates the surface of the water is visible to 
us, while the most violent commotions of the air are wholly invisible, accounts for the disposition we feel to give to the waters, rather than to the air, the character of restlessness.

The phenomena of the ocean present, in a number of points, a striking contrast to those of the air. One of the grand causes of atmospheric movement was found to be increased and unequal temperature: on the contrary, one of the important causes of movement in the particles of the ocean, though far from the most important, is a diminished temperature. Heat applied to the surface of the

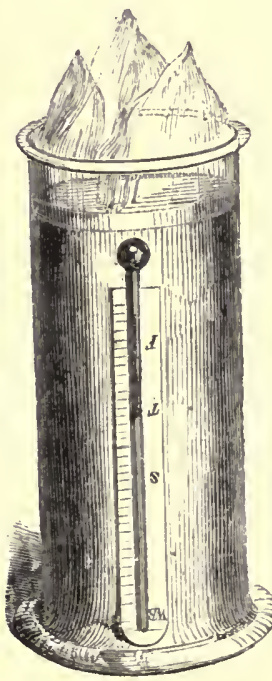
ocean can produce little or no movement in its particles; being expanded by heat, and thus rendered lighter, they of course cannot sink, but remain stationary, or nearly so, at the surface. A very simple experiment will prove this: if water is poured into a tall vessel nearly to its brim, and a very sensitive thermometer be inserted in it, as shown in the cut, so as that the bulb should be just below the surface, and then a 
quantity of pure spirits of wine is poured upon the water, and lighted, it will burn for some time, and of course communicate heat to the surface of the water; yet the thermometer, separated only by a thin layer of water from the burning spirit, will not indicate any, or only the smallest possible rise of temperature. This is because fluids are bad conductors of heat. If the flame were applied to the bottom of the water, instead of its surface, the result would now be different, and the liquid would boil in consequence of what has been before called the convection, or carrying upwards of heat, by the light and expanded particles, as they rise to the surface of the fluid. Let us perform the converse of this experiment, and place, instead of a flaming layer of spirit, a flat piece of ice upon the surface of the water. The effect is immediately perceptible by the falling of the thermometer; the particles of water being cooled become heavier, and sink rapidly downwards. Hence it is evident that while

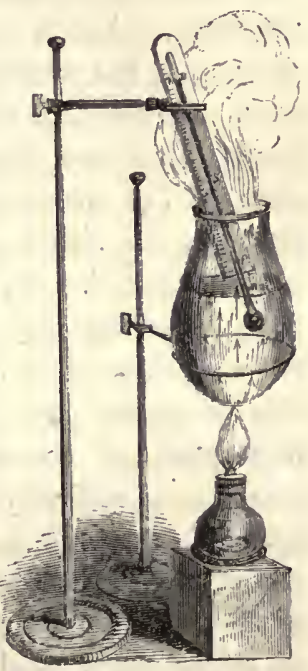


heat, applied to the surface, produces little or no movement in the particles of water, the application of cold, on the contrary, is a constant cause of motion. In the air, heat causes the particles to ascend; in the water, cold causes the particles to descend. Direct observations are still required on this subject, but it appears probable that this class of movements takes place most actively in regions of moderate temperature. Near the equator, during the day the upper stratum of water becomes greatly heated by the sun's rays, but very little disturbance of its particles is thus produced. Again, in the colder regions about the poles, the surface of the water is covered with a dense and solid stratum of ice, or the water when not frozen is scarcely ever higher than $40^{\circ}$, at which point its particles lose their tendency to sink; and here movement is of course arrested. In temperate regions, therefore, while the nights are very cold, although not so cold as to reduce the temperature to $40^{\circ}$, this movement goes on most actively. The surface particles constantly losing heat, and so becoming specifically heavier than the particles beneath, sink; while their place is supplied with warmer particles from below. Thus there is a constant ascent of heated particles, and descent of colder ones, producing, although it is not 
perceptible to our eyes, a phenomenon analogous in its character, though developed by a precisely opposite state of temperature, to the first movement of air on land. By placing several lumps of ice in a tumbler partly filled with water, these movements can be very distinctly perceived; the cold particles in descending becoming partly visible, in consequence of the effect of their greater density upon the refraction of light; but, in consequence of a peculiar law in the constitution of water before noticed, at the $40 \mathrm{th}$ degree on Fahrenheit's thermometer, further movement of its particles from above downwards is arrested. The attention of this singular and beautiful provision has been previously considered. On the whole, however, the actual extent and amount of movement arising from this cause must be slight, although it is doubtless important as a means of preserving uniformity of composition, with regard to the saline contents and the solutions of the gases throughout the whole mass of water.

The movements with which we have thus been occupying ourselves are removed from ocular observation; those which are next to come under our notice, and which are among the most sublime phenomena of the ocean, appeal both to the ear and to the eye, as we behold them agitating mass after mass of water, 
until they dash at length, with a hollow sound, in foaming breakers at our feet. Far as the eye can reach across the surface even of this comparatively tranquil ocean, it beholds nothing but line after line of heaving waves; norv and then a taller and broader billow than the rest marking its pre-eminence by a white crest curling on its summit. It may appear that little interesting to the student or to the philosopher is to be found in the phenomena of waves, beyond their beauty, or their sublimity, or their force. To look upon this widely agitated surface, it would seem a vain attempt to discover anything like harmony or order in phenomena so apparently confused and irregular as those of waves. Yet there is much philosophy, and that of a very abstruse order, concerned in the explanation of their movements; and, incredible though it would seem, there is a real harmony and order of a very beautiful kind, observable in these seemingly disordered and commingled masses of water. Some of these waves are round and long, others are high and sharp; some advance with a great, others with a less velocity; and all present a certain general form familiar to the mind as the form of a sea in agitation, which at once distinguishes it from all other phenomena. How striking the thought, not one of these 
apparently free and fetterless billows, which have supplied poets with the most beautiful similes of liberty and unrestrained action, can move but in obedience to certain laws which control and direct them. To us nothing in nature appears so unshackled; in. reality not a wave heaves but is under the influence of laws which prescribe its movement, velocity, and form. Is it not so in life? The movements of an hour, the fresh-rising events which appear to us the most fortuitous things in the worldthese all have their time, their form, and pressure, and place appointed, in the hands of Him in whom we live, and move, and have our being. The following parts are recognised in a wave:

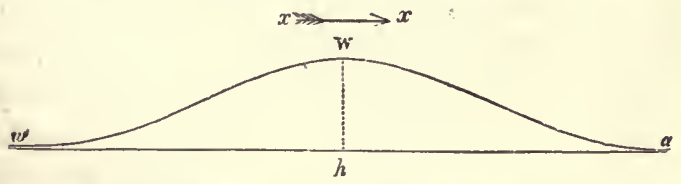

Its highest part is called the crest, $\mathrm{w}$ in the diagram. From $\mathrm{w}$ to $a$, is called the front; from $\mathrm{w}$ to $w$, the back; from $\mathrm{w}$ to $h$, the height; and from $w$ to $a$, the amplitude; $a$ is called the origin, and $w$ the end of the wave. The arrow $x x$ shows the direction of the movement of the wave.

Wave-like movements in the waters of the ocean arise from two causes-the attraction 
of the sun and moon, and the power of the wind. What are called tides are, in reality, vast wave-like movements due to the attraction of these heavenly bodies, but in their effects influeneing vast portions of the watery regions of our planet. Mr. Scott Russell, who has for many years paid much attention to this subject, calls this the Great Primary Wave. In merely beholding the phenomena of the ebb and flow of the tide, it may be difficult to realize the fact that these effects are due to the rise and fall of one mighty wave, which rises in mid-ocean, and in falling casts its wide-extending waters on the shores of half the world. Under the influence of the lunar, or at stated periods, of solar and lunar attraction, a vast mass of the waters of the occan is raised above its general level; obedient to the laws of hydrostatics and of gravity, this great mass of water sinks down again, spreading in every direction around, until at length it rolls its waves upon every shore, which on attaining the highest point to which they ordinarily extend, produce the phenomenon of high tide. When again the waters are "gathered into an heap," to use the beautiful and accurate expression of the word of God, they become withdrawn from our shores; and it is then low water. How sublime the reflection, as we retire from this advancing tide,-these 
onward-moving waters gathered and rose to greet the gentle moon, it may be a thousand miles hence, and separated to bear around the world the evidence of the power and wisdom of Him whose voice the great ocean itself trembles at and obcys! The velocity of this great tidal wave varies from 10 to about 100 miles an hour. It is supposed that fifty or sixty hours are occupied in its reaching our shores, from the time of its dispersion. Its appearance as a great wave cannot, of course, be witnessed by any eye but that of Him who "holds the waters in the hollow of his hand," the general phenomenon of the rise and fall of the tide on our coasts, exhibiting nothing of the wave-like form. This great wave, however, is not the less real that its length is so great, that while one end touches Aberdeen the other reaches to the mouth of the Thames and the coast of Holland. Though its enormous extent and magnitude render it impossible to be recognised as a wave by any single observer, we are able by stationing numerous observers along different parts of the coasts to compare its dimensions, and to trace its progress at different points, and so to represent its phenomena to the eye and mind, in a small scale, as to comprehend its form and nature as clearly as we do those of a mountain range, or extensive country which has been 
mapped on paper by the combination together of trigonometrical processes performed at different places by various observers, and finally brought together and projected on one sheet.

Sometimes the great tidal wave, when met by an opposing current from the waters of some large river, raises a mass of water of great height and force, ealled the Bore. We know little of the power of this remarkable phenomenon on our coasts, although it is observable in some of the rivers, such as the Severn and Trent. But in India, the bore of the Ganges has long had a fearful reputation. Sometimes it appears as a roaring mass of many waters, four or five feet high, often orerwhelming with destruction all the smaller craft exposed to its power. In other rivers it attains a still greater magnitude. But the grandest display of this phenomenon is described as occurring near the mouth of the great river Amazon. At the ebbing of the tide this mighty stream pours down at spring-tides a vast volume of water, with great velocity, into the ocean. The current, at a little distance from land, meets with a powerful opposing oceanic current. The result of this great conflict between opposing waters is to raise a mighty mountain of water, attaining, as it is said, the height of 180 feet, which carries terror and desolation along its 
track. It is even asserted, that such is the violence of this extraordinary phenomenon, which is called by the Indians the Pororoca, that the very islands tremble during its passage.

The second order of waves are produced by the action of the wind. Poets speak of the "inconstant billow;" and vainly, as might be supposed, might we attempt to reduce to form and law, the irregular and agitated movements which, are now throwing the whole sea-surface into tumult. Yet even here order reigns. These waves, which give its restless aspect to the sea, are of the class called oscillatory. Mr. Russell's definition of them is-that they are gregarious, and of two species, progressive and stationary. It appears that a certain degree of adhesion takes place between a moving mass of air and the water over which it sweeps. The result is, that a certain portion of the fluid is lifted above the general level of the surface, and an oscillatory movement is thus set up, which by the continued action of the breeze is increased in magnitude, until waves of considerable dimensions are formed. Waves of this class exhibit a number of interesting phenomena, into which it becomes not our present inquiry to enter. In consequence 'of perpetual changes in the direction of the oversweeping current of air, the direction and 
character of the waves are altered. The configuration of the shores reflects the waves, some in one direction and some in another, and new lines of movement are thus awakened. Frequently, also, there are on the sea three or four series of co-existing waves, each series having a different direction from the other, and the individual waves of each remaining parallel to each otiner. Thus the primary appearance of order is lost by the substitution of another sort of order. The velocity with which wave succeeds to wave varies in a heavy sea; waves have been found running at the rate of upwards of twenty-six nautical miles an hour. Captain Stanley has described an ingenious method by which he marked the speed of waves in a heavy sea, with the ship running before the wind. He caused a spar to be veered astern by the marked lead-line, until the spar was on the erest of one wave, while the ship's stern was on the erest of the preceding one. In order to ascertain the speed of the sea, the time was noted when the crest of the advancing wave passed the spar astern, and also when it reached the ship. By a little calculation it is plain that the speed of the advancing wave could be easily ascertained.

The height of waves in moderate weather is insignificant. Near shore they assume a greater degree of curvature than at a distance from land, 
where they are generally long and low. But when the stormy wind arises in its power, their height and magnitude constitute one of the grandest displays of elemental. motion and power in the world. For measuring the height of waves the following plan has been most frequently pursued:- When the ship is in the trough of the sea, the person observing ascends the rigging, until he can just see the crest of the coming wave on a level with the horizon; and the height of his eye above the ship's water-line will give a very fair measure of the difference of level between the crest and hollow of a sea; deducting half from this for the depression of the hollow below the general level of the surface, we obtain in the remainder the perpendicular height of the wave. It is considered by some that the utmost elevation of waves produced by the action of the wind does not exceed twelve feet. Others state their occasional height at twenty feet. Few persons can realize the magnificent effect of standing on the cliffs of the west coast of Ireland, and observing the great breakers rolling in from the Atlantic, some of which have been ascertained, by the method described, to be fifty feet high, and occasionally they even reached the enormous magnitude of 150 feet.

In addition to the oscillatory gregarious waves, 
$\mathrm{Mr}$ Russell describes another class of waves which he calls Capillary. These minute waves are amongst those phenomena which we most frequently see. When the glassy surface of a lake is broken into countless ripples by the influence of a gentle breeze, the wavelets thus produced are capillary waves. They are mere oscillations of the superficial layer of water, extending to a minute depth, and very short in duration. The velocity of the capillary waves is usually about eight inches in a second of time.

An observer, who will study the surface of a sea during the successive stages of an increasing wind from a calm to a storm, will find in the whole motion of the surface of the fluid appearances which illustrate these various classes of waves, as well as exhibit the laws of their motion. If we suppose this heaving water to be perfectly calm, and ourselves the observers of a storm through all its stages of development, the phenomena of the various forms of waves would appear beautifully pictured before us by the waters at our feet. A gentle movement of the air, not excecding half-a-mile an hour, leaves the glassy surface unbroken; and, mirror-likc, it reflects the surrounding objects with minute accuracy. Let this movement increase in velocity, and a playful zephyr flit across the surface at the rate of about 17 inches a second, or 
a mile an hour, and the glassy smoothness disappears, but on its departure the surface remains polished as before. By and by this fitful movement of the air becomes regular, and the mirror-like appearance . is permanently lost; the surface is covered with countless wavelets, and we have the phenomenon of capillary waves produced. Still, any sheltered spot, where the direct action of the wind is not felt, has the same mirror-like surface at first possessed by the whole, for these waves cease almost instantaneously upon the intermission of the disturbing cause, not being able to travel spontaneously to any considerable distance. The disturbed surface now presents that appearance of blackness which is often justly regarded as the precursor of a storm. This results from the effect of the unevenness of the surface upon the re. flection and refraction of light.

The wind still rises; the increasing clouds gather blackness, and nature is overspread with a certain indefinite appearance of gloom, which is often the sure harbinger of a tempest. The movement of the air is now not less than two miles an hour. Small waves begin to rise uniformly over the whole surface of the water with great regularity. On the ridges of these waves the tiny capillary waves are seen riding, but as the wind increases they disappear, and are then 
found in the hollows between the waves and on their anterior slopes. The true secondary waves are now seen heaving their curling summits far and wide over the agitated surface. Beginning at about an inch of amplitude, and two inches in length, they enlarge their dimensions, unite with other waves, are now and then adorned with a erest of foam, and the surface now presents the regular appearanee of a stormy sea, the waves being of nearly uniform magnitude.

When these waves are now impelled by the wind against the shelving eoast, they break on the margin of the shoal, and they continue to roll along in the shallow water towards the beach, and becoming transformed into waves of the first order, that is, waves of translation, finally break on the shore. What a beautiful scheme of harmony and order is ours, when we find that from the first movement of a ripple to that of the great waves which thunder upon the eoast in elemental power, all these movements of the water are determinate and obedient to certain laws!

From what has been said as to the cause of movements of this kind in water, it will be evident that could we in any way diminish or annihilate the adhesion or friction between the surface and the eurrent of air which impels it into motion, the movements would in a great measure cease. 'This ean be effeeted by means 
of oil. There has been much question raised upon the supposed effects of oil in calming the waves of the sea, and no doubt its power has been much-exaggerated; but it appears certain. that pouring oil on the surface, by neutralizing the force of the wind, has a certain tranquil. lizing influence upon the agitated waters. The same degree of adhesion does not exist between oil and air, as between air and water.

We must now advert to movements in the waters of a different kind to those hitherto spoken of-these are Currents. It may be surprising to learn, that in a body of water apparently so little exposed to causes likely to create a current as is the ocean, currents of determinate direction, and of considerable velocity, actually exist. There are mighty rivers in the ocean as well as on land. Some of these currents are merely due to the mechanical action of the wind; others are ascribable to differences of temperature; thus the melting of a large iceberg, or of an ice-field, would set up, during the whole period occupied in the process, various irregular currents caused by the cold water descending, while its place becomes occupied by the lighter and warmer fluid. In these respects, however, we can trace little analogy between the phenomena. exhibited by the air and those of the ocean. 
The most remarkable and well defined oceanic current is the Equatorial. The Trade-winds were noticed to have a two-fold cause, the high temperature of the tropies, and the revolution of the earth. This great current of water is due to the latter cause, and in part to the impulse of the Trade-winds which blow in the direction which it pursues for a large part of its course; namely, from east to west. This current is very evident, both in the Atlantic and Pacific Oceans, between the parallels of $30^{\circ}$, on each side of the equator, pursuing an average velocity of from nine to ten miles a day. It is connected with another system of currents called the Polar. The direction of the latter is from the poles toward the equator. A flow of water in this direction is induced by two causes. In the equatorial regions; in consequence of the great power of the solar rays, a vast amount of water is raised into the atmosphere by the force of evaporation; to supply this loss, a flow of water sets in from the colder regions lying north and south, and thus a current is produced. In addition, the greater velocity of the earth at the equator tends to draw the water from less swiftly moving regions to that position, and thus also a current is established. That such a current, or system of currents actually exists, cannot be doubted. The evidence of their existence and power is found in the frequency 
with which icebergs are found in the navigation of the Atlantic; sometimes as low even as $45^{\circ}$, and even $40^{\circ}$ of latitude. It appears probable, that the recent strange report of the appearance of the great sea-serpent to the astonished crew of H.M.S. Dxdalus, is explicable, as has been suggested by Professor Owen, upon the ground of a polar current having borne away-a very different creature to the sea-serpent-a species of sea-lion, which had trusted itself to the treacherous dwelling-place of a floating mass of ice, which melting beneath it on arriving in warmer regions, had left the poor animal to breast the waves of the ocean in a vain search for a resting-place. It was also provokingly manifest that such currents existed to the boat-sledge expedition of Captain Parry to the North Pole; for it was found that as they advanced' over the fields of ice to. the northward, they were actually carried at a quicker rate south by the polar currents which bore upon them the ice over which they travelled.

On the polar current reaching the equatorial regions in consequence of its possessing a lesser degree of rotatory motion, owing to its place of origin, than the region into which it is now brought, it appears as a current from east to west, upon the principle before $\mathrm{cx}$ plained under the head of the Trade-winds, 
and uniting with the equatorial currents, flows in one broad current, like a great and mighty river, half way across the globe.

The equatorial current striking against the vast continent of Amcrica, divides into two great currents. Of these, one flows down the east coast of South America, and enters finally the Pacific Ocean, through the Straits of Magellan. The other turns northward, enters the Gulf of Mexico, swceps round the coast in a powerful current, as rapid and well defined as it were a great river, and now known as the Gulf Stream, proceeds on its onward course at the velocity of four or five miles an hour. More northward still, this large current of water traverses the coast of North America, sweeps by Newfoundland, passes eastward, and crosses the world again, cxtending even occasionally to the western coast of the British Isles. After this, it is supposed to bend downwards along the western shore of Africa until its widely circulating waters become once more commingled with those of the great equatorial current from which they originally procecded.

This remarkable portion of the great circle of oceanic currents receiving a large increase of temperature in swecping along the shores of tropical America, and particularly in the Mexican Gulf, is distinguished, by this increase of temper- 
ature, from the waters of the cold ocean around. The entrance into it becomes sensible even to the thermometer; sometimes its temperature is $86^{\circ}$, the waters around being $60^{\circ}$. Its waters are also remarkable for their beautiful indigoblue colour, separating it from the green waters of the Atlantic for hundreds of miles, and by the fogs which in its course near Newfoundland are produced from the condensation of the warm and moist air overhanging them. It is also singular that it is chiefly in the warm waters of this great current that the Gulf-weed is found in long trails; it is a species of fucus, and is known under the name of Sargassum Vulgare.

In the wide domains of the water-world, other important general currents and countless local currents exist, which have their importance and their cause in the places where they appear.

It appears not unlikely that deeply concealed from the pereeption and investigations of man, a number or even a system of submarine currents exist. We are not to suppose all movement is on the surface. From the singular result obtained by Messrs. Kotzebue and Dupetit Thouars, adverted to in a previous page, it appears not improbable that some system of circulation may be in operation in the lower regions of the ncean. It is even stated that in some parts of the Caribbean Sea, where the 
upper branch of the equatorial eurrent runs strongly, a boat may be anchored without the anchor touching the ground, and kept stationary while the waters on which it floats are sweeping rapidly along. This is effected by lowering an anchor or some similar heavy body down to some depth; it there appears to be impelled or dragged by a current exactly opposite to that on the surface, with sufficient force to neutral. ize the drifting power of the upper current. Although the particles of water move much less freely over one another than those of air, it is quite conceivable that extensive submarine currents pass in various directions in the abysses of the ocean, as the lower currents of air over one another and over the surface of the land.

With all these movements of the waters, with the tide, the wave, the ripple, and the current, the chemistry of the ocean is connected in a simple but important manner. It is to be regretted that the subject has, hitherto received so little attention from chemists, and that so much is consequently left to mere conjecture. In proportion as the chemistry of the ocean receives that study by philosophers which has been bestowed upon the phenomena of the earth and air, will it assuredly be found prolific in facts of value and interest in the history of science. The chemistry of the tide, 
as distinguishable from that of the wave and ripple, must first occupy our consideration. Let us ascend the hillock hard by, and thence take a chemical view of the interesting phenomena of the sea-shore.

In considering the tidal chemistries as distinguished from those of the wave, we have chiefly to inquire into the probable effects of a periodic flux and reflux of sea-water upon the objects exposed to its influence. This phenomenon exerts an influence upon the inorganic constituents of the shore, and also upon the various inhabitants of the sea, vegetable and animal, lying within the line of low-water, or ebb of the tide. On almost all sea-coasts, and particularly on such a one as that we are contemplating, where a river brings down constant supplies of material from a rich alluvial soil inland, there exists a certain amount of organic vegetable and animal matters, which, as is common with all such matters, is extremely prone to decomposition, and is here placed in circumstances peculiarly favourable to it. The ebb of the tide exposes such matters to the full influence of the air, leaving them sufficiently moist to forward the changes which immediately commence in organic matter so exposed. A process of putrefactive decomposition is set up, the gaseous elements of the air unite with the solid 
particles of such matters, converting them into water, ammonia, and carbonic acid, and in contact with the saline matter of the sea-water, combinations are formed with it, which await only the return of the waters to be washed away. Upon yonder sands, and particularly near the debouchment of the river, lie various slimy patches, which, if analysed, would be found to consist of the remains of decaying fish and marine creatures, and of decomposing vegetable matter, united with the detritus of the distant riverbanks, rocks, and mountains. Exposed for some hours during the day, not only to direct contact with the air, but also to the heat of the sun, these organic particles bccome rapidly altered, and frequently give token of the activity of chemical decompositions taking place in them by a sensible odour of sulphuretted hydrogen gas. Probably ozone is active in these phenomena.

In addition to the exposure of organic particles to putrefactive decay by the departing waters to the atmospheric influence, the exposure of inorganic substances, comminuted fragments of rocks, mud, and sedimentary matters of all kinds, to the same influence should be considered. Alterations of their composition not complete before, are now completed under the combined and alternate action of 
water and air, and a definite fixedness of composition is attained by the compounds thus situated, preparatory to their removal and submergence beneath the waters of the great deep.

In our own mild climate these decompositions are so slight, though constant, as to be without any perceptible effect upon the air of their vicinity, and it is well known that the air near the sea-coast is generally highly pure and salubrious. But in tropical countries the case is widely different. The full influence of the tropic's sun favours all these decompositions to a fearful extent, and the most subtile and deadly poisons are produced upon the sea-coast.

It was until recently considered that the fearful mortality on the coast of Western Africa, was due to the development. of sulphuretted hydrogen gas as a result of the mutual reaction of vegetable matter and the sulphates in seawater. But Dr. McWilliam, in the Medical History of the Niger Expedition, has shown that it is erroneous to believe the sea on the African coast to be impregnated with this gas. A large number of experiments failed to indicate the slightest trace of this gas in the seawater. It was most probably produced in the bottles submitted to Professor Daniell, who first proposed this theory, by a decomposition subse- quent to the time of the collection of the water. 
Sulphuretted hydrogen is, however, one of the products of decomposition on the sea-shore. In the neighbourhood of Copenhagen, the disengagement of sulphuretted hydrogen gas is so large that the silver at country places near the shore is deeply blackened by it. But its production appears to succeed to a sort of fermenting process, produced on the shore by the heat, moisture, and presence of organic matters in the mud. Where in tropical countries the forests come down to the beach, which is covered with thickets of mangroves, where the small tides are sufficient alternately to cover and uncover the roots and parts of the trunks of the trees-there the mud, the dead leaves, and animal matters putrefy, and give rise to fearful poisons; and also assist in the development of sulphuretted hydrogen gas.

Recent investigations by Professor Forchhammer teach that important consequences follow upon the putrefaction even of a mass of sea-weed on the shore. When this takes place upon a bed of clay containing iron, a series of chemical decompositions is commened, which results in the formation of Iron Pyrites, which penetrates the clay. When this is again exposed to the weather it oxidizes, and Sulphate of Iron is then formed, which reacts upon the materials around it, and forms Sulphate of 
Alumina. The clay thus acted upon may, at some subsequent period, become a source for obtaining alum; and out of clays so formed, alum is now obtained in large quantities on the continent.

The ebbing of the tide produces also important results to the animated and inanimate dwellers on the sea-coast. Although this subject lies in obscurity, can we doubt that it is far from being a matter of no moment to these creatures that half their lives are to be spent under water, and the remainder in the air? Some may require more of the solar rays, or more of the atmospheric oxygen than could be obtained by total submergence. Or it may be they require to separate and discharge gases into the air in exchange for others which they receive, and that these processes could not be accomplished in the water or in the air alone. However this may be, it is highly probable that the all-wise Creator, in appointing as $\mathrm{He}$ has done a zone of exposure to atmospheric and solar influence to some of these marine inhabitants, which has been denied to others which cannot live under similar circumstances, has at the same time appointed it with a view to the fulfilment of cerrtain functions of which we remain at present almost entirely ignorant.

The return of the tide is the signal to all 
the marine plants to recommence their duties, and as the fresh waters sweep over them they gain new life and vigour, and proceed with their periodical task of decomposition upon the gases held dissolved in the water. By their return also the waters put a stop to such of the chemical changes taking place in the substances composing the coast, as require the presence of atmospheric air. Soluble matters in the soil are also dissolved out, and a supply of water, free from the impregnations of the coast, is periodically afforded to all the zoological inhabitants of the shore zone. The consideration of the varied processes of vital chemistry taking place in the waters, is deferred to the next chapter.

As we look to the foaming edge of the majestic element now rolling at our feet, and contrast the colour of the water, for several yards off shore, with the purer and more transparent tint of the waves at a greater distance, we immediately become sensible of the fact, that with every tide certain mechanical effects, of greater or less amount, must be produced upon the materials composing the sea-shore. These heaving billows, which break so unceasingly on the beach, creating that peculiar sound, well described as the "voice of many waters," in so doing churn up all the 
loose materials in their track, and violently agitate and dash them one against another. The power of water in thus destroying by its mechanical effects the most solid masses of rock, is wonderfully great-great not only in its sum, but in each individual effect. Near Kilkee, on the west coast of Ireland, exposed to the buffeting of the long and mighty waves of the Atlantic Ocean, their effects are most remarkable. In consequence of some peculiarities in

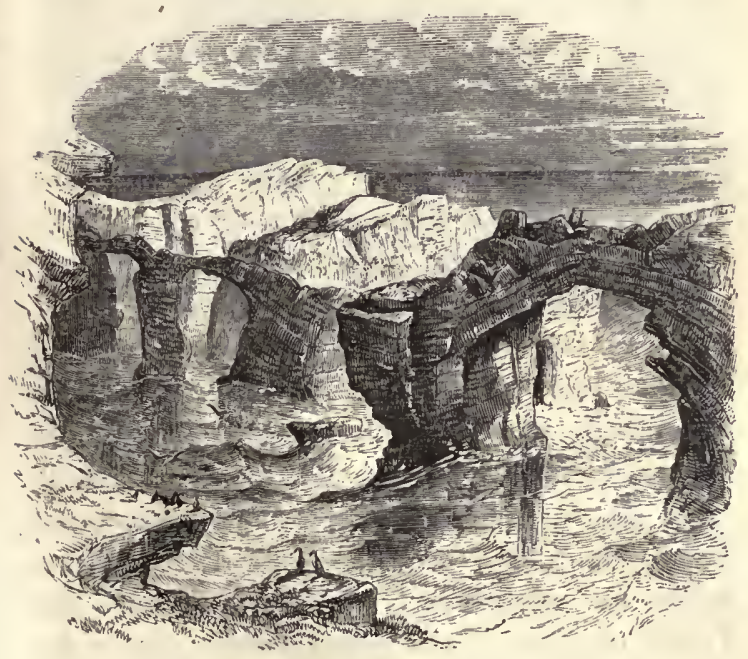

ROCKS NEAT KILKRE.

the chemical composition of the strata, some portions are more easily acted upon than others, 
and the resisting portions consequently stand out in relief, and present the most grotesque appearances. The most curious resemblances of pillars, bridges, and porticos appear as the evidence of the destructive power of these waves. Here and there one might imagine that we beheld a vast eathedral in ruins, the pointed arch is there, but the fretted aisle and stately pillar are not. The roaring music of tumultuous waters forms the harmony of these natural temples, and the congregation, crowds of sea-birds screaming to their young, which line the shelf-like projeetions on the cliffs.

Dr. Hibbert gives an animated deseription of the effects of these great billows upon certain parts of the rocky coast of the Shetland isles: "The most sublime scene is where a mural pile of porphyry, escaping the process of disintegration that is devastating the coast, appears to have been left as a sort of a rampart against the inroads of the ocean. The Atlantic, when provoked by wintry gales, batters against it with all the force of real artillery, the waves having in their repeated assaults forced themselves an entrance. 'This breach, named the Grind of Navir, is widened every winter by the overwhelming surge that, finding a passage through it, separates large stones from its sides, and forces them to a distance of no less 
than 180 feet. 'In .two or three spots the fragments which have been detached are brought

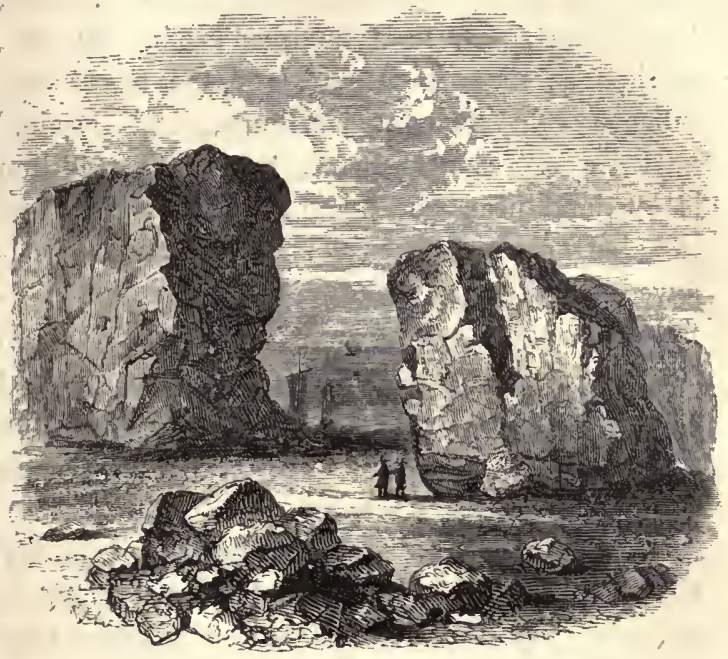

GRIYD OF NATIR.

together in immense heaps, that appear as an accumulation of cubical masses, the product of some quarry." Mr. Stevenson states that during the erection of the Bell-rock lighthouse, such was the force of the waves, that drift rocks, measuring upwards of thirty cubic feet, and more than two tons in weight, have during storms been thrown upon the rock from the deep water which surrounds it.

Almost the whole coast of Yorkshire, from 
the Tees to the Humber, is being gradually destroyed by the action of the sea. "In the old maps of Yorkshire," observes Sir C. Lycll, "we find spots, now sand-banks in the sea, marked as the ancient sites of the towns and villages of Auburn, Hartburn, and Hyde." "Of Hyde," says Pennant, "only the tradition is left, and near the village of Hornsea, a street called Hornsea Beck has long since been swallowed." In one place on the coast of Norfolk, there was at one point in the harbour, in 1829 , a depth of twenty feet, sufficient to float a frigate, where only forty-eight years before there stood a cliff forty feet high with houses upon it!

When we come to inquire into the chemistry concerned in this process of destruction, it will be manifest that it must greatly vary with the nature and character of the sea-coast. Yet the grand chemical operations of nature are all carried on in a remarkably simple manner, and we find that water, carbonic acid, and atmospheric oxygen, are, as in the waste carried on inland, the chief agents of destruction. The hard granitic rocks of the northern Isles cannot withstand the influence of carbonic acid acting upon them in a state of solution, and constantly applied to their surface by the dashing upwards of the waves. Wherever the 
spray touches them they begin to feel the slow but certain influence of the process of decay. Rocks of all varieties of composition, serpentine, porphyry, clay slate, gneiss, limestone, granite, all waste under the gentle touch of the air and foam, and become thus prepared to submit to the force of the overwhelming surges which at times are cast upon them. The soluble portions of the rocks thus exposed become separated and dissolved out by the waves, the surface loses its solidity and compactness, and may be found on examination covered for some inches in depth with a layer of disintegrated matter, which only awaits the coming of the first tempest to be torn off and borne away by the triumphant waters to the depths of the sea. The oxygen and carbonic acid gases held in solution by the waves are largely instrumental in effecting this process, and those portions of the rocks which are submerged, although less influenced than the parts exposed to the air and consequently to greater vicissitudes of temperature, are nevertheless gradually destroyed by this means.

The matter thus produced accumulates at the base of the cliffs, and it may be observed forming a sort of low mound at their foot along the rocky portions of the coast, there to remain, however, only for a time. This leads us, therefore, to ask what becomes ultimately of this 
disintegrated matter? "The current which flows from the north-west," remarks Sir C. Lyell, " and bears against the eastern coast of England, transports materials of various kinds. Aided by the winds and waves, it undermines and sweeps away the granite, gneiss, and trap rocks and sandstone of Shetland, and removes the gravel and loam of the cliffs of Holderness, Norfolk, and Suffolk, which are between fifty and two hundred feet in height, and which waste at the rate of from one to six yards annually. It also bears away in co-operation with the Thames and the tides, the strata of London clay on the coast of Essex and Sheppey. The sea at the same time consumes the chalk with its flints for many a mile continuously on the shores of Kent and Sussex, commits annual ravages on the fresh-water shells, capped by a thick covering of chalk-flint gravel, in Hampshire, and continually saps the foundations of the Portland limestone. It receives besides, during the rainy months, large supplies of pebbles, sand, and mud, which numerous streams from the Grampians, Cheviots, and other chains send down to the sea. To what regions, then, is all this matter consigned? It is not retained in mechanical suspension by the watcrs of the ocean, nor does it mix with them in a state of chemical solution-it is deposited somewhere, 
yet certainly not in the immediate neighbourhood of our shores, for in that case there would soon be a cessation of the encroachment of the sea, and large tracts of. low land, like Romney Marsh, would almost everywhere encircle our island."*

The sediment producing the line of discoloration to which we have alluded is extremely fine. If a quantity of the water were removed and allowed to stand for a time, it would be found precipitated at the bottom as fine smooth mud. But the time occupied in its subsidence is very considerable. The practical chemist, whose business it is to prepare various compounds, by precipitating them from a state of solution, well knows how long and tedious is this process. If we take a tumbler full of lime-water and pour into it a little solution of carbonic acid gas, the liquid will become turbid and white as milk, from the formation of an impalpable powder, but we must wait hours before this powder becomes deposited at the bottom. In like manner, doubtless, a period of many hours is occupied in the precipitation of the fine powder, consisting of the waste of the cliffs and coast. During this time the tide has receded, bearing its turbid water with it, and currents of various kinds then sweep away * Lyell; " Prinoiples of Geology," Book II., p. 108. 
the fine powdery material, and convey it very far from its place of origin.

Wheresoever transported, of its ultimate deposition there can be no doubt. The bed of the ocean is being constantly overlaid with such matter, accumulating from age to age, though with such extreme slowness as to defy in most instances our detection. In 1,000 years the whole surface of the bottom would not be raised a foot by the detritus washed into it from the whole world. Shells and marine creatures of various kinds are becoming imbedded in it, and the time may perhaps arrive when the sediment now washed off in powder, and borne away, we know not whither, may reappear and become dry land again, become adorned with vegetation, and peopled with animals and men.

A lighly interesting event, in connexion with the chemistry of the waves, and important as illustrating their combined mechanical and chemical force, took place on the coast of Ballybunnion in Ireland. The cliffs on this coast contain a large quantity of alum and iron pyrites; and being incessantly exposed to the violent action of the Atlantic billows, they become worn away into the most strange forms. Large caverns, natural bridges, and the resemblanees of human architecture, abound on the 
sea-coast, being produced by the unequal wasting away of different strata. The roofs of these caverns are painted with various hues by the water percolating the overlying strata, and carrying with it a solution of the mineral ingredients encountered in its passage. Streamlets also run down the sides of the cliffs, staining them in ochreous colours, proving that the water contains iron, and probably other salts in solution. These solutions are conveyed into the sea, and there undergo various decompositions in contact with the saline matter of sea-water. Some years since, part of these cliffs assumed an appearance of a very extraordinary character: the waves by continual dashing had worn and undermined the cliff, which giving way, fell with tremendous violence into the sea; the consequence was, that several great strata of pyrites were exposed to the chemical influence of the air and sea-water; rapid oxidation took place, eliminating such an intense heat as very shortly to set the whole cliff on fire. For days the great rucks continued burning with much fierceness, torrents of steam and smoke rising up as the heavy billows of the Atlantic leapt upon the glowing masses, and at a distance presenting all the appearance of some violent volcanic disturbance. After the fresh substances, thus 
exposed, had become oxidized, the steaming cliff gradually cooled down; and now the slow and silent work of mechanical and chemical destruction is being carried on without any external manifestation of its existence. The heat given out during this singular and grand chemical phenomenon was so great as to convert musses of clay in its vicinity into red brick! while melted slags lie about, giving to the whole scene such an appearance as to render it a fit representation of the workshop of the mythological Cyclops.

We have to notice another part of the chemistry of the waves, not less interesting, though less sensible in its effects. It has been mentioned, in treating of the subject of rain, that in order to obtain the solution of a gas, chemists and others have recourse to an apparatus by which the particles of the fluid, generally water, are separated from one another, and beaten into a foam. In the action of waves upon a coast we may olsserve a means of obtaining precisely the same end. If we watch the breaking of a wave, we shall sce, in the manner in which it falls, a beautiful provision for effecting this object. Advancing toward the shore a sloping hillock of water, it increases gradually in height as the waters become more shallow; and becoming higher still, and more 
pointed, it at length totters, becomes crested with foam, curves over, breaks with great violence, and, continuing to break, is gradually lessened in a bulk, until it ends in a fringed margin on the sea-shore-a broken and agitated mass of foam. Nothing could be more perfect than the manner in which the water and air are thus commingled; and the hissing of innumerable air-bubbles, as they birst on the surface, impresses forcibly upon the mind of the thoughtful observer, the conviction that such a process of agitation as this is neither without its effect, nor doubtless without its intention.

. From what has been already said upon the chemistry of the sea, it will be evident that the solution of the gas oxygen, in water, is of the most vital importance to the marine inhabitants. Much of this oxygen, as we shall yet have to notice, is obtained by vital processes; but, as we-look along the shore, white with the foam of countless waves; as we remember the intimate manner in which air is thus mingled with water, and reflect upon the incessant continuance of the same phenomenon, can we doubt that, in the same manner also, a large quantity of this valuable ingredient is added to the waters for the service of the inhabitants of the sea? In consequence of the slight solubility of oxygen 
in water the process is slow, and the amount accomplished in a given time is small. But, listening to the unceasing roar of wave upon wave; remembering that night and day this continual agitation is maintained; ean it be said that, with such means, and so continued, a great result is not both attained and perpetuated? And when we consider the large number of marine creatures which abound, especially near our shores, it does not seem improbable that this is one of the means by which the purity of the waters is sustained. The effect of storms at sea, particularly when cruss seas are produced, is no doubt similar, and the same object may thus be accomplished.

The last point remaining for consideration, in the chemistry of the movements of the waters, is that of currents, and their chemical phenomena. One great function fulfilled by these ocean streams is the equalization of the temperature of the ocean, and the communication of their temperature to the shores along which they roll. The waters of the great gulfstream carry heat with them along the banks of Newfoundland, as high into the northern region as to Spitzbergen, where they are supposed to set free great icebergs, by melting their bases; and, as it pours down the western coast of Europe, it communicates the remains 
of its tropical warmth to countries between which and the source of heat in the current,. lies the broad bosom of the great Atlantic.. The polar currents, on the contrary, pour their cold waters upon the heated shores of the burning tropics, thus mitigating the intensity of their temperature, and communicating a grateful coolness to regions otherwise comparatively intolerable.

It has been before mentioned that there is a notable difference with regard to the amount per cent. of their saline ingredients in the waters of the tropical seas, and of those lying more to the north, in consequence of the greater amount of evaporation suffered by the former compared with the latter. A current, therefore, setting out from tropical regions, and extending to the Polar seas, will convey its high charge of saline matter with it, and throughout its track. On the other hand, a current setting out from the Poles will carry with it water less charged with saline contents. By this means a perpetual circulation of these ingredients is maintained, and the uniform composition of ocean-water is secured. The importance of these two classes of duties fulfilled by marine currents to the preservation of an uniformity of temperature and composition in the whole, can scarcely be exaggerated; and there can be 
little doubt but this grand system of ocean circulation has a most intimate connexion, not only with the inhabitants of the land, but with the well-being of the varied tribes which people the sea.

Imperfect as is our knowlege of the chemical phenomena connected with the movements of the waters, these few considerations may serve to indicate the interesting character of the subject, and to stimulate fresh inquiry. How exalted should be our ideas of that great God, who planned, formed, and set in movement our creation, when we can discover a law in the agitation of a ripple, and a variety of wonderful effects dependent on the breaking of a wave! 


\section{CHAPTER IV.}

LIFE IN THE WATERS.

IT is a reflection calculated to awaken feelings of wondering interest to remember that the world of waters before us is not a blank and desert world, but is tenanted with animals and plants, and is the scene of as much of the bustle of life as is the earth or the air. Little of this appears to the eye, and in a still summer's day, the mind, beguiled into this belief by the calm and unbroken aspect of the water, is unwilling to admit the scarcely-moved ocean to be in reality the theatre where the drama of life is played as universally as on land. But on descending to the shore and investigating matters a little more closely, this idea vanishes, and we become filled with astonishment at the number, beauty, and variety of the marine inhabitants. 'I'he chemical connexion of these with each other, and with the water in which they dwell, will form the subject of the present chapter.

The following extract from Dr. Greville's 
work in the British Algae will furnish an interesting outline of the peculiarities of the regetable tenants of the occan :- "We find the vegetation of the ocean no less conspicuous for beauty and variety of form than splendour of colour, admirably fitted for the place it is designed to occupy, and of direet utility to mankind. The marine Alga is no longer the Alga inutitis-(the worthless Alga). Viewing these tribes in the most careless way, as a system of subaqueous vegetation, or even in a merely picturesque light, we see the depths of the ocean shadowed with submarine groves, often of vast extent, intermixed with meadows, as it were, of the most lively hues; while the trunks of the larger species, like the giant trees of the tropies, are loaded with innumerable minute kinds as fine as silk or transparent as a membrane. Nor must we forget, that while thousands and tens of thousands of quadrupeds, birds, and insects, depend upon the vegetation immediately surrounding us for their very existence, a countless host of ereatures derive protection and nourishment from the plants of the deep, appropriated to their use by that merciful Power in whom they live, and move, and have their being, whose goodness is over all his works. Some of the Algx, placed, on account of the simplicity of their structure, at the bottom of 
the scale, are so small as to be invisible to the naked eye, except by the appearance they give to other species on which they happen to be parasitic in prodigious numbers. From these microscopic forms, Algæ are found, of all sizes, on our own shores, up to thirty or even forty feet in length, an extent to which Chorda Filum not unfrequently attains. This plant resembles an enormous piece of cat-gut, and is, in fact, known by the name of Sea cat-gut in Orkney, while in Shetland it goes by the name of Lucky Minny's lines, and in England of Sea lace." In the southern hemisphere the marine vegetation takes on a more wonderful aspect. A plant described by Bory St. Vincent, is twenty-five or thirty feet high, and has a trunk often as thick as a man's thigh, which divides into numerous branches. A marine plant, abundant on the Australian coast, furnishes the aborigines with instruments, vessels, and food. A trumpet is formed out of the hollow stem of another.

Some of these plants remain constantly beneath the surface of the waters, their roots firmly attached to rocks or stones at the bottom. Others float on the surface, presenting the appearance of green meadows, reposing upon the ever-moving breast of the wave. Near the coast of California these plants grow in such thick masses as to have saved vessels from 
the danger of being driven ashore by the long and heavy swell of the Pacific. They are supposed to grow without attachment to any rock, carried about by the waters which bear them and supply them with all necessary to their existence. In the tropies, where the waters are singularly pure and pellucid, and the light very powerful, it is often a splendid spectacle to look down over the ship's side, and contemplate the beautiful vegetation adorning the sea-bed.

But there exists a limit to the vegetation of the sea, beyond which it is unable to pass. The dark bottom of the ocean is a water desert, unenlivened with a single species of plant. Thousands of miles in area of the bed of the waters are thus waste and barren. Professor Forbes, in his dredging researches in the Egean Sea, found no plants below 100 fathoms. A more singular part of their history is, that they are distributed in zones, at various depths and de- grees of removal from light and warmth. The first zone is the space included between highand low-water marks: this zone, on the British coast, does not descend deeper than 30 fathoms. It is occupied by distinet species of sea-weeds. The second zone on our coast, beginning at low-water mark, extends below it to a depth of from 7 to 15 fathoms. This also has its peculiar vegetable inhabitants. The great sea-tangle 
luxuriates here, together with broad-leaved fuci of various kinds. The last plant of this zone is the nullipora, a coral-like sea-weed, the lowest in the British seas, where it does not extend below the depth of 60 fathoms. In the Mediterranean Sea Professor Forbes has found fuci at a depth of 79 fathoms; below this they altogether disappeared. Nullipore, so curiously resembling coral as to have been long mistaken for an animal rather than a vegetable production, still exists in that sea, forming the food of various marine creatures, at a depth of 105 fathoms. Below this, vegetable existence ceases. In all seas it will probably be found that a similar system of order and arrangement prevails. In the Mediterranean, as the depth increases the number of the plants becomes fewer; until just before the depth of 105 fathoms, the traces of submarine vegetable life are very scarce indeed.

Until recently it was thought that the seaweeds known under the botanical titles Macrocystis pyrifera and the Laniaria radiata, which have been met with on the antarctic coasts, formed the utmost limit of vegetable life in the south polar seas. Beyond the region in which these plants were found, it was thought that the ocean and land were alike barren of vegetable forms. But an interesting account has lately 
been given by Dr. Hooker of a peculiar class of vegetable organisms, discovered between the parallels of $60^{\circ}$ and $80^{\circ}$ south, which proves that at the icy regions of the poles, vegetable life is still to be found. This singular vegetation occurred in such countless myriads as to stain the sea everywhere of an ochreous brown colour, in some cases causing the surface of the ocean, from the locality of the ships as far as the eye could reach, to assume a pale brown colour. Though peculiarly abundant in the Icy Sea, these plants are probably uniformly dispersed over the whole ocean, but being invisible from their minuteness, they can only be recognised when washed together in masses, and contrasted with some opaque substance. While the species of these plants were found to increase in number with the latitude, up to the highest point attained by man, they were also found by Ehrenberg in both Americas, in the south of Europe, and north of Africa, in a fossil state, and even in volcanic ashes. Their remains have been found floating in the atmosphere, overhanging the tropical Atlantic; for Mr. Darwin, during the voyage of the Beagle, collected an impalpable dust which fell on Captain Fitzroy's ship, when to the west of Cape de Verd Islands, and it proved on examination to consist of remains of these plants, including species common in the antarctic regions. 
This vegetation forms undoubtedly the food of many of the countless marine tribes peopling the antarctic waters, and which are subsequently themselves a prey to larger creatures. They were invariably found in the stomachs of sea animals, in all latitudes between that of the north tropic and the highest parallel attained by the antarctic expedition. The death and decomposition of this antarctic vegetation are gradually producing a submarine deposit or bank of vast dimensions. This bank consists mainly of the silicious coatings of the cells, intermixed with infusoria and inorganic matter. Its position is from the 76th to the 78th degree of south latitude, and between the meridians of $165^{\circ}$ east and $160^{\circ}$ west longitude; thus occupying an area of 400 miles long by 120 wide. All the soundings taken over this deposit brought up the finest green mud, mixed with sand occasionally, from the depth of between 200 and 400 fathoms. The lead sometimes sank two feet into this pasty deposit.

Let us now inquire how is the marine vegetation nourished, and what are the chemical functions it discharges? If we were to subject sea-weed to chemical analysis, we should find that it contained a large amount of carbon, a certain portion of oxygen and hydrogen, and a little nitrogen. But there would be more than this; we should find also some earthy, some 
saline, and some metallic matters. On the northern shores of Scotland, a rude analysis of this kind has been performed for many years by the peasant manufacturers of what is called kelp. At certain seasons of the year a lively scene used to be presented to the spectator, which is well described by Dr. Macculloch. "The kelp season," he writes, "had now commenced, and the whole shore was one continued line of fires; the grey smoke streaming away from each on the surface of the water, till, mixing with the breeze, it diffused its odoriferous haze over all the surrounding atmosphere. The rweeds being cut by the sickle at low water, are brought on shore by a very simple and ingenious process. A rope of heath or birch is laid beyond them, and the ends being carried up beyond highwater mark, the whole floats as the tide rises, and thus by shortening the ropes is compelled to settle above the wash of the sea, whenee it is conveyed to dry land upon horseback. The more quickly it is dried the better the produce; and when dry it is burned in coffers, generally constructed with stone, sometimes merely excavated in the carth." * In the act of combustion a sort of rude analysis is performed upon the sea-weed, the earbonaceous and gaseous products arising

* This proeess has been now almost entirely stopped by substituting salt for kelp in the manufacture of soda. 
from it in the form of smoke, while the earthy and saline remain behind in the fused bluish mass called kelp. 'Twenty-four tons of seaweed, at a medium, yield one ton of kelp. Kelp contains chloride of sodium, carbonate of soda -a product of the combustive process, chloride of potassium, and traces of the other mineral constituents of sea-water. In addition to this, kelp, after undergoing chemical treatment, is found to contain sensible proportions of the remarkable element iodine, and very minute traces of another element, bromine.

The existence of these various elements in the ashes of marine plants leads us to ask by what means they were obtained? The roots of sea-weeds differ from those of terrestrial plants both in their structure and offices. They are not the channels of nutriment between the soil and the plant. They appear simply intended to anchor the plant, to enable it to resist the violence of the waves. They most commonly embrace a rock or a stone, from the compact and obdurate surface of which no soluble matter for the nutrition of the plant can be extracted. Many float, unattached, hundreds of miles from any shore, and in deep water. It is plain, therefore, that the whole sum of the ingredients forming a sea-plant is obtained from the water in which it floats. A reference 
to the analysis of sea-water will show that in its composition are to be found all those elements which are present in the sea-weed.

The saline and mineral ingredients forming the food of marine plants must by no means be considered as simply accidentally present, or present merely by imbibition, as they would be in a cotton wick plunged into sea-water. They are absorbed into the plant by the powers of vital chemistry, and are as important to its well-being as the alkaline and earthy matters present in land-plants are to them. This is remarkably illustrated in the case of the element iodine. The chemist can only detect minute traces of iodine in sea-water, yet he extracts it from sea-weed, though it is only present in the proportion of one grain in one million grains of sea-water. Were it not, in fact, for this faculty possessed by sea-weed, and wisely made essential to its growth, man would be deprived of one of the most useful of medicinal substances, in the element thus extracted. All the iodine of commeree is obtained from the fused ashes of the sea-weed. Bromine also is chiefly known to us as one of the minute products of a chemical operation to which kelp is subjected. Both the elements thus abstracted from the water for the use of man by the sea-weeds could not otherwise have 
been obtained in available quantities but by the evaporation of the whole seas!

We have now to seek the origin of the carbon in sea-plants. Here, it is very unlikely that its source should be in the ocean bed. No beds of softened humus line the ocean floor, or form a resting-place for the few and simple roots of the marine plant. It is compelled to derive all its food from the medium in which it lives, and has its being. Just as in terrestrial plants, the source of the carbon in sea-plants is the carbonic acid of the element which surrounds them. Sea-water, in common with all water in a state of nature, contains a certain quantity of this gas in a dissolved state. It is derived from the respiration of fishes and other of the marine tribes, and from a number of chemical processes constantly taking place in the contents of the water, or in the materials which form its bed.

In the decomposition of carbonic acid by marine plants, a simple but highly important part of the chemistry of the ocean is involved. The fact of this decomposition under water may be as strikingly exhibited as that effected by land-plants upon air. If, when winter has sealed with ice the waters of a wayside pond or ditch, we carefully examine the spot on a sunny day, beneath which some aquatic plants are growing, we shall often perceive their leaves 
to be bedecked with silvery bubbles of air. On this air being collected it proves to be pure oxygen gas, derived beyond a doubt from the decomposition of the dissolved carbonic acid of the water.

This is an exact type of the chemical processes effected by plants upon the gas dissolved in the ocean. It is true that they require a peculiar constitution adapted to the peculiar circumstances of their abode. But the mere fact of their living in the water, and some of them never coming into contact with the air at all, does not affect their power to decompose the carbonic acid of the surrounding medium. They have been formed for their present position, and are as active in the fulfilment of their office as the waving grass or the leaf of the forest. Carbonic acid is present in sea-water in still larger quantities than in the air. In ten thousand volumes of sea-water, six hundred and twenty volumes of this gas have been found. By taking a piece of a living sea-weed and preserving it in a basin of sea-water, it will, by the oxygen it gives out, keep the water sufficiently fresh to enable various little marine insects to live in it for some time. The singular plants, called corallines, about which so many erroneous views have been entertained, on the supposition that they were animal in their nature, 
and which occupy so large a tract of the seabed, possess this function in common with the rest of the vegetable inhabitants of the waters. Dr. Johnston performed an interesting experiment upon these plants, which pleasingly illustrates their utility, minute and feeble though they appear in the great waters by which they are surrounded. He placed in a small glass jar, containing about six ounces of pure sea-water, a tuft of living coralline, about the branches of which several little mussels, and other, animals, and a star-fish were crawling. The jar was placed on a table and was seldom disturbed, though occasionally looked at, and at the end of four weeks the water was still pure, the little animals all alive and active, and the plant had grown sensibly larger. At the expiration of eight weeks the water continued pure, and many of the animals were living. Had the coralline not been there, a day would have sufficed for the animals to have extracted all the oxygen of the water, and in a week or two the water itself would have commenced the changes of putrefaction. Nothing could more conclusively exhibit the effect of plants upon the waters of the ocean, for here was a sea in miniature, the animal producing carbonic acid, and the coralline absorbing and decomposing it, and then emitting its oxygen. 
Calling to memory the wonderful faets elicited upon the chemistry of the sunbeam, and its connexion with vegetation, the inquiry naturally arises, whether the vegetation of the deep is also dependent witl that of the land upon the various energies of the solar ray? There exists every reason to believe it is so dependent. Direct experiments of a trustworthy character and sufficiently numerous are yet wanting. But it is found that vegetation generally eeases at such depths as mark the extinetion of the solar ray. The light reecived by these plants is of à greatly diminished intensity. Many of them must live in little better than an alternation of twilight and night. Even those which oceupy the littoral region must enjoy much less of the power of the sun's ray than the humblest plant dangling on the rock in mid-air. The actinic and the luminous rays of light are those which appear chiefly to intluenee the marine vegetation. In what way, it remains for us to learn. Enfeebled though the solar influenees may be by their passage through the water, they suffice to quicken the plant and to enable it to sustain an active existence. We are apt to imagine that sea-weeds are very slow in growth, but this is in the ease of many of them an error; a few months sufficing to cover rocks with plants which had before been per- 
fectly clean and bare. We are apt also to forget that in all the domains of nature organized beings are fitted to the stations they occupy, and exactly perform the duties required of them. The sea-weed, low though it is in the order of vegetable creation, and insignificant as it appears in our eyes, is beautifully adapted to the place of its abode, and amid many apparent disadvantages faithfully executes its chemical task of decomposing carbonic acid and cvolving oxygen.

As in the air, so in the water of the sea also, . ammonia may be detected. It is probably, as in the former case, the source of the chief portion of the nitrogen contained in such plants. It originates in the death and decomposition of the marine animals. Phosphates, earthy and alkaline carbonates, are also present in seawater, and are found in the ashes of marine plants, which is sufficient to show that they are necessary to them.

The marine vegetation acts a part with reference to the preservation of the constancy of composition in sea-water not less beautiful and interesting than the decomposition of carbonic acid by plants growing in the air. The sea is not less exposed to the risk of deterioration than the air. The sources of its gaseous deteriorations and their remedies have just been noticed. 
But in every shower falling on the land, washing out certain mineral ingredients, and by various channels directing them into the great receptacle, we may perceive a large source of impurity, and the question comes to assume a great importance when we note by what means are the otherwise inevitable consequences of these additions to the mineral constituents of sea-water to be averted. The provision to this end is to be found in the varied tribes of marine plants. It will be most evident what ingredients these plants appropriate and separate from the element in which they live, if we examine into the chemical nature of their ashes. This will infallibly inform us in the most correct manner how far they act in the preservation of the purity and constant composition of the waters of the ocean.

From analysis it is found that sulphuric acid and chlorine, potash, soda, lime, and inagnesia are the chief constituents. The sulphuric acid and chlorine occur in combination with the other substances. The quantity of sulphuric acid is very large; on an average, according to Professor Forchhammer, it amounts to four per cent. in the dry plant. Thus it is evident that a large amount of this acid, which would otherwise, in the form of various combinations, accumulate in sea-water, is separated by sea- 
weeds. The quantity of potash is also great, much greater than is contained in sea-water: the fucoidal plants contain two and a half per cent. of this element. They also contain a considerable portion of magnesia, which occurs in great quantities of sea-water, and not-as is the case with regard to lime--being removed by animal life, it would accumulate to a vast extent in the sea but for these plants which absorb it. They also contain a portion of phosphate of lime: this ingredient they separate from sea-water; it is then received by various minute creatures which feed on the sea-weed, and as these form the food of greater marine beings, this ingredient becomes ultimately handed over to them. Thus, just as plants act with regard to ammonia in the air, the sea-weeds may be considered to act with regard to phosphate of lime, a highly . important ingredient to animal life. They absorb it from the surrounding medium; it is then received by minute creatures, crustaceous animals and others living in the heaps of rotting sea-weeds on our shores; to be afterwards appropriated by the higher forms of marine life. The process of conservation thus perpetually going forward, not only purifies the water of the ocean, and assists in maintaining it in a state adapted for the existence of living things; it serves also to form a continually increasing 
store of fertility against the time when the sea bed upon which these plants will rot and perish may become elevated above the waters, and converted into corn-fields, gardens, and vineyards.

If, however, sea-weeds merely separated these ingredients for a short time, and when they died if they were again to return to the sea-water, their effect in preserving its constant composition would be inconsiderable. Such is not the case. When these plants die, they are east by the waves upon our shores in vast heaps. On one point of coast where these plants abound, it has been calculated that about 30,000 two-horse loads of sca-weed are annually thrown on shore in the months of November and December.' This quantity represents not less than the enormous sum of $450,000 \mathrm{lbs}$. of sulphuric acid. On the shore they putrefy; their carbon is dissipated as carbonic acid; a volatile substance resembling spirit of wine is also given off, according to Professor Forchhammer; their nitrogen is dispersed as ammonia, and the sulphuric acid, occurring in the form of several sulphates, undergoes decomposition, sulphurets being formed, and sulphuretted hydrogen gas being given off. A part of the sulphur also combines with the metallic ingredients of the bed in which the heap of plants live. Thus 
in various ways the almost total sum of these ingredients, separated by sea-weeds from seawater, are finally removed from it in such a manner as that they cannot be restored to it again.

The ocean is more prolific in animal even than in vegetable life. From the minute infusorial animalcule, imperceptible to the unaided eye, up to the great animal-the whale, all varieties of size and form exist. Of the vast numbers of the more minute creatures language can convey no idea. .Just as the peculiar vegetation, noticed by Dr. Hooker, by its numbers coloured the waters of the Antarctic Ocean, so, minute animated creatures abound in the arctic seas, turning the ultramarine blue of the waters to a turbid green. The bodies of these animalcules are exceedingly small, yet they are found discolouring patches many miles square, and of great depth. To afford some conception of their numbers, Scoresby has made the statement that in the space of two square miles, supposing the animalcules to exist as low down as 1,500 feet, there would be congregated a mass of individual beings, which eighty thousand persons would not have been able to enumerate, though they commenced the task at the Creation and continued it incessantly to the present time. Yet this would prove but 
a very small portion of the entire sum of these beings existing at one time in these seas. Ehrenberg, after examination of various specimens of sea-water sent to him by Sir J. C. Ross, states that in high "southern as well as in high northern latitudes, and at great ocean depths, the minute forms of organic life are intensely and extensively developed." Near Franklin Island a great quantity of ice of a brown colour was observed. The colour was entirely due to innumerable hosts of these minute organized beings. Samples of water have been taken up in various latitudes, and on accurate microscopic investigation, innumerable extremely minute organisms liave been detected, floating generally in a fragmentary state. Thus, even in the perpetual night of the depths of the ocean, animal life abundantly exists, though of a low type.

"On the coast of Chili," remarks Mr. Darwin, " a fow leagues north of Coneepeion, the Beagle one day passed through great bands of muddy water, exactly like that of a swollen river; and again, a degree north of Valparaiso, when fifty miles from land, the same appearance was still more extensive. Some of the water placed in a glass was of pale reddish tint; and, examined under a microscope, was seen to swarm with minute animalcules darting about and often 
exploding. They were exceedingly minute and quite invisible to the naked eye, only covering a space equal to the square of the thousandth of an inch. Their numbers were infinite; for the smallest drop of water which I could remove contained very many. In one day we passed through two spaces of water thus stained, one of' which alone must have extended over several square miles. What incalculable numbers of these microscopical animals! The colour of the water, as seen at some distance, was like that of a river which has flowed through a red clay district; but under the shade of the vessel's side it was as dark as chocolate. The line where the red and blue water joined was distinctly defined. The weather for some days previously had been calm, and the ocean abounded to an unusual degree with living creatures."

The enormous shoals of herring and mackerel which at times appear on our coasts, and on those of other lands,- - shoals, the number of individuals in which defy the power of calculation and baffle conception,- these, too, furnish us with a striking view of the vast numbers of beings whose abode is the ocean. Yet, just as in the case of marine vegetation, there are laws which regulate the distribution of ocean

$$
\text { * Journal, p. } 16 .
$$


life; and there are in the depths of the ocean tracts without any animated occupants, the counterparts of the lofty and barren mountain elevations of the carth.

The researches of Sir James Ross have shown that as deep down as six thousand feet animated beings exist; but we are not therefore to understand that all marine creatures can endure the vast pressure of a superincumbent bed of water so thick as this. Dr. Williams, in some ingenious experiments, has shown that the pressure of the ocean exercises a mast important influence upon the distribution of life at the bottom. On subjecting water in a glass vessel containing a gold-fish to a pressure of four atmospheres, or about 60 lbs. to the square inch, the fish became paralysed. From a number of experiments upon different fishes the following conclusions were arrived at: -1 . That round fishes having an air-bladder cannot without injury be exposed to a pressure of more than three atmospheres. 2. That the use of the air-bladder is not so much to regulate the specific gravity of the animal as to resist the varying force of the fluid column, and thus to protect the viseera and abdominal bloodvesscls against excess of pressure. 3. That flat-fish exhibit a limited capacity only for sustaining pressure. It is stated that the animals 
occupying the lower regions have experimentally exhibited a greater tolerance of pressure than those of the more superficial zones.

But the distribution of marine life is also influenced by the laws of oceanic temperature, and by the depth. The most systematic observations upon this subject are the researches of Professor E. Forbes in the Egean Sea, to which allusion has already been made. As the result of long-continued and carefully-conducted experiments in that sea, it has been found that eight regions or zones of depth may be distinguished, each characterized by its peculiar inhabitants. These regions are exhibited in the accompanying diagram. But there is a gradual

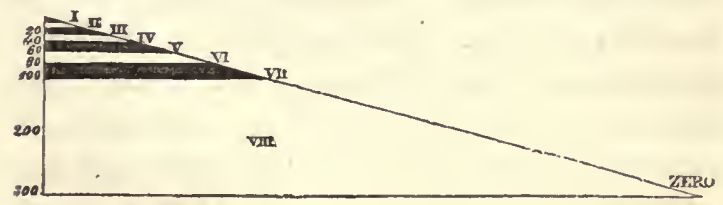

transition observed in the character of the inhabitants of these regions at their commencement, and at their termination. A few from below appear just before the termination of one zone and the commencement of another. While, however, this is the case, the lines of separation are remarkably well defined, very few creatures of the same species being found in more than 
one or two of the eight zones, while only two species are common to them all. It is remarkable, however, that the first zone or coastregion, extending to the depth of two fathoms, contains a greater number and variety of ereatures than any of the rest, or indeed than all the others put together. The lower zone contains fewer animated beings, and on its confines, at the depth of 230 fathoms, or at most at that of 300 fathoms, animal life ceases in the Mediterranean. The remarkable fact has been already mentioned, that as the depth of this sea increases, and the same laws prevail in other seas which have undergone similar investigation, the marine animals occupying the deeper regions assume more and more the characters of those found in northern climates. The occupants of the coast zone represent properly the peculiarities of form and colour characteristic of the inhabitants of southern latitudes. The sea thus, as we examine its depths, presents us with a sort of map representing types of the oceupants of the seas of other climates. The more deeply the shellfish is found down, the more to the north will lie the place where its allies are dwellers on the coast. The coast zone shows the marine inhabitants of the latitude of the region, the lower zones those of higher latitudes.

While a considerable number of the dwellers 
in the deep feed upon the regetation with which to a certain depth it abounds, yet by a wise regulation it is ordered that the greater number prey upon their fellow-occupants of the waters. In eonsequence of the limits to which marine vegetation extends, it would not have sufficed to sustain the wants of the countless millions of marine beings, had they been confined to a vegetable diet, or had the proportion of predacious and herbivorous creatures been in the deep as it is on land, where vegetation almost everywhere abounds. Hence in the ocean generally, and in the polar seas in particular, where the vegetable kingdom which constitutes the support of animal life in milder climates has no representative, if we exclude the minute plants before mentioned, a chain of animal existence has been constituted which as effectually completes the great intention of the preservation of life as that regulating the life of animals on land. Creatures of a higher order prey upon those of a lower, and these again upon those next below them in the scale of created beings, which in their turn feed upon the innumerable infusorial animalcules thronging the ocean.

The vital function in marine creatures generally, with which the chemistry of the ocean is chiefly concerned, is that of respiration. Although not living in the air, these creatures 
breathe, and oxygen is as necessary to them as it is to ourselves. A simple experiment will illustrate this fact. If one or two gold-fish, in a vessel of water, are placed under the receiver of an air-pump, and the air is gradually $\mathrm{ex}$ hausted therefrom by working the pump, bubbles of gas will be seen arising from the water, and in a short time the fish will be quite dead after several violent struggles. If, again, fish are placed into a basin of water, which has had all the air expelled by boiling, they will then likewise soon perish: this arises from the want of oxygen, which was contained in a dissolved state in the water. Chemistry informs us, that the proportion of oxygen dissolved in 100 parts of water is very small (100 cubic inches of water will dissolve about three and a half oxygen); and it is certain, that many other gases, carbonic acid for example, are much more soluble than oxygen. This small proportion is, however, sufficient for the well-being of marine creatures. Had oxygen been very soluble in water, there would have arisen many bad results to the animal world on land, and not less to those of the waters themselves. The effect upon the inhabitants of the deep of a higher charge of oxygen in their respirable medium, would be precisely analogous to its effects upon air- 
breathing creatures; and the loss to the latter, from the vast amount of oxygen thus removed from the atmosphere, it might have been beyond the power of the most profuse vegetation to repair. Although sea-water contains nitrogen in solution as well as oxygen, yet its proportion is only small, and we may regard the water as the diluent for oxygen in the ocean, as nitrogen is for it in the atmosphere.

The manner in which the dissolved oxygen is received by fish from the medium in which they live is very similar to that in which airbreathing creatures receive it from the air. In the gills, and other modifications of the respiratory organs in marine beings, there exists a similar provision for the exposure of the blood to the influence of oxygen as in those of airbreathers. The gills are composed of numerous lamince, or plates of tissue, covered with innumerable minute blood-vessels, and exposing a very large surface to the influence of the oxygen dissolved in the water. The water becoming partially deprived of its dissolved oxygen, is discharged from under the gill covers, a fresh portion being taken in at the mouth. Thus a constant current of fresh water is caused to flow over the laminæ, from which a constant supply of oxygen is obtained by the fish. The blood, after becoming thus oxygen:- 
ated, is further propelled by the heart throughout the body of the creature, and, losing its oxygen in the capillary vessels, returns again by the veins to undergo the same process again. In so doing the venous blood parts with carbonic acid, which is received and retained by the surrounding fluid in a dissolved state. The temperature of fishes is generally two or thrce degrees higher than that of the water in which they live. These facts render it apparent that it is not less important to the residents of the waters than to ourselves to be provided with a full and free supply of oxygen, and explains the cause of the death of fish when placed in a limited quantity of water, even though the water may not have undergone any sensible change. When fish are thus placed, and have exhausted the stock of dissolved oxygen in the fluid, they rise to the surface, and swallow atmospheric air, the oxyger of which becomes then subservient to their uses. 'I'his can rarely occur in a state of nature, but it is constantly seen when fish are kept in small artificial receptacles. It is a most common and painful sight to witness this action in gold-fish, kept within the too narrow confines of a glass globe.

The effect of the respiration of fish and of the presence of other marine inhabitants upon 
the waters in which they live, is similar to that of man, and air-breathing creatures generally, upon the atmosphere; the fluid becomes vitiated, and a necessity is created for its renewal. This process, as in the terrestrial world, is, as we have seen, discharged by plants. There can be little doubt also, that the mere effect of constant agitation, as before noticed in the phenomena of waves, causes the solution of a large portion of uxygen; for it is found that sea-water contains also nitrogen in solution, which has unquestionably been obtained from the agitation of water and air together. The oxygen of the rain which falls on the sea is likewise an important addition to its contents. We may, in fact, see in the grand circle of the evaporation of water from the sea, of its condensation in largest quantity over land, and of its return by innumerable channels to the bosom of its broad parent again, a beautiful system for providing for the due oxygenization of the ocean waters. For no method of dissolving atmospheric oxygen cuuld be devised more complete than this. Rapids and cataracts effect a similar object. Could the chemist draw from the foaming pit of water into which the waterfall at the other end of this valley leaped, a sufficient amount of water to submit to analysis for its gases, and were he to contrast it with a 
similar quantity taken before the leap, he would discover in the former more dissolved atmospheric air than in the latter. These processes are all subsidiary to the oxygenization effected by marine plants; but when we consider the comparative smallness of the number of these plants, together with the fact that a large number of them are for some hours out of every day incapacitated for their office by the departure of the tides, and that probably these, and a still larger number, which live always in deep water, are also unable to fulfil it during the hours of darkness, it will be perceived that the relation subsisting between the ocean and its vegetation is far inferior in importance to that subsisting between the air and plants. Considering the vast preponderance of animal over vegetable life in the ocean, it becomes more than questionable whether the marine vegetation could, unassisted, preserve the purity of the waters as a respirable medium. It has been stated by M. Morren that he discovered a vast number of infusorial animaleules in certain regions of the ocean which, instead of vitiating the water, like all other nembers of the animal kingdom, actually enriched it, by producing oxygen; but this statement requires confirmation.

There remains another portion of the che- 
mistry of the ocean in its connexion with animal life which requires our attention. A large number of marine creatures derive from the waters the solid matter forming their hard outer case. The shells of innumerable molluscous animals, the hard shields of countless millions of animalcules, and the solid substance secreted by the coral animal, are all derived from the water by the processes of vital chemistry. This hard matter consists chiefly of carbonate of lime. It was found in the researches in the Agean Sea, that a most important influence was exercised by the composition of the coast and sea-bottom. Great tracts of a cretaceous limestone border the sea, and by their constant degradation fill its waters with a white sediment of the carbonate of lime. In such water, therefore, those creatures which require this substance for the purposes of their economy, may be expected to abound, and accordingly it was found that large numbers of molluscous animals existed in these regions. On the contrary, where the islands and coast consisted of serpentine, the waters bathing them were almost devoid of molluscous or testaceous animals, owing doubtless to the comparative absence of the necessary mineral constituents of the seawater.

Some idea may be formed of the vast extent 
of this operation of the separation of the salts of lime from the waters of the ocean, when it is stated that the solid limestone rocks of our own and other countries are often visibly made up of the relics of animals possessing this peculiar faculty; and it appears probable that all limestone, with some exceptions of small moment, were thus obtained by the slow but perpetual process of the separation of the salts of lime from a state of solution in sea-water. Professor Forchhammer states the remarkable fact, that in the coral seas the proportion of lime is much less than in other waters.

The coral formations, however, strike us as the most surprising result of the slow but ceaseless operations of vital chemistry upon the constituents of sea-water. Writing of Keeling Island, Mr. Darwin says, "I am glad we have visited these Islands; such formations surely rank high among the wonderful objects of this world. Captain Fitzroy found no bottom with a line 7,200 feet in length, at the distance of only 2,200 yards from the shore; hence this island forms a lofty submarine mountain, with sides steeper even than those of the most abrupt volcanic cone. The saucer-shaped summit is nearly ten miles across: and every single atom, from the least particle to the largest fragment of rock in this great pile, which however is 
small compared with very many other lagoon islands, bears the stamp of having been subjected to organic arrangement. We feel surprised. when travellers tell us of the vast dimensions of the Pyramids and other great ruins; but how utterly insignificant are the greatest of these, when compared to these mountains of stone accumulated by the agency of various minute and tender animals! This is a wonder which does not at first strike the eye of the body, but, after reflection, the eye of reason."*

Upon the outer shores of these lagoon-like islands a great surf continually breaks, strewing the solid flat of dead coral rock with huge detached fragments. Yet the little creatures build on. The long and massive swell of the ocean incessantly dashes with immense force upon the outworks of the fragile coral-builders. "It is impossible to behold these waves without feeling the conviction that an island, though built of the hardest rock, let it be porphyry, granite, or quartz, would ultimately yield and be demolished by such a power. Yet these low and insignificant coral islets stand and are victorious; for here another power, as an antagonist, takes part in the contest. The organic forces separate the atoms of carbonate of lime, one by.

$$
\text { * Journal, p. } 465 .
$$


one, from the foaming breakers, and unite them into a symmetrical structure. Let the hurricane tear up its thousand huge fragments, yet what will that tell against the accumulated labour of myriads of architects, at work night and day, month after month? 'Thus do we see the soft and gelatinous body of a polype, through the agency of the vital laws, conquering the great mechanical power of the waves of an ocean which neither the art of man nor the inanimate works of nature can long resist."

On the east coast of New Holland a reef has been described as being one thousand miles long, and in one portion is unbroken for a distance of between three and four hundred miles! Mr. Lyell states that some groups of coral islands in the Pacific Ocean are from eleven to twelve thousand miles in length by three or four hundred in breadth. Coral islands also exist in vast numbers in the Indian Ocean. Thus, only in the instances in question it is evident that the labours of these minute mechanics-the coral animals-have added no insignificant mass of solid material to the great earth itself. Yet the ingredients of sea-water, from whence every particle was procured, exists in extremely small proportions. In order to add one pound of carbonate of lime to these structures, a quantity of sea-water, not less than 
one hundred and twenty-four thousand pounds, must undergo the processes of vital chemistry. How forcible an illustration of the real importance of things apparently insignificant !

The level rays of yonder descending luminary streaming towards us over the heaving surface of the waters warn us that the day is nearly spent, and that night approaches. We must therefore quit the scene where our steps have so long lingered. But now with what different emotions to those felt at its first contemplation! What thoughts have not been awakened as the Chemistry of Creation has unfolded part after part of the beautiful scheme of nature before us! What links of inter-dependence; what variety of objects, causes and effects, and what unity and simplicity of the whole! Nothing in nature but is now eloquent of the wisdom, love, and power displayed in its creation. Each blade of grass has a tongue; the waters, hills, and forests, and the very rocks and stones have voices.

$$
\text { "In reason's ear they all rejoice," }
$$

and proclaim that the hand that made them, and that has regulated their various organic and chemical phenomena, is indeed Divine. 
Yet how shallow and imperfect are our highest discoveries! Here, alas! with regard to ereated things we are ever learning, but never able to come to the full knowledge of the truth. We see a little way into the mysteries of creation, and there our progress ends. The most advanced philosophy eannot carry us beyond the threshold of knowledge. For the rest we have to wait. It is the subject of many "great and precious promises," which assure us that better things are in store for us; that the time will come when all who now humbly trust in a Divine Redeemer, and are guided by Him in the paths of righteousness, shall attain to the complete renewal of their moral and intellectual powers, and so be fitted to walk in the light of His presence, " in whom are hid all the treasures of wisdom and knowledge."

THE END. 

University of Cailfornia

SOUTHERN REGIONAL LIBRARY FACILITY

405 Hilgard Avenue, Los Angeles, CA 90024-1388

Return this material to the Ilbrary

from which it was borrowed.

JAN 102005

UCLA COL LIB

RECEIVED $1 \mathrm{i} \psi \mathrm{v}, / 2004$

回国限

JAll I 72000
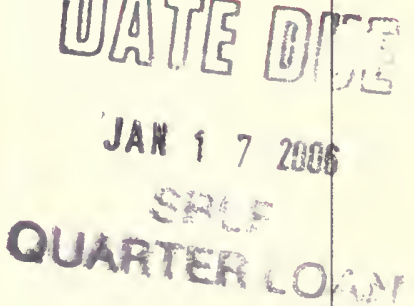

UCLA COL LIB RECEIVED 
UC SOUTHERN REGIONAL LIBRARY FACILITY

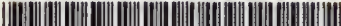

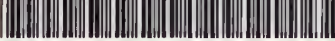

A $000062846 \quad 1$ 
